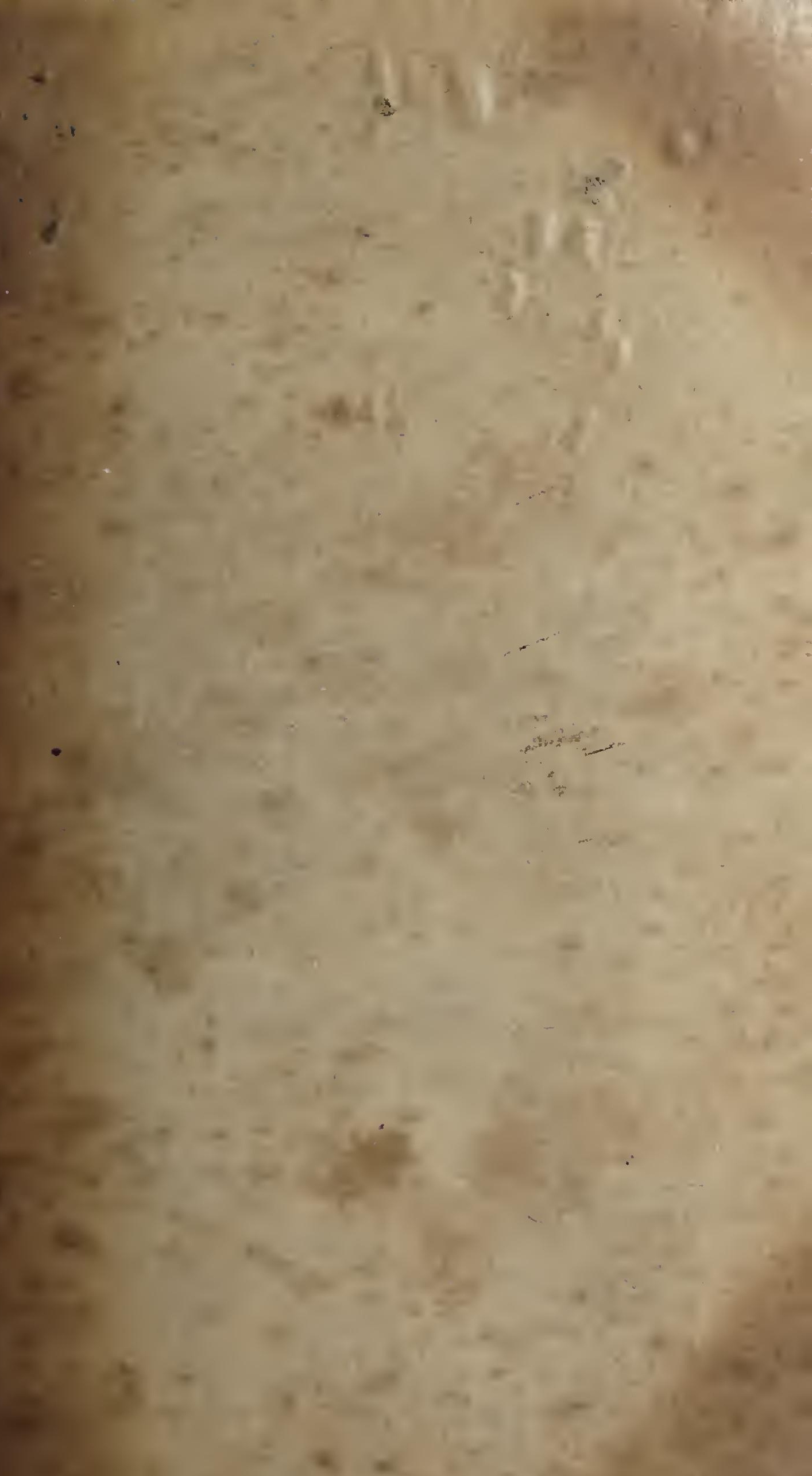




\section{1}

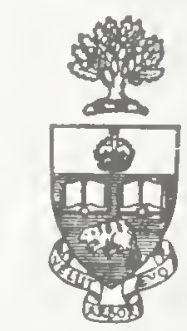

Library

of the

University of Toronto 

Digitized by the Internet Archive in 2018 with funding from University of Toronto 
PUBLISHED UNDER THE SUPERINTENDENCE OF THE SOCIETY FOR THE DIFFUSION OF USEFUL KNOWLEDGE.

\section{THE LIBRARY}

$\mathrm{OH}$

\section{ENTER'TAINING KNOWLEDGE.}

THE

\section{DOMESTIC HABITS OF BIRDS.}




\section{COMMITTEE.}

\section{Chairman-The Right Hon. THE LORD CHANCELLOR.}

Vice-Chairman-The Right Hon. SIR HENRY PARNELL, Bart., M.P.

$$
\text { Treasurer-WIJLIAM TOOKE, Esq., M.P., F.R.S. }
$$

W. Allen, Esq., F.R. and R.A.S.

Rt. Hon. Viscount Althorp, M.P., Chancellor of the Exchequer.

IV. B. Baring, Esq, M.P.

Capt. F. Heaufort, R.N., F.R. and li.A.S., Hydrographer to the Ad. miralty.

Sir C. Bell, F.R.S.L. \& E.

G. Burrows, M.D.

C. Hay Cameron, Eso.

The Right Rev. the Bishop of Chichester, D.D.

William Coulson, Esq.

R. D. Craig, Esq.

IVm. Crawford, Esq.

J. Fred. Daniell, Esq., F.R.S.

Rt. Hon. Lord Chief Justice Denman.

Rt. Hon. Lord Dover, F. R.S., F.S.A.

Lieut. Drummond, R.E., F.R.A.S.

Rt. Hon. Viscount Ebrington, M.P.

T. F. Ellis, Esq., M.A., F.R.A.S.

John Elliotson, M.N., F.R.S.

Thomas Falconer, Esq.

I. L. Goldsmid, Esq. F.R. and R.A.S.

B. Gompertz. Esq., F.R. and R.A.S.

G. B. Greenough, Esq., F.R. and L.S.

H. Hallam, Esq., F.R.S., M.A.

M. D. Hill, Esq., M.P.

Rowland Hill, Esq., F.R.A.S.
Edwin Hill, Esq.

David Jardine, Esq., M.A.

Henry B. Ker, Esq.

'Th. Hewitt Key, Esq., M.A.

J. G. S. Leferre, Esq.

George C. Lewis, Esq., M.A.

James Loch, Esq., M.P., F.G.S.

George Long, Esq., M.A.

J. W. Lubbock, Esq., F.R., R.A., anil L.S.S.

H. Malden, Esq., M.A.

A. T. Malkin, Esq., M.A.

James Manning, Esq.

J. Herman Merivale, Esq., F.A.S.

Janes Mill, Esq.

W. H.Ord, Esq., M.P.

Dr. Roget, Sec. R.S., F.R.A.S.

Rt. Hon. Lord John Kussell, M.P.

Sir M. A. Shee, P.R.A., F.R.S.

Rev. Rich. Sheepshanks, M.A.

J. Smith, Esq., M.P.

John Taylor, Esq., F.R.S.

Dr. A. T. Thomson, F.I.S.

N. A. Vigors, Esq., M.P., F.R.S.

John Ward, Est.

H. Waymouth, Esq.

J. Whishaw, Esq., MI.A., F.R.S.

John Wrottesley, Esq., M.A., F.R.A.S.

THOMAS COATES, Secretary, No, 59, Lincoln's Inn Fields. 
THE LIBRARY OF ENTERTAINING KNOWLEDGE.

THE

\section{DOMESTIC}

\section{HABITS OF BIRDS.}

\section{LONDON :}

CHARLES KNIGHT, 22, LUDGATE STREET, AND

13, PALL-MALL EAST;

LONGMAN, REES, ORME, BROWN, AND GREEN, PATERNOSTER-ROW ; OLIVER AND BOYD, EDINBURGH; ATKINSON AND CO., GLASGOW; WAKEMAN, DUBLIN; WILLMER AND SMITH, LIVERPOOL; BAINES AND CO., LEEDS; ANI JACKSON, NEW YORK. 



\section{CONTENTS.}

CHAPTER I.

Habits of cleanliness in Birds

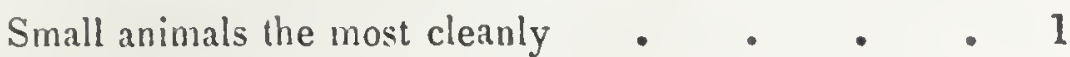

Rump-gland according to Willughby, . . . 3

Argument of Réaumur against its șupposed use . • 4

Experiment by J. R. • • • • • • • 6

Pulverizing Birds . $\quad$ • $\quad$ • 4 . 8

Abreuvoir of the Continent . . . . 10

Washing among young birds . . . 11

Serrated claws of Herons and Night-jars a $\quad 14$

Anecdote of a Swallow. $\quad$ • . . . 20

Use of the tongue as a cleaning instrument $\quad$. 20

Analogy in Quadrupeds . . . . . 21

Analogy from the grub of the Glow-worm . . 23

CHAPTER II.

Birds, solitary and gregarious, on account of food $\quad . \quad 27$

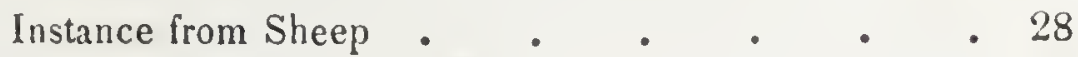

Turkey Buzzard and Black Vulture . . . 30

Anecdote from Wilson . $\quad . \quad$ • $\quad$ • . 32

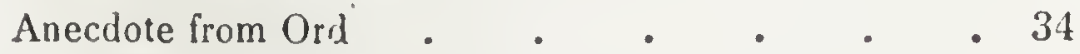

Town Sparrows . • . • . . . 35

Sparrow, Crow, and Stork courts . • • • 37

Rooks appoint sentinels $\quad$ • . . • • • 38

Leader of the Cranes . . . . . . 39

Watch of the Golden Plover . . . . . 41 
King of the Quails . • . . . . 43

Origin of the notion of King Birds . . . . 43

King Eird of Paradise . • . . . . . 44

King of the Tultures . $\quad$. $\quad$ • $\quad$ • 45

lagle as King of the Birds . • • • • • 46

Eagle standards of riations . • . • 47

The Condor • • • • • • • • 48

The Wren, a King Bird . . . . . 49

Solitary Birds . $\quad$ • . $\quad$ • . . 50

The Jack-snipe . • • • • • 50

The Sand-piper and Wagtail . $\quad$ • $\quad .52$

The Dunlin . . . . . . . . 53

CHAPTER III.

Birds, solitary or gregarious, on account of shelter or assistance

The sociable Grosbeak of Africa . . . . 54

Anecdute of a Swallow . • • • • 55

Analogy from Insects and Quadrupeds • • • 56

Crowding together of House Sparrows • • • 59

Contest for places among Bottle-tits • • • 60

Roosting of the Blackbird, Thrush, and Starling . $\quad 61$

Rosting of the Wren . • • • • • 62

Analogy from Sheep • • . • • • 63

Birds solitary and gregarious at different seasons $\quad 65$

The Lark • • • • • • • 65

The Wheat-ear • • • • • • 67

\section{CHAPTER IV.}

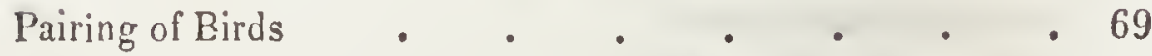

Extraordinary proportion of the sexes • • $\quad 69$

Difference in the male parents of quadrupeds and birds 70 
Instance in Rooks . . . . . . 70

The Capocier of Africa . . . . . 72

The White headed Eagle and the Fish-hawk • . 73

Magpie and Black-cap . . . . . 74

The Goldfinch, Aberderine, and Canary . . . 78

Nigratory agitation . • . . . . . 80

The alleged chastity of the Turtle-dove . . . 82

Allecdote of a Guinea Parrot . . . . 84

CHAPTER V.

Peculiarities in Pairing . • • • . 86

The Wild Turkey . • • • . . 86

Fighting of the males . . . . . . 88

Roosts of Wild Turkeys . . . . . . 89

Black Grouse • • • • • • • 91

Ruffed Grouse of America . . . . . 91

Pinnated Grouse . . . . . . 94

Assemblage of Bustards . . . . . $\quad$ • 97

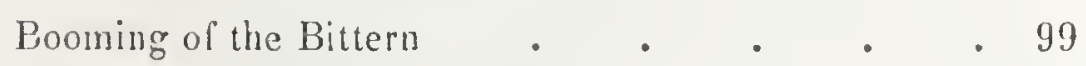

Killing of Ruffs . • • • • • . 999

Fighting of Ruffs . • • . • . 100

Cock-fighting . • • • • • . 103

CHAPTER VI.

Structure of Eggrs

Egg-organ, or ovarium _ . • • . 106

Embryo egg . . . . . . . 107

Parts of the egg . . . . . . 109

Use of the white . . . . . . 111

Singular mechanism . • . . . . 112

Chemical constituents of an egg . . . . 114

Air-bag in the egg . . . . . . 114

Subventaneous eggs . • . . . . 116 
CHAPTER VII.

Colour of Eggs

Use of colours

Instances from flowers, shells, and spiders

. 118

Formation of the egg-shell

Canary's eggs

Variety of markings in the same species.

118

- 119

- 119

. 121

Theories of Darwin and Glöger

- 122

Objections thereto

. 123

. 126

\section{CHAPTER VIII.}

liacts observed in Hatching

. 132

Anecdotes from Pliny and Réaumur . • . 132

Artificial hatching in Egypt . • . . . . 133

Ergytian egg-oven or mamal $\quad$ • • • . 135

Experiments of Réaumur . • • • . . 138

Hatching ergs in dung . . . . . . 143

Hatching in a bake-house . . . . . 14t

Experiment with the eggs of a Wood-wren • 145

CHAPTER I.

Erolution of the Chick :

Egg twelve hours after incubation . . . . 14

After sixteen hours . . . . . . 148

After thirty-six hours . . . . . 150

After four days . . . . . . 157

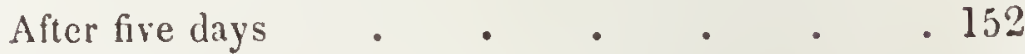

After six days . . . . . . 153

After seven and eight days $\quad$. . . . 154

After nine days $\quad . \quad$. $\quad . \quad$ • . 155

After ten days $\quad . \quad$. $\quad . \quad$. 156

After fourteen days . . . . . . . 158

After eighteen days . $. \quad . \quad$. . 160 
Ego after twenty days .

- 162

Exit of the chick

- 162

Bill scale .

Fracture of the shell

163

Fertility of eggs

170

Chick glued to the shell

. 172

.173

CHAPTER X.

Sheltering of the Young

. 175

Difference of small birds from poultry

. 175

Training of capons as nurses .

- 177

Curious instance of a cat . . . . . 178

Legend of Romulus and Remus . . . . 180

Experiments on capons $\quad . \quad$. $\quad . \quad$. 181

Artificial mothers . . . . . 184

Réaumur's stove hatching-house $\quad . \quad$. 187

Artificial mother for water-fowls . • . . 188

CHAPTER XI.

Feeding of the Young

. 189

John Hunter's remarks on Pigeons

Mistakes of Vieillot and Temminck

Legend of the Pelican

Origin thereof.

. 190

- 193

- 194

. 196

Pelican confounded with the Spoonbill . $\quad .197$

Eagles carrying off children-Ganymede .

- 199

Owls

Chaffinches and Tom-tits

Calculations of Bradley

Remarks of Kuapp

Rooks

Swallows

200

. 202

. 203

. 204

. 205

. 206

Affection of parent birds

Humming-bird .

- 208

. 210 
CHAPTER XII.

Training of young Birds by their Parents

Instillet

212

Training of young Eagles

212

The Stork

Remarks on the common opinion

Instance from Salmon-fry

. 214

Swallows and Sparrows

Warnings of danger

Anecdote from Smellie

. 214

Instructions in catching prey

Rooks

. 216

.216

. 218

CHAPTER XIII.

Vocal Organs of Birds

Mechanism of the voice

Aldrovand's account of the Wild Swan

- 225

. 231

Another Wild Swan discovered by Mr. Kingcote

. 233

Vocal organs of birds according to Herissant

. 235

Remarks of Hunter, Cuvier, and Kircher

. 236

'Tongue of the Nightingale .

. 237

Call-note of the Bittern

- 239

Mistake of Thomson.

. 243

Bleating of the Snipe .

- 245

Crowned Pigeon of Africa $•$ • • • • . 246

\section{CHAPTER XIV.}

Language of Birds

The Richel Bird.

Natural notes of alarm.

Theory of Darwin

Variety in the language of birds

Social signals for congregating

Fables originating thereirom 
Page

The Butcher Bird . . . . . . 257

Various notes from Kircher . . . . . 258

\section{CHAPTER XV:}

Songs of Birds

Female birds rarely sing

Supposed cause of singing

Autumnal and winter songs

Recording

Singing infiuenced by weather and food

Theory of imitation

Experiment on a Sky-lark by J.R.

Vocal organs of song-birds

Characters of the Nightingale's song

. 272

. 272

.279

. 283

. 284

\section{CHAPTER XVI.}

Song of Birds contilued

Comparative table by Barrington and Syme

The Wood-thrush and Song-thrush .

. 290

The Dunnock and Chaffinch .

- 291

. 293

Nightingales of the north and the south . . . 294

Theory of Buffon

. 297

Remarks of Goldsmith . . . . . . . 298

The Pine Grosbeak . • . . . . 299

American song-birds . . . . . . 302

Keys of bird music

Chanting Falcon .

Singing of the Swan

Night-song birus

Dreams of birds 


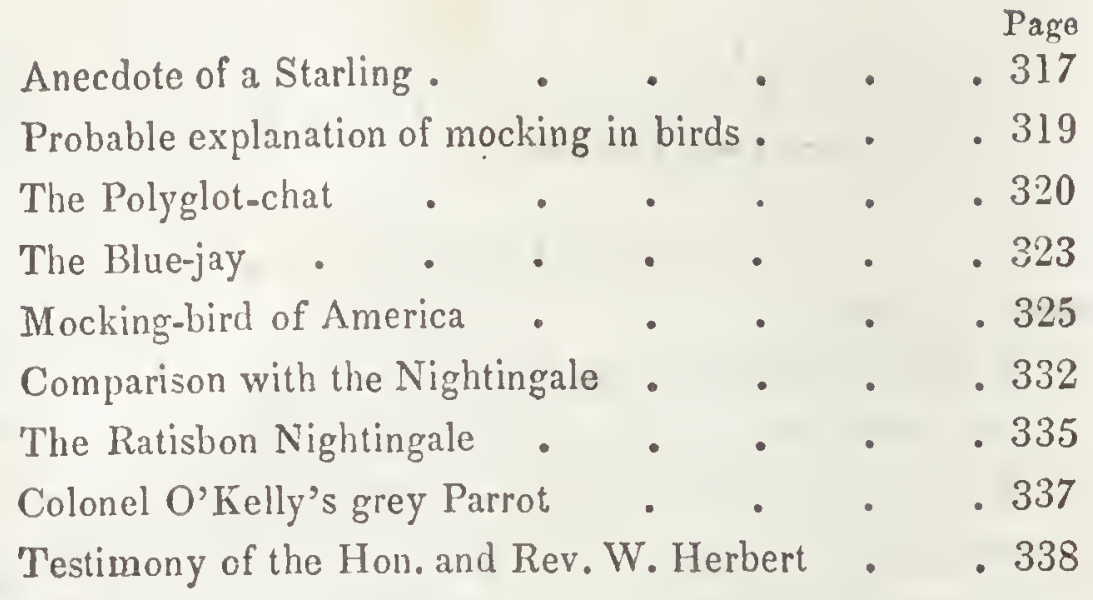

\section{CHAPTER XVIII.}

Longevity of Birds . • . . . . . 340

Physical causes of old age • • • • . 340

Diseases in a state of nature . . . . . 342

The Raven, the Pelicall, and the Eagle . . . 345

Fabulous account of the Eagle . • • . 348

Grey-headed Sparrows . • . . . 350

\section{CHAPTER XIX.}

The Phœnix.-the Bernacle Goose . . . 351

Account of the Phœnix by Herodotus . . . 351

A'ccount by Tacitus . . . . . . . 354

Probable origin of the legends . • . 356

Fanciful accounts thereof . . . . . 357

Account from Bruce . . . . . . 359

Anecdote from Pliny . • • • • . 362

The Bernacle, or Claik Goose . • • • 362

Ocular witnesses of its fabulous origin . . . 363

Gerard's figure . • • • • • . 369

Its true history knoẃn before 1280 . . 373

Origin of the legends . $\quad$. . . . 375

The Flying-fish. • . • . • . 378 


\section{ILLUSTRATIONS.}

No.

1. Rumkin, or Tail-less Cock . . . . . 5

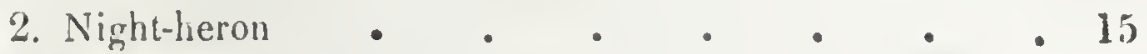

3. Pectinated Claw of Night-heron . • • 15

4. Carolina Night-jar, or Chuck-will's-widow • 16

5. Night-jar's Foot, showing the Pectinated Claw . 17

6. Podargus Auritus • • • • • • • 19

7. Magnified Plan of the Cleaning Instrument . $\quad 24$

8. Larva of the Glow-worm, using its Cleaning Instrument 25

9. Grub of the Glow-worm devouringr a Snail • 26

10. 'Turkey Buzzard and Black Vulture . • • 31

11. The Crane . • . . . . . 40

12. King-bird of Paradise . . . . . . 45

13. King of the Vultures . . . . . . 46

14. Condor attacking a Puma . . . . . 48

15. The Jack-snipe . . . . . . . 50

16. The Dunlin . • • . • . 53

17. The White-headed Eagle and Fish-laawk • • • 73

1S. Tlie Black-cap . • . • • • 75

19. The Aberderine and Nest . . . . . 78

20. The Wild Turkey and Young • • • • $\quad$ • 87

21. The Ruffed Grouse . • • • • • 92

22. Pinnated Grouse in the act of strutting . . . 96

23. American Grouse (Tetrao obscurus) • • . 98

24. 'The Ovarium, or Ligg-orgall . • • • • . 106

25. Embryo impregnated Egg . . . . . 107 
No.

26. New-laid Egg, with part of the Shell removed .

27. Egg of Black-cap

28. Egg of the Tom-tit

29. Egg of the Sky-lark

30. Egg of the Blackbird

31. Egg of the Magpie

32. Egyptian Eggr-oven

33. Ground-plan of an Egyptian Lgg-oven

34. Transverse section and elevation of an Egyptian Eggoven

35. Transverse section and perspective elevation of an Egyptian Egg-oven . . • • • . 139 36. Egg-frame .

37. Hatching Eggs in Dung

38. Hatching-room orer the bake-house orens of the Priory of L'Enfant Jésus at Paris .

39. An Egg as it appears twelve hours after incubation, with a magnified view of the Embryo Chick . I I47

40. An Egg as it appears sixteen hours after incubation, with a magnified view of the Embryo Chick . . 148

41. An Egg as it appears thirty-six hours after incubation, with a magnified view of the Embryo Chick . . 149

42. An Egg opened thirty-six hours after incubation, with a magnified view of the Embryo Chick, in which is shown the first appearance of the principal bloodvessels • • • • • • • • • . 150

43. An Egg opened four days after incubation, with a magnified view of the Chick

44. An Egg as it appears five days after incubation, with a magnified view of the Chick

45. An Egg as it appears six days after incubation, with a magnified view of the Chick 
No.

46. An Egg as it appears seven days after incubation, with $\mathbf{a}$ magnified view of the Chick . • • . 154

47. An Egg as it appears eiglnt days after incubation, with a magnified view of the Chick . . . . 154

48. An Egg as it appears nine days after incubation . 155

49. The same Egg turned more to its right side • 155

50. An Egg as it appears ten days after incubation . . 156

51. The Embryo Chick taken from the preceding Egg, with the amnion and vesicle removed • • • . 157

52. An Lgg as it appears fourteen days after incubation . 158

53. The same Egg, with the external balf of the vesicle removed . $. \quad . \quad . \quad . \quad . \quad 158$

54. The Embryo of the preceding Egg, opened to show the course of the principal blood-vessels which go to the vesicle and to the aleolar membrane • • 159

55. An Egg as it appears eighteen days after incubation $\quad 160$

56. The same Egg, with part of the vesicle removed, to show the Embryo Chick more clearly . • 160

57. The Embryo Chick opened to show the absorption of the yolk into the body . . . . . . . $16 \mathrm{l}$

58. An Egg as it appears twenty days after incubation, the vesicle and amnion ale removed, to show the position of the perfect Chick • • • • • . 162 59. Position of the Chick in the Egg . . . . 164 60. Position of the Chick in the Egg . . . 165

61. Egrs fractured by the included Chick • • . 170 62. Positions of the Shell after the escape of the Chick . 171 63. Artificial Mothers . • . • • . 184 64. Improved artificial Mother . . . . 185 65. Réaumur's Stove Hatching-house . • . . 187 66. Artificial Mother for IVater-fowls . . . . 188 67. Crops of Pigeons . . . . . . 191 
No.

68. Breast-bone of a Wild Swan, with part of the Keel removed to show the convolutions of the Trachea within it .

69. Point of the Keel-bone, showing the opening through which the Trachea enters and returns . . . 232 70. Trachea of C. Bewickii . . . . . . 234 71. Singularly formed Windpipe of the Butor . • . 245 72. Crowned Pigeon of Africa . . . . . . 246 73. The Wood-thrush . . . . . . 292 74. Pine Grosbeak, or Hawfinch • • • • . 299 75. Chanting Falcon • . . . . . . 307 76 The Polyglot-chat . . • . . . 320

77. Lammer Geyer, Bearded Eagle, or Vulture • . 361 78. Bernacle, or Claik Goose . • • • • 363 79. Bernacle Goose-tree, from Gerard's Herbal • 369 80. Bernacle Goose-tree, from Aldrovand . . . 372 81. Bernacle Shell • • • • • • . 376 82. Fowlers of St. Kilda • • • • • . 377 


\title{
DOMESTIC HABITS OF BIRDS.
}

\author{
Chapter I. \\ HABI'TS OF CLEANLINESS IN BIRDS.
}

AnIMALS appear to be cleanly in proportion to their sprightliness and activity; and small animals, with few exceptions, are also more active and more cleanly than those of a larger size. The domestic habits of birds, as well as what may be called their personal habits, furnish us with many illustrations of their peculiar attention to cleanliness, some of which it may prove interesting to detail. The instant any of their feathers are soiled they set about trimming them, and they are no less attentive to their nests.

It is, no doubt, the same uncomfortable feeling which we experience when our hair becomes disarranged or tangled that induces birds to smooth their feathers; the matting together, for example, of two contiguous feathers at the points, causing them upon every motion of the muscles of the skin to twitch away the parts from which they spring. 'The irritation thus produced incites the bird to examine the feathers contiguous to the part; and by nibbling every plumelet with its beak, it soon succeeds in bringing them into their proper position, while it frees them, at the same time, from any extraneous matter that may adhere to them.

It is surprising how soon nestling birds may 
be "seen 'thus trimming themselves. A short time after they are able to open their eyes, while the down which covers them when hatched has not begun to be replaced by feathers, we have, in numerous instances, seen them turning round their heads and going over all the tiny bits of down and the ends of the sprouting feathers within their reach. This might be plausibly supposed to be rather the mother's task, and it is usually so stated in books; but though the mother is very attentive, as we shall presently see, to every species of cleanliness, Providence has ordered that so important a circumstance should not be left wholly to her care. Those who have not an opportunity of verifying our remark in the case of nestling birds, may readily observe the same thing in domestic animals. Cats, for example, are very assiduous in cleaning the fur of their kittens, for which purpose their rough tongue is admirably adapted: but a kitten, like the nestling bird, when only a few days old, may be seen dressing itself assiduously; and as soon as it can run about, it will even endeavour to clean its dam. This circumstance we never observed among young birds and their mothers; though it is by no means uncommon among rabbits, horses, and other domestic quadrupeds. Mutual assistance in cleaning is even given by individuals not of the same family, as may be seen in horses dressing each other's necks; and Wilson relates an instance of the same thing in the case of two birds, not even of the same species, in his inimitable account of the blue jay (Garrulus cristatus, Brisson). An individual of this species, which had been caught in the woods, was put into the same cage with an orchard oriole (Icterus spurius, Bonaparte), who at first received the newcomer with no little jealousy; but this all vanished in a few hours, and they lived together in good humour. 
"When the jay goes to drink," the narrative proceeds, " his messmate very impudently jumps into the water to wash herself, throwing it in showers over her companion, who bears it all patiently; venturing now and then to take a sip between every splash, without betraying the smallest irritation. On the contrary, he seems to take pleasure in his little fellow-prisoner allowing her to peck (which she does very grently) about his whiskers, and to clean his claws from the minute fragments of chesnuts which happen to adhere to them*",

Ducks and other water-birds are, if possible, more assiduous in trimming their feathers than land-birds, one reason for which appears to be, that their plumelets being of very close texture, any slight derangement in them is readily felt from the air getting access to the skin through the breach thence occasioned. The closeness of feather in aquatic birds serves to present an impenetrable texture to the water in which they swim, as well as a smooth surface which diminishes the effects of friction in their progress.

The greater number of authors, in addition to this, tell us that birds, and more particularly aquatic birds, dress their feathers with a peculiar oil furnished for this purpose by a gland on the rump; but this is an opinion which we shall presently see admits of considerable doubt. It may be well, however, to state the particulars of the common notion. "Upon the rump," says Willughby, "grow two glandules, designed for the preparation and secretion of a certain unctuous liumour, and furnished with a hole or excretory vessel. About this hole grows a tuft of small feathers or hairs, somewhat like to a painter's pencil. When, therefore, the parts of the feathers are shattered, ruffled, or any way discomposed, the bird, turning * Wilson, Amer, Ornith。i. 15. 
her head backward to her rump, with her hill catches loold of the fore-named tuft, and pressing the glandules, forces out the oily pap, and therewithal anointing the disjoined parts of the feathers, and drawing them out with her bill, recomposes and places them in due order, and causes them to stick faster together*." "The glands which secrete the oil," says Blumenbach, "on the upper part of the tail, are largest in aquatic birds; in some of which, as the Muscovy duck (Anas moschata), the secreted substance has a musk-like odour †." 'The statement just given from Willughby is adopted by most of the systematic writers, though a few of them take no notice whatever of the existence of the rump glands. "On the back," we are told by Linnæus, "or upper surface of the rump, there are two glands which secrete an oily fluid, with which the birds anoint their feathers +." "The lower part of the back," says Dr. Latham, " is furnished with a double gland, secreting an oily fluid for the use of dressing the feathers $\S . "$

The recent authors who adopt this opinion would appear, from their taking no notice of them, to be unacquainted with the observations of $M$. Réaumur, which we shall abstract. The glands on the rump, he remarks, secrete an unctuous fluid, discharged in some birds by one, and in others by two excretory canals. Poultry have but one of these canals, which consists of a conical fleshy pipe of a series of rings, placed almost perpendicular to the rump; and when this gland is pressed by the fingers, the fluid, thickish in consistence, is seen to exude. But in a peculiar species of barn-door fowls, without

* Ray's Willughby, p. 3.

† Comp. Anat. by Lawrence and Coulson, p. 147.

\$ Ker's Linnaus, p. 409.

$\S$ General History of Birds, i, 22 , 
tails (Gallus ecaudatus, TEMmrNCK), originally it would appear from Ceylon , the tail, the rump, and the gland are all wanting, the part where these grow in other species being depressed and smooth

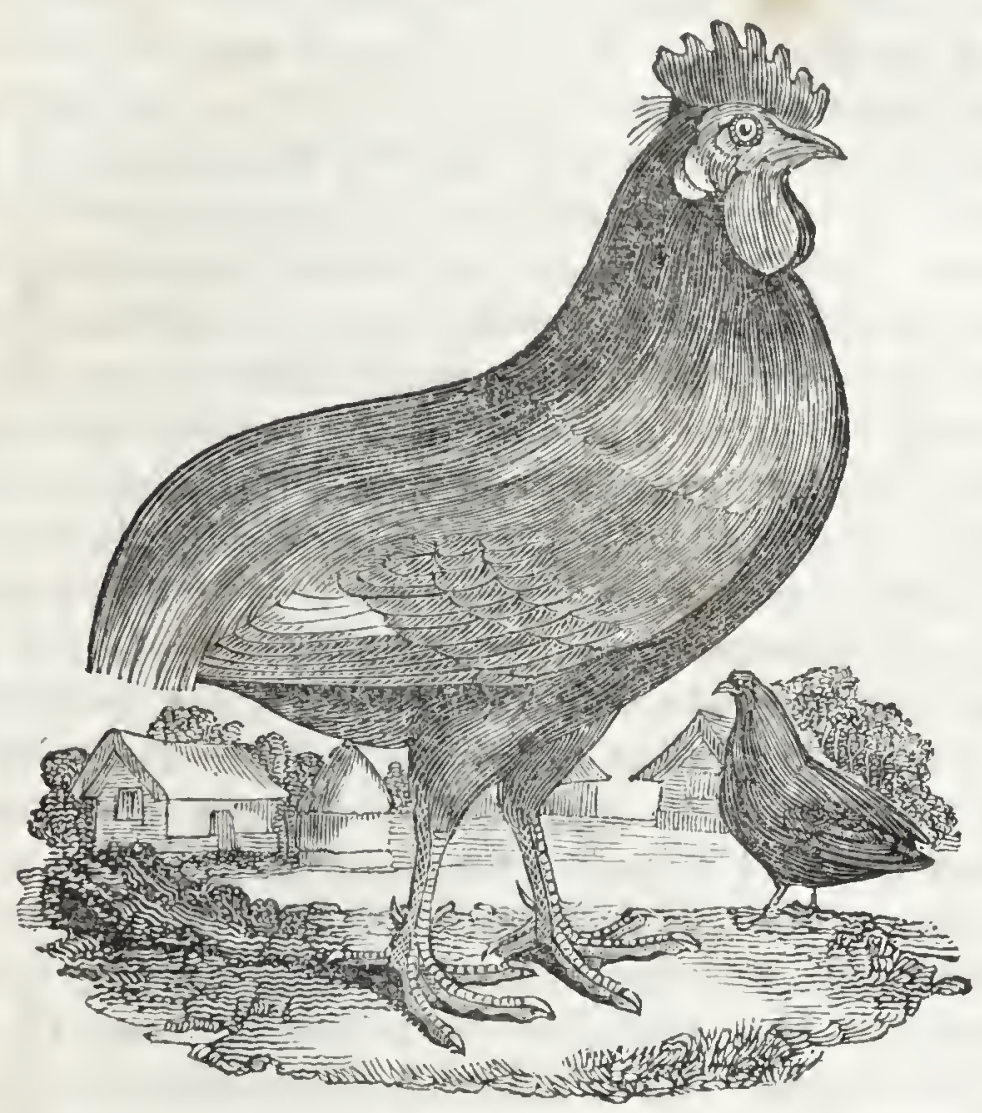

Rumkin or Tail-less Cock.

Were an attempt made to assign a reason why these Ceylonese fowls have no unctuous gland on the rump, a mistake might as readily be committed as has, it would appear, been done in the theory framed to account for the use of the gland in birds which possess it. All the works of nature being lavishly filled with wonders, fitted to raise most just admiration of the Creator, those who, with very laudable intentions, undertake to exhibit these won* Temminck, Hist, des Pig. et Gall. ii. 267. 
ders, may be considered as in some degree blameable when they introduce into their enumeration circumstances that are vague and uncertain. Among such doubtful things appears to be the opinion that the feathers of birds require to be done over with a kind of oil or grease, in order to cause the rain or other water to run off without penetrating them, the unction, when wanted, being supplied by the gland on the rump. If those who adopt this opinion, plausible as it seems to be, had taken the trouble to ascertain the small quantity of fluid actually secreted by this gland from day to day, and compared it with the proportional extent of surface constituted by the assemblage of the numberless feathers of any particular bird, not to speak of the instrument with which the dressing is said to be effected, they would have seen at once that the theory is untenable, as the quantity secreted in one day would scarcely suffice to anoint a single feather, much less the whole. We have just squeezed out all the oil contained in the double rump gland of a common wren, and found it impossible to make it go over one of the tail feathers*. "One fact," says M. Le Vaillant, "is frequently sufficient to demolish a theory +;" and the fact that the feathers of the rumpless fowls which have no gland are as sinooth and proof against rain as those which possess the gland, furnishes a striking illustration of the remark.

The fact, however, is unquestionable that birds are sometimes seen pecking about the gland in question. But the observing of a bird thus engaged, so far from authorizing the received conclusion, might have shown that the point of the bill could never squeeze out enough of fluid for the purpose alleged. The only legitimate inference would have been that some slight pain or irritation had caused the bird to peck the gland; and every school* J. R. $\quad$ + Hist. Nat. des Perroauets, i. 20. 
boy knows that the canal of this gland often becomes obstructed in his pet birds, and occasions a troublesome and sometimes fatal engorgement*.

The remark of Blumenbach $\dagger$ that the gland is largest in aquatic birds, contains a generalization not warranted by facts; for grebes, divers, and such as want tails, have the gland much smaller + , though their feathers are as smooth and as impenetrable by water as those of the terns and the gulls which have considerable tails.

It is only requisite, indeed, for any one to watch a bird preening its feathers, to be convinced of the fallacy of the theory. We have attended for hours to various species of birds when thus engaged; and so far from constantly returning to the rump-gland, which by the hypothesis would be indispensable for dressing every successive feather, it is rarely visited at all during the operation, and when it is, the sole object seems to be to trim the pencil of feathers which surrounds the gland $\S$. Had we any doubts upon the subject, the simple experiment of covering the gland in one hen or duck so as to prevent the bird having access to it, and leaving it uncovered in another, for a few days or weeks, would, by the state of the feathers in each, set the question at rest. Independently of such an experiment, common to all birds, the circumstance of the feathers on the head being equally trim, smooth, and glossy with those on the body, though they cannot be oiled, as it is impossible to reach the head with the bill-the only instrument by which the oil could be applied-is of itself fatal to the theory.

Should we be asked what we consider to be the use of the gland, we must at once say that we do

* Réaumur, Oiseaux Domestiques, ii. 332. + See p. 4 . $\$$ Ray’s Willughby, p. 3. $\S J . R$. 
not know; but our jgnorance of its real use furnishes no support to the conjectural theory which the preceding facts prove to be erroneous, no less than some others connected with cleanliness which we shall now mention.

The Mohammedan Arabs of the desert, when they cannot procure water to perform the stated ablutions enjoined by the Koran, have recourse to dry sand, with which they rub their bodies as a substitute* ; and it is no doubt as a substitute for washing that some birds, thence called pulverizers (Pulvinatores), are fond of squatting in dust and hustling it into their feathers. Caged larks may thus be seen rubbing their breasts amongst the dry mould at the side of their withered turf with the utmost eagerness. A hasty observer might perhaps be led to conclude that this was done with the design of looking for insects; but the eye of the bird directed away from the spot and expressive of inward pleasure, would show him that such a conjecture could not be supported. A more familiar instance of pulverizing may be observed in the barn-door fowl, even the unfledged chickens of which we have observed muddling in the dust by instinct, it should seem, as they were too young to have learned the practice from experience or by imitation. Now, had the feathers of these pulverizers been previously smeared with any unctuous matter, such as that in the rump-gland, the dust would have adhered, and thus tended to soil rather than to cleanse them. The design with which these birds hustle amongst dust is supposed to be to suffocate or banish the birdlice (Nirmi), with which most birds are infested; on the same principle as swine wallow in the mire, and as the rhinoceros and elephant in Nubia roll themselves in mud to defend themselves from the terrible breeze

* Volney, Egypt and Syria, vol. ii. 
fly called $z i m b$ *. Be this as it may, we have not observed birds, after pulverizing, employed in combing the dust out of their feathers with their bills; they seem, on the contrary, to prefer its remaining.

This curious subject may be illustrated by a circumstance observed by the traveller just quoted, in an eagle (Gypaëtos barbatus, SтовR) which he shot in Abyssinia. "Upon laying hold," says he, " of his monstrons carcass, I was not a little surplised at seeing my hands covered and tinged with yellow powder or dust. On turning him upon his belly and examining the feathers of his back, they also produced a dust, the colour of the feathers there. This dust was not in small quantities; for, upon striking the breast, the yellow powder flew in full greater quantity than from a hair-dresser's powderpuff. 'I'he feathers of the belly and breast, which were of a gold colour, did not appear to have anything extraordinary in their formation; but the large feathers in the shoulder and wings seemed apparently to be fine tubes, which, upon pressure, scat. tered this dust upon the finer part of the feather; but this was brown, the colour of the feathers of the back. Upon the side of the wing, the ribs or hard part of the feathers seemed to be bare, as if worn; or, I rather think, were renewing themselves, having before failed in their functions. What is the reason of this extraordinary provision of nature, it is not in my power to determine. As it is an unusual one, it is probably meant for a defence against the climate, in favour of birds which live in those almost inaccessible heights of a country doomed, even in its lowest parts, to several months' excessive rain $\uparrow . "$ A powdering of dust, however, we may remark in reference to this conjecture, would seem to be a bad protection against a heavy shower.

* Bruce's Travels. + Travels, Appendix, p. 155. 
A great number of birds are fond of washing their plumes, by throwing water over them with their beaks, and even dipping their bodies in ponds or streams. So universal is this habit, that it is taken advantage of on the Continent to entrap wild birds by means of what is called an Abreuvoir. "Nothing," says M. Bechstein, "can be more agreeable, during the hot weather of summer, than the sport thence arising, while seated tranquilly under the shade of thick foliage, by the side of a slow running brook. According to the extent of the place, a net from three to six feet long, by three or four feet in width, is extended over a rill which has been dug expressly for conducting the water of the adjoining stream. A number of rods, about an inch in diameter, are stuck in this rill upon a level with the water, where rings are fixed to prevent the net from being wetted, - the remainder of the little canal being covered over with boughs. When the place is well chosen it will be surrounded all day long, but particularly early in the morning and near sunset, the time for beginning to place the net being about the middle of July*."

Mr. Knapp mentions the linnet (Linaria Linota) as the cleanliest of birds in this respect,- - since it delights to dabble in the water and dress its plumage in every rill that runs by $\dagger$; but we do not think the linnet washes more frequently than any of the other smaller birds (Sylvicola, Vieillot). The linnet, the chaffinch, and all the seed-eating birds, indeed, we have remarked to wash less frequently than the slender-billed birds (Sylviada, Vigors), to which washing seems almost as necessary as food and air. These are accordingly amongst the most frequent captures in the Abreuvoirs, as we learn from M.

* Manuel de l'Amateur, p. 67, 2 d edit. $\dagger$ Journ, of a Naturalist, p. 154, 3d edit. 
Bechstein; and in water near their haunts we see them every day assiduously bathing. In confinement, again, they wash much oftener than the seed-eaters. A redbreast, which we at present possess, will wash at any hour of the day or night when he is furnished with water, and his feathers are scarcely dry before he is eager to renew his bath, which he would do, if permitted, a dozen times a day; while a goldfinch in a neighbouring cage does not care about washing. above once or twice a week. A fine black-cap, which is also in our possession, is nearly as fond of frequent washing as the redbreast*. Mr. Sweet finds that when his more tender birds are allowed to wash as often as they would do, particularly in winter, it is apt to prove injurious, and sometimes fatal $\dagger$.

"One of the most remarkable propensities that manifest themselves in young birds," says the Hon. and Rev. W. Herbert, "is the ardent desire of washing themselves, in some species, and of dusting themselves, in others, as for instance in the common wren. This, I conceive, must be an instinctive incitement. It is barely possible that the little wrens might see through the aperture of their covered nest the parents dusting themselves on the ground in some instances; but their nests are often placed where this could not be perceived, and the desire is equally powerful in all individuals. On the other hand, the nests of the wood-wren and many others which wash themselves eagerly on the first opportunity that presents itself after they can feed themselves, could never have seen the like, their nest having been situated under the roots of a tree upon a dry bank in a wood. This impulse is, therefore, inspired by the Creator ; and it is inspired with a force that in captivity is like unto madness. It is very injurious to a $* \mathrm{~J}$. R. + British Warblers, passim. 
nightingale to wash in the winter, and it is fatal to it to do so often; yet the moment a pan of water is put into its cage, it rushes into the water and soaks itself, and then stands shivering the very image of chilliness and despair; yet will it eagrerly repeat the operation, if allowed to do so, every day till it dies. Young whinchats, sedge-warblers, woodwrens, yellow wrens, \&c. as soon as they can feed themselves, if offered water in a cage, wash with similar avidity; yet if the temperature be much under $70^{\circ}$, and the sun not shining, it is sure to kill them. In the younger birds it produces, some hours after and perhaps the next day, a sudden stroke of palsy, by which they drop with a scream, having lost the use of one or both legs, and often with the mouths distorted. In this state the general health does not seem to be affected, but if both legs are paralysed, they must soon perish. At a little more advanced age, the consequence of a single washing in cool weather is epileptic fits, which are repeated at shorter intervals till they occasion death. In a state of liberty the bird would dry itself quickly by rubbing against the leaves and by very active motion, in the same manner as the wrens by perpetual activity resist the severest frost, of which the least attack would kill them in confinement; and probably when birds have opportunities of washing always at hand, they choose the most favourable moments. In a cage it is necessary to give such birds their water in a very narrowmouthed fountain, to prevent their lilling themselves by washing. They will repeat it with equal eagerness, if not prevented, until they die, so strong is the in ward impulse. I think the desire of washing belongs most strongly to the birds which migrate to hotter climates in winter, that of dusting to those which remain with us; a substitution wise as all the dis. 
pensations of the Creator; for if the little wren in winter were to wash in cold water instead of dusting, it must perish from the chill *."

The largest birds of prey are no less fond of washing, though they care so little for water to drink that it has been erroneously asserted they never drink. "What I observed," says the Abbé Spallanzani, " is that eagles when left even for several months without water did not seem to suffer the smallest inconvenience from the want of it; but when they were supplied with water, they not only got into the ressel and sprinkled their feathers like other birds, but repeatedly dipped their beak, then raised their head in the manner of common fowls, and swallowed what they had taken up; hence it is evident that they drink. For the eagle it was necessary to set the water in a large vessel, otherwise, by its attempts to drink, the vessel was sure to be overturned t."

In books of falconry also directions are given for furnishing the birds with water to bathe. "Having weaned your hawk," says Willughby, "from her ramageness, she being both ways lured, throughly reclaimed, and likewise in good case, offer her some water to bathe herself in, in a basin, wherein she may stand up to the thighs, choosing a temperate, clear day for that purpose. Having lured your hawk and rewarded her with warm meat, in the morning carry her to some bank, and there hold her in the sun till she hath endued her gorge, taking off her hood that she may preen and prick herself: that being done, hood her again and set her near the basin, and taking off her hood, let her bathe as long as she pleases; after this take her up, and let her pick herself as before, and then feed her. If she refuse

* Notes to White's Selborne, Letter 12, edit. 8vo. 1832.

+ Dissertations, i. 173. 
the basin to bathe in, show her some small river or brook for that purpose. By this use of bathing she gains strength and a sharp appetite, and thereby grows bold; but that day wherein she batheth give her no washed meat. If you would malie your falcon upwards, the next day after she hath bathed get on lorseback, either in the morning or evening, and clionse ont some field wherein are no rooks or pigeons; then take your lure well garnished on both sirles, and having unlooded your hawk, give her a bit or two on the lure, then hood her ; afterwards go leisurely against the wind, then unhood her, and before she bate or find any check in her eye, whistle her off from your fist fair and softly*."

Did these birds require to oil their feathers after every washing, an immensely larger gland than any of them are finmished with, would be indispensable to siipply the requisite quantity; while it would prevent their feathers from being wetted at all, thongh this seems to be their aim in the operation, for the purpose, amongst other things, of getting rid of parasite insects. The head, however, which they cannot reach with their bill, and which eamot therefore be daubed with the oil, is the most liable to be thus infected; and accordingly we often see eage birds content themselves with wetting their heads, without touching the rest of the body. They may also be frequently seen combing or scratching their heads with their claws, no donbt with a similar design. This circumstance has given rise to a curious discussion concening the intended use of the claws of some species, among which are the night-jar and the herons, that are furnished with small teeth like a saw or comb.

* Ornithology, by Ray, p. 402. 


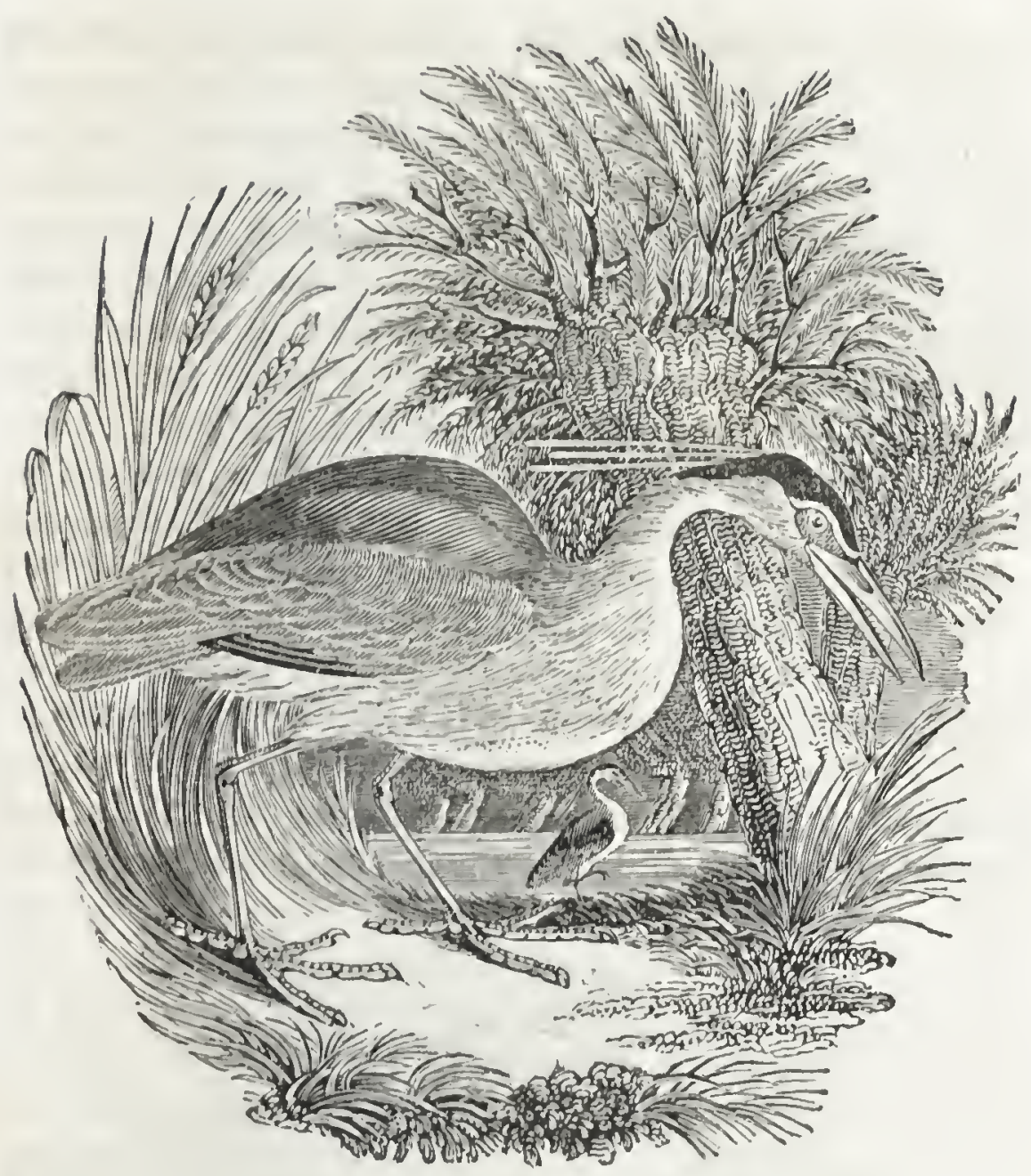

Night-IIeron.

Wilson remarked that in specimens which he procured of the night-heron (Nycticorax Europaus, Stephens), the middle claws, serrated on the with from thirty-five to forty teeth, contained "particles of the down of the bird, showing evidently from

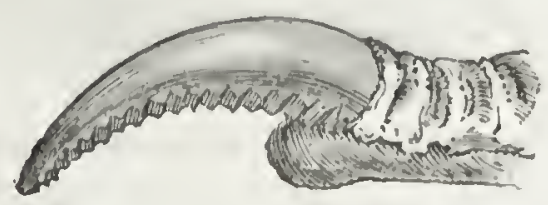

l'oetinated claw of Night-Heron. 
this circumstance that they act the part of a comb, to rid the bird of vermin in those parts which it cannot reach with its bill*." With respect to the night-jars Wilson gives a similar statement. His night-hawk, for instance, he says, has its "middle claw pectinated on its inner edge, to serve as a comb to clear the bird of vermint." Again he says, "the inner edge of the middle claw of the whip-poor-will, another of the night-jars, is pectinated; and from the circumstance of its being frequently found with small portions of down adhering to the teeth, is probably employed as a comb to rid the plumage of its head of vermin, this being the principal and almost only part so infested in all birds t." He further proves this in the case of the Carolina night-jar, or chuck-will'swidow, by actual observation of the fact; speaking of which species he says, "reposing much during the heats of the day, they are much infested with

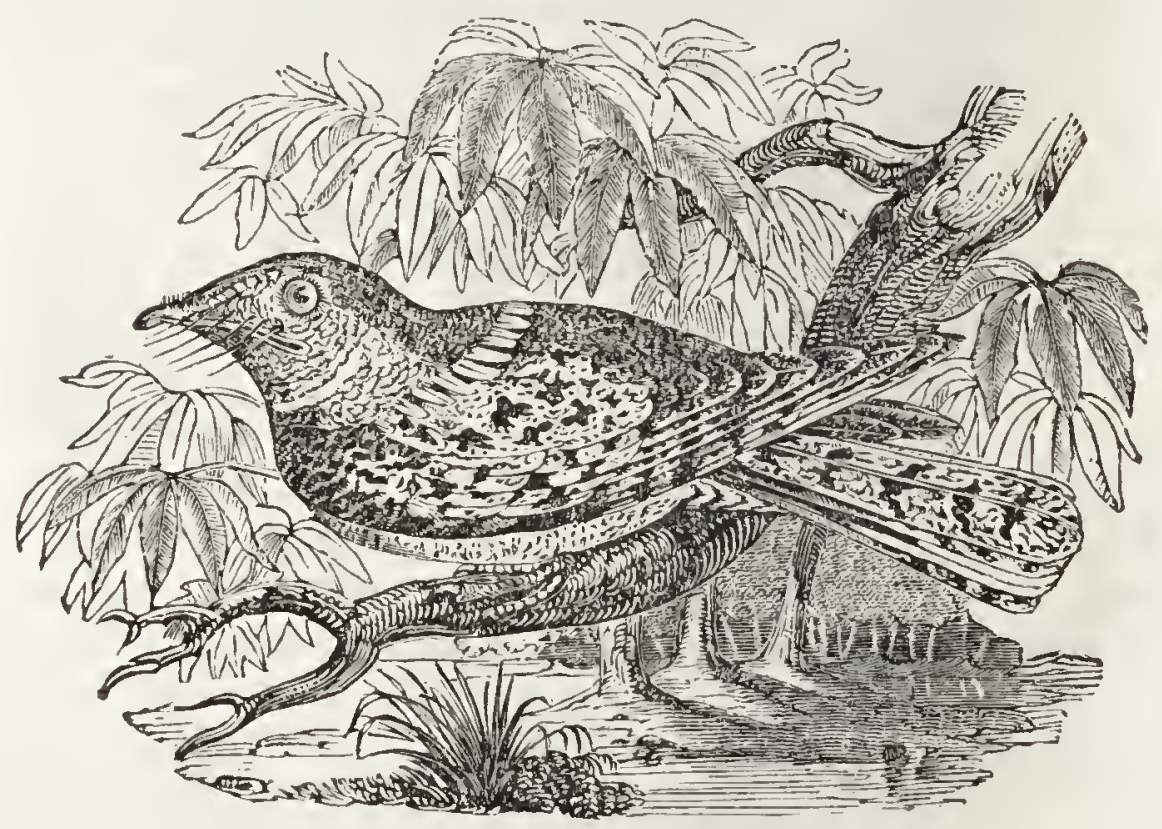

Carolina Night-jar or Chuck-will's-widow.

- Wilson, Amer. Ornith. vii. 1]0, 2 d ed. + Ibid. v. 70. 
vermin, particularly about the head, and are provided with a comb on the inner edge of the middle claw, with which they are often employed in ridding themselves of these pests when in a state of captivity*."

White, of Selborne, on the other hand (with whose account Wilson does not seem to have been acquainted), was persuaded that the serratures in the claw of the European night-jar were designed to enable it to secure beetles (Zantheumia solstitialis, \&c.), on which he observed it preying. "The circumstance," he says, "that pleased me most was, that I saw it distinctly, more than once, put out its short leg when on the wing, and, by a bend of the head, deliver somewhat into its mouth. If it takes any part of its prey with its foot, as I have now the greatest reason to suppose it does these chafers, I no longer wonder at the use of its middle toe, which is curiously furnisleed with a serrated claw.$+ "$ Mr. Dillon has recently argued with considerable plausibility against this conjecture of White's, considering the chief use of the serrated claw to be the combing or dressing the bristles (Vibrissa). For this purpose, he thinks the entire mechanism of the leg, foot, toe, and claw, adapted with wonderful precision; while for the seizing of beetles there does not appear the least suit ability. The middle toe, he says, compared with the

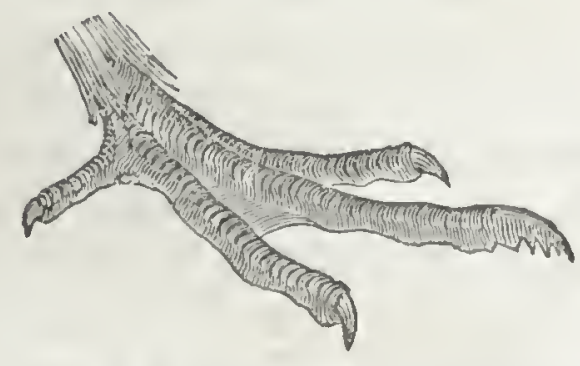

Night-jar's foot, showing the pectunated claw. * Wilson, Amer. Ornith. vi. 97, 2d ed. + Letter 47. 
others, is very long, and its claw is somewhat flat, slightly curvilineal outwards, and serrated on the concave edge, something like a sickle placed flatwise, with its point outwards, though Bewick's figure erroneously represents it as bending inwards like the other claws.

This form of the claw peculiarly unfits it for an instrument to seize with, while it renders it well adapted for a comb; and when we consider how the bristles around the gape may become bent or clotted at their points, the necessity of such an instrument will scarcely be disputed. Mr. Dillon adds, "I think I have seen the bird several times use his foot as I have described: I am almost sure my eyes could not have deceived me*."

In reply to this it has been contended, "that there is an American group of this family, which have no bristles round the bill, and yet have serrated claws; and another group in Australia having bristles, and yet the claw smooth and simple;" and in reply to Wilson's account the same writer remarks, that to suppose " nature has given to one or two families of birds the exclusive power of freeing themselves from an enemy which, in like manner, infests all birds, is preposterous," adding, that " the Australian Podargus (the family just referred to as having a smooth middle claw) is so tormented, since some of the empty nits still adhere to the feathers of my specimens $t . "$ We may add, that in all the specimens we have examined the claw is bent inwards, as Bewick represents it, and not outwards, upon which circumstance chiefly Mr. Dillon founds his opinion +.

Perhaps it might be as well to imitate the modesty of Audubon, who says, "I wish I could have discovered the peculiar use of the pectinated claw which * Mag. of Nat. Hist. iii. 33. + Ibid. iv. 276. $\pm J . R$. 
this bird (chuck-will's-widow) has on each foot; but, reader, this remains one of the many desiderata in ornithology, and I fear, with me at least, it will continue so *." Yet, while we do not pretend to be able to decide the question, we think Wilson's account the most plausible. The recorded fact, which he actually observed, cannot surely be overturned by the general remark that it is preposterous to suppose these birds furnished with a peculiar instrument which would be no less useful to all birds. In answer to this, we are entitled, by parity of reasoning, to say that it is equally preposterous, according to the other explanation, to suppose the serrated claw confined to the night-jars, as other birds which feed upon chafers, the kestril (Falco tinnunculus, $\mathrm{R}_{\mathrm{AY}} \dagger$ ), for example, are not furnished with any thing of the kind. After all, the serratures may be intended for none of these purposes, but for enabling the bird to hold more firmly when it alights

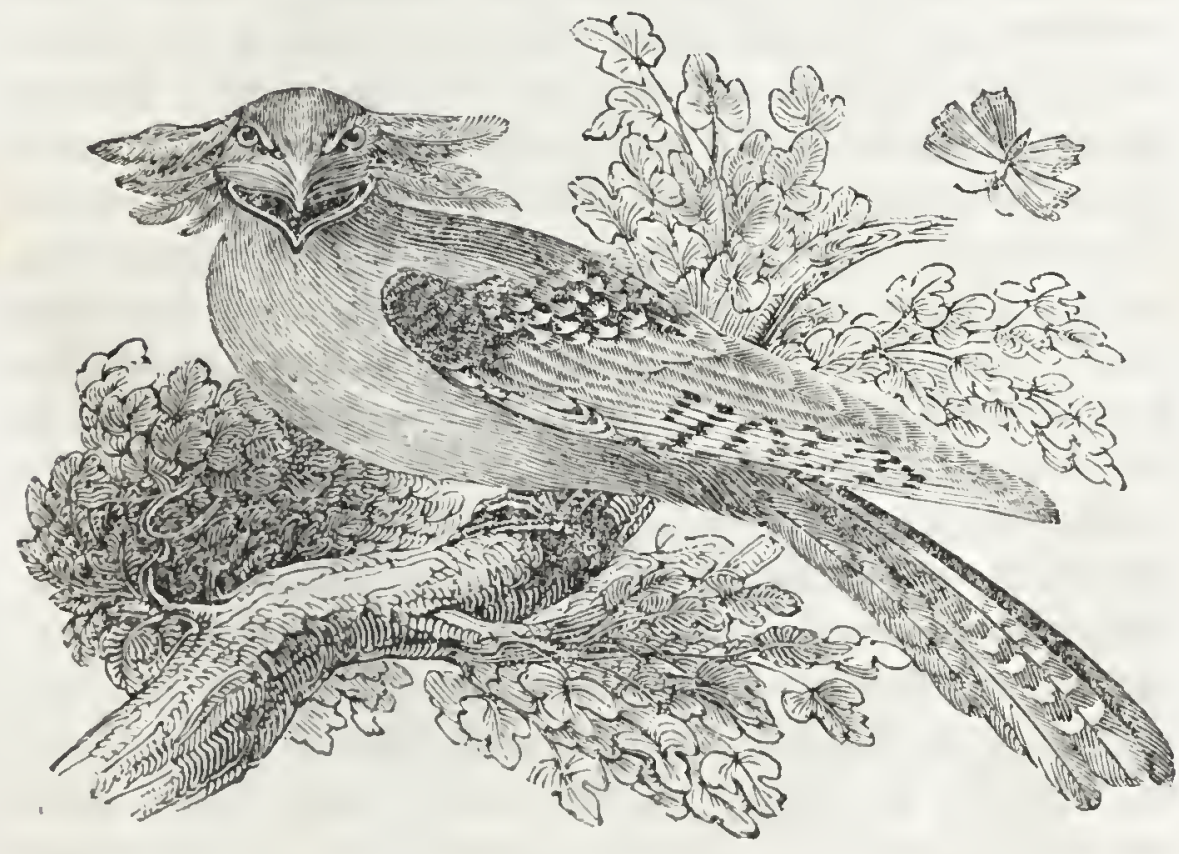

Podargus Auritus.

* Ornithological Biography, p. $276 . \quad$ Selby, p. 44. 
on a branch, in which case it has the peculiarity of sitting lengthwise, and never, like other birds, in a cross position. It would be interesting to learn whether the Australian Podargus, which wants the pectinated claw, perches in this singular manner.

The following circumstance, which fell under our observation, appears to show that swallows are not provided with the means of freeing themselves from parasite insects. On going to visit the ruins of Brougham Castle, in Cumberland, we were struck by the unusual tameness of a swallow (Hirundo rustica, Pluny), which we found sitting on the parapet wall of the bridge which crosses the Emont, on the road from Penrith. Swallows are, indeed, far from being generally shy, trusting, perhaps, to their rapidity of flight, should danger threaten; but this poor swallow allowed itself to be approached without offering to escape. It seemed, in fact, instinctively courting human aid, at least we were inclined so to interpret its pitiful looks. On taking hold of it, we found the feathers swarming with an insect (Craterina hirundinis, OLfERs), somewhat larger in size than the common house bug (Cimex lectularius). We took the poor bird immediately to the river, and, on being freed from its tormentors, it flew off joyfully to join its companions. Had it been furnished with a comb, like the night-jars, it would not probably have required our assistance *.

The main instrument, however, by which birds trim their feathers is the bill; and if any fluid is used, it must be produced from the salivaryt, and not from the rump-glands. By attending minutely to the operation, indeed, the tongue may be perceived to be as actively employed as the other parts of the bill,

* J. R.

$\dagger$ Huber, De Lingua Pici viridis, and Architecture of Birds, chap. $x v$. 
and is certainly the organ which apprizes the bird of any rumpling or clotting of the plumelets; and when such derangement is perceived, a pause is instantly made till the part is properly adjusted. We have observed a young green-bird (Fringilla chloris) preening its wings as they became dry after washing; and we could distinctly perceive the tongue employed both for ascertaining the parts that were rumpled, and for licking them straight when merely passing them through the bill was found to be insufficient*

That this, though it may be considered a novel statement, is notwithstanding a correct one, may be corroborated analogically, by referring to the similar manner in which other animals clean themselves. Quadrupeds have no glands similar to those in birds erroneously conjectured to furnish a dressing oil; yet the greater number of quadrupeds have their fur smooth and even glossy, simply from licking it, as our young green-bird was seen to do its feathers. The cattle in our pastures may in this way be seen passing their moist tongues over their hair; and the elephants in our menagreries may be observed using the moist extremity of their proboscis to clean their rough hairless skin. Even among the insects, whose habits and economy are so very different, we have, at least in one curious instance, remarked the process of cleaning performed on the same principle by a moistened instrument. Onr readers may be pleased, by way of illustration, to see the original account of this instrument observed in the grub of the glow-worm (Lampyris noctiluca).

"In an excursion for the purposes of natural history to the woods of Dartford, in Kent, the 14th of last March, I found an insect, which I had not * J. R. 
hitherto met with, creeping upon the mossy trunk of an oak, which, besides, was entwined with honeysuckle, and near the bottom a ferm plant was rooted among the decaying bark. This insect much resembled the female glow-worm in external appearance, but it was considerably longer, and the colours were different. Its head, though small, was formed like those of the grubs of predaceous beetles, whence I conjectured it might belong to some of their numerous families; but lest I might be deceived in this, and that after all it might be a vegetable feeder, $\mathbf{I}$ put some of the oak bark, moss, fern, and honeysuckle, along with it into a collecting box. Into the same box I afterwards put several specimens of small snails, with pellucid shells, which I found in the same locality - a circumstance which led me to the discovery of one of those facts that, after eluding direct research, are often the result of accident.

"It was not till next day that I looked into the box, when I perceived that none of the vegetable substances had been touched, for the snails had glued themselves to the lid, according to their usual custom when put into a dry place; and though the little stranger was sufficiently lively, and walked about in all directions, nothing within reach appeared to suit its taste. After watching it for some time, my attention was drawn to some very singular movements which it made with its tail, and which the reader will understand better if he has observed how the common earwig, or the insect popularly called the devil's coach-horse (Goërius olens, Ste phens), bends up its tail over its back, somewhat in the manner of a spaniel when it trips along well pleased before its master. The forked tail of the earwig, however, as well as that of the Goërines, is said to be used in assisting to unfold its long and closely-folded wings, 
an operation which I have never myself witnessed; but as the strange insect had evidently no wings, this could not be the design of the movements to which I have alluded. I have more than once seen a female moth strip the down from lier body to furnish her eggs with a warm covering, for which purpose she bent in the required direction an instrument like a pair of tweezers, situated at the extremity of the tail; but in the instance in question this could not be the case, as there was no down on the body; and yet, upon closer inspection, it seemed to be pulling off something very assiduously from the parts upon which the extremity of the tail was furned back.

" 'There appeared to be something so uncommon in these movements, that my curiosity was excited to observe them more minutely; and as the creature was not at all timid, I could easily observe it through a glass of some power. The caudal instrument I discovered, by this means, to consist of a double row of white cartilaginous rays, disposed in a circle, one row within the other; and, what was most singular, these were retractile, in a similar manner to the horns of a snail. The rays were united by a soft moist gelatinous membrane, but so as to be individually extensile; one or two being frequently stretched beyond the line of the other. The rays were also capable of being bent as well as extended, and they could therefore be applied to the angles or depressions of an uneven surface.

"It was not long before I convinced myself that this singular instrument was employed by the insect for cleaning itself; and it would have been difficult to devise any thing more effectual for the purpose, though its action was different from all others of this kind with which I was acquainted, inasmuch as it operated by suction, and not as a comb, a brush, or 
a wiper; of which I shall mention some examples in the sequel. It was, moreover, furnished in the interior with a sort of pocket, of a funnel shape, formed by the converging rays, into which was collected whatever dust or other impurities were detached from the body, till it could hold no more, when, by a vermicular movement of the rays, the accumulated pellet was extended, and placed with great care in some place where it might be out of the way of again soiling the glossy skin of the insect. This skin, if I may call it so, was of a soft leathery appearance, exhibiting, when magnified, a minute delicate clothing, similar to shagreen-but to the naked eye this was not apparent.
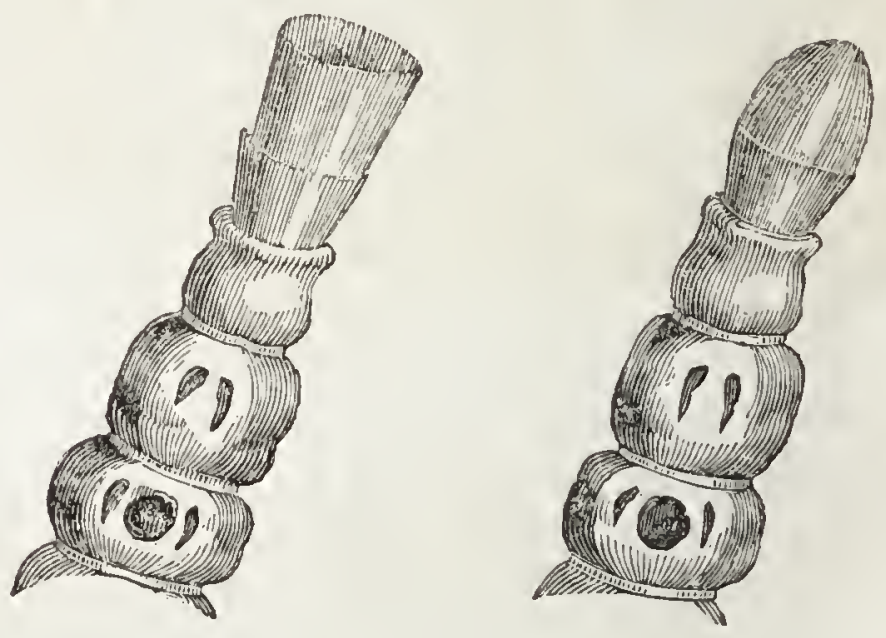

Magnified plan of the Cleaning Instrument, open and closed.

"The instrument just described, accordingly, when expanded over a portion of this shagreened surface, was subsequently drawn out, with an evident effort, (repeated if necessary,) in the same way as boys draw their moist leather suckers when they amuse themselves in dragging stones after them. Every particle of dust or other extraneous matter is thus detached 
from the skir, and, by a peculiar movement of the retractile rays, is lodged in the funnel-shaped pocket.

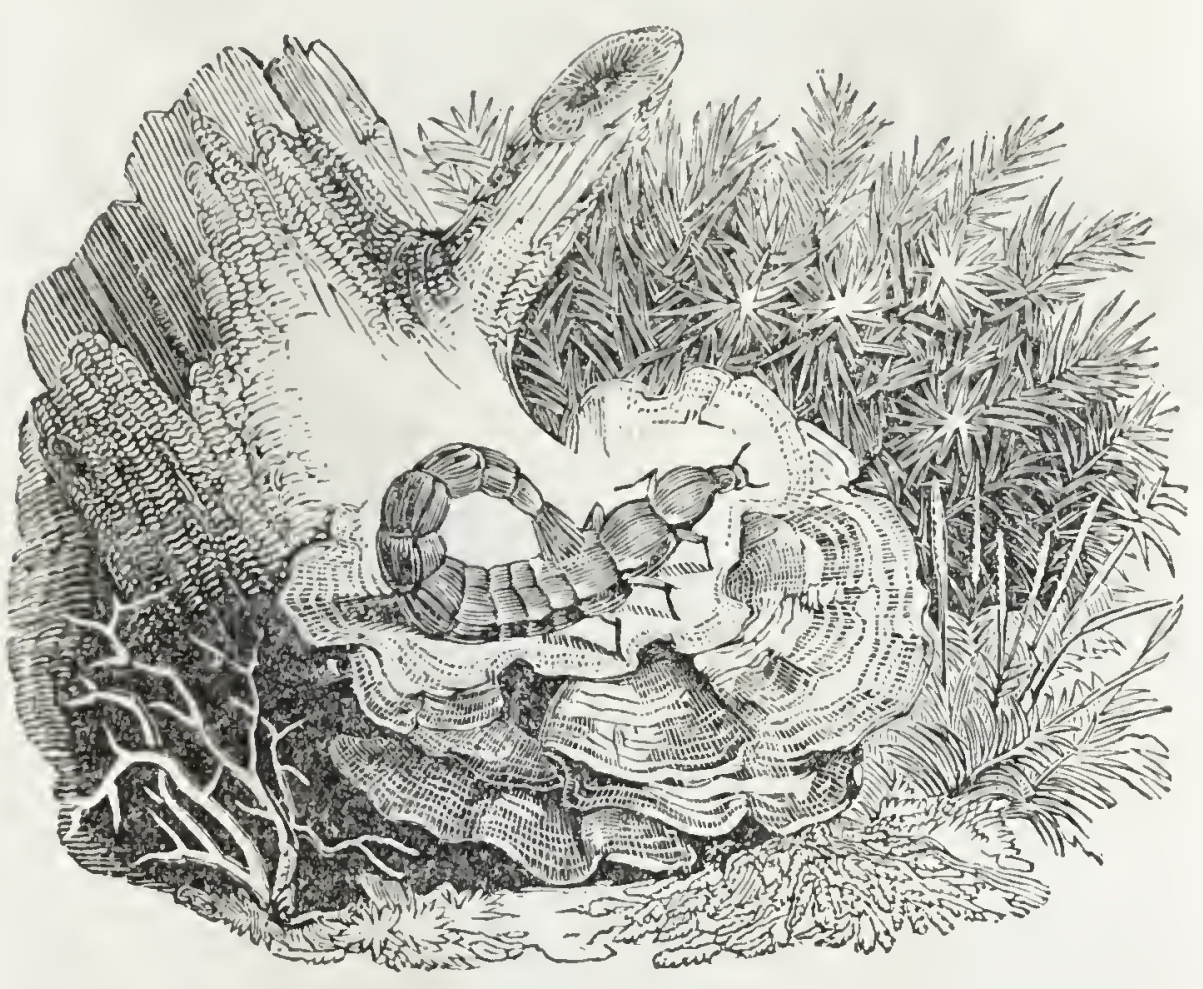

Larva of the Glow-worm, using its cleaning instrument.

"The actual food of the grub in question (as. certained to be snails) shows, in a very striking point of view, the design of Providence in furnishing it with the instrument which I have described, for it caunot well devour one of its victims without being soiled by slime; and accordingly, after every repast, I observed that it went carefully over its head, neck, and sides, with its cleaning instrument to free them from slime ${ }^{*}$."

We may also mention, in illustration, the pe-

* J. Rennie, in the Journal of the Royal Institution for Oct. 1830. 


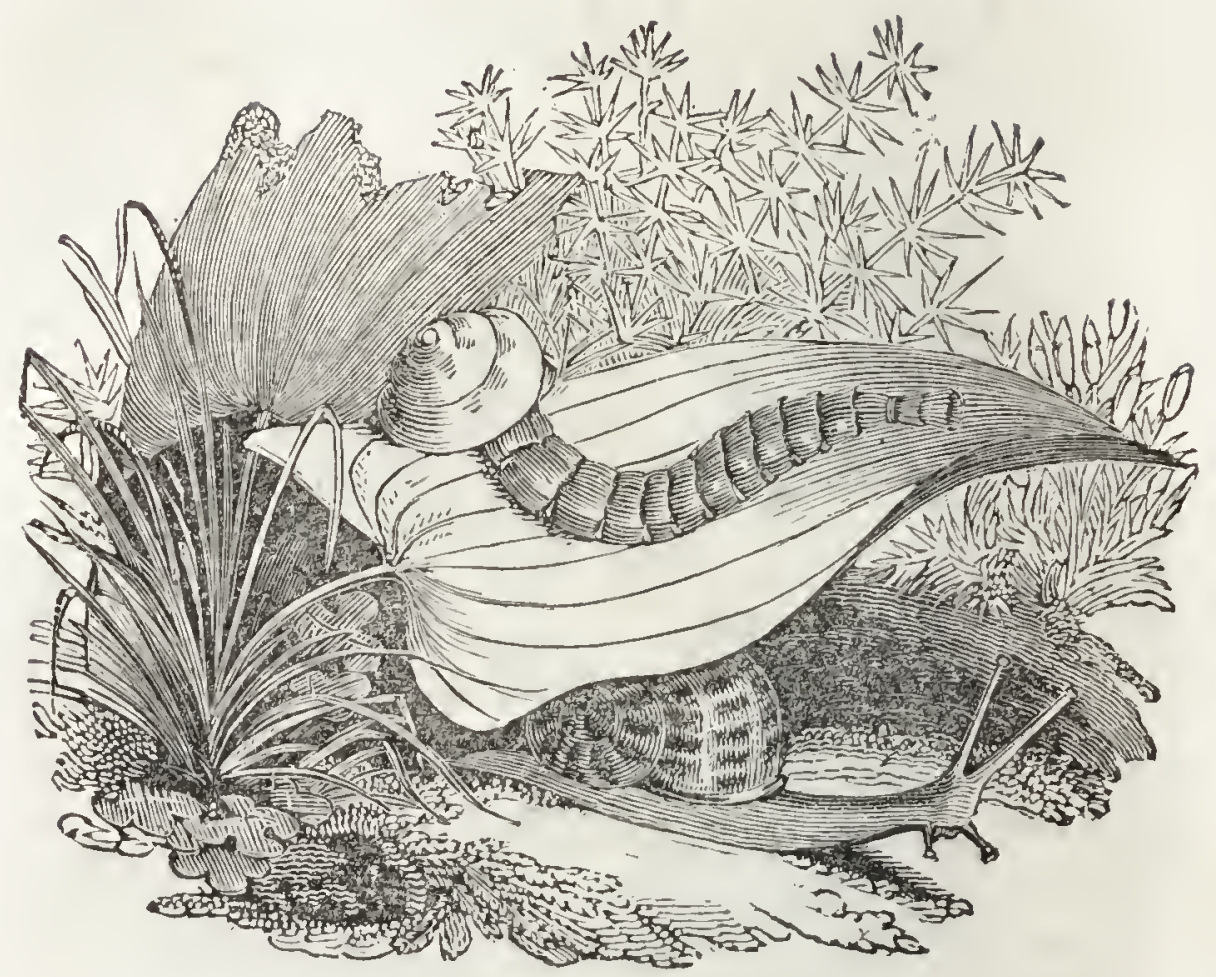

Grub of the Glow-worm devouring a Snail.

culiar structure of the foot of flies (Diptera) considered as an instrument for cleaning, particularly as it does not seem to be noticed in books of natural history, though most people may have remarked flies to be ever and anon brushing their feet upon one another to rub off the dust, and equally assiduous in cleaning their eyes, head, and corselet with their fore legrs, while they brush their wings with their hind legs. In the foot of the common blow-fly (Musca carnaria) there are two rounded combs, the inner surface of which is covered with down, forming a fine brush; and some crane flies (Tipulida) have three such combs on each foot, as may be seen in a drawing of them which we have given elsewhere for a different purpose* .

* Insect Transformations, p. 391. 


\section{Chapter II.}

BIRDS, SOLITARY $\Lambda N D$ GREGARIOUS, ON $\Lambda$ CCOUNT OF FOOD.

$I_{T}$ is one of the common amusements of the inhabitants of Aleppo and other eastern places, while promenading, as their custom is, on the flat roofs of their houses for the purpose of enjoying a cool breeze, to scatter grain, or make a motion as if they were scattering grain, when, in a short time, flocks of pigeons and other birds, though previously invisible, will make their appearance at the well-known signal*. In the same way we can attract to a particular point all the fowls in a barn-yard, or the ducks or swans in a pond, who will crowd eagrerly to the spot where they expect to obtain food. In the early spring also, when the willows, in defiance of cold days and colder nights, expand their palms, we have seen a numerous assemblage of insects of very different species, butterflies, bees, wasps, and various Diptera, all crowding around the golden blossoms, attracted, no doubt, by the rich perfume diffused around the vicinity of the tree, and giving goodly token of the honey to be there procured.

'The causes of the assemblage of species, otherwise so different in habits, in such instances as these, are very obvious and easily explained; but in many other cases of animals congregating in numbers, the chain which binds them together is more or less hidden. We may mention the case, for example, of a flock of sheep in a meadow huddling themselves so closely * Volney, Voyage dans l'Egypte et la Syrie, vol.ii. 
together that there is barely room for each to feed. At the moment of writing this, we can see from our study-window sevell out of a flock of a score feeding so closely crowded as to have their fleeces in actual contact. And yet the field is by no means small, and other parts of it have grass equal in goodness to the corner where these seven sheep are nibbling it to the very root, while the rest of their companions are only at a few feet distance, in the same quarter of the field.

In order to arrive at the cause of this sociality, which seems not only to be without any reasonable motive arising from mutual advantage, but to be rather disadvantageous from the pasture being exhausted by the crowd of feeders, we must consider these sheep as domesticated, and, of course, in different circumstances from the species in their original state of wildness and freedom, in which such sociality may serve some important purpose. The sheep of mountainous countries, where they are in a state of comparative wildness, though unconfined by fences, like those in the meadow just alluded to, are observed to keep together in bands, and to pass from one mountain platform to another in regular ranks, one deep, always headed by a leader. The duty of this leader is to give warning of the approach of danger to his troop, both when on a march of removal to a different pasture and also while they are feeding. 'This fact, which has often been recorded, we have had more than once an opportunity of witnessing in Wales. On ascending Snowdon, for example, our attention was attracted by the deep harsh krroup of a raven sailing about on the air, looking out, no doubt, for some luckless sheep enfeebled by accident or disease upon which he might pounce. Immediately from the shoulder of the mountain above us the note of 
the raven was answered by the alarm-call of the leader of a sinall flock of sheep who were feeding on the scanty herbage of this lofty region; and, at the signal, they quickly drew closer together, and, forming a " serried phalanx," eyed their enemy with a bolder bearing than we could have deemed possible in animals proverbial for timidity. The raven was not long in discovering that he had little chance of singling a victim from so watchful and wary a band, and flew off towards the neighbouring cliffs, where he might chance to light upon the carcass of one left undevoured by some fox scared from his prey, or accidentally precipitated, as we have seen happen, from the rocks above. On the departure of their enemy, the sheep began to feed again, but warily at first, raising their heads at intervals to assure themselves that he was really gone; while, to render assurance doubly sure, their leader again took his station as sentinel for the common weal *.

Now we are disposed to conclude, that these two cases of the sheep and the raven may, so far as food is concerned, be taken as the general conditions of the solitary and gregarious habits of birds. One whose food is confined to living prey will prowl alone, because along with associates he might fare scantily; while those who feed on seeds and other vegetable substances, easily obtained in abundance, congregate that they may feed more safely, by appointing, as the mountain sheep do, a sentinel to warn them of danger. The raven, indeed, can hardly be looked upon as subsisting wholly on living prey. It is not furnished by nature with sufficiently formidable weapons for this purpose; and almost uniformly when carrion cannot be obtained, it attacks lambs, sickly sheep, or such as have fallen into a ditch or bog, * J. R. 
perching on the head and pecking out the eyes. In temperate climates, birds that prey on carrion are less llecessary as scavengers than in tropical countries, where flocks of vultures collect together from distances that have astonished all observers by whom the circumstance is recorded. The gregariousness of these birds, however, may be plausibly referred to the wise care of Providence to have offensive caroasses speedily removed; and it is manifestly with this design, that such birds are endowed with extremely acute senses, either of vision or of smell, probably both, so as to enable them to discover carrion afar off.

This is well exemplified in two species, which have been frequently confounded, the 'Turkey buzzard (Catharista aura, Vieiluot) and the black vulture (C. Umebu, VIEILLOT), both of which are looked upon as so useful that there is a considerable penalty for killing them. 'The former, indeed, as we learn from M. Descourtilz, is at Charleston commonly called by the name of Five pounds, from the amount of the penalty. "These birds," he adds, "are thus respected for the actual services which they render in removing from the city and its vicinity all dead animals and other garbage upon which they exclusively feed. Hence, if even a clicken die, it is not long before its bones are picked clean. 'The vultures are occupied the whole day in making their rounds to discover carrion and offal, and, coming down in legions, they mutually contend for the prey, which instantly disappears. They are so familiar that they may easily be knocked down with a stick. I had a great desire to procure a specimen in this way; but I was not disposed to pay five louis d'or of penalty *." "The great number of these birds" (C. Urubu), says Ulloa, "found in such hot climates, is an excellent * Voyages d'un Naturaliste, i. 244. 


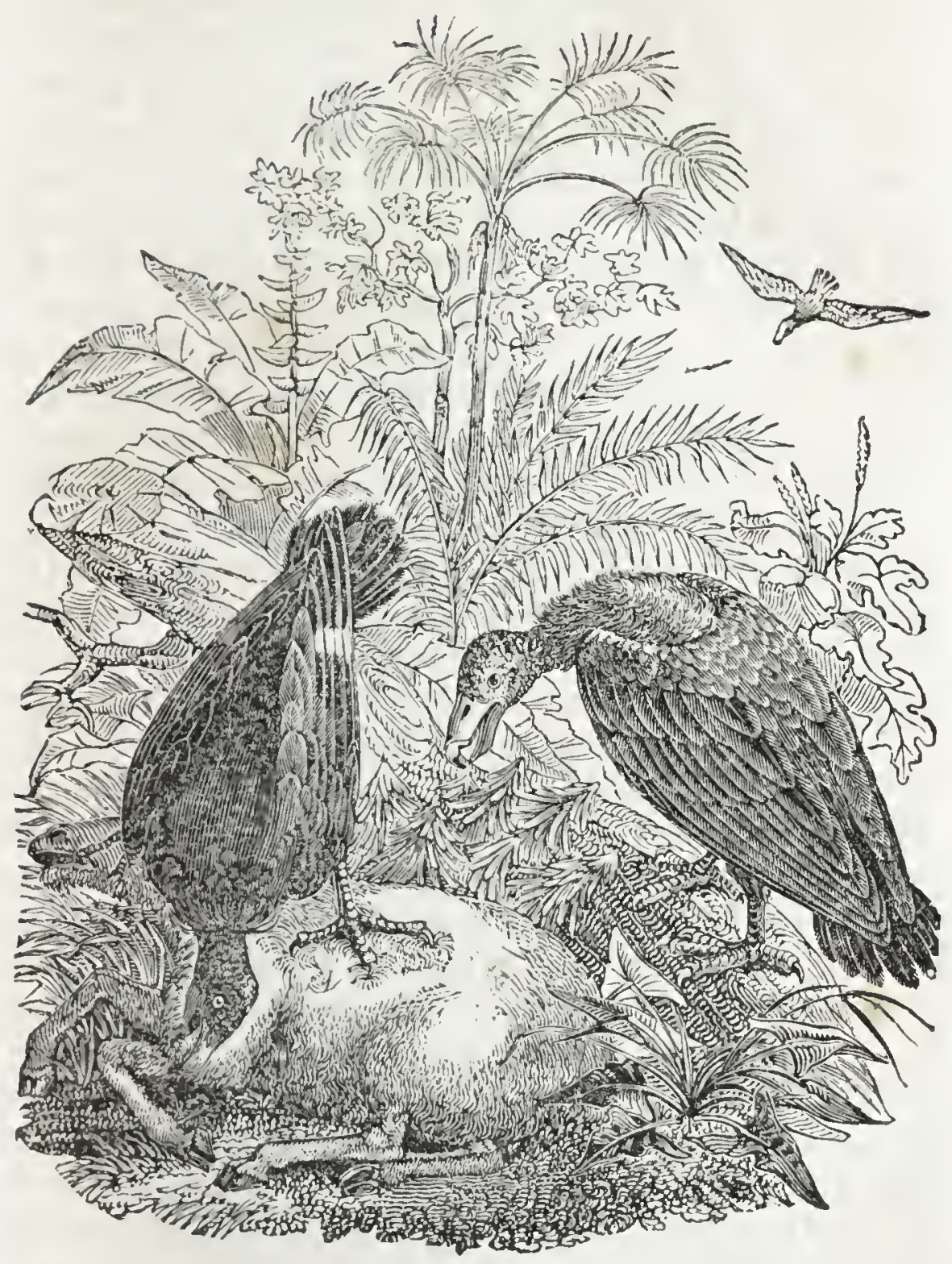

Turkey Buzzard and Black Vulture.

provision of nature; as otherwise, the putrefaction caused by the constant and excessive heat would render the air insupportable to human life. These birds are familiar in Carthagena; the tops of the houses are covered with them: it is they who cleanse the city of a!l its animal impurities. There are few 
animals killed whereof they do not obtain the offals; and when this food is wanting, they have recourse to other garbage. Their sense of smelling is so acute, that it enables them to trace carrion at the distance of three or four leagues; which they do not abandon till there remains nothing but the skeleton*." The following account of the same bird is in Wilson's best manner. It is dated Hampstead, near Charleston, Feb. 21, 1809.

"A horse had dropped down in the street in convulsions, and dying, it was dragged out to Hampstead and skimned. The ground for a hundred yards around it was black with carrion crows; many sat on the tops of sheds, fences, and houses within sight; sixty or eighty on the opposite side of a small run. I counted at one time two hundred and thirty-seven, but I believe there were more, besides several in the air over my head, and at a distance. I ventured cautiously within thirty yards of the carcass, where three or four dogs and twenty or thirty vultures were busily tearing and devouring. Seeing them take no notice I ventured nearer, till I was within ten yards, and sat down on the bank. Still they paid little attention to me. The dogs being sometimes accidentally flapped with the wings of the vuitures, would growl and snap at them, which would occasion them to spring up for a moment, but they immediately gathered in again. I remarked, the vultures frequently attack each other, fighting with their claws or heels, striking like a cock, with open wings, and fixing their claws in each other's head. The females, and I believe the males likewise, made a hissing sound, with open mouth, exactly resembling that produced by thrusting a red-hot poker into water; and frequently a snuffling, like a dog clearing his nostrils, as, I suppose, they were theirs.

* Voyage, Hist, de l'Amer. Merid, i. 52, 4to, Amst., 1752. 
On observing that they did not heed me I stole so close that my feet were within one yard of the horse's legs, and again sat down. They all slid aloof a few feet; but sceing me quiet, they soon returned as before. As they were often disturbed by the dogs, I ordered the latter home; my voice gave no alarm to the vultures. As soon as the dogs departed, the vultures crowded in such numbers, that I comnted at one time thirty-seven on and around the carcass, with several within; so that scarcely an inch of it was visible. Sometimes one would come out with a large piece of the entrails, which, in a moment, was surrounded by several others, who tore it in fragments, and it soon disappeared. They kept up the hissing occasionally. Some of them, having their whole legs and heads covered with blood, presented a most savage aspect. Still, as the dogs advanced, I would order them away, which seemed to gratify the vultures; and one would pursue another to within a foot or two of the spot where I was sitting. Sometimes I observed them stretching their necks along the ground, as if to press the food downwards *."

'These appear to be the same birds described by Acosta, under the name of Poullazes, which, as he tells us, "have a surprising agility and a piercing eye, and are very useful for clearing cities, not suifering the least vestige of carrion or putrid matter to remain. They spend the night upon trees and rocks, and resort to the towns in the morning, perching upon the tops of the highest buildings, whence they look out for their plundert." We shall only add to these accounts that of M. Desmarchais, who strangely supposes the C. aura to be a sort of turkey, that, instead of living upon grain, had become accustomed to feed on carrion. "These birds," he adds, * Amer. Ornith. ix. 107. $\div$ Quoted by Buffon. 
"follow the hunters, especially those whose object is only to procure the skins; these people neglect the carcasses, which would rot on the spot, and infect the air, but for the assistance of these birds, which no sooner perceive a flayed body, than they call to each other and pour upon it like vultures, and in an instant devour the flesh, and leave the bones as clear as if they had been scraped with a knife. The Spaniards, who are settled upon the large islands, and upon the continent, as well as the Portuguese, who inhabit those tracts where they traffic in hides, receive great benefit from these birds, by their devouring the dead bodies and preventing infection; and therefore they impose a fine upon those who destroy them. This protection has extremely multiplied this disgusting kind of turkey*."

But it may be remarked, that in all the accounts given of these gregarious vultures, nothing is said of their appointing a sentinel like the mountain-sheep, or like several species of birds to which we shall presently attend. For this, however, there is the obvious reason, that the vultures have no formidable enemies, being protected by man to serve his conlvenience, besides that, like the mole, they seem to be too disgusting to be preyed upon by any animal. The colonists, indeed, have tried every device to render the flesh palatable; but though they have cut off the rump and extracted the entrails, the instant the birds have been killed they still retain an insupportable odour of carrion which nothing can remove $t$. This is not all ; for they have also a singular manner of defending themselves if they happen to be attacked. "A man in the State of Delaware," says Mr. Ord, " a few years since, observing some Turkey buzzards regaling themselves upon the carcass of a horse, which was in a highly putrid state, conceived the * Quoted by Buffon。 + Desmarchais, as above. 
design of making a captive of one, to take home for the amusement of his children. He cautiously approached, and, springing upon the unsuspicious group, grasped a fine plump fellow in his arms, and was bearing off his prize in triumph, when, lo! the indignant vulture disgorged such a torrent of filth in the face of our hero as for ever cured him of his inclination for Turkey buzzards"."

Other gregarious birds, however, may be observed always to have a sentinel stationed near them while feeding, whose office it is to give timely alarm of threatening danger or indications of its approach. When a flock of sparrows, accordingly, alight in the corner of a wheat-field, and, as Bloomfield says,-

"Drop one by one upon the bending corn,$+ "$

we may always be certain of discovering one, or perhaps several, perched on some commanding station in the adjacent hedge-row, prying into the probable design of every movement among men or animals which lies within ken of the watch-tower. The instant the sentinel perceives anything which he deems worthy of notice, he gives his well-known signal, at which the whole flock hurry off from their banquet with the utmost celerity and trepidation. Their fears are, for the most part, only momentary, for as soon as they ascertain that there is no immediate danger, they hasten back to finish their meal.

Sparrows which are denizens of towns and cities act much in the same manner, though they are forced to learn to be, if possible, more quick and cautious than their rural kindred of the farm-yards. The city sparrows, abundant in the very centre of the metropolis, seldom congregate in very numerous flocks,

* Amer. Ornith. ix. 98.

+ Farmer Boy. 
and are more commonly observed in foraging parties of from two to half-a-dozen, subsisting in the more. open streets on what they can find on the pavements, and particularly haunting stables, to pick up oats and grass-seeds shaken from hay. We have watched by the hour the devices of these sparrows to avoid being surprised by boys or by cats. When they discover a scattering of oats, they seldom fly directly to the spot, but take several turns around it as if to ascertain the safest point of approach. If it is near the wall they will cling, with their backs downwards, to rough projections of the mortar, or to an accidental crevice between the bricks, looking round the while with the utmost caution; and thus will they descend the wall, by little and little, till within a few feet of their wished-for prize, upon which they will pounce down, one or more at a time, and carry off a mouthful to the nearest roof where they can eat it in leisure and safety. But what we particularly wish to call attention to is, that though each individual of a party manifests such extraordinary caution, they have usually the farther safeguard of a sentinel stationed on some adjacent projection of a roof-lead or a window, who fails not to announce to his companions below the approach of every passenger, and particularly of every cat that endeavours to steal upon them unawares*.

From all we have been able to observe, there does not seem to be anything like an election or appointment of such sentinels. The fact appears rather to be, that, probably from being less impelled by the calls of hunger, the bird of the flock who chances to be the last in venturing to alight, feels then reluctant to join his companions in consequence of an instinctive foresight that they might all be thence exposed to

* J. R. 
danger. We only offer this, however, as a plausible conjecture, which appears more applicable to the case of sparrows than to that of some other gregarious birds. Were we disposed, indeed, to indulge in the fancies sometimes found in books of natural history, we might give the sparrows credit not only for appointing sentinels, but for trying them for neglect of dity by a regular court-martial.

Sparrow-courts, or assemblies of sparrows for some common object regarding one of their community, are of frequent occurrence; and in truth they can scarcely escape the observation of any one who attends to the habits of animals. The birds usually select a spot somewhat remote from their usual haunts, such as the centre of a copse or the edge of a wood, where they may be seen crowding closely around one of this number, and scolding him in all the terms of their vocabulary. Whether they proceed from verbal reproof, however, to corporal chastisement, we have never ascertained, for they are so jealous, on such occasions, of intruders, that they immediately stay process and break up their court, should a prying naturalist venture within the precincts. Descriptions precisely analogous have been given by different authors of assemblies of rooks, or crow-courts, as they are called. In the latter, however, if we may believe what is reported, there is a regular trial of a delinquent, who, upon being found guilty, receives a severe drubbing from the whole court, and is even sometimes killed outright*

Pliny reports something similar to this as occurring among storks. "There is a place," he says, " in the open plains and champaign country of Asia Pithonas-Come, where (by report) they assemble altogether, and, being met, keep up a jangling one with another; but, in the end, look which of them * Landt, Description of the Feroe Isles. 
lagged behind and came tardy,--him they tear in pieces, and then depart*."

It is not improbable, we think, that this legend (for it can be nothing more) of the crow-courts has originated in the quarrels which take place when rooks are building their nests $\dagger$, in consequence of their propensity to pilfer. In such cases, as Goldsmith records from his own observation, "thefts never go unpunished; and probably, upon complaint being made, there is a general punishment inflicted: I have seen," he adds, "eight or ten rooks come, upon such occasions, and setting upon the new nest of the young couple, all at once tear it in pieces in a moment. Such is the severity with which even native rooks are treated; but if a foreign rook should attempt to make himself a denizen of their society, he would meet with no favour; the whole grove would at once be up in arms against him and expel him without mercył."

Rooks, if we may judge from our own observation, are more particular even than sparrows in the circumstance of having sentinels while they are feeding in parties after the breeding season; for while providing for their young family, they, in general, cater apart. These rook sentinels are so vigilant, that it is by no means easy to get within shot of a foraging party; and hence it is popularly believed that rooks can smell gunpowder. We have often proved, however, that it is just as difficult to approach them without alarming the sentinels, when only carrying an umbrella as when armed with a fowling-piece; but that they seem to have some knowledge of firearms appears from their being alarmed if a'walkingstick is levelled at them, though no noise is made,-

* Holland's Plinie, x. 23.

$\uparrow$ See Architecture of Birds, p. 219.

+ Animated Nature, iii. 168 . 
a knowledge most probably acquired by the reiterated experience of having their nest-trees fired at when the young are fit to be made into pies. It is stated in some accounts of newly-discovered countries, that the birds were not at first frightened by the presentment of a fowling-piece, but soon became so after some experience of its effects. We also think it not mulikely that the crows acquire part of the skilful vigilance which they exhibit as sentinels during the building of their nests, when one of a pair usually watches the nest while the other makes excursions to procure materials*.

Our observations by no means bear ont what is recorder of rooks being so determined to keep their associates together, that "if a pair offer to build on a separate tree, the nest is plundered and demolished at oncet." On the contrary, we do not recollect ever observing a rookery without seeing one or more nests on detached trees, sometimes at some little distance from the main establishment. In the rookery at Lee there were, in the summer of 1831, two such nests, each on a detached tree, which, we are certain, were not molested during the season $t^{\text {. }}$.

The sentinels of gregarious birds were observed by the ancients, and legends told of them no less exagrgerated than those of our modern crow-courts. 'The crane, in this respect, the most celebrated bird among the ancients, was placed, by Aristotle, at the head of gregarious birds $\S$; and Festus, the grammarian, is of opinion that the words congruous and similar derivatives are from Grues, the Latin name (Grus) of the crane\|. "The cranes," says Aristotle,

$$
\begin{gathered}
\text { * J. R. } \\
\text { \$. J. R. Bingley, Anim. Biog. ii. } 240 . \\
\text { § Hist. Anim. viii. 12. }
\end{gathered}
$$

|| "Congruere," says Festus, "quasi ut grues conveniere."De Significatione Verborum, ex Verio Flacco. 


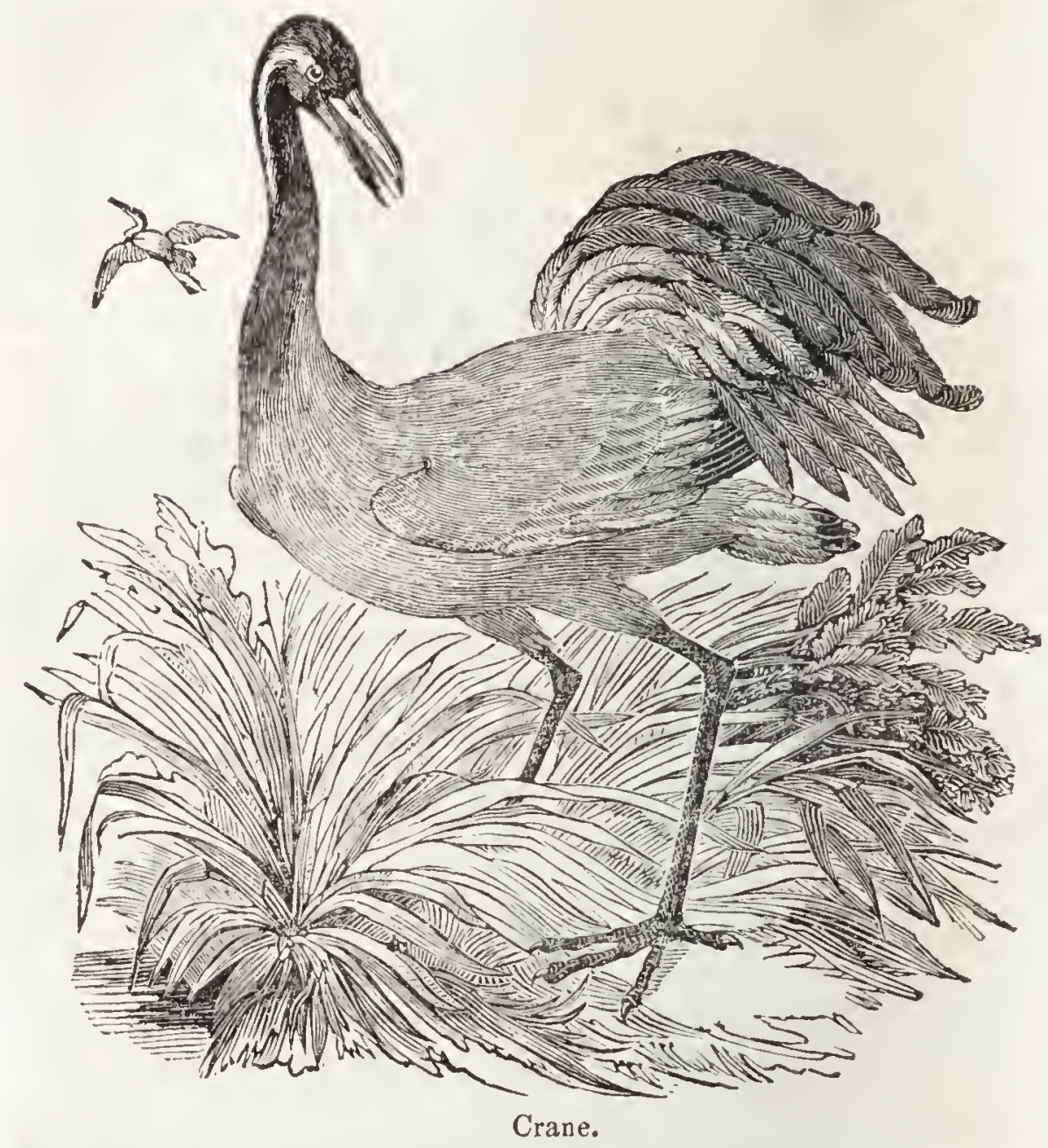

as we may translate the passage, "have a leader, as well as sentinels placed in their rear rank, so that their alarm-call may be heard *." Pliny gives a still more minute detail of their proceedings. Speaking of their migration, he says, "They put not themselves in their journey, nor set forward without a counsel called before, and a general consent. They flie aloft, because they would have a better prospect to see before them; and for this purpose a captain they chuse to guide them, whom the rest follow In the rereward behind, there be certain of them * Hist. Anim, ix. 10. 
set and disposed to give signal by their manner of cry, for to range orderly in ranks, and keep close together in array: and this they do by turns each one in his course. They maintain a set watch alt the night long, and have their sentinels. These stand on one foot, and hold a little stone within the other, which by falling from it, if they should chance to sleep, might awaken them, and reprove them for their negligence. Whiles these watch, all the rest sleep, couching their heads under their wings; and one while they rest on the one foot and otherwhiles they shift to the other. 'The captain beareth up his head aloft into the air, and giveth signal to the rest what is to be done ${ }^{*}$."

The old grammarian, Johannes Tzetzes, has rendered this story into Greek verse; and the historian, Ammianus Marcellinus, tells us, that in imitation of their ingenuity, to ensure vigilance, Alexander the Great was accustomed to rest with a silver ball in his hand suspended over a brass bason, which, if he began to sleep, might fall and arvake him $†$.

The golden plover (Charadrius pluvialis, TenIMINCK) is another bird celebrated for setting a watch. Longolius says these birds are so attached to society, that a single bird is never seen $\ddagger$. Belon gives a minute account of their proceedings, which we shall translate. "The plovers," says he, "call to one another at day-break, whistling in a manner similar to that of a man, and answering to the word hinc. The peasants, hearing this, try the next day to discover a covey; for the plover by day remains in society, but at the approach of night strays from his flock, and on the following morning his companions are scattered about at a quarter or half a

* Holland's Plinie, x. 23.

$\uparrow$ Apud Aldrovandi Ornith. iii. 137. ;. Apud Aldrovandi, iii, 206. 
league's distance from each other. There is one in the flock who is looked upon and acknowledged as master, or king. His voice is louder than the others, and well-known, and is their signal for congregating. The peasants name him the caller, and pretend to distinguish him by his notes being longer than those of the rest. At his rising he utters a cry resembling The bien huit. The peasants on the frontiers, who go in bands, assemble in the evening, where they have heard the king plover, and where they may find him at dawn ; and having set out before day, some here and some there, scattering themselves about over the corn lands, they wait till day-break, and when they hear the whistle of the king, which may be heard at a league's distance, calling his company together, they make straight towards him, being certain that the whole covey will repair to the same place. The plover is not so early a bird as the partridge, the lark, or the lapwing; but rises soon after dawn. And when the plovers of the flock have heard the notes of their caller they immediately hasten to him. If by chance, also, two flocks are upon the plain, and mixed together, the plovers will distinguish the cries of their king and make towards him. When day appears the peasants assemble, and report to each other what they have heard, and resolve what they shall do. Then the company depart, marching in battle array and keeping the same road. But when they approach the spot where the plovers are encamped, they spread into an arch or crescent, and as they advance attentively look before them to ascertain all they can of the covey which is around its caller. Each peasant carries a long pole, and one or two among them bear the 'harnois,' or net, to take the plovers, which they have observed in the level plain. And the peasants knowing that plovers are exceedingly timid, stretch the net as near them as they 
can. Whilst one of them is busy about this, the rest are spread behind on all sides, and creep upon their bellies as near to them as possible; and when they perceive that the net is laid and that the peasant is ready to draw it, they quickly stand upright, raise a shout and throw their sticks into the air to scare the plovers. And when he who holds the net open sees them approach, he lets go his cord, and encloses them beneath. The peasants cast their sticks into the air, to frighten the plovers and make them fly close to the ground, in order that they may take them in their nets; for the plovers are exceedingly quick. But if the covey rise high in flight they will not take one of them $*$."

Authors also tell us that the quails have a king to conduct their migrations; and it is further pretended that they are shrewd enough not to select for a monarch one from their own body, but make choice of a land-rail (Ortygometra Crex); for upon coming to their place of destination, the first of the band usually falls a victim to some bird of prey that is waiting their arrival, and foreseeing this the quails contrive to provide a victim from another species. Such legends, as Buffon well remarks, by ascribing incredible sagacity and design to birds, give us good room to doubt whether the authors themselves pos-

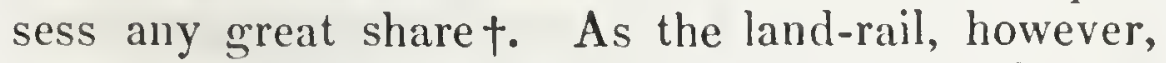
migrates about the same period with the quails, this is not quite so extravagant a notion as that recorded by Aristotle, that the quails are led by an owl $(\Omega \tau o s)_{+}^{+}$, as their king.

M. Vaillant remarks, that the idea of these kingbirds scems to have originated from the casual observation of a strange species among a flock of gre* Belon, Orscaux, p. 261, fol. Paris, 1555.

+ Oiseaux, Art. La Caille. \$ Hist. Anim. viii. 12. 
grarious birds. Thus the Dominican widow bird (Fringilla Serena, ILLIGER) is at the Cape called the king of the Bengal sparrows (Passer Bengalensis, Brisson), and of the wax-billed finches (Fringilla undulata, Pallas). Vaillant once observed a few cross-bills (Loxia curvirostra) in the king's garden at Paris, intermingling with other gregarious birds. These being uncommon birds were very likely to attract popular attention, and give rise to the fancy of their being royal birds. He once also observed a field-fare (Turdus pilaris), which having strayed from its companions and associated with starlings, was called king of the starlings by the peasants of Sezaune, in La Brie*. It is in this way that M. Vaillant accounts for the origin of the name of the king-bird of Paradise (Paradisea regia), of which so many legends are current in the islands of Arrou in the Eastern Archipelago, where these birds are indigenous. It is averred, for example, that the two principal species of Paradise birds (P. Apoda and P. Magnifica?) have each their leader, whose imperial mandates are received with submissive obedience by a numerous train of subjects; and that his majesty always flies above the flock to issue his orders for inspecting and tasting the springs of water where they may drink with safety t,- - the Indians being in the practice of taking whole flocks of birds by poisoning the water where they resort to drink. M. Vaillant's explanation accords with the account given by M. Sonnerat of the manuers of the kingbird of Paradise; for, being a solitary bird, going from bush to bush in search of the berries upon which it feeds + , it may occasionally be seen near the

* Oiseaux de Paradis, Art. Manucode.

† Valentyn, Beschr. Van Oude, iii. ed. 1724.

$¥$ Voyage à la Nouv, Guinée, p. 156. 


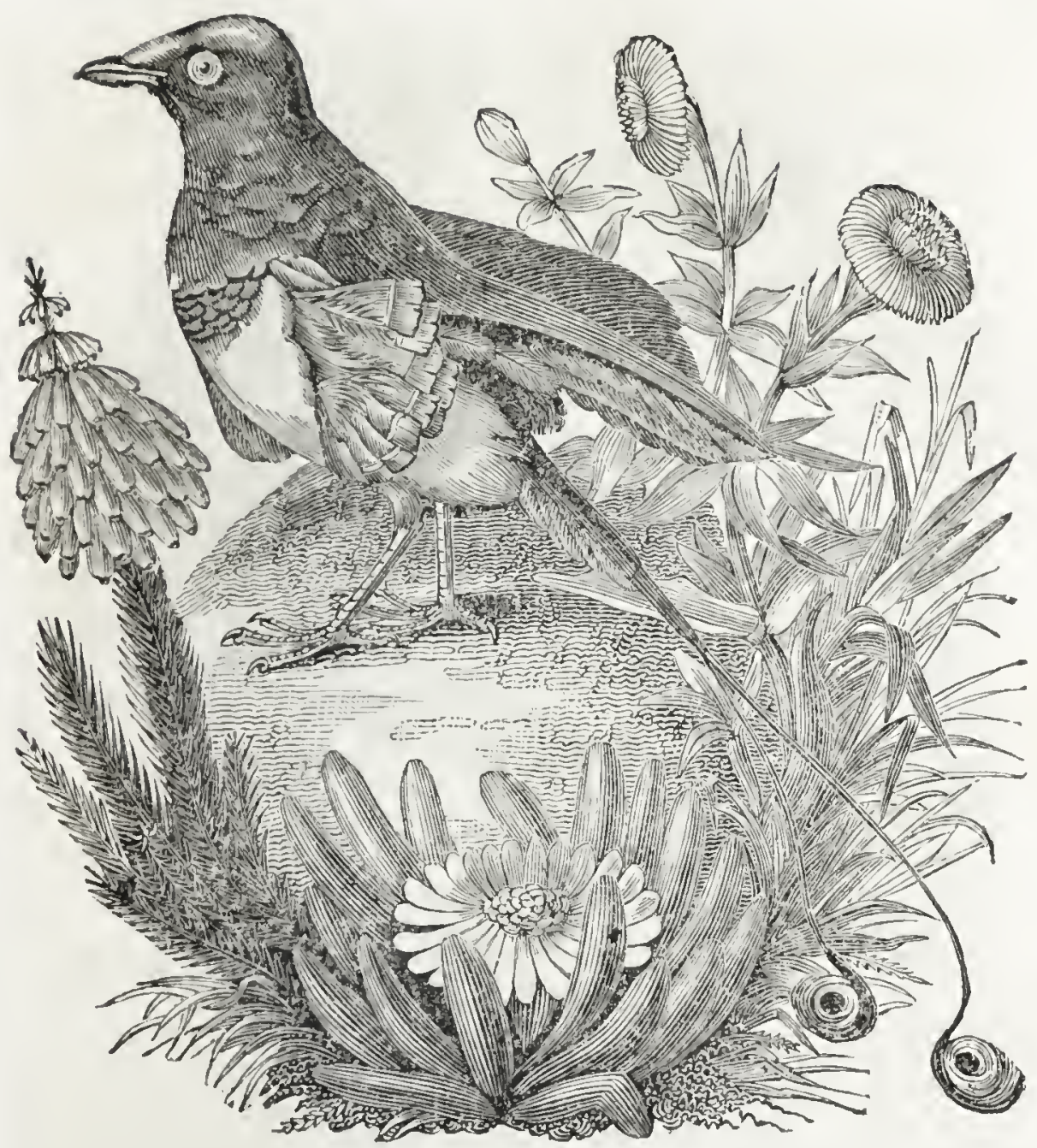

King-Bird of Paradise.

flocks of those which are gregarious, where its singular plumage ${ }^{*}$ must render it conspicuous.

The same remark will apply no less forcibly to the king of the vultures (Sarcoramphus papa, DuMERIL), which is seldom seen congregating in flocks, hut of whom one or two solitary birds will intermingle with the 'Turkey buzzard (Catharista aura, VIEILLOT), and of course appear conspicuous among them from their more striking form and colours.

* Audebert, Hist. Nat. Ois. de Paradis, p. 22. 


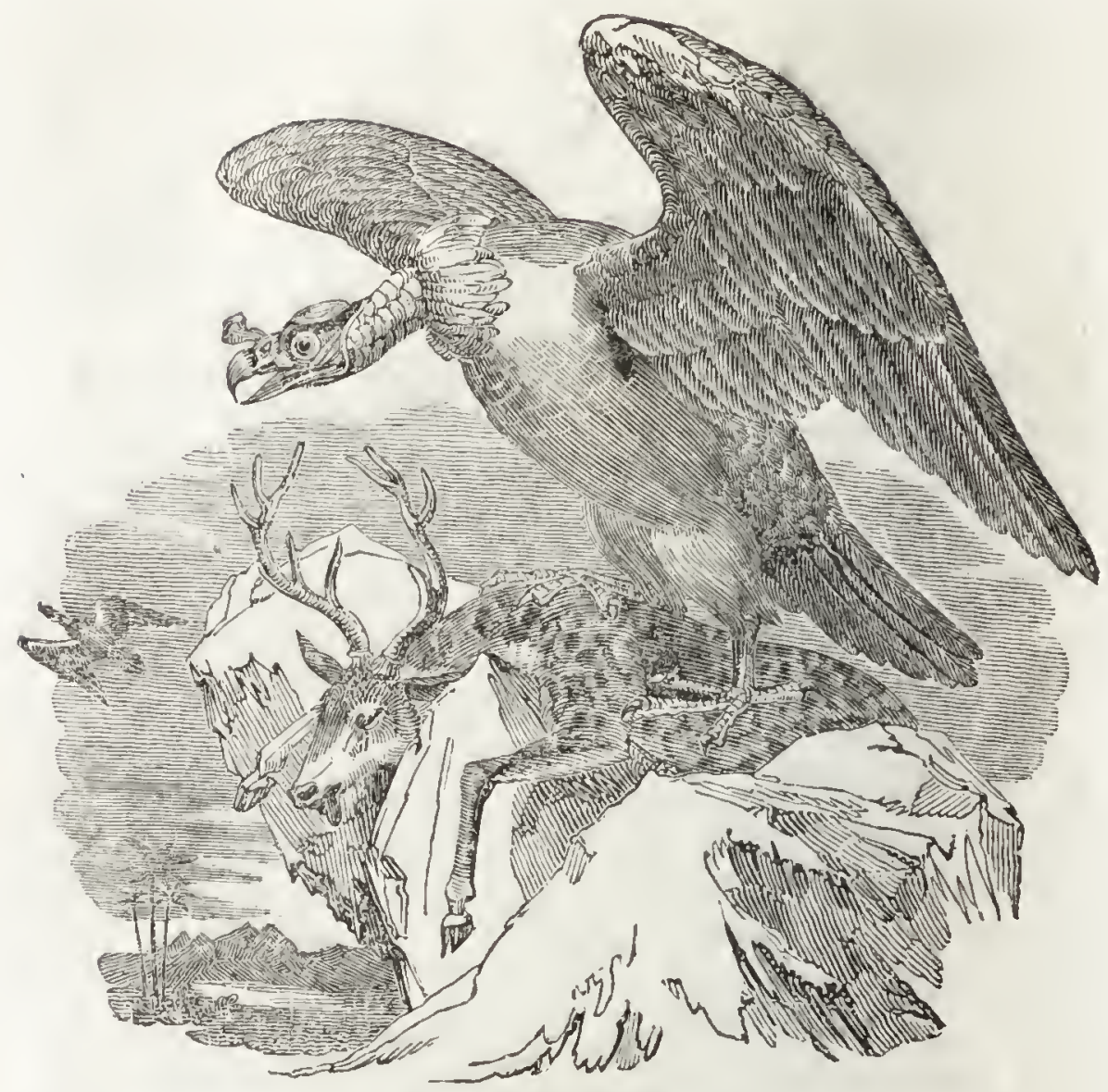

King of the Vultures.

It is not improbable that similar solitary habits in the lion and the eagle, together with their magnitude and their strength, have given origin to the titles of king of the beasts and king of the birds, current all over the world. "The eagle," says Jonston, " challengeth the first place, not that it is the best dish at table, for none will eat it, but because it is the king of the birds*." The ancient Greeks used the same term, as we find Pindar talking of "the great eagle, the chief magistrate of the birdst." Josephus, the Jewish historian, also says the eagle was selected for * Miracles of Nature, Englished by a Person of Quality, p. 167, fol. Lond. 1657.

t Ode vi. Isthmior. 
the Roman legionary standards, because he is "the king of all the birds and the most powerful of them all, whence he has become the emblem of empire and the omen of victory *;" and this conclusion is singularly enforced by Aldrovand, who tells us that the eagle "challenges dragons to battle and fights with them; attacks bulls and slays them;" adding the anticlimax that "he overcomes leverets; tears foxes; and feeds upon snakes $t^{. "}$

"Caius Marins," says Pliny, " in his second consulship, ordained that the legions of Roman soldiers only should have the eagle for their standard, and no other ensign; for before-time the eagle marched foremost indeed, but in a ranke of four others, to wit of wolves, minotaurs, horses, and boars, which were borne each one before their own several squadrons and companies. Not many years past, the standard of the eagle alone began to be advanced into the field to battle, and the rest of the ensigns were left behind in the camp; but Marius rejected them altogether and had no use of them at all. And ever since this is observed ordinarily, that there was no standing camp or leagner wintered at any time without a pair of eagle standards t."

Josephus and Pliny, however, were wrong if they thought the ensign of the eagle peculiar to the Romans; for the golden eagle with extended wings was borne by the Persian monarchs $\$$, from whom it is probable the Romans adopted it, as it was subsequently adopted from them by Napoleon and the United States; while the Persians themselves may have borrowed the symbol from the ancient Assyrians, in whose banners it waved till Babylon was conquered by Cyrus. This may serve to explain why the expanded eagle is so frequently

* Josephus, De Bello Judico, iii. 5.

† Ornithologia, i. 10. ‡ Holland's Plinie, $x .4$.

$\S$ Xenophon, Cyropædia, vii, 
alluded to in the prophetical books of Scripture*. Referring, for example, to the king of Babylon, Hosea says, "he shall come as an eaglet;" and Ezekiel describes Nebuchadnezzar as " a great eagle, with great wings, long-winged, full of feathers which had divers colours ;" and the king of Egypt as " another great eagle, with great wings and many feathers.." It was, no doubt, on the same account that the eagle was assigned in the ancient mythologies as the bird of Jove, a notion which Lucian with his usual satire ridicules without mercy, making Momus tell Jupiter he may think himself well off if it do not take a fancy to build a nest on his head $\$$.

So fal as size and appearance are concerned, as well

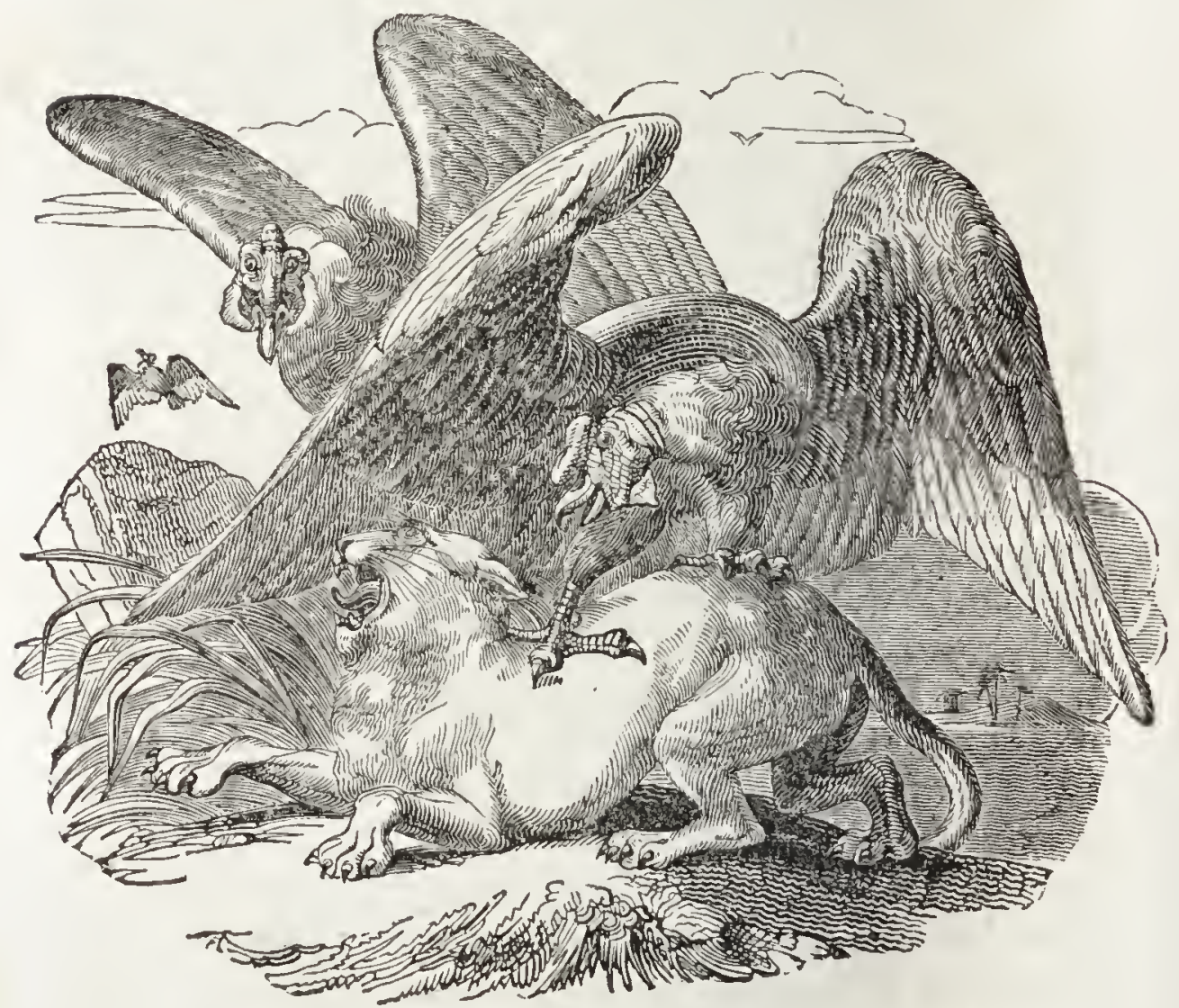

Condor attacking a Puma.

* Paxton, Illustr. of Script. ii. 13.

$\dagger$ Hosea, viii. 1.

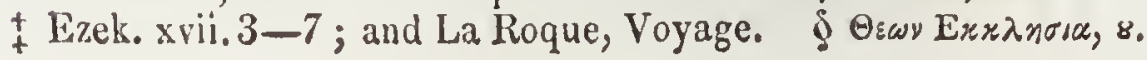


as in power of flight, the eagle (Aquila chrysaëtos, KuEIN) must yield the palm to the condor of America (Surcoramphus gryphus, Dumeral), while the head of the latter, "the likeness of a kingly crown has on." 'The condor, however, has not the honour of ranking among eagles, being evidently, both from structure and habits, nothing but a vulture.

We can readily understand why the least of our British birds, the gold-crested wren (Regulus cristatus, $\mathrm{RAY}_{\mathrm{Ax}}$ ) should have been considered a royal bird in most countries, from its having a fine coronet of a bright gold colour on its head, as Áristotle correctly remarks*. But why the common wren (Anorthura communis) should be called a king-bird we cannot conjecture, except it has been from irony or antiphrasis, in the same way as M. Hebert tells us it is called the ox (bceuf) in some provinces of France. From being unable to account for the latter fact, Gesner, Willughby, and other naturalists accuse Belon, Brisson, and Oliva, of confounding the two species. 'To us, however, this charge appears groundless, for Aristotle very clearly distinguishes the two birds; and yet he says the gold-crested one is called a king (tupravos), and the common one $(\tau \rho \circ \chi \iota \lambda \circ s)$ also is called a magistrate and $\operatorname{king}(\pi \rho \in \sigma-$ $\beta v$ s rul $\beta a \sigma \iota \lambda \epsilon v s)$, " for which reason," he adds, "the eagle is said to fight with it.$+ "$ Independently of this authority, the popular titles given to the common wren, in most languages, by the peasants who know nothing of the disputes of naturalists, prove that there must be some cause for the term unconnected with any confusion of the species. For example, the Italians call it the little king (reattino), the king of the hedge (re di siepe), the king of the birds (re degli uccelli); the Spaniards, the kinglet, (reyezuelo); the Portuguese, the bird-king (ave rei); * Hist. Anim, viii. 3. † Ibid. ix. 2. 
the French the little king (roitelet), or king-berry (roi-berry), or the king of cold (roi de froidure); and the Germans, the snow-king (schnee-könig), and thorn-king (thurn-könig). At the same time, we are aware that the gold-crested wren has obtained similar titles, such as in Italy the little pope (papazzino); in Germany, the king-let (königchen); and in Sweden, king-bird (kongs-vogel). We pretend not to account for the universal diffusion of the same notion, but it is most evident it does not arise from the mistake that has been supposed.

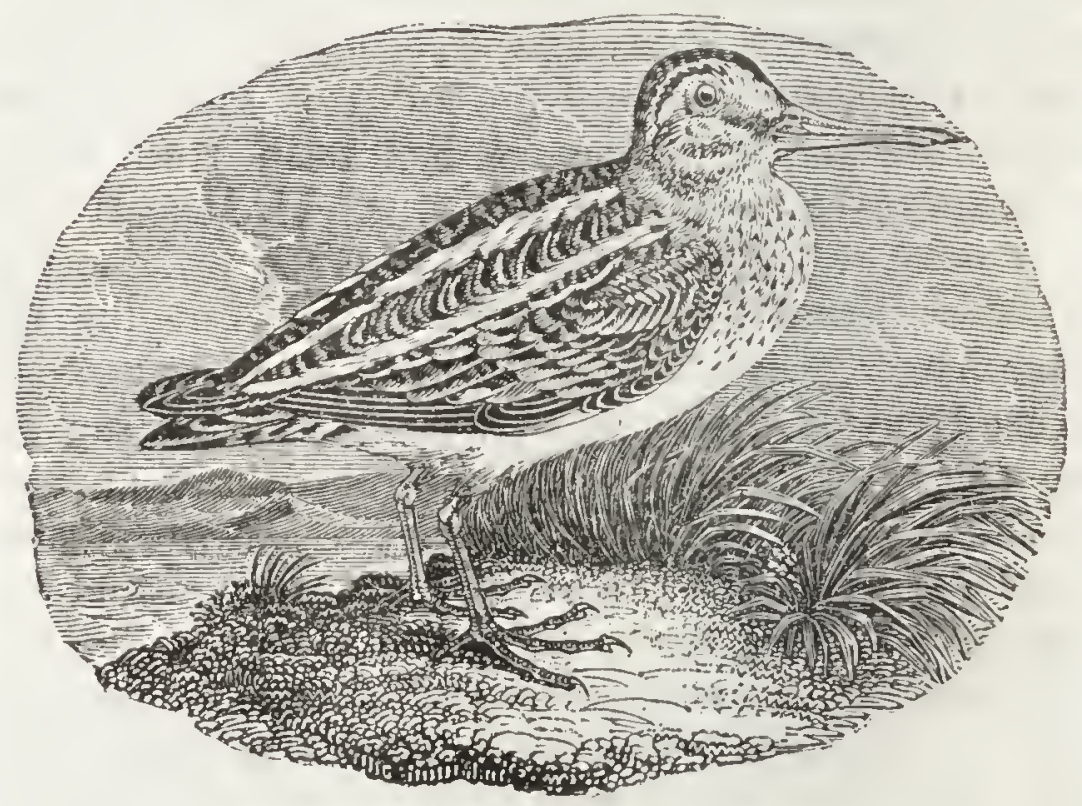

Jack-Snipe.

It would appear to originate from the singularly solitary habits of the jack-snipe (Scolopax gallinula), that young sportsmen are disposed to take it for the male of the common snipe (S. gallinago), though it is so very different in size and even in plumage. "The jack-snipe," says Mr. Knapp, " is a solitary, unsocial bird, an anchorite from choice. With the exception of our birds of prey, the manner of whose existing requires it, and a few others, all 
the feathered tribe seem to liave a general tendency towards association, either in flocks, family parties, or pairs; but the individuals of this species pass a large portion of their lives retired and alone, two of them being rarely, or, perhaps, never, found in company, except in the breeding season. They are supposed to pair and raise their young in the deep marsliy tracts or reedy districts of the fen-counties, which afford concealment from every prying eye, and safety from all common injuries. Driven by the frosts of winter from these watery tracts, their summer's covert, they separate, and seek for food in more favoured situations, preferring a little, lonely open spring, trickling from the side of a hill, tangled with grass and foliage, or some shallow, rushy streanlet in a retired valley. Having fixed on such a place, they seldom abandon it long, or quit it for another, and though roused from it, and fired at repeatedly through the day, not any sense of danger seens to alarm them; and if we should seek for the little judcock on an ensuing morning, we find it at its spring again. The indifference with which it endures this persecution is amazing. It will afford amusement or vexation to the young sportsman throughout the whole Christmas vacation; and from the smallness of its body, will finally often escape from all its diurnal dangers.

"The causes that influence this snipe to lead so solitary a life are particularly obscure, as well as those which stimulate some others to congregate, as we compreliend 110 individual benefit to arise from such habits. Wild-fowl, the rook, and some other birds, derive security, perhaps, from feeding in society, as a sentinel appears to be placed by them, at such times, to give notice of danger. But our congregating small birds talie no such precaution; security or mutual protection does not seem to be obtained by 
it, as the largeness of the flocks invites danger ; and warmth in the winter season it does not afford. For the purposes of migration, such associations are, in many respects, serviceable and consistent; but, in our resident species, considered in its various results, it becomes rather a subject of conjecture than of explanation. Timid creatures generally associate commonly upon the apprehension of danger, and, without yielding any mutual support, become only the more obnoxious to evil; and this snipe, though its habits are the very reverse of connexion with its species, yet affords no clue to direct us to the causes of its unusual habits. These associations of some, and retirement of others, are not the capricious actions of an hour in a few individuals; but so regularly and annually observed in the several species, that they are manifestly appointed provisions of nature, though the object is unknown*."

Similar remarks may be applied to the sand-piper (Totanus hypoleucos, 'Temm тоск), which is so solitary in habit that we have seldom observed two of them together, even during the breeding season; though individuals are very frequently seen tripping along the sands by the sides of lakes and rivers, in pursuit of water-insects, which they capture by speed of foot, seldom, if ever, taking wing to continue the pursuit, as is often done by their fellow-hunter the wagtail (Motacilla lotor). We are not aware that they congregate, even during their migrations. The comparative scarcity of water-insects may probably account for their remaining solitary, since, though these insects are found in sufficient abundance at particular times and places, as in the clouds of dayflies (Ephemerida) upon which we observed several sandpipers feasting luxuriously on the banks of the Rhine in autumn, yet this is only occasional, and the supply is never regular, as it may be said to be on

* Journal of a Naturalist, p. 254. 
the sea-shore, where the dunlin (Tringa variabilis, Meyer), a bird, similar in its feeding to the sandpiper, congregates in considerable bands. These birds pick up an abundant supply of small marine insects within the tide mark, and, at the same time, keep so close to their companions, that we may say we never saw one a yard from the flock. Whether they appoint a watch or not we have not been able to determine; but they are so wary that several keen sportsmen, at a watering-place, failed in procuring us a single specimen, though they tried for two or three months to get within shot of several flocks that frequented the coast*

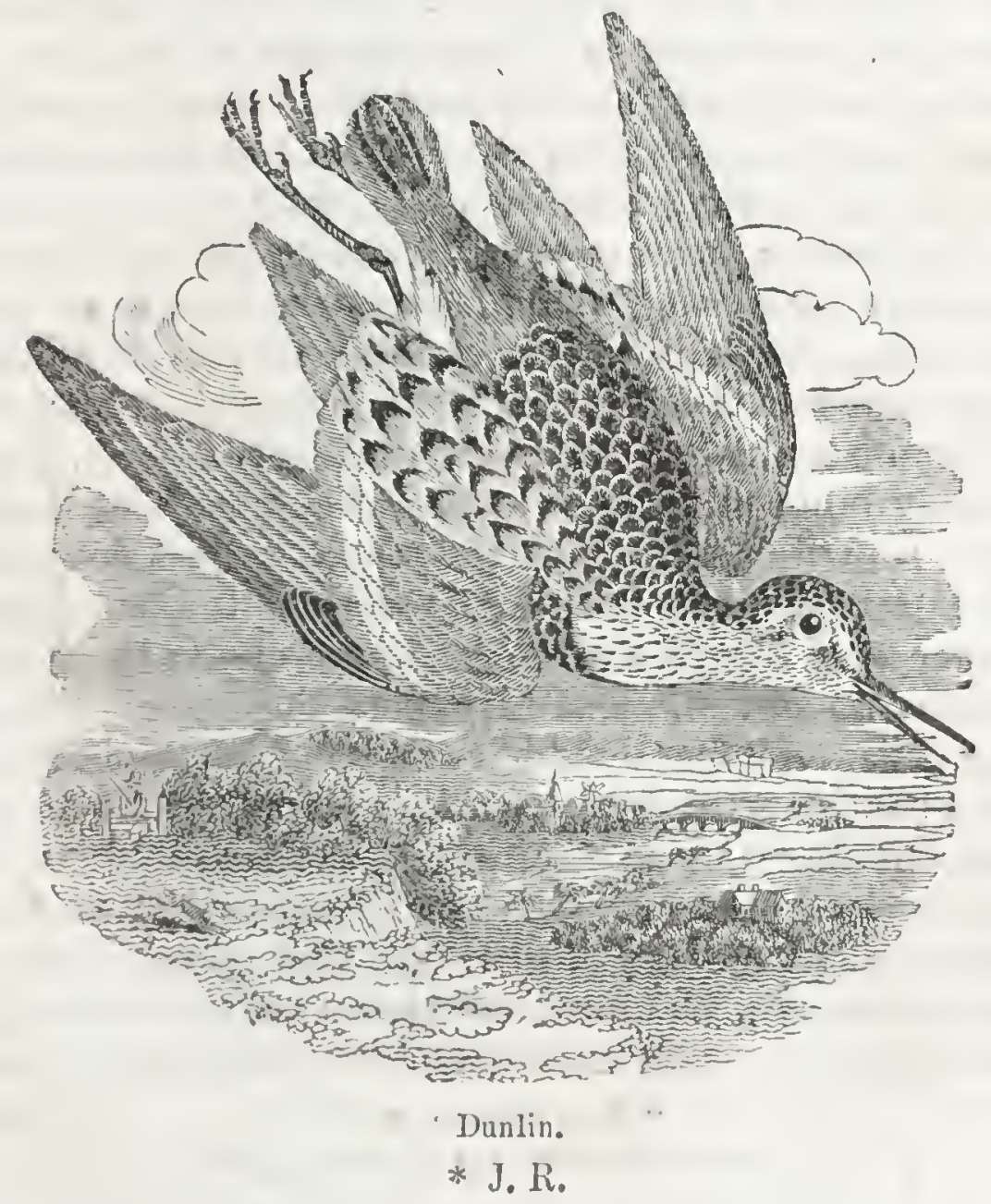




\section{Chapter III.}

BIRDS, SOLITARY OR GREGARIOUS, ON ACCOUNT OF SHELTER OR ASSISTANCE.

UPon glancing back over the details which we have already given of the solitary and social habits of birds, it will be obvious, that their sociality produces no apparent result, except it may be the appointment of a sentinel to give intimation of danger, if such appointment (as may well be (loubted) actually takes place. Except in the instance of the sociable grosbeak (Loxia socia) of Africa, we do not recollect any authentic instance of birds uniting their efforts to assist in performing a common work. Even in this instance, the accurate observations of M. Vaillant have proved, that so far from building streets, as Paterson and others represent these birds to do, they merely build their nests in actual contact*, as rooks may sometimes be observed to do in this country. The notion of their building streets is of the same character with Pliny's account of the swallows in Egypt raising an embankment to oppose the inundation of the Nile, adopted by him from some hasty observer who had seen the bank-swallows (Hirundo riparia), not building (as he supposed), but mining into an escarpment of the rivert. In the same way we find it related by authors of celebrity, that when a pair of sparrows take felonious possession of the nest of a swallow, the swallow summons its companions to its * See Voyage, $p .3$.

$\dagger$ See Architecture of Birds, p. 96. 
assistance, when they all unite in a body to bring a sufficient quantity of mortar to entomb the robbersparrows alive in the nest. "This story is obviously imaginary, and the fiction is shown from the impossibility of so entombing, by means of clay, a bird with so powerful a bill as the sparrow*.

M. Dupont de Nemours gives the following singular acconnt of what fell under his own observation : - "I remarked," he says, "a swallow which had unhappily-and I cannot imagine in what mannerslipped its foot into a slip-knot of packthread, the other end of which was attached to a spout of the College of the Four Nations. Its strength was exhausted,-it hung at the end of the thread, uttered cries, and sometimes raised itself as if making an effort to fly away. All the swallows of the large basin between the bridges of the Tuileries and the Pont Neuf, and perhaps from places more remote, had assembled to the number of several thousands. Their flight was like a clond; all uttered a cry of pity and alarm. After some hesitation, and a tumultuous counsel, one of them fell upon a device for delivering their companion, communicated it to the rest, and began to put it into execution. Each took his place; all those who were at hand went in turn, as in the sport of running at the ring, and, in passing, struck the thread with their bills. These efforts, directed to one point, were continued every second, and even more frequently. Half an hour was passed in this kind of labour before the thread was severed and the captive restored to liberty. But the flock, only a little diminished," adds M. Dupont de Nemours, "remained until night chattering continually in a tone which no longer betrayed anxiety, and as if making mutual felicitations and recitals of their achievement+."

* See Architecture of Birds, p. 335.

† Antoine, Animaux Célèbres, ii. App. p. 18. 
Now we doubt not that these swallows crowded to their companion, as M. Dupont has recorded, for all small birds are apt to come when called by their. fellows, as is well known to bird-catchers, who employ call-birds to bring the wild ones to their nets; but we much doubt whether they united their efforts: with the design of cutting the string, and think the observer must have been deceived as to this particular. In a similar instance of a pair of sparrows becoming entangled, which fell under our observation, their neighbours crowded to the place, but; apparently, only for the purpose of scolding, not of assisting, the entangled birds*.

It is rare indeed among quadrupeds, and rarer still, if it occur at all, among birds, to meet with instances of mutual assistance, such as we find so strikingly exemplified among social insects $\uparrow$. Beavers unite in forming dams across a stream and in burrowing out chambers in the banks; but stories are told of the mutual assistance of some other quadrupeds, evidently as much overcoloured as that of M. Dupont's swallows. Thus the preparation of a winter abode by the marmot (Arctomys marmota, A. Bobac, \&c.,) which has always excited admiration, has been, as is usual in such cases, greatly exaggerated by the fancies of inaccurate observers. "Their wit and understanding," says Gesner, "is to be admired; for, like beavers, one of them falleth on the back, and the residue load his belly with the carriage, and when they have laid upon him sufficient, he girteth it fast by taking his tail in his mouth, and so the residue draw him into the cave; but I cannot," he well adds, "affirm certainly whether this be truth or falsehood; for there is no reason that leadeth thereunto, but that some of them have beell found bald on the backt." This evident fable is still gravely stated by some writers

* See Architecture of Birds; p. 319.

† Insect Miscel, §iii. : Hist, of Anim, by Toplis, p.407. 
as an ascertained fact; and M. Beauplan goes so far as to imagine that he has seen a party trailing owe of their companions by the tail, taking care not to overset him*. This feat, however, seems to be outdone by the one recently given on anonymous authority as authentic, of the marmot's skill in haymaking. "They bite off the grass," it is also said, "turn it and dry it in the sun $\dagger^{. "}$

'The only obvious and decided instance of mutual assistance which we recollect as occurring among birds, is that of parents feeding their young, keeping them clean and warm, and defending them against enemies, of all which habits we shall give ample details in the sequel of this volume. But in order to secure warmth, many species certainly take advantage of the animal heat of their kindred, and we may with some plausibility say, that in most cases this is done by mutual sufferance, if not by distinct permission.

It is one of the most extraordinary as well as one of the best ascertained facts in the animal economy, though by no means as yet satisfactorily explained, that the interior heat of warm-blooded animals varies extremely little in the coldest and in the hottest climates. 'To the uninstructed it appears no less erroneous to say that the body is equally warm on a cold winter's morning and on the most sultry of the dog-days, as to affirm that the sun is stationary contrary to the apparent evidence of the sensis; yet the one truth is as well ascertained as the other. For example, Captain Parry found that when the air was from $3^{\circ}$ to $32^{\circ}$ at Winter Isle, lat. $66^{\circ} 11^{\prime} \mathrm{N}$, the interior temperature of the foxes when killed was from $106 \frac{30}{4}$ to $98^{\circ}+$; and at Ceylon, Dr. Davy found that the temperature of the native

* Descript. Ukraine.

+ Mag. Nat. Hist. i. 377 . \$ Second Voyage, p. 157. 
inhabitants differed only about one or two degrees from the ordinary standard in England*. At very high temperatures, however, there is a somewhat greater difference, as appears from the ingenious experiments made by MM. Delaroche and Berger, who exposed themselves to a heat of $228^{\circ}$, or sixteen degrees above that of boiling water: they ascertained that at such very high temperatures there is an increase of seven or eight degrees of the centigrade thermometert. The increase of cold on the contrary does not appear to influence the temperature of the body in a similar way; and hence we discover the cause why great cold proves less injurious and fatal to animals than might be reasonably anticipated. White of Selborne, speaking of gipsies, says: "These sturdy savages seem to pride themselves in braving the severity of the winter, and in living in the open air (sub dio) the whole year round. Last September was as wet a month as ever was known; and yet during those deluges did a young gipsy girl lie in the midst of one of our hop-gardens on the cold ground, with nothing over her but a piece of a blanket extended on a few hazel rods bent hoop-fashion and stuck in the earth at each end, in circumstanices too trying for a cow in the same condition: within this garden there was a. large hop-kiln, into the chambers of which she might have retired, had she thought shelter an object worthy her attention +." Some half-wild cats (Felis domestica), which frequented a solitary farm-house on the borders of a wood, were more attentive to their comforts than this young gipsy; since a neighbouring kiln for drying corn was their favourite resort during winter when the fire was lighted§.

The law by which animal temperature is thus maintained at nearly the same degree on exposure to con* Phil.Trans. for 1814, p. 600. + Journ. de Physique, lxxi. 289.

$\ddagger$ Nat. Hist, of Selborne, lett. 67. $\S \mathrm{J} . \mathrm{R}$ 。 
siderable heat or cold, though it is not easy to reconcile it to any of the received theories, supplies the only known reason why some of the smaller and seemingly tender animals outlive the rigours of our severest winters. 'The magpie ( $P$ ica caudata, $\mathbf{R A Y}_{\mathrm{AY}}$ ), though rather a hardy bird, has been found having recourse to what is often practised by smaller birds-several of them huddling together during the night, to keep each other warm. A gentleman of intelligence and veracity informed us that he once saw a number of these birds (probably a young family with their parents) on a tree, in a fir plantation, sitting so closely together that they all seemed to be rolled up into a single ball. Little is known of the roosting of these birds; but among smaller species the habit in question is not uncommon. Even during the day, in severe winter weather, we have observed a similar practice in the house-sparrow (Passer domesticus, RAY). On a climney top, which can be seell from our study window, we have often remarked the whole of a neighbouring colony of sparrows contest by the hour the warmest spot on the projecting brick ledge, which happened to be in the middle. Here the sun shone strongest, the kitchen fire below sent hither its most powerful influence, and here the forturate occupant was best sheltered from the frosty wind which swept by its companions that had been jostled to the two extremities of the row. But none remained long in quiet, for as soon as the cold air pinched them on the exposed side, they removed to the middle, scolding and cackling most vociferously; and as those who held the best places refused to give them up, the new-comers got upon their backs and insinuated themselves between two of their obstinate companions, wedge fashion, as you thrust a book into a crowded shelf. The middle places were thus successively contested, till hunger drove the whole colony to decamp in search of food. 
We once witnessed, near Eltham, a similar contest for places among a family of the bottle-tit (Parus caudatus, $\mathrm{R}_{\mathrm{AY}}$ ), whose proceedings we had been watching while they flitted from spray to spray of a hawthorn hedge in search of the eggrs of a coccus (Coccus cratcegi? FABr.). The ground was covered with snow, and as evening approached, the little creatures, whose restless activity had no doubt tended to keep them warm, retreated from the open hedge to the shelter of a thick holly - " the leading bird," as Mr. Knapp correctly describes their manner of proceeding, " uttering a shrill cry of tw̌t, tw̌̌t, twăt, and away they all scuttled to be first, stopping for a second, and then away again*." When they had all assembled, however, on an under bough of the holly, they began to crowd together, fidgetting and wedging themselves between one another as the sparrows had done; but whether they intended to roost there, or were merely settling the order of precedence, before retiring into some hole in the tree, we did not ascertain, for, in our eagerness to observe what they were about, we approached so near as to alarm them, and they all flew off to a distant field + .

'That this contest for places among the little bottletits was only previous to retreating into some more suug corner for the night, appears to us probable, from the known habits of their congeners, and also from what we daily observe among sparrows. Every evening, before going into their roosting holes, the sparrows assemble on some adjacent tree or housetop, squabbling and shifting places for a considerable time, and then dropping off one by one according as they seem to have agreed upon the etiquette of precedence. Hardy as they certainly are, sparrows manifest great dislike to exposure during the night; and, accordingly, they may be observed taking ad-

* Journal of a Naturalist, p. 164, 3d edit. tJ.R. 
vantage of every viriety of shelter. They are most commonly seen, indeed, creeping under the eaves of houses or the cornices of pillars; but they are equally fond of a hole in a hay-stack, of getting under the lee side of a rook's nest on a lofty tree, or of popping into a sand hole burrowed out for its nest by the bank swallow (Hirundo riparia, $\mathbf{R}_{\mathrm{AX}}$ ). They are exceedingly partial, on this account, to the shelter of ivy on a wall, or of a thick tuft of clematis; but when they can find such a shelter, they do not, so far as we have observed, huddle together side by side, each individual merely selecting the warmest coping of leaves he can discover*.

It is not a little remarkable that the thrush and blackbird, though so careful to provide shelter and warmth for their eggs and young, show no wisdom in procuring the same comforts for themselves during winter, as they usually roost along with redwings and chaffinches in the open hedges, where they are often frozen to death in severe weather $\psi$, or captured by bat fowlers. The starling (Sturnus vulgaris) exhibits more care for itself, by roosting in the holes of trees, in the towers of churches, or under the tiles of an old house, like the sparrows, and frequently among the thick tops of reeds in marshes. Yet will they sometimes suffer from frost even there. One winter's day in 1822, after a very keen frost in the night, when we were searching for lichens on the trees in Copenhagen-fields, we found a cock starling in a hole frozen to death. It was in very fine condition, and more perfect in plumage than we ever saw this species : but it did not appear, upon the closest examination, to have received any shot or other injury, to cause its death besides the effects of the frost.

It may be remarked, that like the sparrows and * J.R. † White's Selborne, letter 105. 
other birds which roost in holes, the starlings huddle closely togcther, coutending for places; a circumstance, indeed, recorded by Pliny. "As touching sterlings," says he, "it is the property of the whole kind of them to fly by troups, and in their flight to gather round into a ring or ball, whiles every one of them hath a desire to be in the middest*," a statement corresponding exactly with what we have above mentioned of the sparrows and bottle-tits. It is not a little interesting thus to verify facts which were observed by the ancients; and Mr. Knapp has done so in the instance of the starling now under consideration. "There is something," he remarks, " singularly curious and mysterious in the conduct of these birds previous to their nightly retirement, by the variety and intricacy of the evolutions they execute at that time. They will form themselves, perhaps, into a triangle, then shoot into a long pear.shaped figure, expand like a sheet, wheel into a ball, as Pliny observes, each individual striving to get into the centre, \&c., with a promptitude more like parade movements than the actions of birds $\uparrow . "$

In the instance of the red-breast, the hedge-sparrow (Accentor modularis, BECHSTEIN), and the wren (Anorthura communis), one can scarcely imagine how any of the species survive the winter, were it only for the difficulty they must have in procuring food. Selby, indeed, has observed wrens to perish in severe winters, particularly when accompanied with great falls of snow. "Under these circumstances," he says, "they retire for shelter into holes of walls, and to the eaves of corn and hay-stacks; and I have frequently found the bodies of several together in old nests, which they had entered for additional warmth and protection during severe

* Natural Historie, by P. Holland, p. 284, ed. 1634. $\dagger$ Journal of a Naturalist, p. 195. 
storms*" Buffon says a sportsman told him he had often found more than twenty collected in the same hole $†$.

We are informed by an intelligent friend, that he once found several wrens in the hole of a wall, rolled up into a sort of ball, for the purpose, no doubt, of keeping one another warm during the nivit; and though such a circumstance is only to be observed by rare accident, we think it very likely to be nothing uncommon among such small birds as have little power of generating or retaining heat in cold weather. This very circumstance, indeed, was observed by the older naturalists. Speaking of wrens, the learned author of the Physicæ Curiosæ says, " They crowd into a cave during winter to increase their heat by companiouship +."

Those who keep wrens in cages usually furnish them with a box, lined and covered with cloth, having a hole for entrance, where they may roost warmly during the night $\$$. Yet even in keen frost the wren does not seem, in the day-time, to care much for cold, since we have in such cases fiequently heard it singing as merrily as if it had been enjoying the sunshine of summer, contrary to the remark of White\|, that wrens do not sing in frosty weather $\Phi$.

During a fall of snow, sheep seem both to take advantage of natural shelter, and to huddle together in order to economize their animal heat; and they accordingly, during a snow-storm, always flee to the nearest shelter, though this is certain to end in their destruction, if the snow fall deep and lie long. It,

* Illustrations of Brit, Ornith, i. 197.

+ Ois. Art. Le Roi-telet.

+ Multi uno specie in hyeme conduntur, ut parvus in tam minutis corporibus calor societate augeatur, p. 1249.

$\S$ Syme, Brit. Sung Birds, p. 159.

II Selborne, lett. 60 . J.R. 
therefore, becomes one of the most painful tasks of the shepherd, in such circumstances, to keep his sheep steadily in the very brunt of the blast. So at least we were told by an old shepherd, whom we encountered at night-fall the end of December, 1808, in a wild mountainous pass, near Douglas, on the borders of Ianarkshire, who was actually engaged in thus guarding his flock in as heavy a fall of snow as we recollect ever witnessing *. 'The Ettrick Shepherd, in a most interesting narrative, entitled 'Snow Storms,' in his Shepherd's Calendar, does not allude to this propensity in sheep; though it may be inferred that they had acted upon it on one of the occasions which he describes, from his having found a number buried under the snow by the side of a high bank, to which no doubt they had fled for shelter at the onset of the storm. Though sheep, from their mode of life, ought to be hardy, they exhibit an anxiety for procuring shelter well worthy of remark. It is mentioned by Lord Kamest, that the ewe, several weeks before yeaning, selects some sheltered spot where she may drop her lamb with the most comfort and security; and Mr. Hogg, in the volume just referred to, gives an instance in which a ewe travelled over a great distance to the spot where she had been accustomed to drop her lambs; but what was still more remarkable, a ewe, the offspring of this ewe, though removed to a distance when a few days old, returned to the same spot to drop her first lamb ${ }^{\ddagger}$.

It is a very curious and remarkable circumstance, that many species which are solitary at one period of the year, are gregarious at another; and though it is possible to account for this in some instances, it becomes not a little difficult in others. It is obvious,

* J.R. $\quad+$ Gentleman Farmer, p. 15.

\$ Shepherd's Calendar, Chapter oul Sheep. 
for example, that the winter nest of the gold-tail moth (Porthesia chrysorrhea) is constructed as a common domicile for a whole brood ${ }^{*}$, which in their young state can find enough of food though they keep together; but when they increase in size the following spring, and require a larger supply, they naturally separate, each to forage for itself. The fry of salmon and most other fish keep together in crowds in the early stage of their existence, not probably from any propensity to sociality, but because they are hatched about the same time at the head of the same pool, and as yet have no cause to be alarmed on account of the ravenous propensities of their companions. But this is very different from the congregating of birds after they have lived solitary for several months, as is the case with larks, linnets, the window and chimney swallows, and many others.

The lark during the summer months is decidedly unsocial; for though we may meet with two or three pairs in the same field, we seldom find their nests near each other. They are not quarrelsome and pugnacious, like the red-breasts, but they seem to prefer a secluded spot to a crowded neighbourhood. The young larks, after leaving the nest, seem equally unsocial, and do not, like most nestlings, keep together in a band; but prefer to wander about the field by themselves, though this must increase the trouble of their parents in bringing them food. Yet these seemingly unsocial birds, as soon as the breeding season is fully over, flock together in numbers almost incredible, and have then beell caught for the table in most countries of Europe from the earliest times, as in Greece, Italy t, and Fingland ${ }_{+}^{+}$The numbers taken in France may be guessed at from the account

* See Insect Architecture, p. 331.

巾 Oppian in Ixeuticæ.

$\ddagger$ Polyd. Virgil. Hist. fol. 1534. 
of Montbeillard, who says, "a hundred dozen or more are sometimes taken at once, and it is reckoned very bad sport when only twenty-five dozen are got *." It would indeed require such numbers to liquidate the expense of the snares employed, it being usual to plant about two thousand limed willow rods in one field. On the Continent this is reckonerd a princely sport; and the French nobility were also wont to be fond of it. But in England lark fowling is only followed by bird-catchers, who chiefly use a day clap net, or a night net, and a low bell, with which they take the larks at roost in stubble-fields. 'Though these larks, however, associate in such numerous flocks during the winter, no sooner does the pairing season commence than they separate again, each pair choosing a particular field, or a portion of a field, for a breeding place.

What we have said of larks will nearly apply to linnets, chaffinches, the two house-swallows, and several other species of our indigenous birds, which breed in solitary pairs, and congregate at the approach of winter. It is worthy of remark, that most, if not all, of these broods are more or less migratory, either leaving the country altogether or shifting from one district to another; and, looking at the facts in this point of view, we may plausibly conjecture that the young broods take advantage of the experience of the older birds in removing to a more genial climate, or to places more abounding in food. Yet how plausible soever this may appear (and to us it seems almost the only solution of the difficulty), we meet with many species apparently in the same or very similar circumstances, which never congregate, or at least very partially. The pipits (Anthi), for example, whose habits and appearance so nearly resemble the larks that they are usually called titlarks, never * Oiseaux, Art, L'Alouette. 
congregate in numbers; and though Colonel Montagu's authority cannot be disputed, when he states, that he has observed the meadow-pipit (Anthus pratensis, BEchstern) "keeping together in small flocks" during winter, we doubt whether this be a common occurrence, or whether the birds he saw might not be the families bred the preceding summer. The rock-pipit (Anthus rupestris, Nrusson), which we had good opportunities of observing on the wild rocky shores of Normandy, might almost be considered gregarious from the numbers that are crowded together in a small space; but though a dozen or more may be put up within a few yards, they never take flight simultaneously in flocks, but always separately, and they roost in the same manner*.

The wheat-ear (Saxicola Enanthe, Bechstein) is another striking exception to our general remark. Colonel Montagu, indeed, as in the case of the meadow-pipit just mentioned, tells us of a vast number of these birds having, on the 24th of March, 1804, " made their appearance on the south coast of Devon, near Kingsbridge, in a low sheltered situation, and continued in flock the whole of the day, busied in search of food. The flock consisted entirely of males, without a single female amongst them t." Pennant, likewise, says, " about Eastbourne, in Sussex, they are taken by the shepherds in great numbers-the numbers annually insnared in that district alone

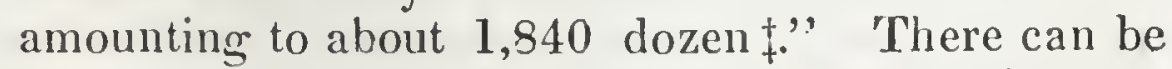
little doubt, however, that the statement of White is the more correct. "During autumn vast quantities," he tells us, "are caught on the South-downs, near Lewes: there have been shepherds, I am credibly informed, who have made many pounds in * J. R. + Ornith. Dict. p. 553, $2 \mathrm{~d}$ edit. \$ Brit. Zool. p. 102, fol. edit. 
a season by catching them in traps; and though such multitudes are taken, I never saw (and am well acquainted with those parts) above two or three at a time, for they are never gregarious*." A recent writer, agreeing with White, well remarks, that " if the flocking of wheat-ears in the south of England be an actual accumulation of them from other parts of the country, it is different from their habits in other places. They there both come and go without any indication, and appear to have no association beyond a single pair. 'They may flock there, however, for there are many places where birds accumulate at certain seasons without any explained cause, though seldom more than two or three are seen together at any other time of the year $\dagger . "$

There can be little doubt, we think, that the most probable reason for the solitary habits of the wheatear is the nature of its food; for living, as it seems to do, on the few insects which frequent such places as the little heaps of stones collected from the ridges of a corn-field, it would be impossible for more than a pair of these birds to find subsistence near one spot. Pennant mentions as one cause for these birds being so numerous at Easthourne, that the neighbourhood "abounds with a certain fly which frequents the adjacent hills for the sake of the wild thyme," adding that the fly deposits its eg'os, and also feeds upon the thyme+. We are acquainted with no fly of this description except the very small gall-fly (Cynips thymi?), but which can never, we think, be so abundant as to make it an object for so large a species of bird as the wheat-ear to assemble, with the hopes of a plentiful banquet.

* Selborne, letter 13.

† Brit. Naturalist, ii. 361 .

+ Brit. Zool., as before quoted. 
Chapter IV.

PAIRING OF BIRDS.

It would not be easy to select a more striking instance of the wisdom displayed in regulating the works of creation, than the extraordinary, and, to us inexplicable, fact of the males and females of all animals being always found in nearly the same proportional numbers. With respect to mankind, for example, it has been proved by taking a census of the population in different countries, that the ratio of the two sexes shows very little variation. Hufeland found that in Germany there are about twenty-one males to twenty females*; by an average of 58,000 births at the Dublin I,ying-in-Hospital the proportion of males to females was found to be as ten to nine + ; and by the population returns for England and Wales from 1811 to 1820 , the number of males born was $1,664,557$, and of females, $1,590,510 \ddagger$ It has been inferred that the uniform excess of male births is providentially designed to meet the greater mortality arising from men being, by their habits of life, more exposed to dangers. No physiological investigation hitherto attempted has been successful in elucidating the more inmediate causes of these wonderful facts, though some of the laws by which they are regulated have recently been successfully traced by the curious experiments of M. Girou de

* Edin. Phil. Journ. iii. 296-9.

+ Cross, Med. Schools of Paris, p. 191.

$\ddagger$ Population Abstract, p. 154 . 
Buzareingues *, who fonnd, that with respect to the ages of the individuals paired, and the proportion of the sexes produced, nearly the same principles held good among fowls as among quadrupeds, at least when both were domesticated.

The males of quadrupeds seldom lend any assistance whatever in taking care of the young. The assistance of the male indeed in most animals which suckle their young is not at all wanted, and hence he seldom takes any notice, or even knows of the existence, of his offspring. Amongst insects there is still less need of the aid of the male, so far at least as food is concerned; for very few insect parents live to see their offspring. Insects, in most cases, finding their own food as soon as they are hatched, it is the chief care of the mother to deposit her eggs where appropriate food may be readily obtained by her progeny. Food indeed is in some instances collected by the mother and brought to the place where her eggs are deposited + ; but the male parent never shares either in the labour of procuring it or in the construction of the nest for its reception + ; while in the singular exceptions furnished by ants and other insects living in communities, neither the males nor the females, but a peculiar race of nurse insects provide the necessary food for the young §. Amongst birds, on the other hand, food for the young has in most instances to be brought from a distance, and much assiduity is required to collect it in sufficient quantity, the voracity of nestlings being almost insatiable. Among them, therefore, the assistance of the male in this work is in most species almost indispensable. When the brood is numerous, it would be extremely difficult if not impossible for

* Expériences sur la Generat. 8vo. Paris, 1828.

巾 Insect Architecture, p. 32.

$\S$ Insect Miscellanies, p. 242,

+ Ibid. p.45. 
the female alone to procure the requisite supply. Rooks, for example, which feed their young upon the grubs of chafers and similar insects, have often to make long excursions from their nest-trees before they can find the required prey; and if this task were assigned to the female alone she could not obtain enough to sustain her own wants and the incessant cravings of five young ones, which will readily devour their own weight of food in the course of a single day. Accordingly, when rooks, as they sometimes do, build a second nest late in the season, in consequence of the first being destroyed, they find it scarcely possible to rear their young; the warmth of the advancing summer drying up the ground and forcing the grubs and worms so deep into it as to be out of reach, while, the operations of ploughing and digging having almost ceased, they have little aid from the labours of man. In such cases it has been remarked, that "the constant clamour" of the young for food, so unusual in nestling birds, renders it manifest that the labour and exertion of the parents cannot supply a sufficiency for their requirements*." If then the difficulty is so considerable when both parents conjoin their labours, it may be inferred that it would even in ordinary circumstances be too much for the female alone, more particularly as her energies must be somewhat impaired by the previous fatigue undergone in the process of hatching. During this process the aid of the male is no less indispensable than in feeding the young.

It is obvious, that while the hen has to sit for a number of days in order to hatch her eggrs, and cannot, as we shall afterwards see, leave them for many minutes, withont incurring the risk of destroying the embryo chicks, she must either run this hazard or perish of hunger, unless she had food brought to * Journal of a Naturalist, p. 257, 3d edit. 
her. This indeed may be considered as almost the commencement of the labours of the cock; for though he helps a little in the building of the nest, he does not work at it with the unwearied assiduity of the female. In the instance of the capocier (Sylvia macroura), Vaillant tells us that he observed the female to be much more active and anxious about the building than the male, even punishing him for being frolicksome and idle by pecking him with her beak; while, in revenge, he would sometimes set about pulling portions of the nest to pieces*.

Independently, then, of assisting to build the nest, the female evidently could not well perform her domestic duties, if left to her own efforts; though amongst polygamous birds, as we shall subsequently notice, this remark requires to be taken with some modification. The instinct, or whatever it may be called, which leads birds to anticipate, foresee, and provide for this necessity, we cannot, in our present state of knowledge, trace to its immediate causes; and we must therefore rest contented with the knowledge of the observed facts. Some of these are not. a little interesting, particularly on account of the close resemblance of the proceedings of birds to our own, a resemblance that does not hold with those of other classes of animals.

It might be supposed that birds of prey would be in the first instance somewhat afraid of each other in their preliminary communications; at least an entomologist would readily suppose so from knowing that it is no uncommon thing among predacious insects for the females to malie prey of the males, even after pairing. Birds of prey, however, tlough, when pressed by liunger, they might not refuse to destroy their own species, are not like spiders actuated by indiscriminate cannibal voracity; and though * Oiseaux d'Afrique, iii. 77; and Architect. of Birds, p. 282. 
some of the more powerful eagles (Halicetus lcucocephalus, Savigny, \&c.) will pursue their congeners and force them to surrender the prey they may have

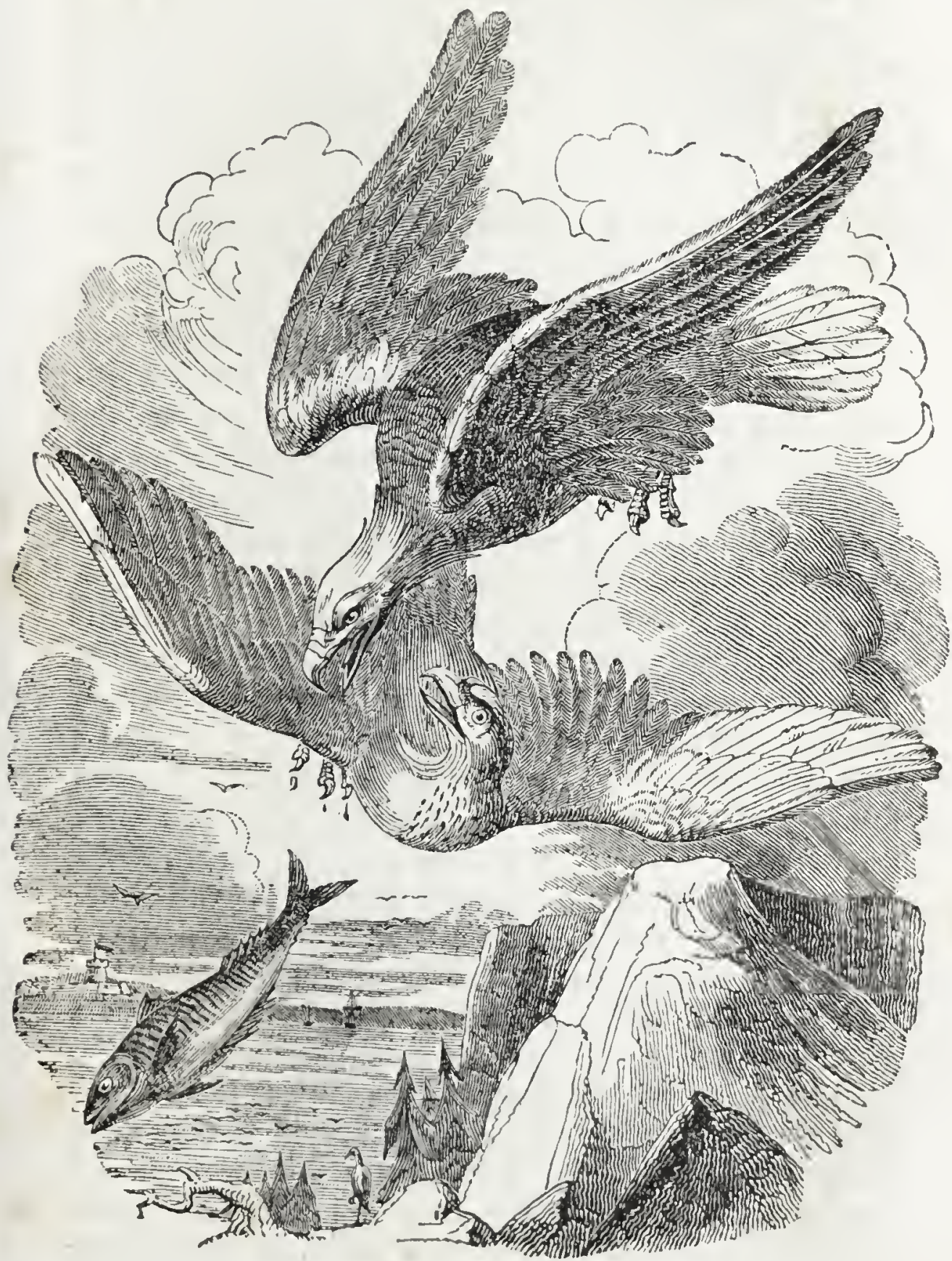

White-headed Eagle and Fish.Hawh 
caught, yet we are not aware of any recorded instance. of one eagle making prey of another, as spiders are known to do, and as is common amorg fish. On the contrary, the males and fenuales of birds of prey appear to be more closely attached than those of most other species. They continue together not only during the breeding season, but throughout the year, and even for a long succession of years, at least if we may trust to the circumstantial evidence of a pair of eagles frequenting the sane locality, and building on the same spot.

The evidence indeed for the hirds beingr always the same is incomplete; yet on the supposition that it is not the same but successive pairs which are observed in the same place, we are led to the curious inquiry how the death or disappearance of one pair is supplied by another. We have in nore than one instance observed a pair of magpies nestle on the same tree for a series of years, where they reared a brood of four or five young ones every season. All of these disappeared from the neighbourhond, - at least we observed no increase in the number of nests. In one instance we observed a magpie's nest thus successively occupied for ten years. ${ }^{*}$ 'The number of young, therefore, annually reared in such an hereditary nest, as it may well be called, must be nearly proportional to the supply of the mortality among these birds either from accident or disease. Should the female, for instance, which has just reared a brood, be accidentally killed, the male must either seek for another partner or abandon the nest to sorne of his descendants. That the former is the usual manner of proceeding, will appear from facts which we shall immediately state; but that the latter inay also occur may be inferred from the young birds, upon leaving their parents, establishing * J, R. 
themselves, as they must do, in the best situation they can discover.

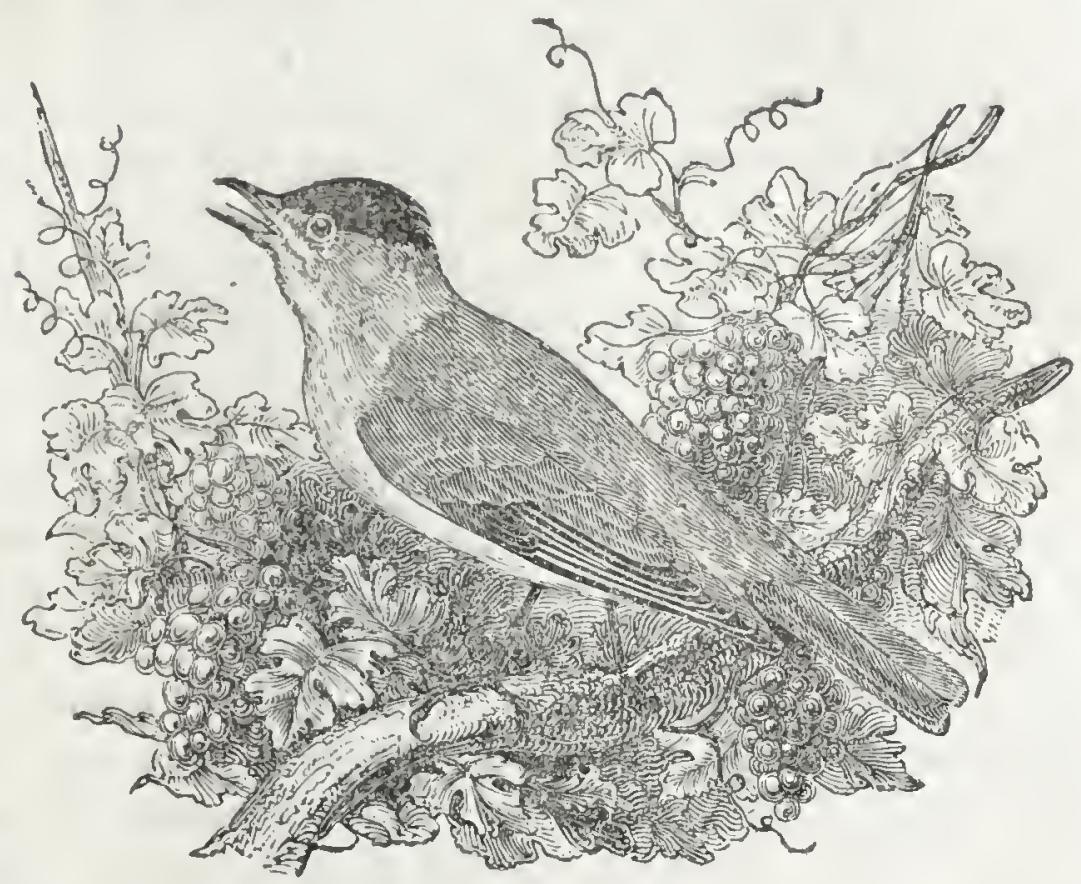

Black-cap.

The continuance of a nest in the same spot for several years is more remarkable in the case of migratory birds than in that of magpies, which do not migrate, and seldom go to any considerable distance from their breeding trees. There has been in a garden adjacent to ours, the nest of a black-cap (Sylvia atricapilla) for a succession of years, and broods have been successively reared there, withont any observable increase in the population of the species. Yet this bird, which is little biggrer than a wren, weighing only half an ounce, has to traverse annually the whole of the south of Europe, and probably a great proportion of the north of Africa, exposed of course to numerous accidents, as well as to occasional scarcity of its appropriate fuod. From the regular annual restoration, however, of this nest at the same spot, it is obvious that one, if not both of 
the black-caps, must have been wont to perform this extensive migration to and from Africa as safely as the more hardy cuckoo or the more swift-winged swallow. During the spring of 1831, the black-caps, which we suppose to be the same birds, from their keeping to the same place of nestling, were more than usually late in arriving; for in another garden about a mile off, there were young in the hereditary nest of black-caps before our little neighbours made their appearance from the South. When they did arrive, their attention was immediately attracted by the unusual circumstance of hearing the loud song of a rival in the vicinity of their premises. This was a cock black-cap, which we had purchased the preceding autumn in the bird-market at Paris, and which was daily hung out in his cage to enjoy the fresh air and the sunshine, within a gun-shot of their usual place of nestling. The wild birds did not appear to like the little stranger at all ; and the cock kept flying around the cage, alternately exhibiting curiosity, fear, anger, defiance, and triumphant exultation. Sometimes he would flit from branch to branch of the nearest tree, silently peeping into the cage with the utmost eagerness; all at once, he would dart off to a great distance as if afraid that lie was about to be similarly imprisoned; or getting the better of his fears, he would perch on a conspicuous bough and snap his bill, calling check, check, seemingly in a great passion; again he would sing his loudest notes by way of challenge, or perhaps meaning to express his independence and superiority. Our cage-bird, meanwhile, was by no means a passive spectator of all this; and never failed, on the appearance of the other, to give voice to his best song and to endeavour to out-sing him, since he could not get at him to engage in personal con. flict. 
This sort of altercation continued for more than a week, but the wild bird hecame gradually less eager to pry into the cage or to take any other notice of the cage-bird; and at length ceased altogether to approach it, his attention being now wholly occupied in attending to his mate and aiding her in building their nest. It is worthy of remark, that though on their first appearance they resorted to the garden where the nest had hitherto been built, they finally fixed their resirlence in another garden, at some distance, induced no doubt by the vicinity of our cagebird to theil former haunts. The distance of the place to which they removed is such, that we can readily hear the song of the cock, and our bird is no less eager to answer and to endeavonr to outsing. him than at first; while it is worthy of remark that the wild bird seems no longer interested in such rivalry, and sings as if his only concern was to please himself and his mate*.

Now we think it a very probable inference from this little narrative, that had the wild cock black-cap by any accident been killed, the hell would have readily paired with our bird or any other which had made its appearance; for it must have been the natural dread of her preferring our bird, that actuated the wild cock in his various expressions of passion which we have just recorded. This conclusion is corroborated by his subsequent behaviour as soon as he felt secure in the affections of his mate by her commencing the nest under his own auspices.

A bout the same period of time, we had an opportunity of observing the proceedings of some other cage-birds of different species in their preparations for breeding. It is well known to be a common practice among bird-fanciers to pair hen canaries with cucks of other species of the same g'enus, or such as re*J. R. 


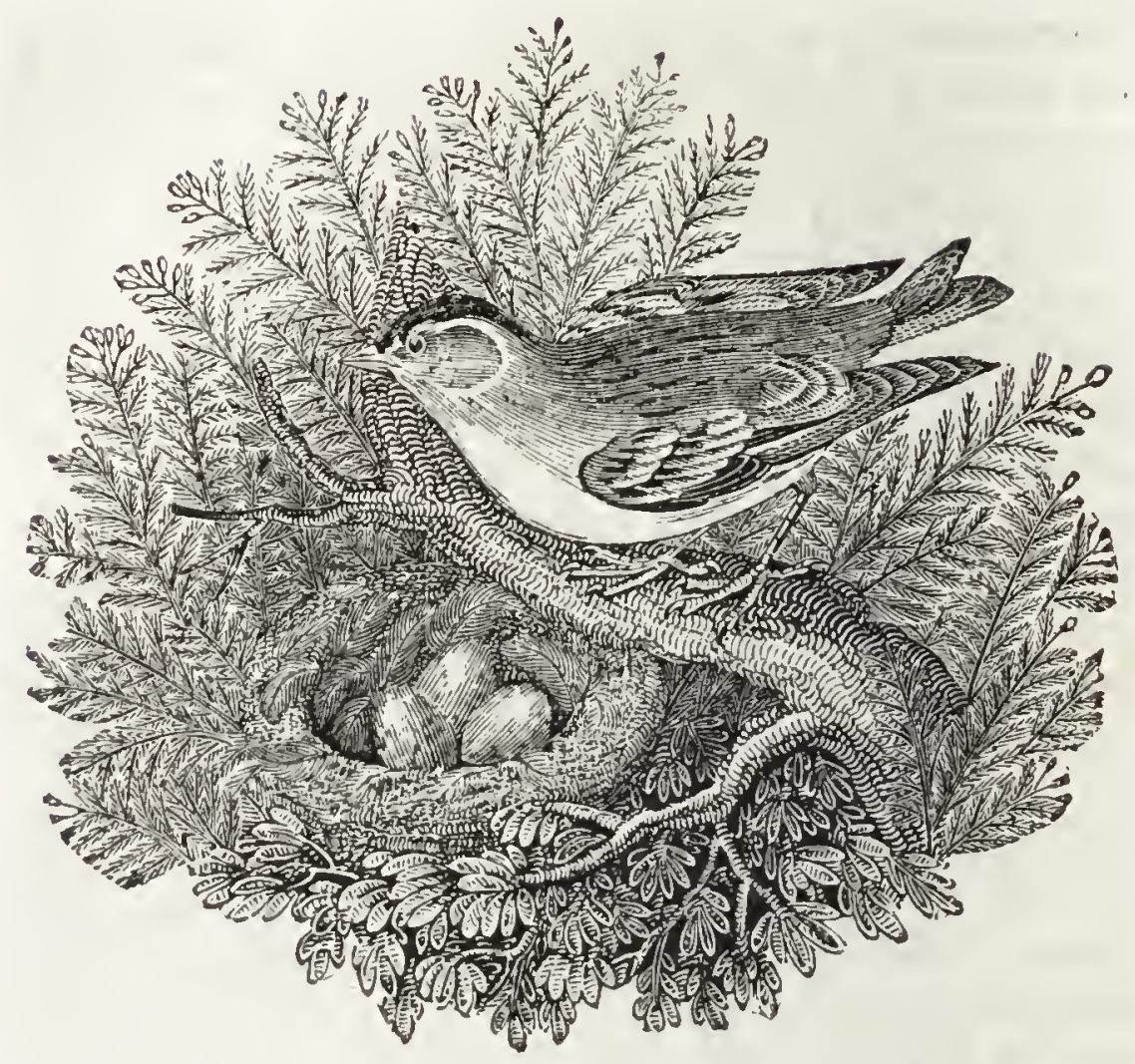

Aberdevine and nest.

semble them the nearest in size and habits; and as we possessed two such cocks in a goldfinch and a siskin (Carduelis spinus, Brisson), we put them both into a large breeding-cage along with a hen canary. It was not a little amusing to observe the exertions of these two birds in trimming their feathers, singing at the utmost pitch of their voices, as if each were determined not to be out-sung by his rival; and more than once, before any nest was begun, we observed them bringing her food in their bills by way of present. From the first, however, she showed a marked dislike to the goldfinch, though the finest beau of the two, being the brightest-coloured bird even of this beautiful species we ever saw; while the siskin, independently of his less gay colours, had lost his tail, and was besides quite bald, from the habit he had of 
rubbing his head along the wires of the cage. With all these disadvantages, nevertheless, in the personal appearance of the siskin, added to his inferiority of song, (rendered worse by the harsh cackling note which he seldom failed to give as a finale to his most melodious passages, contrasting strongly with the merry musical twinkle of the goldfinch's finale,) the latter received nothing for his assiduities, but a loud scolding or sometimes a hearty drubbing, the canary being by far the most powerful bird, and being never loth to let him feel the sharpness of her beak. The siskin being evidently the favourite, we had the goldfinch removed; but as his cage was hung up near the other, he continued to give himself all the airs which had already proved so unavailing. But the siskin, precisely like the wild black-cap already mentioned, almost immediately relaxed in his assiduities to please; and, though he was not inattentive during the incubation which followed, yet he seldom strove to out-sing the goldfinch, but warbled in a subdued under tone of voice, as much as to indicate that he cared not how well or how loud his old rival might now sing *.

Montagu was of opinion that birds which have not paired wander about continually till they find a mate, in support of which he adduces several curious facts which fell under his observation. In the instance of the nightingale, if by accident the female is killed, the male, who has become silent about the end of June, will resume his song and will continue to sing late in the summer or till he finds another mate. "'This," continues Montagu, "we have proved by taking the female on her nest, when the mate assumed his usual vociferous notes, which attracted another female." It would appear, indeed, that in birds which pair, nature has produced nearly an equal

$$
\text { * J. R. }
$$


number of both sexes; and yet, if either the cock or the hen be killed hefore breeding, the remaining bird usually finds a second mate. The cock of the migrative species Montagu thinks never quits the place he first resorts to, but attracts the females by his song; and lience, he conceives, it is probable that such females as have not at first paired, or lost their mates by accident, continually wander about in search of another.

If we may be permitted to draw an inference from a bird in confinement, we should be disposed to question the fact of the cuck of migratory birds selecting a station, and singing there till a hen was attracted. Our caged black-cap, already mentioned, appeared to be actuated by different feelings; for he continued to exhibit the migratory agitation of hopping inpatiently about his cane during the night, long after the species had arrived in this country. His agitation commenced exactly on the lst of April, though, on the same day, we heard three or four of those newly arrived singing in the gardens; and one had been observed in the neighbourhood more than a week before. It is worthy of remark, also, that he had been in song from before Christmas, which could not well have been intended to attract a mate. But what we consider most to the point, his migratory arritation did not cease till the 10th of June, and he hopped about as incessantly on the night of the 9 th as he had done at the commencement on the 1st of A pril. Now though, from confinement being an unnatural state, we camnot reason with certainty from circumstances then occurring, yet it seems probable that our bird, if he had been at liberty, would have continued to migrate every night, and to sing, as he did, part of every day (snatching a 'few minutes' sleep occasionally) till he had found a mate*. 
We have a similar instance to those mentioned by Montagu, recorded by Professor Kalm. "A couple of swallows," he says, "built their nest in a stable, and the female laid egrgs in the nest, and was about to brood them. Some days afterwards the people saw the female still sitting on the eggs; but the male, flying about the nest, and sometimes settling on a nail, was heard to utter a very plaintive note, which betrayed his uneasiness. On a nearer examination, the female was found dead in the nest; and the people flung her body away. The male then went to sit upon the eggrs; but after being about two hours on them, and perhaps finding the business too troublesome, he went out, and returned in the afternoon with another female, which sat upon the nest, and afterwards fed the young ones till they were able to provide for themselves *."

'That it is not the cock alone, however, which is thus able to procure a second mate, appears from the remarks of White. "Among the monogamous birds," he says, "several are to be found, after pairing time, single, and of each sex; but whether this state of celibacy is matter of choice or necessity is not so easily discoverable. When the house-sparrows deprive my martins of their nests, as soon as I cause one to be shot, the other, be it cock or hen, presently pro. cures a mate, and so for several tirnes following. I have known a dove-house infested by a pair of white owls, which made great havock among young pigeons. One of the owls was shot as soon as possible; but the survivor readily found a mate, and the mischief went on. After some time the new pair were both destroyed, and the annoyance ceased. Another instance, I remember, of a sportsman, whose zeal for the increase of his game being greater than his humanity, after pairing time he always shot the * Travels in America. 
cock-bird of every couple of partridges upon his grounds, supposing that the rivalry of many males interrupted the breed. He used to say, that though he had widowed the same hen several times, yet he found she was still provided with a fresh paramour that did not take her away from her usual haunt *."

In opposition to this ductrine there is one instance, which lias been celebrated from the earliest ages, the turtle-dove being represented as the very emblem of conjugal love and fidelity. The dark or blackcoloured turtle-dove, it is said, was employed by the Egyptians as the hieroglyphic of chaste widowhood, it being understood that when one of a pair was killed the other never joined with a second mate. "They be passing chaste," says Pliny, "and neither male nor fenale change their mate, but keep together one true unto the other. 'They live, I say, as coupled by the bond of marriage; never play they false; one by the other, but keep home still, and never visit the holes of others. 'They abandon not their own nests, unless they be in a state of single life, or widowhood by death of their fellow. 'The females are very meek and patient; they will endure and abide their imperious males, notwithstanding, otherwhiles, they be very churlish unto them, offering them wrong and hard measure, so jealous be they of the hens, and suspicious, though without any cause, for passing chaste and contillent by nature they are $\uparrow . "$ The poets follow naturally in the same opinion, and hence, from Ovid and Dante + down to our own times, we meet with comparisons and allusions thence derived, as if the fact were ascertained beyond question.

The fact, however, of doves acting in this manner, so far from being correct, may be easily disproved by

* Nat. Hist. of Selborne, letter 34.

† Holland's Plinie, x. 34. $\ddagger$ Iuferno, Cant. 5. 
any one who will take the tronble, as well as by circumstances mentioned by the very writers just quoted. Aristotle, indeed, though he hints in one place his belief in the common opinion, mentions in another that he had known doves change their mates. The fact, moreover, that these birds are easily enticed from their own dove-cots to others, and thus become lost to their owners, is but too well known to every body who has ever kept them. "Some," says Pliny, " use means to keep pigeons in their dove-honse (for otherwise they be birds that love to be ranging and wandering abroad), namely, by slitting and cutting the joints of their wings with some thin sharp piece of gold; for if you do not so, their wounds will fester and be dangerons. And in very troth, these birds be soon serluced and trained away from their own homes; and they have a cast with them to flatter and entice one another: they take a great delight to inveigle others, and to steal away sone pigeons from their own flocks, and evermore to come home better accompanied than ther went forth*" Now all this is evidently in direct contradiction to what we have quoted from the precerling page of the same work. M. Ray also informed Buffon, that notwithstanding the reputation of the turtle-dove for conjugal constancy, he found the females of those which were confined in voleries living almost promiscuously with the males. Nay, M. Ray asserts that he has observed the wild turtle-doves living in the same manner on the same tree + . The common opinion, therefore, appears from these circumstances to be manifestly erroneous.

We meet, however, with instances among other birds of affectionate conjugatity well worthy of being recorded; and we shall give one example of this kind,

* Holland's Plinie, x. 37.

$\uparrow$ Oiseaux, Art. Tourtcrelle, 
as described by Bingley, that occurred in a pair of the Guinea parrot (Psittacus pullarizs). "A male and female of this species were lodged together in a large square cage. The vessel which held their food was placed at the bottom. The male usually sat on the same perch with the female, and close beside her. Whenever one descended for food, the other always followed; and when their hunger was satisfied, they returned together to the highest perch of the cage. They passed four years together in this state of confinement; and from their mutual attentions and-satisfaction, it was evident that a strong affection for each other had been excited. At the end of this period the female fell into a state of languor, which had every symptom of old age; her legs swelled, and knots appeared upon them, as if the disease had been of the nature of gout. It was no longer possible for her to descend and take her food as formerly; but the male assiduously brought it her, carrying it in his bill, and delivering it into hers. He continued to feed her in this manner, with the utmost vigilance, for four months. The infirmities of his mate, however, increased every day; and at length she became no longer able to sit upon the perch: she remained crouched at the bottom, and from time to time made a few useless efforts to regain the lower perch; while the male, who remained close by her, seconded these feeble attempts with all his power. Sometimes he seized with his bill the upper part of her wing, to try to draw her up to him; sometimes he took hold of her bill, and attempted to raise her up, repeating his efforts for that purpose several times. His countenance, his gestures, his continual solicitude, every thing, in short, indicated, in this affectionate bird, an ardent desire to aid the weakness of his coinpanion, and to alleviate her sufferings. But the 
scene became still more interesting when the female was at the point of expiring. Her unfortunate partner went round and round her without ceasing; he redoubled his assiduities and his tender cares; he attempted to open her bill, in order to give her nourishment; his emotion every instant increased; he went to her, and returned with the most agitated air, and with the utmost inquietude; at intervals he uttered the most plaintive cries; at other times, with his eyes fixed upon her, he preserved a sorrowful silence. His faithful companion at length expired: he languished from that time, and survived her only a few months *."

* Bingley, Anim. Biog. ii. 224 . 


\section{Chapter V.}

\section{PECULIARITIES IN PAIRING.}

THERE are some species of birds, among which the assistance of the male is less necessary during incubation, as well as in procuring food for the young, than among those whose habits have been described in the preceding chapter. In such species domestic attachment is much less binding, and in some instances can scarcely be said to exist. We have never observed cuckoos, for example, associating in pairs, though single birds may be seen in considerable numbers throughout the summer; and, among domestic fowls, the peacock is seldom seen in company with the peahen. 'The turkey-cock indeed is artificially brought to feed along with the hen; but in the case of the latter bird, this is contrary to what takes place in a wild state. As a contrast to what we are familiar with from observation, it may be interesting to give a sketch of the singular manners of the turkey, as it has been observed in its native woods, by Audubon, Charles Bonaparte, and the earlier travellers in America.

About the heginning of October, turkeys, young and old, move from their breeding districts towards the rich bottom lands near the Ohio and the Mississippi. The males (called gobblers by the Americans) associate and feed in comparies of from ten to a hundred apart from the females, which advance sometimes singly, sometimes followed by their young, and sometimes in united families, forming a band of from seventy to eighty individuals. All these exhibit 


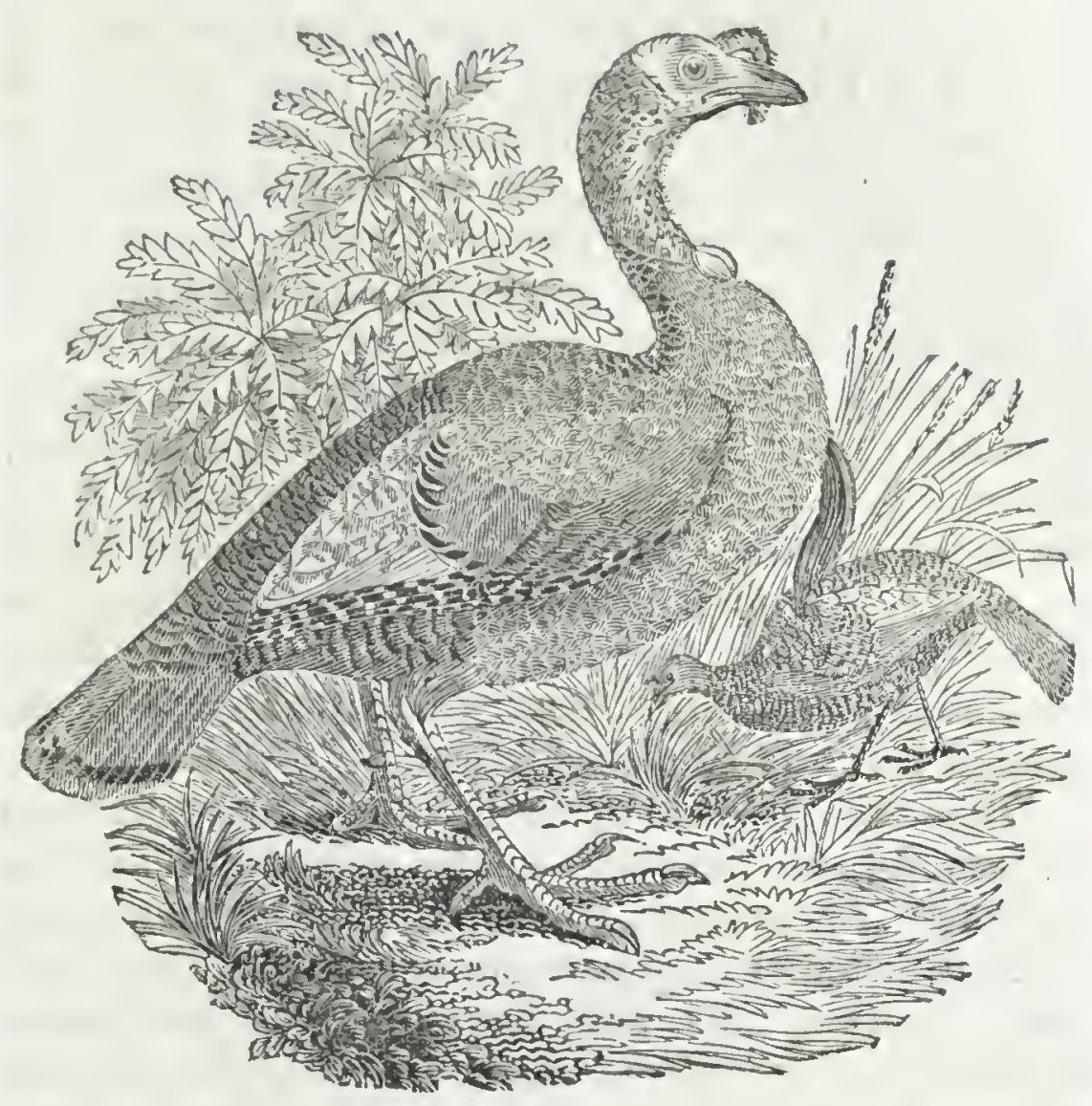

Wild Turkey and Young.

a dread of the old cocks, and are constantly on the watch to avoid them; for though the young birds are now about two-thirds glown, the males seem already to regard them as rivals, and whenever they liave an opportunity they will attack and often kill them by repeated blows on the head.

'I'owards the middle of February, or early in March, the turlieys begin to prepare for breeding, the females at first shumuing the males, who eagerly pursue them and utter their peculiar gobbling call. At night, the two sexes roost apart, though usually at no considerable distance. When a female cliances to utter her call-note, all the males within hearing return a 
loud response, in a rolling gobble of rapidly successive notes, as if with the design of emitting the last as soon as the first,- - much in the same manner as the tame turkey when he responds to any unusual or frequently repeated noise, but not with the spreading tail and strutting gait as when fluttering around the hens on the ground, or practising similar movements in the morning on the branches of the roost trees. When their numbers are considerable, the woods from one end to the other, sometimes for many miles, resound with this singular hubbub, continued from the roosting places in alternate responses for about an hour. All then becomes still again, till at the rising of the sun they leap down in silence from their roost trees, and begin to strut about with expanded tails and drooping wings.

When the call-note of the hen turkey ascends from the ground, all the cocks in the neighbourhood immediately fly towards the spot. The moment they reach it, whether they perceive her or not, they erect their spreading tails, and throw the head backwards between the shoulders, which are at the same time shrugged up; they distend the comb and wattles, depress their' wings with a quivering motion and a rustling sound, strutting the while with great pomposity, and ejecting from the lungs successive puffs of air. At short intervals they may be seen to stop short, listening and looking all about; but whether they descry the female or not, they resume their strutting and puffing, moving with as much celerity as the nature of their gait and their notions of ceremony seem to admit. Should the males, during such movements, encounter each other, as often happens, furious battles ensue, which are only terminated by the flight or the death of the vanquished, and many lives are thus lost. "I have often," says Audubon, " been much diverted while watching two males in 
fierce conflict, by seeing them move alternately backwarls and forwards, as either had obtained a better hold, their wings drooping, their tails partly raised, their body feathers ruffled, and their heads covered with bloud. If, as they thus struggrle and gasp for breath, one of them should lose his hold, his chance is over; for the other, still holding fast, hits him vio'ently with spurs and wings, aud in a few minutes brings him to the ground. 'The moment he is dead the conqueror treads him under foot; but, what is strange, not with hatred, but with all the motions which he employs in caressing the female*."

When the male and female turkey meet, the ceremonies of strutting and opening the wiugs are carried on by both parties, with the same pomp of movement that used to distinguish the stately minuets of the old Courts of St. James's and Versailles. The match being at length agreed upon, the attachment appears to continue during the season, though the cock is by no means constant to his mate, and does not hesitate, should opportunity offer, to bestow his attentions on others. But when the above preliminaries have been settled, the hens follow their favourite cock, roosting on the same tree, or, at least, in its immediate vicinity, till the time of laying, when the hen has recourse to every stratagem of cunning to conceal her eggs from the male, who always breaks them, in order, it is alleged, to prevent her from withdrawing from his society, by attending to the duties of incubation. At this period the hens shum the cocks during the greater part of the day, the latter becoming clumsy and listless, meeting each other without exhibiting any rivalry, and ceasing to gobble or strut as they had previously done.

"Turkey-cocks, when at roost," says Audubon, "somelimes strut and gobble; but I have more * Ornithol. Biogr. p. 4. 
generally seen them spread out and raise their tail, and emit the pulmonic puff, lowering their tail and other feathers immediately after. During clear nights, or when there is monnshine, they perform this action at intervals of a few minutes, for hours together, without moving from the same spot, and indeed sometimes without rising on their legs, especially towards the end of the breeding season. The males now become greatly emaciated, and cease to gobble, their breast-sponge becoming flat. They then separate from the hens, and one might suppose that they had entirely deserted their neighbourhood. At such seasons I have found them lying by the side of a $\log$, in some retired part of the dense woods and cane thickets, and often permitting one to approach within a few feet. They are then unable to fly, but run swiftly, and to a great distance. A slow turkeyhound has led me miles before I could flush the same bird. Chases of this kind I did not undertake for the purpose of killing the bird, it being then unfit for eating, and covered with ticks, but with the view of rendering myself acquainted with its habits. They thus retire to recover flesh and strength, by purging with particular species of grass, and using less exercise. As soon as their condition is improved the cocks come together again, and recommence their rambles *."

Similar manners are not uncommon among other species belonging to this group of birds (Rasores, ILlJGER). But several of these pair in the usual way. Some of the grous family (Tetraoniai, LEACH) are polygamous, while others are monogamous. In the moor-fowl (Tetrao Scoticus), for example, which sometimes pairs so early as Januaryt, we have remarked, that the cock and hen keep

* Ornith. Biogr. p. 5.

+f Selby, Illustrations, p. 308. 
together during the greater part of the summer. We have also had opportunities of observing the polygamous manners of the black grouse (Tetrao tetrix), which much resemble those of the wild turkey, inasmuch as the males collgregate in autumn, and may be seen in parties of a dozen or more in Glendaruel and other wooded and marshy defiles of the Western Highlands of Scotland. On the approach of spring, however, those which have spent the winter in harmonious companionship gradually become irascible, and not only separate by reciprocal consent, but exhibit rancorous hostility whenever they encounter any of their former associates. Each cock chooses a particular station, over which he assumes paramount authority; and if a rival venture within his boundaries, he must either conquer the first settler, or pay the penalty of his intrusion by defeat, and probably by death. That none may be unapprized of the situation of his territory, he takes care to proclaim his rights by crowing aloud, particularly in the morning, when birds leave their roosts to forage for the day. His call, while it warns his rivals off his domain, invites such females as may be within hearing to resort to the place, where he receives them with proud strutting and drooping of the wings and tail, somewhat similar to what we have just recorded respecting the turkey-cock*. During the pairing season the skin of the eyebrows becomes intensely red, and the whole plumage more brightly coloured $t$, as in other birds. At the beginning of May the hens begin to lay.

Another species, the ruffed grouse of America (Tetrao umbellus) proceeds much in the same manner; though the call of the cock, as described by Audubon $\ddagger$ and Wilson $\S$, is very peculiar. When
* J.R.
+ Selby, Illustrations, p. 305.
$\ddagger$ Ornith. Biog. p. 215.
\$ Wils. Am. Orn, vi. 46. 


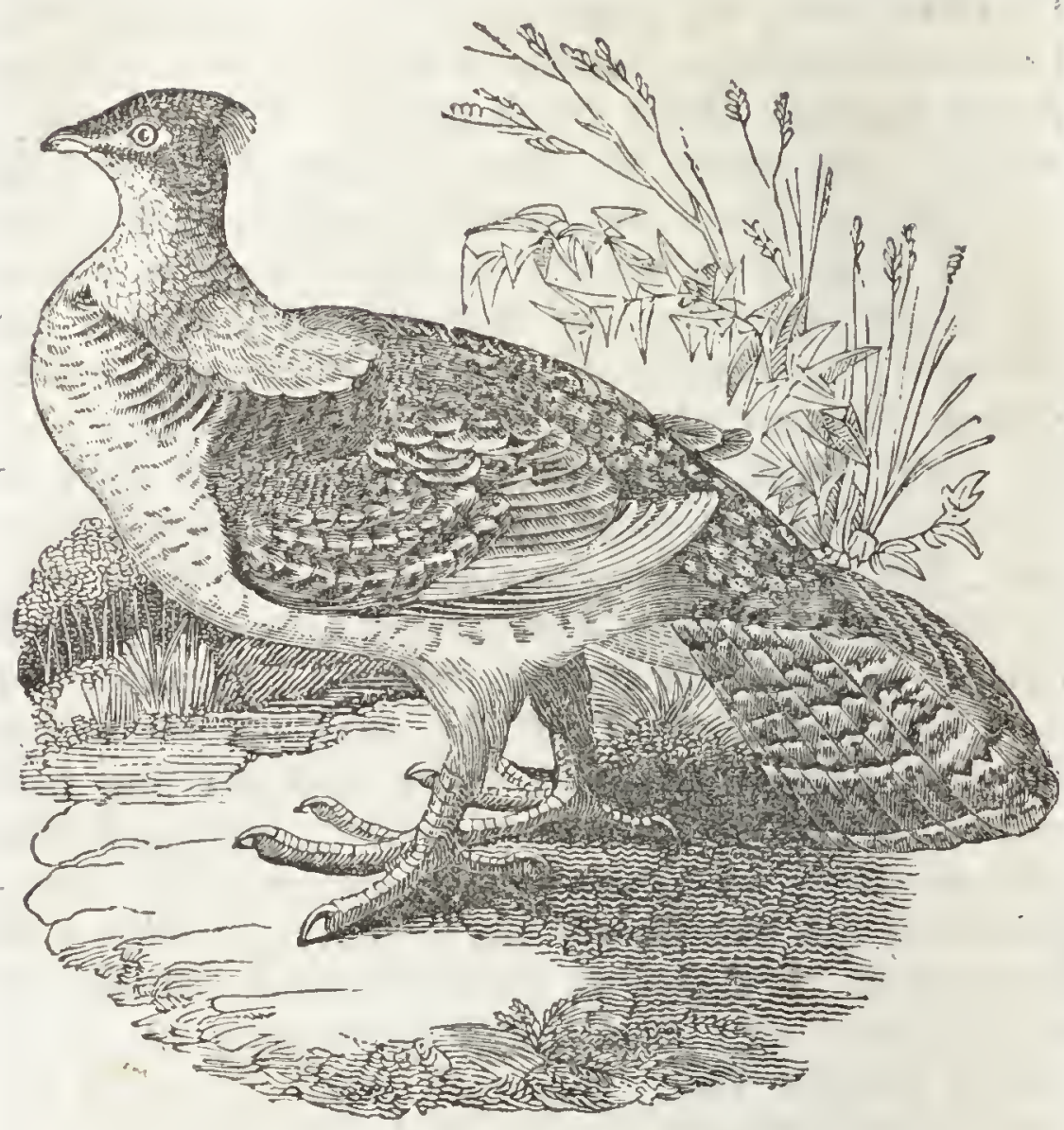

Ruffed Grouse.

walking through the solitary woods frequented by the ruffed grouse, a stranger is surprised by sudderily hearing a sort of bumping sound, similar to that produced by two full-blown bladders struck smartly together, but much louder. At the commencement, the strokes are distinct and slow; but they are gradually increased in rapidity, till they at length run into each other like the rolling beat of a drum, or the rumbling of very. distant thunder dying away by degrees on the ear. In a calm day this drumming may be heard half a mile off. It is repeated after a pause of a few minutes.

"These birds begin to drum early in April, com- 
mencing immediately after dawn, and renewing the noise about night-fall. The cock, when drumming, usually stands upon a knoll or a felled tree, in a retired or sheltered situation, and, proudly erecting himself, raises his feathers, lowers his wings, elevates his expanded tail, contracts his throat, throws the two tufts of feathers on the neck into the form of a ruff, and inflates his whole body, strutting and wheeling about upon the leg with great stateliness. A few moments elapse, in these preliminary gesticulations, when he draws the whole feathers close to his body, and stretching himself out, begins to strike upon lis sides with his stiffened wing's in short and rapid strokes, somewhat in the manner of the domestic cock, but much more loudly, and with so much rapidity of motion, after a few of the first strokes, as to cause a rumbling sound not unlike distant thunder. This sound is very deceptive, appearing for the most part to be much nearer than it really is, though it is sufficient to point out the place to the sportsman.

"During the spring," says Audubon, "and to. wards the latter part of autumn, at which times the ruffed grouse is heard drumming from different parts of the woods to which it resorts, I have shot many a fine cock by imitating the sound of its own wings striking against the body, which $\mathbf{I}$ did by beating a large inflated bullock's bladder with a stick, keeping up as much as possible the same time as that in which the bird beats. At the sound produced by the bladder and stick, the male grouse, inflamed with jealousy, has flown directly towards me, when, being prepared, I have easily shot it. An equally successful stratagem is employed to decoy the males of our little partridge by imitating the call-note of the female during spring and summer; but in no instance, after repeated trials, have $I$ been able to entice the pinnated 
grouse to come towards me, whilst imitating the booming sounds of that bird *".

The account given of the pairing of the pinnated grouse (Tetrao cupido), by Dr. S. Mitchell of New York, is worth extracting. "The season for pairing," says the Doctor, "is in March, and the breeding time is continued through April and May. Then the male grouse distinguishes himself by a peculiar sound. When he utters it, the parts about the throat are sensibly inflated and swelled. It may be heard on a still morning for three or more miles; some say they have perceived it as far as five or six. This noise is a sort of ventriloquism. It does not strike the ear of a by-stander with much force; but impresses him with the idea, though produced a few rods from him, of a voice a mile or two distant. This note is highly characteristic. 'Though very peculiar, it is termed tooting, from its resemblance to the blowing of a conch or horn, from a remote quarter."

"During the period of mating," he continues, " and while the females are occupied in incubation, the males have a practice of assembling, principally by themselves. 'To some select and central spot, where there is little underwood, they repair from the adjoining district. From the exercises performed there, this is called a scratching-place. The time of meeting is the break of day. As soon as the light appears, the company assembles from every side, sometimes to the number of forty or fifiy. When the dawn is past, the ceremony becrins by a low tooting from one of the cocks. This is answered by another. They then come forth, one by one, from the bushes, and strut about with all the pride and ostentation they can display. 'Their necks are incurvated; the feathers on them are erected into a sort of rutl; the plumes of their tails are expanded like * Ornith. Blog. p. 215. 
fans; they strut about in a style resembling, as nearly as small may be illustrated by great, the pomp of the turkey-cock. They seem to vie with each other in stateliness; and as they pass each other, frequently cast looks of insult, and utter notes of defiance. These are the signals for battles. They engage with wonderful spirit and fierceness. During these contests, they leap a foot or two from the ground, and utter a cackling, screaming, and discordant cry. They have been found in these places of resort even earlier than the appearance of light in the east. This fact has led to the belief that a part of them assemble overnight. The rest join them in the morning. This leads to the further belief that they roost on the ground; and the opinion is confirmed by the discovery of little rings of dung, apparently deposited by a flock which had passed the night together. After the appearance of the sun they disperse.

"These places of exhibition have been often discovered by the hunters ; and a fatal discovery it has been for the poor grouse. Their destroyers construct for theinselves lurking-holes made of pine branches, called bough-houses, within a few yards of the parade. Hither they repair with their fowling-pieces in the latter part of the night, and wait the appearance of the birds: Watching the moment when two are proudly eyeing each other or engaged in battle; or when a greater number can be seen in a range, they pour on them a destructive charge of shot. This annoyance has been given in so many places and to such an extent, that the grouse, after having been repeatedly disturbed, are afraid to assemble. On approaching the spot to which their instinct prompts them, they perch on the neighbouring trees, instead of alighting at the scratching-place; and it remains to be observed, how far the restless and tormenting 
spirit of the marksmen may alter the native habits of the grouse, and oblige them to betake themselves to new ways of life.

"They commonly keep together in coveys, or packs, as the phrase is, until the pairing season. A full pack consists, of course, of ten or a dozen. Two packs have been known to associate. I lately heard of one whose number amounted to twenty-one. They are so unapt to be startled, that a hunter, assisted by a dog, has been able to shoot almost a whole pack, without making any of them take wing.

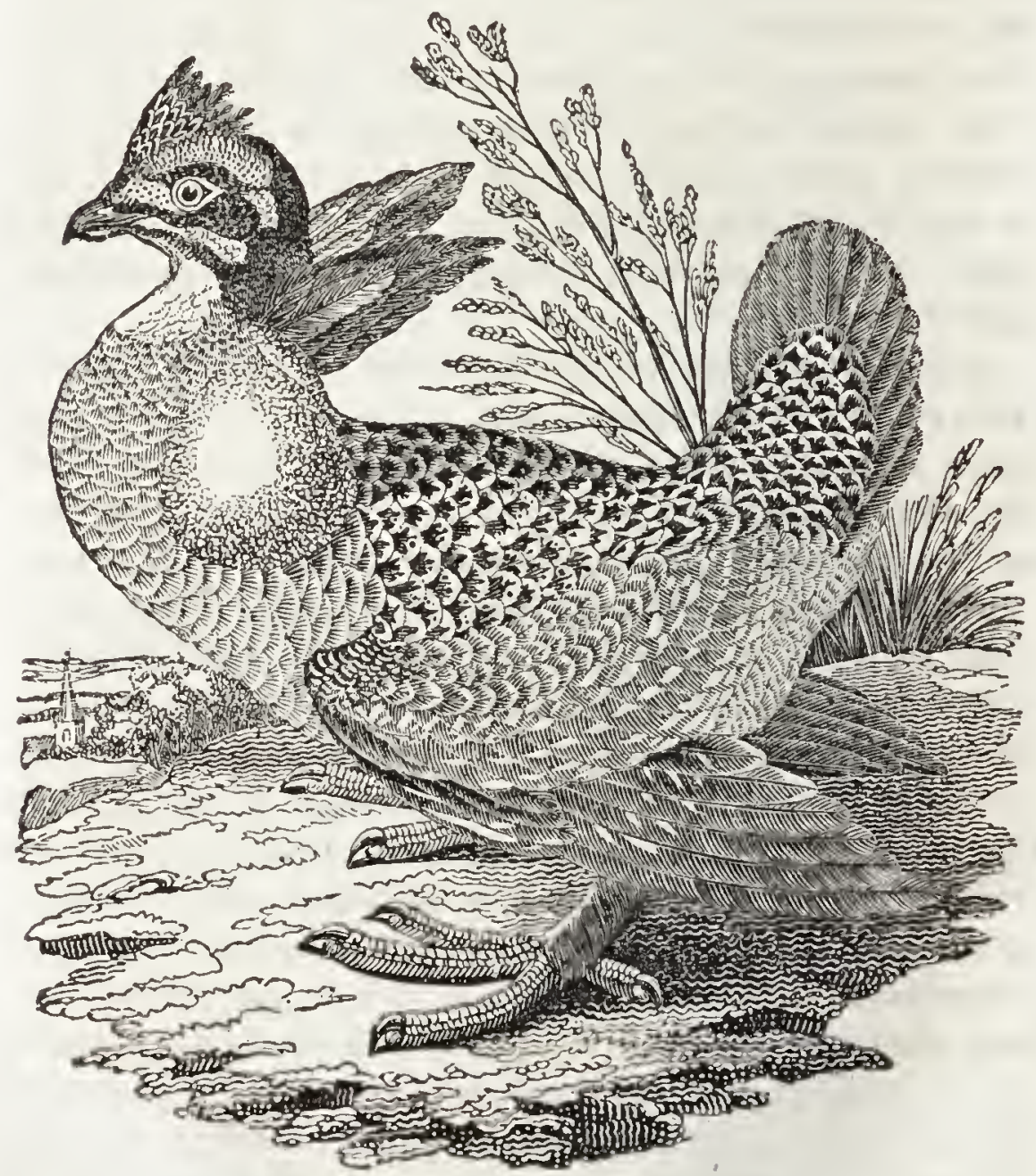

Pinnated Grows in the act of strutting. 
In like manner, the men lying in concealment near the scratching-places have been known to discharge several guns, before either the report of the explosion, or the sight of their wounded and dead fellows, would rouse them to flight. It has further been remarked, that when a company of sportsmen have surrounded a pack of grouse, the birds seldom or never rise upon their pinions while they are encircled; but each runs along until it passes the person that is nearest, and then flutters off with the utmost expedition*."

We have here copied Wilson's excellent figure of the cock of the pinnated grouse in the act of strutting and inflating his throat. "So very novel and characteristic," he says, " did the action of these birds appear to me at first sight, that, instead of shooting them down, I sketched their attitude hastily on the spot, while concealed among a brush-heap, with seven or eight of them within a short distance + ."

Another species of American grouse (Tetrao obscurus, $\mathrm{SAY}_{\mathrm{AY}}$ ) has very similar manners; and has given occasion to Charles Bonaparte to remark of the whole family, that no birds are more decidedly and tyrannically polygamous. The males very soon desert the females, caring nothing about them and their progeny, to lead a solitary life

'The bustards appear to have similar habits to the preceding, being equally polygamous, and the males calling the females by a peculiar cry during the night. 'They have also places of assemblage somewhat like the scratching-places of the American grouse; for though we have no record of such assemblages having been actually observed, their places of rendezvous have been seen in corn-fields and pastures, trod down like

\footnotetext{
* See New York Med. Repos. vol. viii. + Am. Ornith. iii. 114.

士 Bonaparte, Am. Orn. iii. 29.
} 


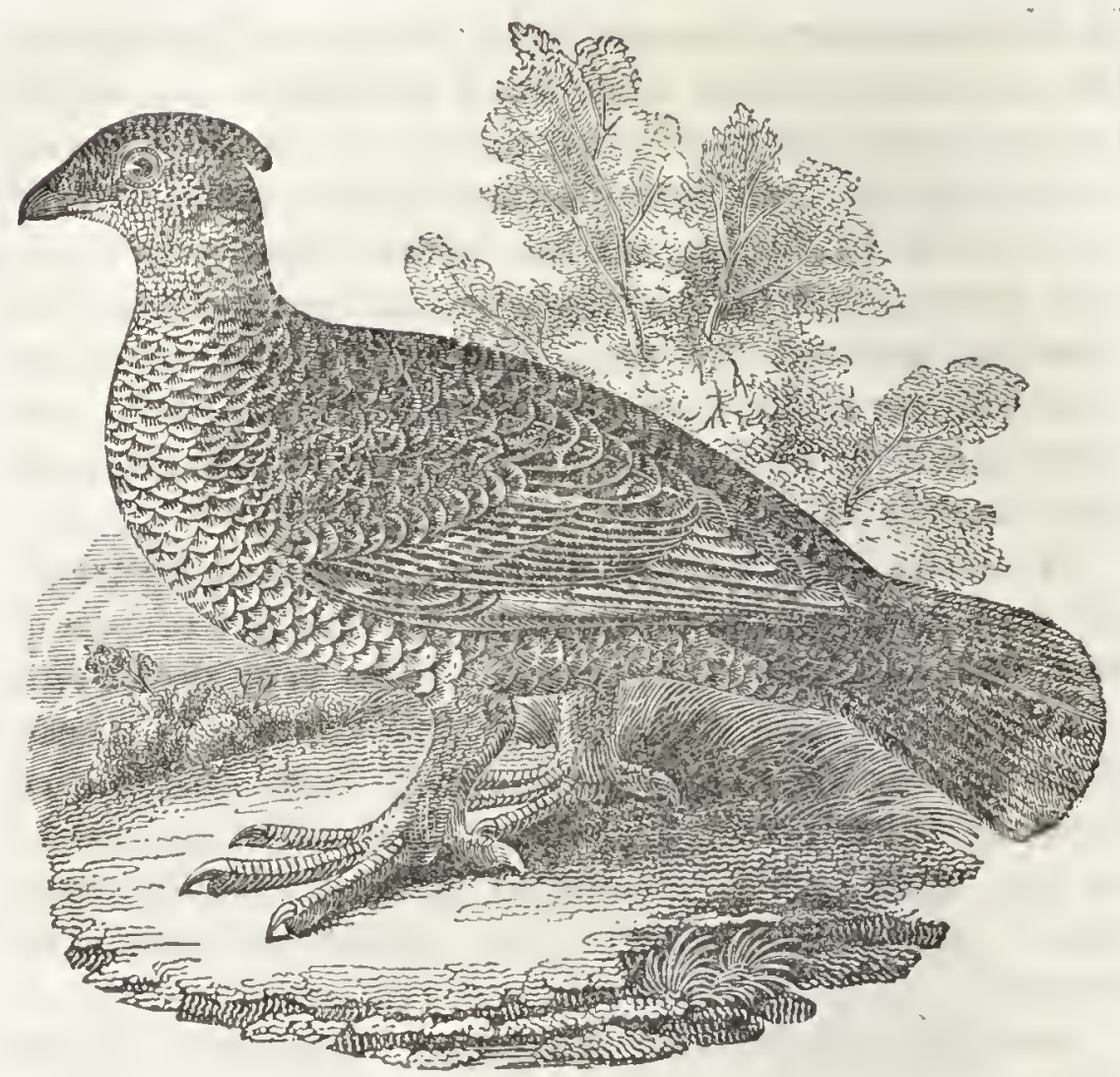

[letrao Obscurus.]

a thrashing-floor, giving evidence of the strife which had ensued among the contending rivals.

From their resemblance to the herons, we might suppose the bitterns would pair like them; though they are, on the contrary, not only polygamous, but, if we may believe some authors, the males evince extremely little attachment to the females,-less, indeed, than is recorded of any other bird. Salerne, however, must surely be mistaken when he says the females have to court the attention of the male by bringing him food, since this is contrary to the whole economy of birds, and would require the most unequirucal testimony to render it credible. The antipathy exhibited by a male and a female, when put together, by way of experiment, by M. Hebert, 
proves little, in consequence of their being in a state of unmatural restraint. The sound which the male bittern makes in the spring is singularly harsh, and so loud, that it may be heard at more than a mile's distance. It is termed bumping ol booming, and exceeds the grunt of the largest bass string. It is supposed to express the passionate feelings of the bird.

"During the months of February and March," says M. Baillon, "the males utter, in the morning and evening, a cry, which may be compared to the explosion of a large musket. The females run to the somnd, sometimes a dozen round one male, the male bitterns strutting among their mates and endeavouring to drive off their rivals." The same excellent observer says of the ruff (Tringa pugnax), "I know no bird that exhibits more ardour in the season of pairing, as displayed in the impetuosity of the males, which can only be reterred to jealousy and rivalship. I have often followed these birds in the marshes about Montreuil-sur-Mer, where they arrive in April. Their first object is to pair, or rather to fight with their rivals, while the feeble screams of the females rouse and exasperate their hostility, and their battles are often ling, obstinate, and sometimes bloody. The vanquished betakes himself to flight, but the cry of the first female he hears dispels his fears and re-awakens his comrage, and he renews the conflict if another opponent appear. 'Ihese skirmishes are repeated every morning or evening till their departure, which happens some time in May."

In the fens of England, in spring, the ruffs hill, as it is termed, - that is, they assemble upon a rising spot of ground contiguons to the breeding places, which are selected by the reeves or femules, and upon this rising ground they fight after the manner of the wild turlieys and other polygamous birds, till 
the turf is trodden bare by their obstinate strife. But the place is not as is usually represented in the exact form of a circle, its shape being varied according to the circumstances of the contest.

Advantage is taken of this peculiar habit of the bird by the fowlers, who look out in the districts frequented by ruffs for their battle fields, as they may be termed; and when they have made the required discovery, they repair to the spot before day-break, spread their nets, place their decoy-birds, and take their stand at the distance of a hundred and fifty yards or more, as they may judge advisable. The net is what is termed a single clap-net, about seventeen feet in length and six feet wide, having a pole at each end and uprights fixed in the ground, each furnisled with a pulley, by means of which it is easily pulled. It rarely fails to secure all the birds within reach. It is usual, in order to facilitate the pulling, to place the net so as to fold over with the wind; though some fowlers prefer pulling it against the wind, as being less apt to alarm the birds. Ruffs feed chiefly by night, and repair to their battle-fields about the dawn of day, nearly all about the same time. The fowler is accordingly in waiting to make his first pull, and afterwards prepares for the stragglers which traverse the fens without having yet fixed upon any particular hill.

Some fowlers leep the first ruffs which they catch for decoy-birds; while others employ stuffed skins of which the imitation is executed in a very rude manner. The stuffed birds are prepared by filling the skin with a wisp of straw tied together, the legs having been previously cut off; and the skin is afterwards sewed along the breast and belly, but with no great attention to cover in or conceal the straw. Into this straw a stick is tlurust to fix it into the ground, and a peg is also driven into the 
top of the head, and down the neck into the stuffing or straw body, which at the same time is made to fix the wings. Rough as this preparation is, and as unlike a living bird as slin and feathers can be made, it is found to answer the purpose sufficiently well. 'These stuffed skins are fastened down to the ground by a string about two feet long tied above the knee; but sometimes a long string is so managed as to make the decoy jerk upwards, to represent the jumping movement common amongst the rulfs, which, upon seeing a straggler fly past them, will leap or flirt a yard from the ground, upon which the flying bird alights for the sake of a skirmish.

The ruffs thus caught are fattened for the table with brearl and milk, hempseed, and sometimes with boiled wheat; but if expedition be required, sugar is added, which will make them, in a formight's time, a lump of fit. Mr. Towns, a noted feerler, at Spalding, told Colonel Montagu, that his family had been a hundred years in the trade, and he never knew the price to be under thirty shillings a dozen when the birds were fit for the table, though they are often much higher. Mr. Allan, of Grange, informed Bewick, that in 1794 he dined at the George Inn, York, where four ruffs made one of the dishes at table, which, in the bill, were separately charged sixteen shillings.

The ruffs are so addicted to fighting, that the feeders are obliged to shut them up in a dark room, for they attack one another the moment the light is admitted, and never desist till most of them are exterminated. The success of Towns, therefore, in carrying a great number to Ireland becomes the more extraordinary. At the request of the Marquis of 'Iownsend, at the time Lord Lientenant of Irefand, he set off from Lincolnshire with twenty-seven 
dozen; and after leaving seven dozen at the Duke of Devonshire's, at Chatsworth, continued his route across the kingdom to Holyhead, and delivered seventeen dozen alive in Dublin, having lost only three dozen, though they were by necessity closely crowded in baskets.

We do not find that ruffs are ever made to exhibit their pugnacious disposition by way of amusement, as some other polygamous birds are, though it would appear they might be thus exhibited. We are told that Solon, the Athenian lawgiver, directed that quails should be made to fight in the presence of the youths of the state, with a view to inflame their courage. The Romans, it would appear, held quail-fighting in still higher estimation, as we may infer from the circumstance of Augustus punishing a prefect of Egypt with death for buying and bringing to table a quail which had acquired celebrity by its victories. Even at present this sort of amusement is common in some cities of Italy, and still more annong the Chinese. In Italy they give two quails high feeding, and then place them opposite each other, at the ends of a long table, and throw between them a few grains of millet seed, as a ground of quarrel. At first they show a threatening aspect, and then rush on with great impetuosity, striking with their bills, erecting their heads, and rising upon their spurs, till one is forced to yield. Formerly, combats were performed between a quail and a man, the bird being put into a large box and set in the middle of a circle traced on the floor. The man commenced the assault by striking it on the head with his finger, or plucking out some of its feathers ; and if the quail in defending itself did not pass the limits of the circle, its master gained the wager that had been previously laid. If, again, through the fury of passion, it transgressed upon the space beyond 
the circle, its antagonist was declared the victor; and such quails as repeatedly won prizes in this manner were sold for high sums*.

The most common battles, however, of this sort are between game-cocks, man having learnt to set into action for his amusement the jealous rivalry of these polygamous birds. "A lover of cock-fighting," says Mr. Payne Knight, "would think it very strange to be told that he condemned his own taste for so heroic a diversion, by expressing a dislike to see cocks killed in a poulterer's yard; and the frequenters of bull-baiting in England, or of bull-feasts in Spain, would by no means allow that a butcher's slaughterhouse could afford them equal or similar amusement. 'To render such spectacles interesting, there must be a display of courage, vigour, and address; for it is by sympathizing with the energetic passions that the spectators are amused or delighted; and though the energies of passive fortitude might have been displayed by the victims of superstition, as well as by those of justice or injustice, they must, nevertheless, have been very flat and insipid, compared with those which shone forth in the varied and animated contests of the amphitheatre, where the contention was equal, and life and honour the prize contended fort."

Marsden informs us, that in the island of Sumatra the passion for cock-fighting is so great, that it is rather a serious occupation among the inhabitants than an amusement. A man in that country is rarely met travelling without a cock under his arm; and sometimes there will be fifty persons in company with their cocks. They often risk every thing upon the event of a battle, even their wives and daughters; and the loser is frequently stripped of his goods and reduced to despair. We need not, however, be sur-

* Julius Pollux, De Ludis, lib. ix.

+ Principles of Taste, p. 33, 4th edit. 
prised at this, since, even in our own countrv, men of all ranks may be found at cock-pits, dividing into parties, taking intense interest in the fortune of a particular cock, and staking extravagant sums upon the issue. The mode of fighting is considerably varied in different countries, the birds being variously trained, and armed with offensive and defensive armour. The Athenians, as Eilian records, instituted a festival, which was celebrated by cock-fighting, in memory of a victory gained over the Persians by Themistocles, who, upon observing his troops dispirited at the commencement of the battle, pointed to two cocks that were figliting: "See," said he, "the unshaken courage of these animals; yet they have no o her motive than the love of victory; while you fight for rour household gods, the tumbs of your fathers, and your liberty." "Inspired by this appeal, they rushed upon their fues ind were triumphant. 
Chapter VI.

STRUCTURE OF EGGS.

BEFORE entering upon the details of hatching, it seems indispensable to give some account of the structure of eggs; and in order to render this curious but difficult subject as plain as possible to those but little acquainted with physiology, we shall trace the egg from its appearance in the ovarium, or "eggorgan" (as we may call it), of the hen, till the final exclusion of the chick in the process of hatching. 'This subject has been investigated with much care and skill by some of the most distinguished observers and experimentalists, in consequence of the light it was expected to throw upon obscure points in the early history of other animals, whose development was of more difficult if not of impossible observation. Amongst the illustrious mell who have engaged in these researches we may name Harvey, Malpighi, and Haller; and, in our own times, Spallanzani. Blumenbach, Scarpa, Prander, Meckel, Dutrochet, Sir E. Home, and Dr. Paris. The chief facts which they have ascertained we shall now endeavour to condense into a brief but explicit sketch.

The egg of a bird appears in the egg-organ (ovarium) under the form of a small yellow globe or sphere, frequently smaller than mustard-seed, but gradually increasing in size till it drops from its slender fastening and falls into the egg-tube (oviductus). 'The egg-organ contains all the eggs which are to be 
laid for several years, each egg differing from the rest in size as well as in composition and colour. The largest of them, which are destined to be first laid, are yellowish, while the rest gradually decrease in size, and are less and less yellow *. It has been attempted to establish an analogy between this detachment of the egg and the dropping of ripe fruit from a tree; but though we cannot deny the resemblance of the

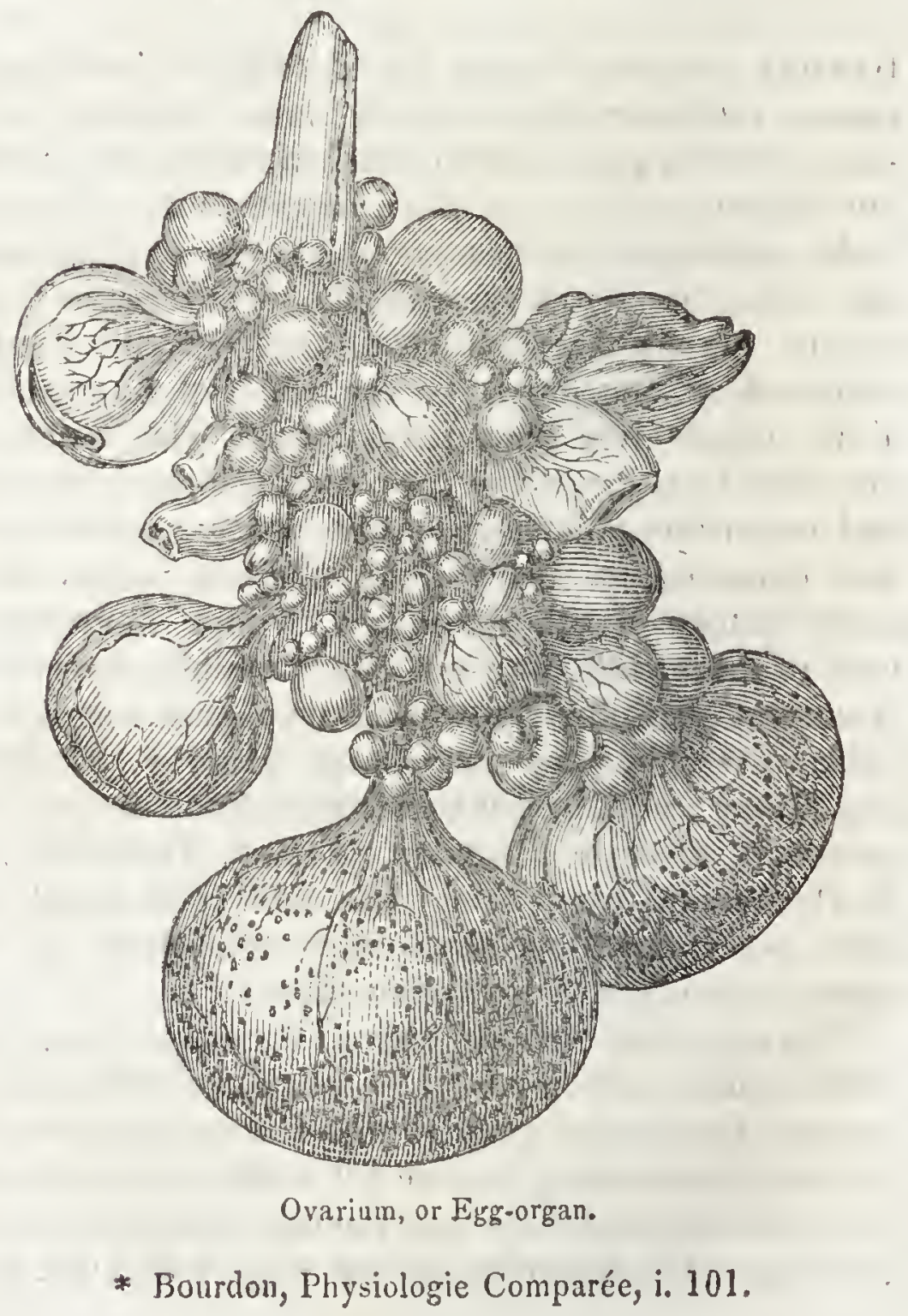


circumstances, we believe that such an analogy, as M. Dutrochet remarks, will not stand the test of observation. That the increasing weight of the egg, however, may, by stretching the slender attaching pedicle, so attenuate the blood-vessels that supply it with nourishment, as to greatly weaken and uttimately to break it, we may with some probability suppose.

Before dropping into the egr-tube, there is no white nor shell, both of which are formed there by the addition of the glutinous substance called albrmen, and of the calcareous or limy substance constituting the shell, as we shall immediately shew in detail.

From ill health or accidents, ergrs are sometimes excluded from the eng-tube before the shell has berun to be formed, and in this state they are provinciatly. termed oon egrgs.

When we examine the egrg of a hen in the eggorgan, we perceive 11 merous blood-vessels branching in a sort of hair-like, very irregular net-work over the whole surface, through the substance of the envelope or

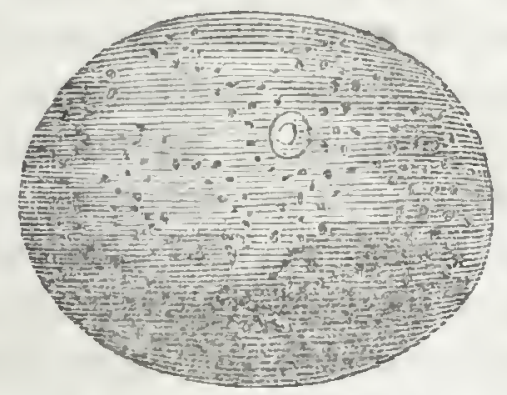

Fmuryo impregnated Egg.

membrane which encloses the whole, and which may be called the outer skin or covering, as there is within this another membrane similarly furnished with bloodvessels for supplying nourisliment to the yolk and 
contributing to its enlarged growth. By cutting through both these envelopes with great care, we bring into view a third, of extreme delicacy, very transparent, and of a white colour. This seems to be unconnected with the two envelopes, and no bloodvessels are seen branching through its substance. Immediately within this transparent envelope, which is similar in texture to our own scarf-skin (epidermis) lies the yolk, as yet imperfectly formed; and at the side opposite to that where it was attached to the egg-organ, is placed the rudiment of the future chick (cicatricula). The latter consists of a white bland substance which is not separated by any membrane from the yellow matter of the yolk, but merely lies over it, waiting till the heat imparted in the process of hatching shall develope it so that it may feed upon the yolk supplied for its first nourishment.

This germ, or rudiment of the chick, has no connection, M. Dutrochet assures us, with the proper enveloping membrane of the yolk, - a fact which he took great pains to ascertain. He removed the proper membrane of the yolk, which did not exhibit the slightest adhesion to the germ, but left it perfectly entire; and when he examined the membrane thus removed by means of the microscope, he could not perceive the least breach in its substance, nor any difference in its texture or structure. At the point opposite to this, there may be observed, as the egg enlarges, a whitish line or streak, occupying nearly a third of the sphere, which indicates the approaching rupture through which the egg is about to escape from the pouch where it has been confined. In fact, when the egr is separated, the pouch, formed by the two enveloping membranes already mentioned, opens, in the direction of this whitish line, and the egg covered by its outer membrane (which is not connected 
with the pouch) quits the egr.organ, and is laid hold of by the broad extremity of the egre-tube. After this escape of the egg, the pouch or sac which contained it very much resembles the bivalve capsule of plants; and being now no longer of any use, it diminishes rapidly in size, and at last altogether disappears.

When the egg falls into the egg-tube, it is covered only by a single membrane, exceedingly thin, and resembling the scarf-skin in its nature; but soon after it falls, it exhibits a second covering, a little thicker than the first. 'This is produced by the irritation arising from the presence of the egg exciting the vessels on the interior of the tube to throw out lymph, which by coagulating forms a coating around the egg. This coating juts out into small knobs at eacl end, which terminate in the feculent extremity of the white, and are termed chalazes, the envelope itself being termed the yolk-bag, or chalaziferous membrane. M. Leveille supposes the chalazes to be absorbing vessels destined to take up the white and mix it with the yolk during incubation*; but this is only a conjecture.

Having been thus furnished with this second membrane, the egg advances farther along the egg" tube, and becomes deeply imbedded in the white (albumen) that fills the tube. The white being thence formed, the egg makes a still farther advance; and again is furnished from the secreting vessels of the tube with another envelope, constituting the first layer of the membrane of shell which surrounds the white and attaches itself to the loose extremities of the two chalazes. Over this, another covering is formed, being the second layer of the membrane of the shell; and by this time the egg has got beyond half the egro-tube. In its passage through the re* Nutrition des Foetus, 8vo. Paris, 1799. 
maining portion, it receives the hard covering of the shell, previous to its exclusion.

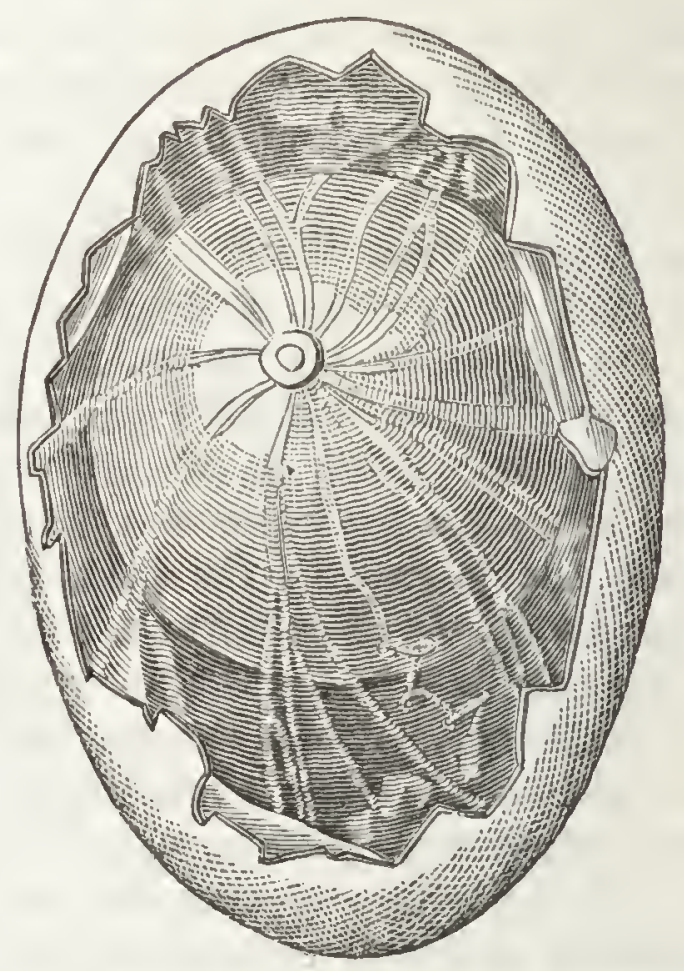

New-laid Egg with part of the Shell removed.

It will hence be manifest that, reckoning from the shell inwards, there are six different envelopes, one only of which could be detected before the descent of the egg into the egrs-tube. 1. The shell; 2. the external layer of the membrane of the shell; 3 . the internal layer; 4 . the white; 5 . the chalaziferous membrane; 6 . the proper membrane.

Harvey was the first who demonstrated two separate whites in an egg, each enveloped in its proper membrane, "the one," he tells us, "thinner and more liquid, the other thicker and more clammy, and a little more inclining to whiteness, -in staler eggs, after some days' incubation, growing yellowish. As this second white covers the yolk round, so the exterior liquor encompasses it. That these two 
whites are distinct is from hence manifest, that, the outward bark or shell being taking away, if you pierce both the subjacent membranes, you shall see the exterior liquid white forthwith flow ont. Then turning back the same membranes this way and that way in the platter (in which the egr is supposed to lie), the interior and thicker white will still retain its place and globose figure, being, in fact, terminated by its proper membrane, which is so thin as to be altogether invisible to the eye. If you cut this, the second white will straightway run out and diffuse itself this way and that way, and lose its round figure, just as any liquor runs out of a bladder containing it when it is cut*."

We are disposed to agree with the opinion first stated by Dr. Paris on the use of the white, as being mainly designed to regulate temperature. "'The albumen, he reinarks, being a most feeble conductor of caloric, retards the escape of heat, prevents any sudden transition of temperature, and thus averts the fatal chills which occasional migrations of the parent might induce. As an illustration of the use and importance of such a structure, I may observe, that those fish which retain their vitality a considerable time after their removal from the water, as eels and tench, have the power of secreting a slimy and viscid fluid, with which they envelope their bodies. Is it not extremely probable that this matter, by acting like the albumen of the egg and preventing evaporation from the surface of the animal and the consequent change of temperature, may be the principal cause of this tenacity of life + ?"

M. Dutruchet found that the proper membrane of the yolk and the chalazilerous membrane are so. closely applied to each other that they cannot be

* Exercit. de Gener. p. 11. † Linn. Trans, x. 306 . 
separated after the egg is laid, though they may be found loose and perfectly distinct at the period of incubation. It is very remarkable, and the fact has long been known, that the chalazes and the germ (cicatricula) always observe determinate relative positions, the germ being uniformly situated at the equator of the egg, while the chalazes occupy the poles, or rather a place very near the poles, for they divide the yolk into two parts of unequal size, and are not always placed in the direction of its axis. The portion opposite the germ being the heaviest, of course always tends to occupy the lowest station, so that the germ being always uppermost, is disposed in the most favourable manner for receiving the in fluence of the heat in hatching. Harvey's explanation of this was, that the chalazes served, as it were, for the poles of the egrg and the connections of all the membranes twisted and knit together, by which the liquors are not only conserved each in its place, but also retain their due position to one another*. But this, as Derham well remarks, was short of the facts; the chalazes "serve not barely to keep the liquors in their place and position to one another, but also to keep one and the same part of the yolk uppermost, let the egg be turned nearly which way it will; which is done by this mechanism: the chalaze are specifically lighter than the whites in which they swim; and being braced to the membrane of the yolk, not exactly in the axis of the yolk, but somewhat out of it, causeth one side of the yolk to be heavier than the other; so that the yolk being by the chalazæ made buoyant and kept swimming in the midst of two whites, is by its own heavy side kept with the same side always uppermost $f . "$ It is on this account, as Willughby remarks, that it is nearly

* Exercit. de Gener. p. 13.

+ Physico-Theology, B. vii. c. 4. n. 6. 
impossible to balance an egrg on its larger end while the membranes within remain unbroken, though this may be readily effected by violently shaking the egg till the membranes be ruptured *

This mechanism, simple and admirable as it is, results, according to M. Dutrochet, from the nature of the previous relations between the situation of the egg in the egg-organ, the position of the broad extremity of the egg-tube, and its general form. 'The egg presents to the mouth of the tube that part of it which is opposite to the germ. 'The mouth of the tube being placed laterally, transmits the egg in the same position in which it received it, - that is to say, with the germ placed on the equator of the yolk, the axis of which is nearly in the direction of the eggtube; and this is so formed that its axis is not quite the same as the axis of the yolk.

It follows from the preceding observations of M. Dutrochet that the embryo chick contained in the germ has no organic connection with its mother. It does not adhere to the proper membrane of the yolk, and the yolk does not itself adhere to the vascular membrane in which it is contained. This accords with what is generally observer in the vegetable kingdom, the germs of plants from the instant of their appearance being like greenish white points, devoid of all connection with their capsules, and consequently with the seed organs (ovaria). M. Dutrochet was the first to demonstrate, that the egg. contained in the pouch of the egg-organ lias but one proper membrane under which the substance of the yolk lies loose; - an observation which overturns Baron Haller's theory respecting the existence of the chick previous to fecundation, supported as it was on the solitary fact of an egg on which a bird had sat, exhibiting a portion of intestine enveloping * Ornithology, by Ray, p. 11. 
the yolk, which intestine was inferred without proof to have existed previous to fecundation. M. Dutrochet, on the contrary, found that the intestine enters the yolk by a development extended by successive processes over the whole periphery of the yolk.

The chemical constituents of these several parts of the egg are as follows. The shell consists principally of carbonate of lime, similar to chalk, with a small quantity of phosphate of lime and animal mucus. When burnt, the animal matter and carbonic acid are separated, the first being reduced to ashes or animal charcoal, and the second dissipated; while lime, mixed with a little phosphate of lime, is obtained. The white is without taste or smell, of a viscid glary consistence, readily dissolving in water, coagulable by acids, alcohol, and water heated to $165^{\circ}$ Fahrenheit. When it has been thus coagulated, it is no longer soluble in either cold or hot water, and acquires a slight insipid taste. The experiments of Dr. Bostock show that it is composed of 80.0 parts of water; 15.5 of albumen; and 4.5 of mucus; exhibiting, besides traces of soda, benzoic acid and sulphuretted hydrogen gas. The latter we observe on eating an egg with a silver spoon to stain it with blackish purple, by combining with the silver, and forming sulphuret of silver. The yolk possesses an insipid, bland, oily taste, and when agitated with water forms a milky emulsion. When long boiled it becomes a granular, friable solid, yielding by expression a yellow, insipid fixed oil. Its chemical constituents are water, oil, albumen, and gelatine. In proportion to the quantity of albumen, the egg boils hard. The oil of the yolk is soluble in sulphuric æther.

An important part of the egg which we have not hitherto named is the air-bag (folliculus aëris), 
placed at the obtuse extremity, and well described by Dr. Paris. "The external shell," he says, " and the internal membrane by which it is lined, constitute the parietes [walls] of the cavity, whose extent in the recent egg scarcely exceeds in size the eye of it small bird: by incubation, however, it is extended to a considerable magnitude. That its most essential use is to oxygenate the blood of the chick, in my opinion there can be no doubt; but to establish completely the truth of such a theory, it is necessary to discover the nature of the air by which it is inflated, and which has hitherto remained unexamined."

From experiments made to ascertain this point Dr. Paris concludes that " before incubation it contains atmospherical air. No other chemical change takes place in the constitution of the air, than a small inquination with carbonic acid. It gains by incubation an increase of volume, which takes place nearly in the ratio of 10 to 1 . I must here remark, that its extent does not increase equally in equal successive portions of time, but observes a rate of progression, which is accelerated as the latter stages of incubation advance: it seems, however, to arrive at its maximum of dilatation a few days previous to exclusion of the animal.

"The same apparatus exists in the egrgs of all birds, and contains a similar air : its capacity, however, does not seem to vary either with the size of the egg or of the bird to which it belongs; but I think I have discovered a beautiful law by which its extent is modified. I have uniformly found, as far as my contracted inquiries have led me, that the folliculus aëris is of greater magnitude in the eggs of those birds which place their nests on the ground, and whose young are hatched, fledged, and capable of exerting their muscles as soon as they burst from their shell, than in the eggrs of those whose nests are 
generally built on trees, and whose progeny are born blind and forlorn. Thus the folliculi in the eggs of fowls, partridges, and moor-hens, are of considerable extent, whilst those in the eggs of crows, sparrows, and doves are extremely contracted; the chicks, therefore, of fowls and partridges have a more perfect plumage, and a greater aptitude to locomotion, than the callow nestlings of doves and sparrows. Such an instance of the agency of oxygenation in the promotion and increase of muscular power is not solitary in physiology; for the history of ruminating animals will furnish us with a parallel example." "Their cotyledons," observes the author of "Zoonomia," "seem to be designed for the purpose of expanding a greater surface for the termination of the placental vessels, in order to receive oxygenation from the uterine ones: thus the progeny of the class of animals are more completely formed before their nativity, than that of the carnivorous classes. Calves, therefore, and lambs, can walk in a few minutes after their birth; while kittens and puppies remain many days without opening their eyes."

"It is," continues Dr. Paris, " a very curious fact well known to every one employed in the concerns of the farm-yard, - that if the obtuse extremity of an egg be perforated with the point of the smallest needle (a stratagem which malice not unfrequently suggests) its generating process is arrested, and it perishes like the subventaneus egg. Hence Sir Busick Harwood was led to suspect that the elastic fluid contained in the air-bag was oxygen, and I was induced to examine its nature. Can this curious problem be solved by supposing that the constant ingress of fresh air is too highly exciting? A parallel example may be adduced from the veretable kingdom in support of such an opinion. The young and tender plant, before it puts forth its roots, is often destroyed by 
having too free a communication with the atmosphere, by which its powers are exhausted: it is to obviate such an effect that the horticulturist, taught only by experience, covers it with a glass, by which means he limits the extent of its atmosphere, and consequently decreases its respiration, transpiration, and the inordinate actions which would prove fatal to it*."

* Linn, Trans, x, 309. 


\section{Hapter VII.}

\section{COLOUR OF EGGS.}

Though we may safely lay it down as an invariable principle of nature that nothing is made in vain, and that every circumstance comnected with organic life is designed to fulfil some purpose; yet we are frequently at a loss in our researches to discover the designs of the Creator in particular instances. In reference to this consideration, the subject of colours is one of considerable interest, but of no less difficulty. It has given origin to many ingenious theories founded upon a few facts partially selected; while little has hitherto been done in grouping ascertained facts into a general view. It has been maintained, for example, that the varied colours of flowers were intended to please the eye of man,-an assumption to which, as well as to many others of a similar kind, the lines of Pope may perhaps be thought a sufficient answer:-

"While man exclaims, 'see all things for my use,' 'See man for mine!' replies a pamper'd goose."

Again, if we suppose that the colour of each particular flower is peculiarly adapted to its economy by the refraction or reflection of various-coloured rays of light, an opinion, at first sight, extremely plausible, we are immediately met by the fact of the varying colour in the same species, when equally healthy, and, so far as we can perceive, efficient in performing the functions of growth and seed-bearing. We have, for example, at present a collection of primroses and another of heart's-ease (Viola tricolor), of almost every 
shade of colour from nearly pure white to dark purplish black, and yet all these varieties seem to be equally thriving and untainted with dicease, or what the Limnæan botanists are accustomed to designate monstrosity. The case is the same with animals, as may be shown, anlong numerous other instances, in the banded snail-shell (Helix nemoralis). Within the space of half a mile we have collected not less than a dozen varieties of this species, having from one band to seven, and the bands as diversified in the shades of their colour as in their breadth and arrangement, some being very pale and others of a dark blackish brown. In the garden spider (Epeira diadema) there is an equal diversity of markings and shades of colour, some being bright orange, others dark brown, and others greenish grey, while the spots are sometimes large and conspicuous, and sometimes small and indistinct*. The causes of this diversity we have been unable to trace in a satisfactory manner, though we have for many years paid considerable attention to the subject; we have mentioned it here merely to introduce what we are about to say on the subject of the diversity of colour in the egrgs of birds, by reminding the reader that the phenomenon, however obscure as to its final cause, is not unexemplified in other natural productions.

If we advert to the manner in which the shell of an egg is formed, we may discover some of the circumstances attendant on the colouring and the markings. The shell has been ascertained to be a secretion whose basis is lime, derived from the glands of the egg tube after the nucleus, consisting of the yolk and white, has advanced from the egg-bag (ovarium). The white colour of the eggs of the barn-door fowl, the dull cream colour of those of the pheasant, the greenish brown of those of the nightingale, and the

J. R. 
bright pale blue of those of the redstart and the hedge-sparrow (Accentor modularis), must be produced, like the black bones in the fowls of Malabar, by a uniform colouring matter in the calcareous secretion; and we accordingly find, that when subjected to the action of dilute hydrochloric acid, the whole shell of an egg, uniformly coloured, becomes dissolved, the dissolution being as perfect in the instance of the blue egg of the hedge-sparrow and the green egg of the nightingale as in the ivory-white egg of the woodpecker. A similar experiment upon any uniformlycoloured shell, such as the common pale yellow snailshell (Helix hortensis) is attended with nearly the same result, a thin membranous pellicle only remaining undissolved by the acid. But when the banded snail-shell ( $H$. nemoralis) is subjected to the acid, the coloured bands having less calcareous and more animal matter, remain in a loosened and somewhat flocculent form, but considerably thicker than the portion where the ground colour prevails, proving that the bands consist chiefly of animal matter. On examining the mantle of the snail from which the shell is secreted, we find that it is marked with dark translucent bands, exactly correspondent to the bands on the shell; and it may be that these bands, being less brittle than the other portions of the shell, are intended to strengthen its texture.

The various markings on the eggs of many species of birds are, in all probability, formed in a similar manner to the bands on snail-shells, namely, by glands secreting colouring matter, distributed amongst those which secrete the general ground colour or the uncoloured portions. From the formation of the eggshell, however, taking place within the egg-tube, it is out of the reach of observation, while the process of forming the suail-shell can be seen at every step. This probability is strengthened by the similar effect 
of the dilute hydrochloric acid on the markings of the egges of birds; for, if we apply this acid to the egg of a song-thrush, which has a ground colour of a bright blue, with irregular spots and blotches of black, these blotches remain while the blue portion is dissolved and disappears. The same takes place with respect to the markings on the eggrs of the lapwing, the chaffinch, the yellow-hammer, the butcherbird, the magpie, and the louse-sparrow.

From the various examinations which we have made of the coloured narkings of these and other egg's, they appear to consist of an animal oil, partly soluble in spirits of wine, similar to that which, as M. Odier has shown, forms the colouring matter of the wingcases (elytra) of beetles* ; but there seems to be some mucilage also present. This view of the matter is further confirmed by the observations of Mr. Knapp, who tells us that the calcareous matter is partly taken up during incubation, the markings upon the eggs remaining little injured, and even to the last being almost as strongly defined as when the egrs are first laid + .

From these markings being for the most part either exclusively or more numerous at the larger end of the egg. it would appear that the glands that secrete the colouring matter require the stimulus caused by the pressure of the egg to bring them into activity; and hence, also, we may account for the zone of markings frequently conspicuous on the eggs of the white-throat, the flusher (Lanizes Collurio), and many others. We have just witnessed a fact corroborative of this explanation. A lien canary which we paired with an aberdevine (Carduelis Spinus) in her second laying, (the first having proved abortive,) had two eggrs of different sizes, one of the regular size,

* Mem. Soc. d'Hist. Nat. de Paris, tome i.

† Journal of a Naturalist, p. 223, $3 \mathrm{~d}$ edit. 
bluish white, and marked at the larger end with a zone of irregular reddish streaks, the other about a third smaller, quite spotless, not the slightest marking being perceptible. We infer that these appearances were in consequence of this egg being too small either to stimulate the glands to secrete, or to press them to give out their colouring matter*

This, if correct, as it appears to be, will account in a satisfactory manner for the great diversity of markings in egges belonging to the same species, and even to the same bird. "The eggrs of birds," says Mr. Knapp, " in general vary much, and are occasionally very puzzling to identify, when detached from their nests, as the colourings and markings differ greatly in the same species, and even nest. 'Those of one colour retain it, with only sliades of variation; but when there are blotchings or spots, these are at times very dissimilar, occasioned, in great measure, probably by the age of the bird; thongh this cannot account for the difference of those in an individual nest. 'Those of marine birds, especially the guillemot (Colymbus Troile) are often so unlike each other, that it requires considerable practice to arrange them †." He adds, "that though the marks are so variable, yet the shadings and spottings of one species never wander so as to become exactly figured like those of another family, but preserve, year after year, a certain characteristic figuring:"

This is indeed generally true, although the eggs of the goldfiuch and the chaffinch frequently exhibit nearly the same markings; and we have seen more than one egg of the chaffinch so like in marking to those of the yellow-hammer that they could only be distinguished by an experienced eye $\ddagger$. The eggs of the house-sparrow, as Mr. Knapp remarks, are

$$
\text { * J. R. † Journ, of a Nat.p. 224。 \$J. R。 }
$$


perhaps the most variable of all *. Among some hundreds which we have examined, we have seldom found two alike, even from the same nest, some being marked with large streaks and blotches, while others were so finely mottled or rather marbled, that it required minute inspection to discover the markings, as they appeared to be rather of a uniform grey. The same diversity is observable in the shades of these markings, some being of a very pale grey, and others nearly black. 'The eggs of the blackcap (Sylvia atricapilla) again are usually stained

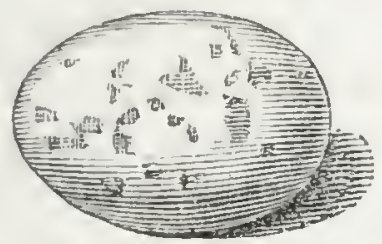

Egg of Black-Cap.

rather than blotched with either a deeper or a paler flesh colour than that of the ground; but in many instances these stains are scarcely, if at all perceptible + .

We have elsewhere $\ddagger$ adverted to the fanciful notions which have been entertained respecting the final cause of the various colours in the eggs of insects, the common supposition being that they are adapted to the purposes of concealment from their natural enemies. 'The snake, says Dr. Darwin, the wild cat, and the leopard, are so coloured as to resemble dark leaves and their lighter interstices; and birds resemble the colour of the brown ground or the green hedges which they frequent. M. Glöger, a German naturalist, has followed up this fancy, as it respects the egrgs of birds, into some detail. He considers it to be a remarkable provision of nature, that birds whose nests are most exposed, and whose egg's are most

$$
\begin{aligned}
& \text { * Journ. of a Nat. p. } 222 . \\
& \ddagger \text { Insect Transformations, p. } 33 .
\end{aligned}
$$


open to the view of their enemies, lay eggs of which the colour is the least distinguishable from that of the surrounding objects, so as to deceive the eye of those animals who have a desire to destroy them; while birds, the eggs of which have a bright decided colour, and are consequently very conspicuous, either conceal their nests in hollows, or only quit their eggs during the night, or begin to sit immediately after laying. It is also, he states, to be remarked, that in the species of which the nest is open, and the female brings up the brood without the assistance of the male, the former is generally of a different colour from the latter, less conspicuous, and more in harmony with the objects around. The foresight of nature has, therefore, provided for the preservation of the species of which the nest is altogether exposed, by imparting to the eggs a colour which will not betray them at a distance; while she has been able, without inconvenience, to give the brightest colour under circumstances where the eggs are concealed from view. Or perhaps, to speak more correctly, numerous birds can deposit their egrg's in places accessible to view, because the colour of the eggs enables them to be confounded with the surrounding objects; while other birds are obliged to conceal their nests, because the conspicuous colour of the eggs would have attracted their enemies. Eggs, according to the patrons of this hypothesis, must be distributed into two series according as their colour is simple or mixed. The simple colours, such as white, blue, green, yellow, are the brightest, and consequently the most dangerous for the eggs. The pure white, the most treacherous of colours, is found among birds which breed in hollow places, like the woodpecker, the wryneck, the roller, the merops, the king-fisher, the snow-bunting, the robin, the dipper, the swallow, the martin. It is only among these birds that the 
eggs are of a remarkable whiteness. The eggs are also white among some species which, like the domestic swallow, certain Passeres, the Troglodites, \&c., construct their nests with such narrow openings that the eye of their enemies cannot penetrate within. White egrs are also found with birds that quit them only during the night, or, at least, very late during the day, such as the owls and falcons. Lastly, this colour is found among birds which lay only one or two eggs, and sit immediately after, like the pigeons, the boobies, and the petrels. As to the bright green or blue colour, it is found to belong to many species which make their nests in hollows, like the starling, the bullfinch, the flycatcher, \&c. In the second place, this colour is common to the eggs of birds, the nests of which are constructed with green moss, or placed at least in the midst of grass, but always well concealed, such for example as the tom-tit, linnet, \&c. Lastly,

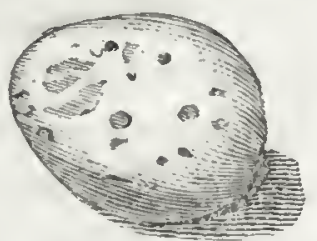

Egg of the Tom-tit ('arus coruleas).

green eggs are met with among many strong birds, such as the herons, able to defend themselves against plunderers. A light green colour, verging toward a yellowish tint, is found among the eggs of the many Gallinaces which lay among the grass, without making more than an imperfect nest, which soon disappears bencath the quantity of eggs; like the hoopoc, the Perdrix cinereus, the pheasant. The same colour is also remarked amoug several of the Palmipedes, which quit their eggrs when they lay them, but which are attentive in watching them, as the swans, the greese, the ducks, the divers, \&c. The 
eggs of certain great birds which make their nests in the open air, but are well able to defend themselves, are a dirty white, as may be observed among the vultures, eagles, storks. Among the eggs of a mixed colour, those are to be distinguished which have a white ground, and those of which the ground differs from white. 'The eggs with a white ground are those of the European oriole, the long-tailed-tit, the cole-tit, the nut-hatch, the creeper, and the cominon swallow. Most of the egg's with a white ground are concealed in well-covered nests. The eggs of a mixed colour, and of which the ground is not white, at least a pure white, are those of the lark, the grass-hopper bird (Curruca locustella,

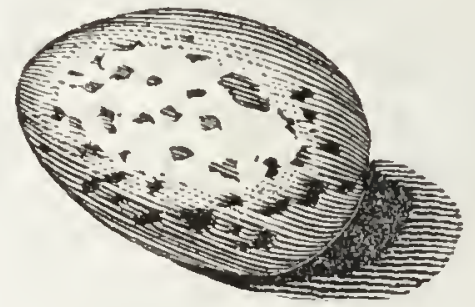

Egg of the Sky-Lark.

Fieming), the yellow-hammer, the wagtail, \&c.; then those of the crows, the jays, the thrushes, the quails, \&c., with most of the singing birds, the colour of the interior of whose nest harmonizes with that of the eggrs *

Such is the theory; and M. Glüger, after examining all the birds of Germany, is said to have proved that the facts universally correspond to it. In conformity with the same notion, Dr. Darwin remarks that the eggs of the hedge-sparrow (Accentor modularis) are greenish blue, like those of magpies and crows, which are seen from beneath in wicker nests, between the eye and the blue of the firmament; but he forgets that the eggrs of the songthrush, which are no less bright blue than those of * Verhand, der Gesellschaft Nat. Freunde, in Berlin. 
the hedge-sparrow, cannot be seen between the eye and the firmament, for the nest is compactly plastered. Still less will his doctrine apply to the eggs of the stone-chat (Saxicola rubicola, BECHSTEIN), which builds on the ground; and least of all to those of the red-start, which nestles in the hole of a wall or of a tree. Were the notion of these writers, indeed, not so commonly diffused as we have observed it to be in popular compilations, it is so obviously wrong to those who are acquainted with the facts, that it would be wasting time to enter upon its refutation. As it is we shall state a few other objections.

"Rooks," says Professor Brande, "build a nest particularly exposed on the highest trees; the jackdaws conceal theirs in holes; while the lapwing, woodcock, and snipe lay on the bare ground, and yet the colour of the eggs of all these birds is nearly identical. Again, the blackbird and song-thrush are birds of very similar habits; they build in the same places; but the blackbird lays a dull rusty-coloured egrr, and the thrush a clear blue one, with a few dark, well-defined spots.

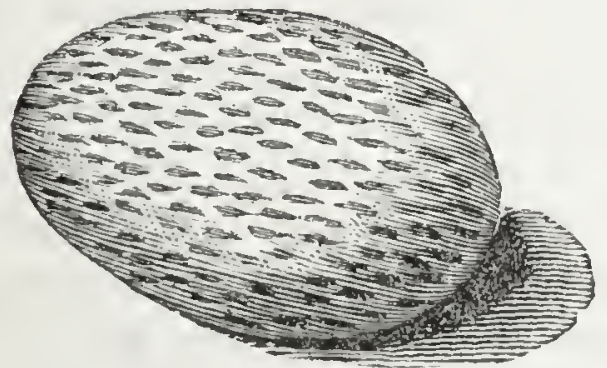

Egg of the Blackbird.

The woodpeckers, it is asserted, lay white eggs; they ought according to the theury, but their practices seem very diflerent. The hawks, which are so able and accustomed to defend their nests, we should expect to find with pure white eggs, but they are dullcoloured and inconspicuous; the buzzards, the most 
cowardly among the tribe, have perhaps the most conspicuous eggrs of any. The magpie is a strong bird, its eggs well concealed, and the nest fortified; but the colour of this $e^{\circ}$ is dull, like those of the rook, woodcock, \&c. Two very similar eg'os are those of the redstart and hedge-sparrow: the former builds in holes, the latter does not. The cuckoo very commonly selects the rest of the hedge-sparrow, depositing a spotted brown egg among bright blue ones. After this, if we admit that the brightest white eggs are to be found with birds whose nests are the most concealed, as the king-fisher, wryneck, wren, tit, sparrow, and especially the bank-swallow, may we not rather infer that, the interior of these nests being peculiarly dark, the bright white colour is convenient to the bird to enable her to distinguish one egr from another? At all events, we must regard M. Glöger's hypothesis as ingenious, rather than supported by facts *"

M. Glüger has been unfortunate in his example of the king-fisher ; for though this bird hides her shining white eggs in a hole, yet that will not conceal them from the piercing eyes of her chief enemy the water. rat, which, like all burrowing animals (the mole not excepted), can see with the least possible light. He seems also to have overlooked the obvious fact, that many birds, which lay bright-coloured eggs, make open nests; the song-thrush, for example, whose clear blue eggs, with a few black blotches, are far from being concealed by the plastering of cowdung upon which they are deposited. A similar remark applies to the stone-chat (Saxicola rubicola, Bechstein). The green-finch (Fringilla chloris, 'Temminck) again, which builds an open nest of green moss lined with horse-hair, black or white as it can be had, lays clear white egg's with red spots, * Brande's Journal for December, 1829, p. 441, note. 
very little different from those of the wren or the haybird (Sylvia Trochilus), which build covered nests with a small side entrance; while the house-sparrow (Passer domesticus, $\mathrm{R}_{\mathrm{AY}}$ ) lays eggss of dull greenish or bluish-white, streaked with greyish-black, and always builds in holes or under cover.

As these objections appear to be unanswerable, it will not be necessary for us to follow Dr. Darwin into his fanciful account of the origin of the colours of eggrs, which he ascribes to the colour of the objects amongst which the mother-bird chiefly lives, acting upon the shell through the medium of the eye; for if this were correct, we should have the green-finch and the red-breast, instead of their white eggs, laying. blue ones, like the red-start.

In the case of the eggs of insects, the colours are sometimes, though not in every instance, occasioned by the colours of the embryo shining through the shell, an example of which we have in the small rhinoceros beetle (Oryctes nasicornis, ILLIGER*). In birds, however, this never occurs; and the markings on the eggs seem, so far as we can perceive, to have no connection with the colours and shadings on the feathers. Birds, indeed, of the most varied plumage, such as the peacock and the humming-bird, are produced from white eggs. It is reasonable to conclude, however, that these colours and markings on egros are intended to serve some particular purpose, though we may not, in the present state of our knowledge, be able with certainty to say what.

Without advancing any theory as to the cause of the phenomenon, Mr. Griffiths has deduced some general inferences from the facts in a more cautious way than Darwin and Glöger. "The eggs," he remarks, "of diurnal birds of prey are of a whitish colour, spotted with red, or red spotted with brown.

* Insect Transformations, p. 36. 
The eggs which border on a red diminish in tint in proportion as they are laid; so that some of the last is merely a light reddish or whitish, pricked out with clear red. The owls and howlets have white or whitish eggs, without spots. Among the speckled magpies, the eggs, on a white ground, have at the broad end a circle of red, brown, and bluish spots, over which the same colours are sprinkled.

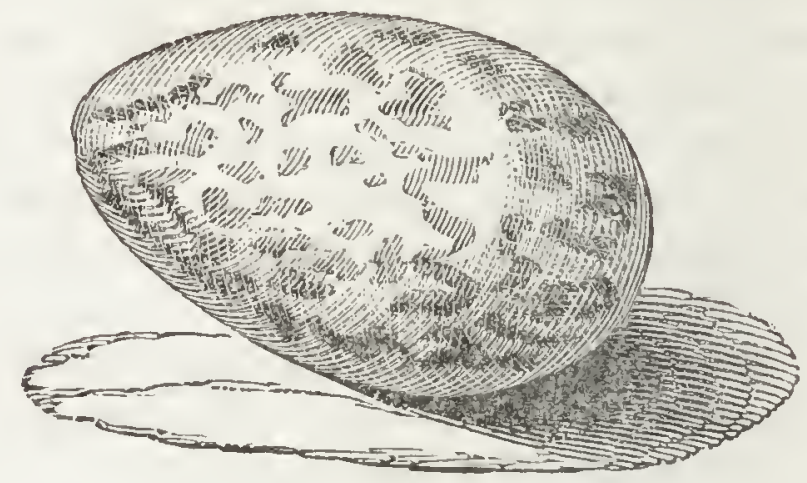

Egg of Magpie.

" Birds which nestle in the hollows of trees, of walls, or rocks, have, in general, egg's of a pure white. Such are those of the hoopoe, the pici with black plumage, the toral, the martin [king] fisher, the beeeater. 'The woodpecker's eggs have a few red points. Birds which nestle to a certain height in trees, as ravens, crows, pies, \&c., have nsually green or greenish eggs, spotted or picked with brown. It has been remarked that the white or whitish eggs in swimmingbirds are short and rounded, while the yellow or greenish and spotted eggs are very much elongated. The eggs of the grallæ [waders] have spots on a grey, yellow, yellowish, green, greenish, bluish, red, or reddish ground. They are rarely spheroid, being mostly elongated, and diminishing very rapidly from the large end. White is the commonest colour of the eggs of the gallinacea; some, however, have a green, 
greenish. or yellowish ground. It is remarkable that the egoss which certain species deposit on green herbs partalie more or less of this colour. The passeres have egres, the ground of which is white or whitish, blue or bluish, green usually spotter with deep colours, such as red, brown, and black. The tom-tit kind, which nestle in the hollows of trees, have eggs altogether white, or white picked with red. The same is the case with the swallows and martins. The larks, pipits, dc. have the egg's of an earthy hue *."

* Cuvier's Animal Lingrom, Ares, i. 138. 


\section{Chapter VIII.}

\section{FACTS OBSERVED IN HATCHING.}

It is indispensable to hatching, that an equable temperature be kept up of about $96^{\circ}$ Fahr. or $32^{\circ}$ Réaum., for at lower temperatures the living principle appears to become torpid and unable to assimilate the nourishment provided for developing the embryo. Proceeding upon this principle, the Egyptians, as well as those who have tried the experiment in Europe, have succeeded by means of artificial heat in hatching eggs without any aid from the mother birds.

One of the most remarkable stories respecting artificial hatching is that arising out of a girlish superstition of the Roman Empress Livia. 'The tale is told by Pliny: "She took an egge, and ever carried it about her in her warme bosome; and if at any time she had occasion to lay it away, she would convey it closely out of her own warme lap into her nurse's for fear it should clill *." M. Réaumur mentions some modern instances of a similar lind: "One lady hatched four goldfinches out of five eggs from the same nest; one of the eggs having proved a rotten one, she was obliged to keep them warm only for ten days. Another lady," he adds, "told me a more extraordinary, though by no means an incredible fact of the same kind, assuring me she had seen a female lap-dog sit on eggs quite

* Holland's Plinie, x. 55. 
to the time of the hatching of the chickens, the creature having taken an affection for the egos, which she was fond of having under her, for some reason not easily assigned, though assuredly not with the desire of hatching chickens"."

Pliny seems to infer that the story of the Empress Livia gave origin to "the device of late, to lay eggrs in some warme place and to make a gentle fire underneath of small straw or light chaffe, to give a kind of moderate heate; but evermore the eggrs must be turned by man or woman's hand both night and day, and so at the set time they look for chickens and had them + ." But though such experiments may have been then revived, they were assuredly not new, for they are mentioned by Aristotle and Diodorus, though in a rather vague manner. Aristotle says that egrss may be warmed and chickens hatched in the earth, probably deducing such an inference from the circumstance of the eggs of crocodiles and other reptiles being thus hatched. In the same way lie appears to have been thinking of the eggs of snakes which are hatched in dung-hills, when he tells us that in Egypt they cover eggs with dung in order to hatch chickens,--a circumstance quite impossible, as we shall presently see. Diodorus is more particular in detailing the process, which consisted, he says, in filling a vessel with the dung of fowls passed through a sieve, over which were laid feathers, and upon these the eggs, with their smallest ends upward; the eggs were then covered with a similar layer of feathers and dungt. Cardan, in commenting on this passage, says, the dung both below and above ought to be put into pillows $\$$.

M. Réaumur, however, assures us that all this must be pure fancy; for after a whole year's varied * L'Art de faire Eclorre, chap. i. $\ddagger$ Aldrovandi Ornithologia, ii.

$\dagger$ Holland's Plinie, x. 55. $\S$ De Subtilitate. 
experiments, repeated incessantly, and with such assiduity as almost to tire out his patience, he was unsuccessful in hatching a single chicken by means of du1ng, though he at length succeeded in doing so by a different method. Success, as Thevenot informs us, also attended an experiment made in Tuscany, but it was under Egyptian direction; 'for the grand duke, in order to indulge the laudable curiosity long characteristic of the house of Medici, sent to Egypt for a person skilled in the management of the process.

Modern travellers, who mention the art as practised in Egypt, are very deficient in their details; but we ought to wonder the less at this when Father Sicard informs us that it is kept a secret even in Erypt, and is only known to the inhabitants of the village of Berme, and a few adjoining places in the Della, who leave it as an heir-loom to their children, forbidding them to impart it to strangers. When the beginning of autumn, the season most favourable for hatching, approaches, the people of this village disperse themselves over the country, each taking the management of a number of eggs entrusted to his care by those unacquainted with the art. The subsequent operations consist, first, in the building of suitable ovens; and, secondly, in causing the eggrs placed there to be subjected to a regular heat. 'The mystery does not, however, lie in the construction of the oven, for the outside is not only open to all, but strangers are even allowed to witness the curious process going on in the interior. The grand secret is the manner of causing the eg'gs to be warmed that the chickens may be gradually developed, and at last hatched. The most essential condition of this process consists in keeping the eggrs at the proper degree of temperature, and consequently in knowing how to manage the fire that heats the oven. 


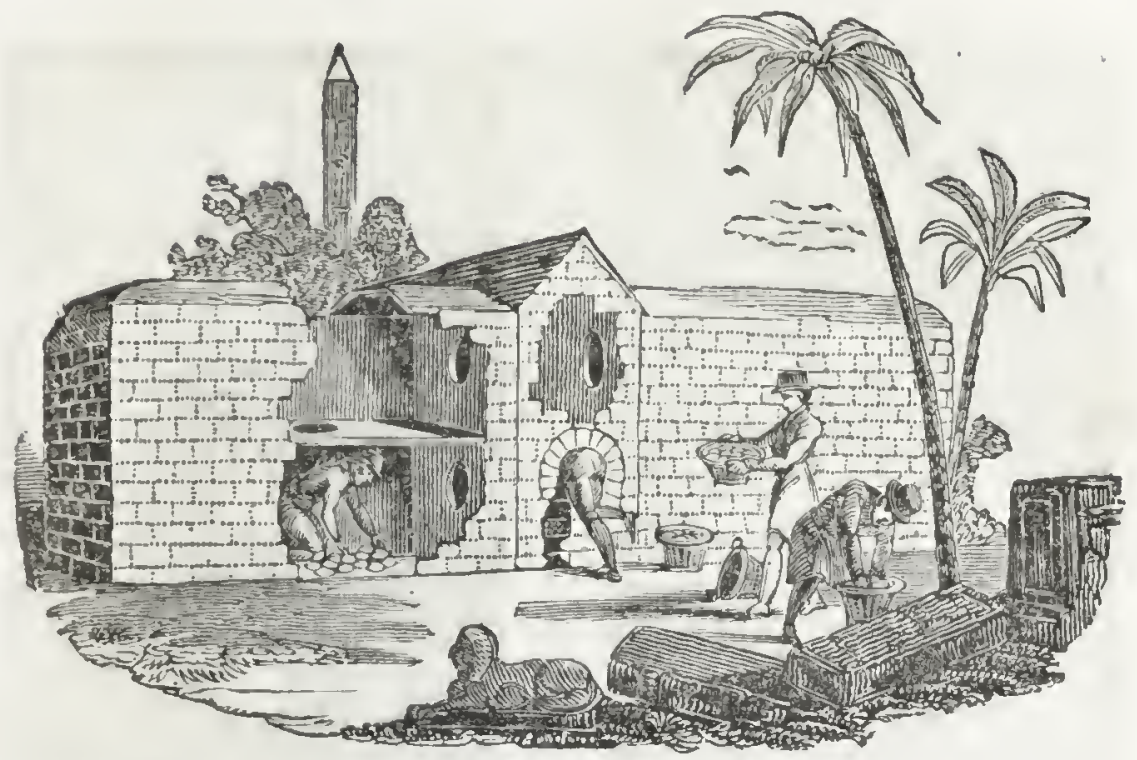

Egyptian Egg-oven.

According to the best descriptions of the Egyptian mamal, or hatching-oven, it is a brick structure about nine feet high. The middle is formed into a gallery about three feet wide and eight feet high, extending from one end of the building to the other. This gallery forms the entrance to the oven, and commands its whole extent, facilitating the various operations indispensable for keeping the eggs at the proper degree of warmth. On each side of this gallery there is a double row of rooms, every room on the ground-floor having one over it of precisely the same dimensions, namely, three feet in height, four or five in breadth, and twelve or fifteen in length. These have a round hole for an entrance of about a foot and a half in diameter, wide enough for a man to creep through; and into each are put four or five thousand eggs. The number of rooms in one mamal varies from three to twelve; and the building is adapted, of course, for hatching from forty to eighty thousand eggs, which are not laid on the bare brick floor of the oven, but upon a mat, or bed of flax, or other non-conducting material. 


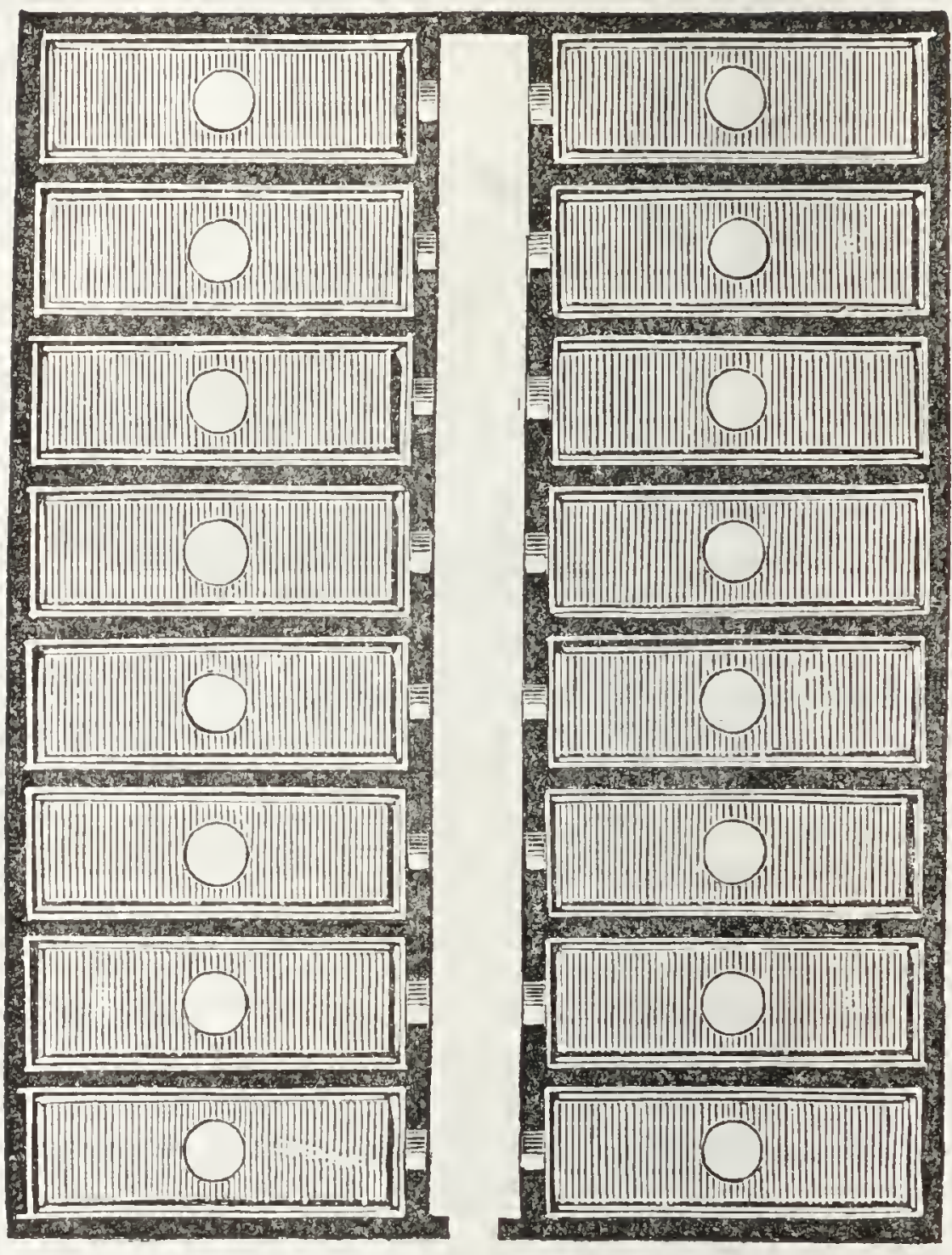

Ground-plan of an Egyptian Egg-oren.

In each of the upper rooms is a fire-place for warming the lower room, the heat being communicated through a large hole in the centre. The fire-place is a sort of gutter, two inches deep and six wide, on the edge of the floor, sometimes all round, but for the most part only on two of its sides. As wood or charcoal would make too quick a fire, they 
burn the dung of cows or camels, mixed with straw, formed into cakes and dried. The doors which open into the gallery serve for chimneys to let ont the smoke, which finally escapes through openings in the arch of the gallery itself. The fire in the gutters is only kept up, according to some, for an hour in the morning and an hour at night, which they call the dimner and supper of the chickens; while others say it is lighted four times a-day. The difference probably depends on the temperature of the weather. When the smoke of the fires has subsided, the openings into the gallery from the several rooms are carefully stuffed with bundles of coarse tow, by which the heat is more effectually confined than it could be by a wooden door.

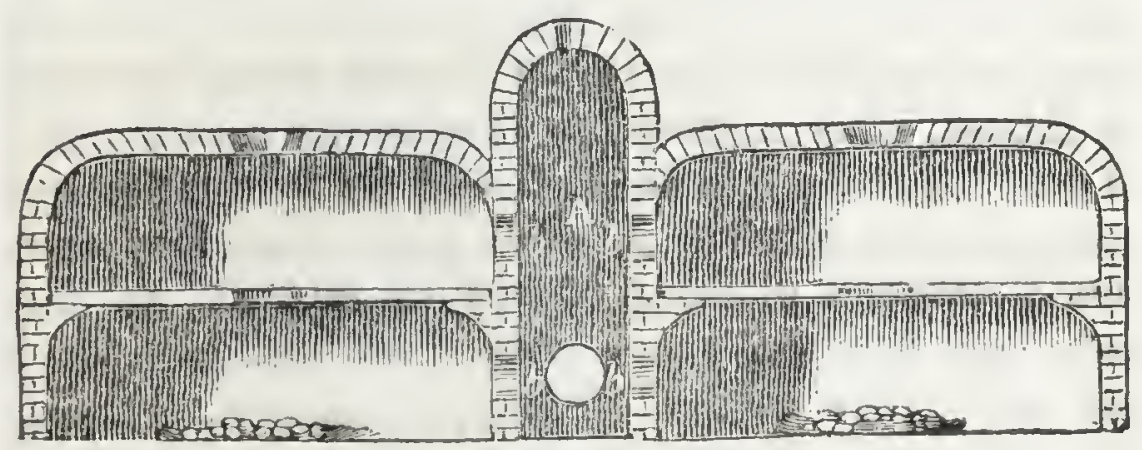

Transverse section and elevation of an Egyptian Egg-oven.

When the fires have been continued for an indefinite number of days, eight, ten, or twelve, according to the weather, they are discontinued, the lieat acquired by the ovens being then sufficient to finish the hatching, which requires in all twenty-one days, the same time as when egrs are naturally hatched by a hen. About the middle of this period a number of the eggrs in the lower are moved into the upper rooms, in order to give the embryos greater facility in making their exit from the shell, than they would have if a number of eggs were piled up above them. 


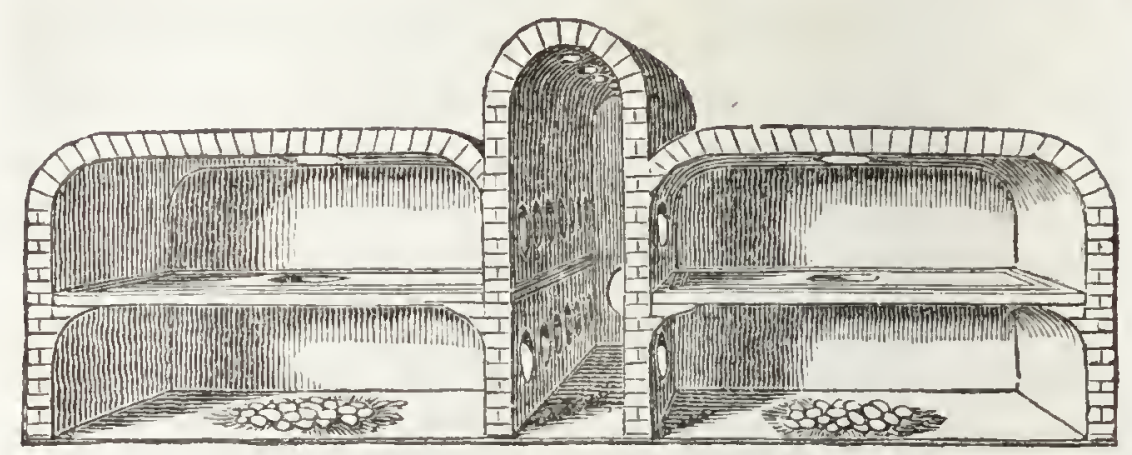

Transverse section and perspective elevation of an Egyptian Egg-oven.

The number of ovens dispersed in the several districts of Egypt has been estimated at 356; and this number can never be either increased or diminished without the circumstance being known, as it is indispensable for each mamal to be managed by a Bermean, none of whom are permitted to practise their art without a certified licence from the A ga of Berme, who receives ten crowns for each licence. If, then, we take into account that six or eight broods are annually hatched in each oven, and that each brood consists of from 40,000 to 80,000 , we may conclude that the gross number of chickens which are every year hatched in Egypt amounts to nearly $100,000,000$. They lay their account with losing about a third of all the eggs put into the ovens. The Bermean, indeed, guarantees only two-thirds of the eggs with which he is entrusted by the undertaker, so that out of 45,000 eggs he is obliged to return no more than 30,000 chickens. If he succeeds in hatching these the overplus becomes his perquisite, which he adds to the sum of thirty or forty crowns, besides his board, that is paid him for his six months' work.

Proceeding upon the mistaken account of the Egyptian method of hatching, given by Aristotle and Diodorus, M. Réaumur tried a number of ingenious 
experiments with dung in a state of fermentation, an abstract of which may be interesting, were it only to show the importance of certain circumstances to the success of hatching. It is well known to gardeners that beds of fresh dung become hot a few days after they have been made up; and that the heat subsequently increases more and more every day till it becomes considerable enough to give pain to the hand, and consequently much stronger than what ought to be employed in hatching. In fact the dung hot-bed used by M. Réaumur almost dressed the egro's and made them fit for eating, though they were in a pot. The heat in question, however, is by no means steady or uniform in temperature, neither is it ever the same at different depths, or in different parts of the same bed. In order to obviate these difficulties, this ingenious experimenter conceived the idea of only employing the dung to heat a cavity or oven instead of plunging the eggs into it; and he began by trying two beds, not so wide as cucumber beds, parted by a narrow path, closed at the ends, and forming an oblong oven or cavity, the air of which was liept warm by the fermentation. 'The whole was covered in by boards, though not very closely, and the temperature was ascertained by means of thermometers placed in various parts; and, to shelter it from rain which would have injured the eggs, it was placed in a large coachlouse.

" A few days after it had been constructed," continues the enthusiastic naturalist, "the thermometer informed me that the heat of the oven was much superior to what I wanted; but as soon as it was reduced to the degree desired I introduced 200 eggs into the oven, enough for a first experiment, though it was large enough to contain above 1000. The greater part of the eggs in question were ranged 
upon shelves, the rest were put in baskets, and $\mathbf{1}$ made myself very certain that they were all kept nearly in the same degree of heat they would have had under a hen. I could hardly let the first twentyfour hours pass without attempting to ascertain the effect produced upon the eggs; and I broke two, in which I had the pleasure of seeing the little heart, by this time developed, already begin to beat, and the small drop of blood, sufficient to fill it, entering and departing. 'This was a sight which a naturalist could not soon be tired of were it to last much longer than its usual time of six or eight minutes. For the next four or five days I had the satisfaction of being able to keep up the uniformity of temperature, and of observing the progress made by the embryos in the eggs, some of which I broke daily to ascertain this. I even began at length to feel regret in breaking them, under the notion that I should lose so many chickens out of my number.

" The eggs of this as well as those of a great many other broods began, at the eighth or tenth day, to disappoint my expectations. Till then I had found in the eggs which I broke the chickens as forward as I conld wish; the scene soon changed, and the odour diffused over the oven informed me that some of the eggrs, at least, had begun to be tainted. These, indeed, were easily distinguished from the sound ones, by the tainted matter in some instances having burst through, and, in others, oozed out of the pores of the shell. I had these tainted eggs all carefully taken out; but as they every day increased in number, I concluded that some accident had occurred fatal to them all; for though the chicks in some of them were formed, and even feathered, they were all dead.

"As I had succeeded in bringing these chickens through two-thirds of the regular period of hatching 
as well as they wonld have grown and been formed if the eggrs had been kept all the time under a hen, there alppeared to be sufficient hope that, by redoubling my attention, I might afterwards fully succeed. I therefore put some fresh eggs into the same oven, continuing every day to put in the egg.s laid by my owil hens, taking the precaution to write the date upon each. But I was again disappointed, several of them giving evidence of being tainted as early as the twelfth day.

"Upon resuming" my experiments the following November, I caused chicken-ovens to be constructed of different forms, one after another, some in the form of a baker's oven; but these not appearing to suit, I reverted to my first plan, and had one constructed in the month of February in a stable large enough to contain six horses. When the temperature had risen to the proper degree, I put in the egg's. The dung of the bed was very moist, and the season being ill suited to dry it, the inside of the oven, whenever the cover was taken off; was seen to be filled with a thick fogrgy vapour, so very considerable that the eggs were continually bedewed with it as if sprinkled with water. Some of the eggs were laid in open boxes, having sand strewed over the bottom, which was converted by this moist vapour into a sort of mire. But though the eggs in this mire were nearly as moist as if they had been plunged in water, the embryos continued to be developed till the seventh day, beyond which none of them lived.

"I'he sides of this oven, however, at length became dry, and no perceptible vapour remained, yet all my trials with it during two months and a half proved equally abortive, though I was daily imagining and endeavouring to obviate the causes of the failure. After many such trials, enouglı to wear ont the most enduring patience, I at last clearly perceived 


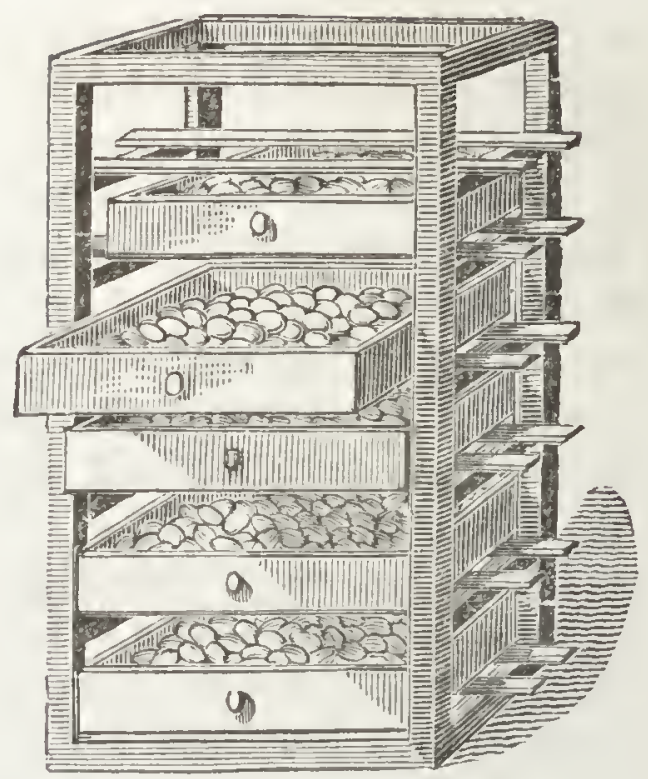

Egg-frame.

that the chief point to be attended to was to keep the eggs properly warm by the heat of the dung, without being exposed to the vapour exhaled from it, which pervaded the pores of the shell and became fatal to the embroyo.

"With this view I caused one of those casks, called half-hogsheads, to be sunk into the bed of dung, after having had a hole dug large enough for its admission, taking great care to have the edges raised three or four inches above the surface of the hot-bed. The top alone had been previously converted into a moveable lid by means of cross-bars, and one larga and eight smaller holes were made in it and bunged with corks, to serve as regulators of the temperature within. The eggs were let down into the casks in round baskets, about two inches in diameter less than the cask, some being deep and others shallow, the former containing two and the latter one layer of eggrs. I caused three of these baskets to be placed in the oven, which contained about two hundred eggs, in such a manner that the lowest was some inches 
distant from the bottom, and the highest a few inches lower than the upper edge. When the time had elapsed in which my previous experiments had failed, not one egg in this new oven was tainted, and at the end of twenty days the gardener, who had taken care of so many unsucessful broods, came in the evening to tell me, with the greatest possible emotion, what he knew must be very pleasing news, namely, that one of my eggs was chipped, and the chick could be heard within endeavouring to chirp. This chicken did not disappoint our hopes, having been hatched next day, and it was even preceded by some others, and followed by a great many more. From that time, indeed, I began to see some hatched every day*."

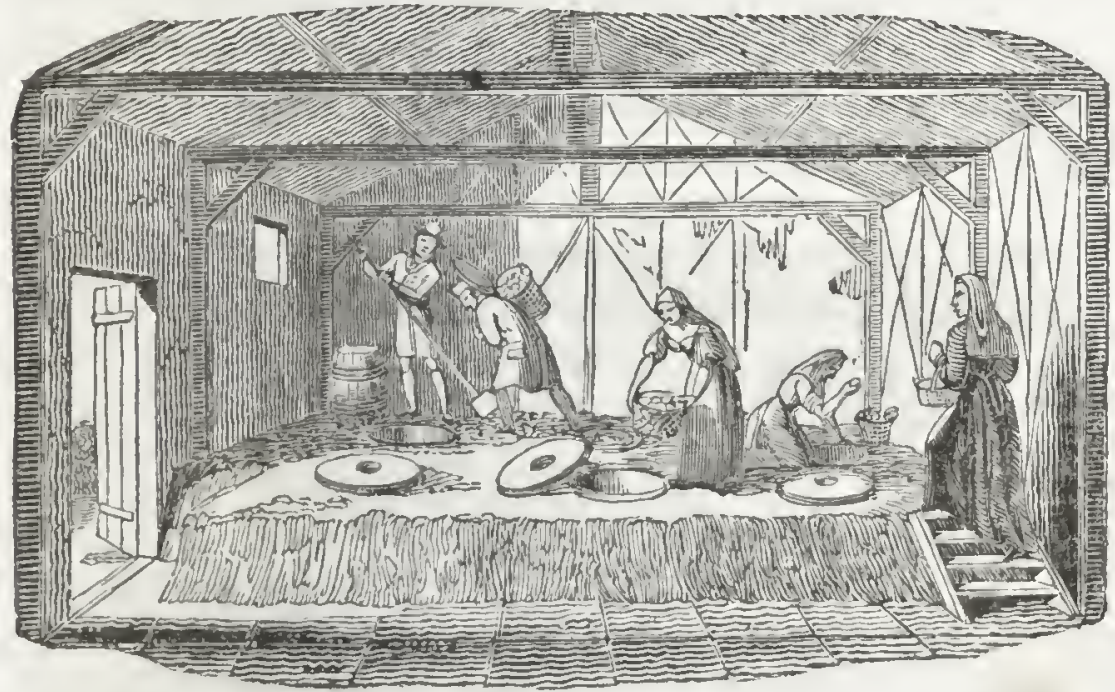

Hatching Eggs in dung.

The problem with respect to heat generated by fermentation was thus solved; but M. Réaumur did not stop here. The rector of St. Sulpice, anxious to introduce the plan, applied to the naturalist for instructions on the subject; but, instead of recommending dung-beds, M. Réaumur imagined he might * L'Art de faire Ecclorre, Mem. ii. 
take advantage of the heat of the bread-ovens belonging to the extensive benevolent institution called L'Enfant Jésus. After several trials to ascertain the heat of a room which was situated over this bake-house, and such arrangements as were necessary to insure uniformity, it was determined to arrange the eggrs on the shelves of a small cupboard placed there, and the care of them was entrusted to the nuns of the establishment. In one of the first experiments made here, the charge of keeping a single box, containing a hundred eggs, was entrusted to a very ingenious nun, who was really enthusiastic in the business. Above half of these eggs proved abortive; but it was worthy of remark, that about twenty were hatched one day sooner than they would have been under a hen. When the first of them appeared the nun was transported with joy, and directly ran to tell the news to every body she could find.

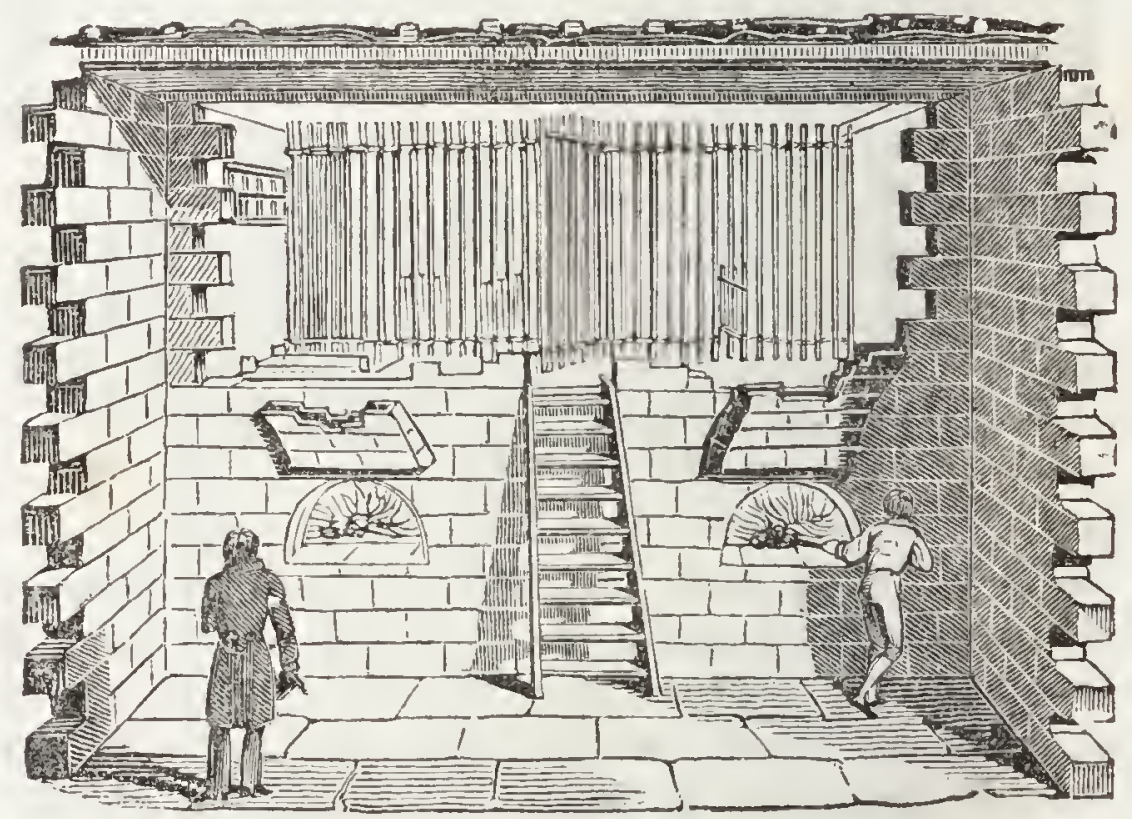

Iatching-room over the bake-house ovens of the Priory of L'Enfant Jésus at Paris. 
It was an obvious inference from the success of these experiments, that bakers and pastry-cooks might apply their ovens to a similar use by constructing over them hatching chambers, and that in this way the multiplication of chickens might be extended to an immense anount-far exceeding even that of Egypt. It does not appear, however, that these notions have ever been carried into effect, or that anything has been attempted beyond a few experiments of small extent, in any part of Europe. A few years ago an individual in the vicinity of London contrived an apparatus for hatching by means of steam, and exhibited it in the Egyptian Hall, Piccadilly; but we have not learned that he ever carried his invention so far as to make a trade of the chickens which he hatched.

The importance of keeping the eggs at a uniform temperature is beautifully illustrated by the care which hens may be observed to take in arranging the eggs they are hatching. Amongst other curious facts connected with this subject, is that of a hen throwing out or eating the eggs which she cannot conveniently cover.

A few days ago we had brought to us three eggs of the wood-wren (Sylvia sibilatrix, Bronstrin), and being anxious to have them hatched we introduced them, after warming them slightly, into the nest of a canary, then sitting upon four eggs of her own. In the course of the day two of her own eggs had disappeared, having, we inferred, been destroyed by her because she could not cover the seven so as to keep them at a uniform temperature, the three small eggs being nearly equal in size to the two which were gone*. It is, no doubt, for the same

$$
\text { * J. R. }
$$


reason that the birds in whose nests the cuckoo parasitically deposits her egrr, often, if not always, turn out or destroy their own to make room for hers.

During the process of hatching the mother-bird acts as if she knew that by keeping the eggs all in one position, some would be more favourably treated than others. 


\section{Chapter IX,}

\section{EVOLUTION OF THE CHICK.}

Ir has long, been a favourite occupation with philosophical naturalists, to observe the changes which an eg' indergoes in hatching, from the first day that the mother sits upon it till the chick breaks through the prison-walls of the shell and emerges into open day. The chief writers who have attended to the various stages of this curious and interesting progress, are Fabricius d'Aquapendente, Harvey, Malpighi, Maitre-Jean, Réaumur, Haller, Scarpa, Meckel, Blumenbach, Prout, Dutrochet, and Sir E. Home. The statements of these different inquirers we shall now compare and condense.
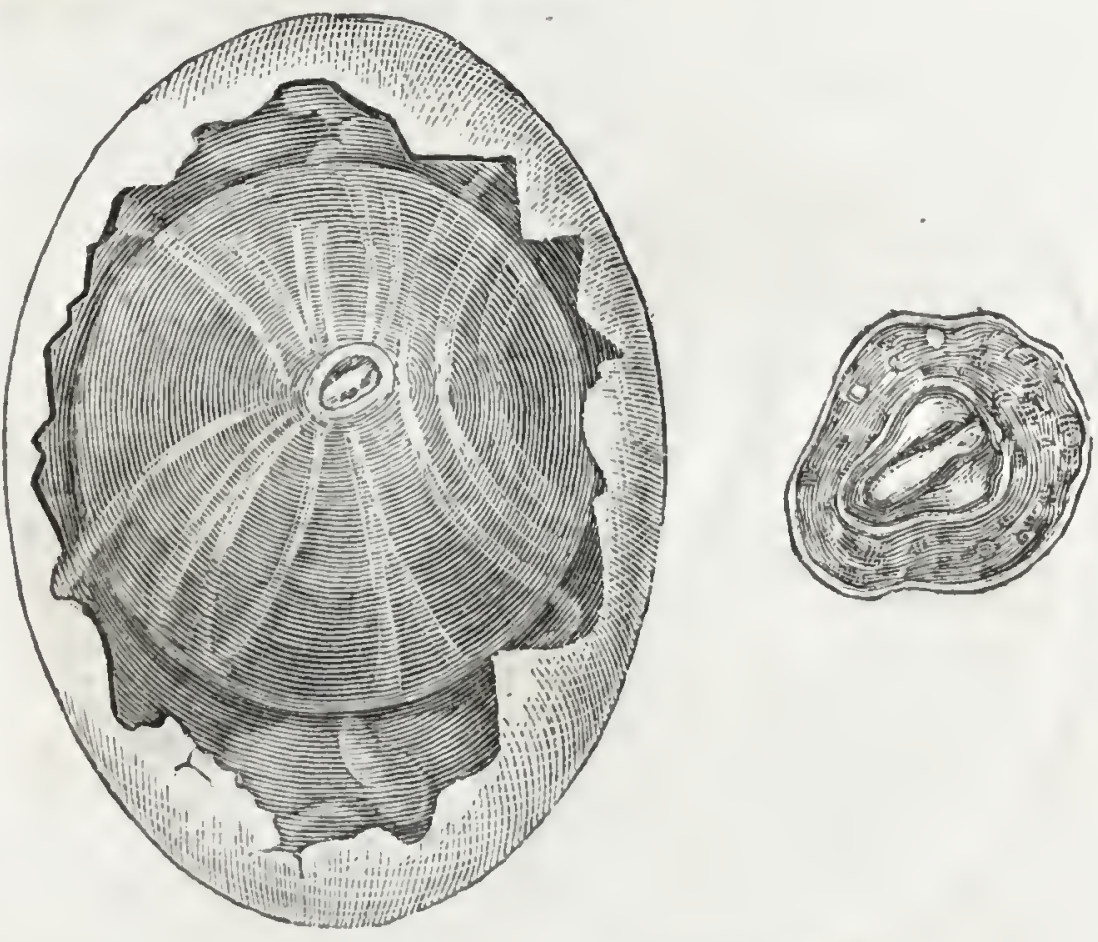

An Egg as it appears twelve hours after incubation, with a magnifed view of the Embryo Chict.

(This and the following cuts, which illistrate the changes in the egg, are copied, by permission, from Sir E. Home's Comparative Anatomy.) 
In about twelve hours from the time the mother begins to sit, the commencement of life is perceptible in the germ (cicatricula). What seems to be the head of the chick appears joined to the body and swims in the surrounding fluid; and towards the close of the first day this apparent head is seen bent back by its enlargement. So says Haller; but Blumenbach thinks this a deceptive appearance, produced only by the destined abode of the future chick, no trace of which, he says, is perceptible before the second day, when it assumes an incurvated form resembling a thread of jelly enlarged at the extremities, very closely surrounded by fluid, from which it is scarcely distinguishable. The first appearance of red blood is perceptible on the yolk-bag towards the end of the second day, a series of points being observed which form grooves; these closing consti-
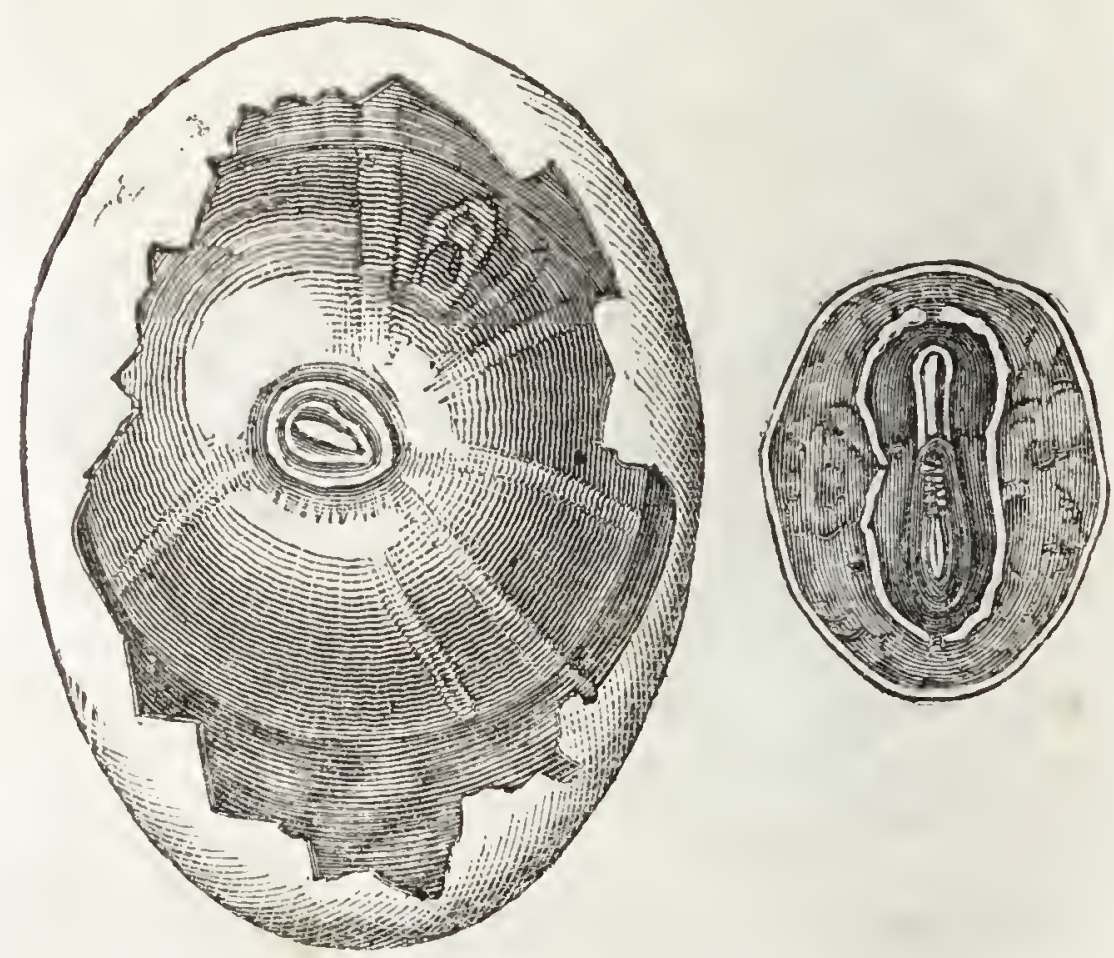

An Egg as it appears sixteen hours after incubation, with a magnified view of the Embryo Chich. 
tute vessels, the trunks of which become attached to the chick. Haller says, we can now perceive traces of the back-bone (vertebre), like small globules, disposed on the two sides of the middle of the spine, the wings and the blood-vessels of the navel, distinguished by their dull colour, also beginning to appear. The neck and breast are unfolded, the head is enlarged, the outlines of the eyes and their three surrounding coats now become perceptible, and the heart is seen pulsating and the blood circulating.
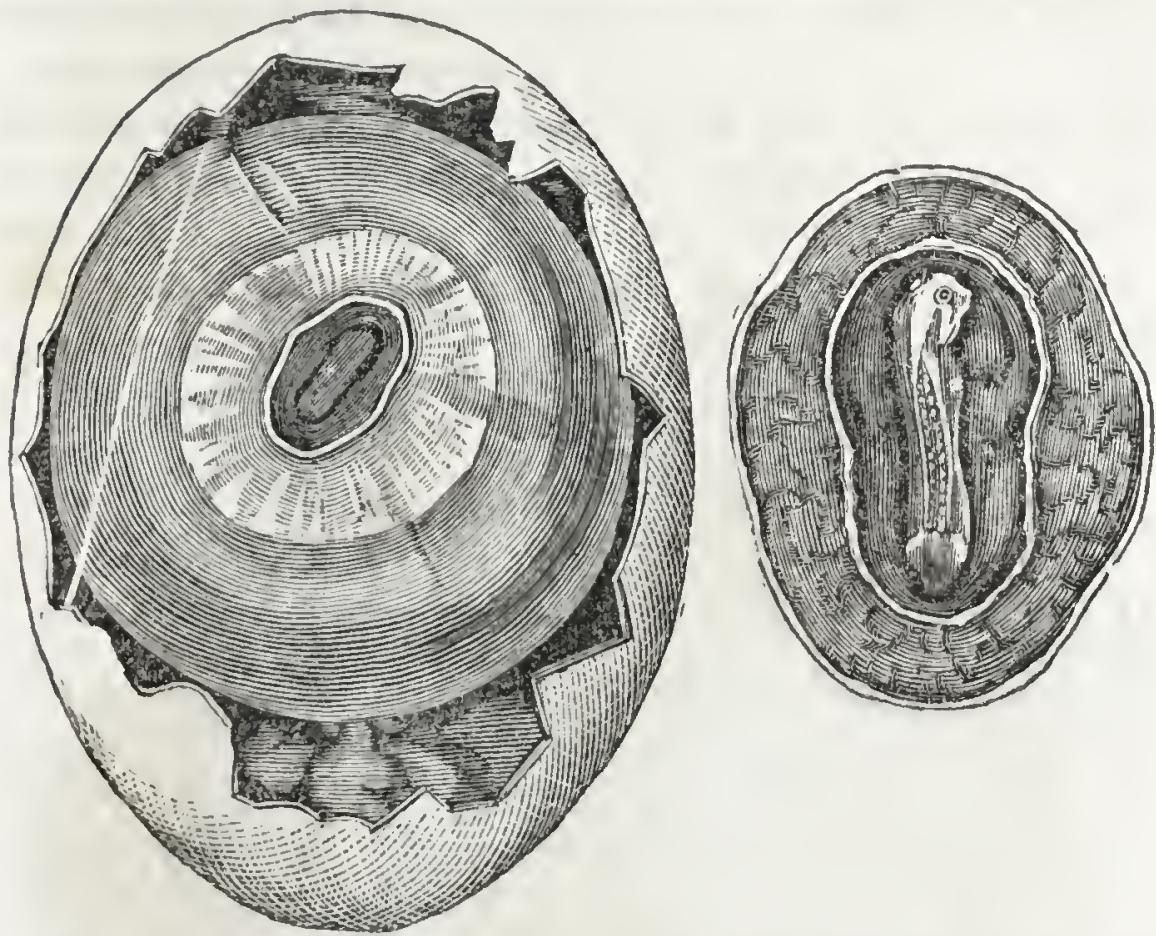

An Egg as it appears thirty-six hours after iucubation, with a magnified view of the Embryo Chick.

Blumenbach does not mention his having seen the heart before the commencement of the third day, when it resembles a tortuous canal, and consists of three dilatations lying close together and arranged in a triangle, one part of which is properly the right auricle, forming at this period a common auricle, and another is the only ventricle, which afterwards 
becomes the left ventricle; the third part (bulbus aorta) is considerably bulged out. It is remarkable that the heart at this period projects beyond the breast, and beats in triplets: first, on receiving into the auricle the blood from the veins; secondly, on discharging this blood into the arteries; and thirdly, on forcing it into the vessels of the navel,-motions which will continue for twenty-four hours, if the embryo be taken out of the egg. The veins and arteries may now also be seen branching over the surface of the brain, and the spinal marrow beginning to extend along the back; or rather, as has been beautifully shown by Marcel de Serres*, Tiedemann ${ }^{\text {, }}$, and Carus + , the spinal

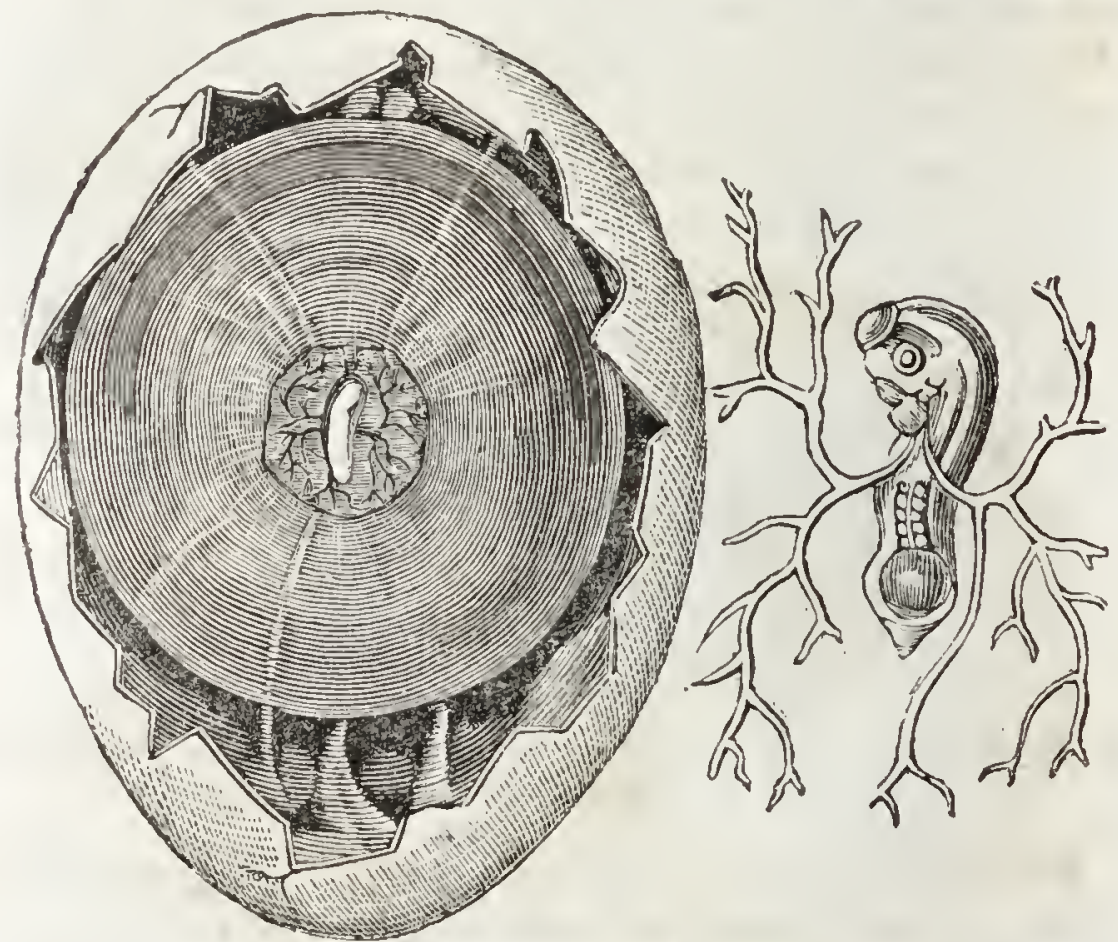

An Egg opened thirty-six hours after incubation, with a magnified view of the Embryo Chick, in which is shewn the first appearance of the principal blood-vessels.

* Du Cerveau, Paris, 1826 ; and Sur le Cervelet, Paris, 1823.

$\dagger$ Geschichte des Gehirns des Fotus, 4to. Leipzig.

+ Comparative Anatomy, by Gore. 
marrow itself, becoming enlarged, forms the brain. At this period the fluid surrounding the fotus becomes more consistent and less transparent. About the same time also the spine, which was at first extended in a straight line, becomes bent, and the joints of the bone (vertebra) become distinct. The eyes are distirguished by their black pigment and comparatively large size, as they afterwards are in consequence of a peculiar slit in the lower part of the iris, a circumstance also observable in the nimble lizard (Lacerta agilis) and other animals which have no pupillary membrane.

On the fourth day the pupil of the eye can be distinguished as well as the aqueous and vitreous humours. In the head are perceived five vesicles, filled with a fluid; and these as they enlarge approach each other, coalesce, and form the brain, invested with its membranes. The wings also grow, the thighs begin
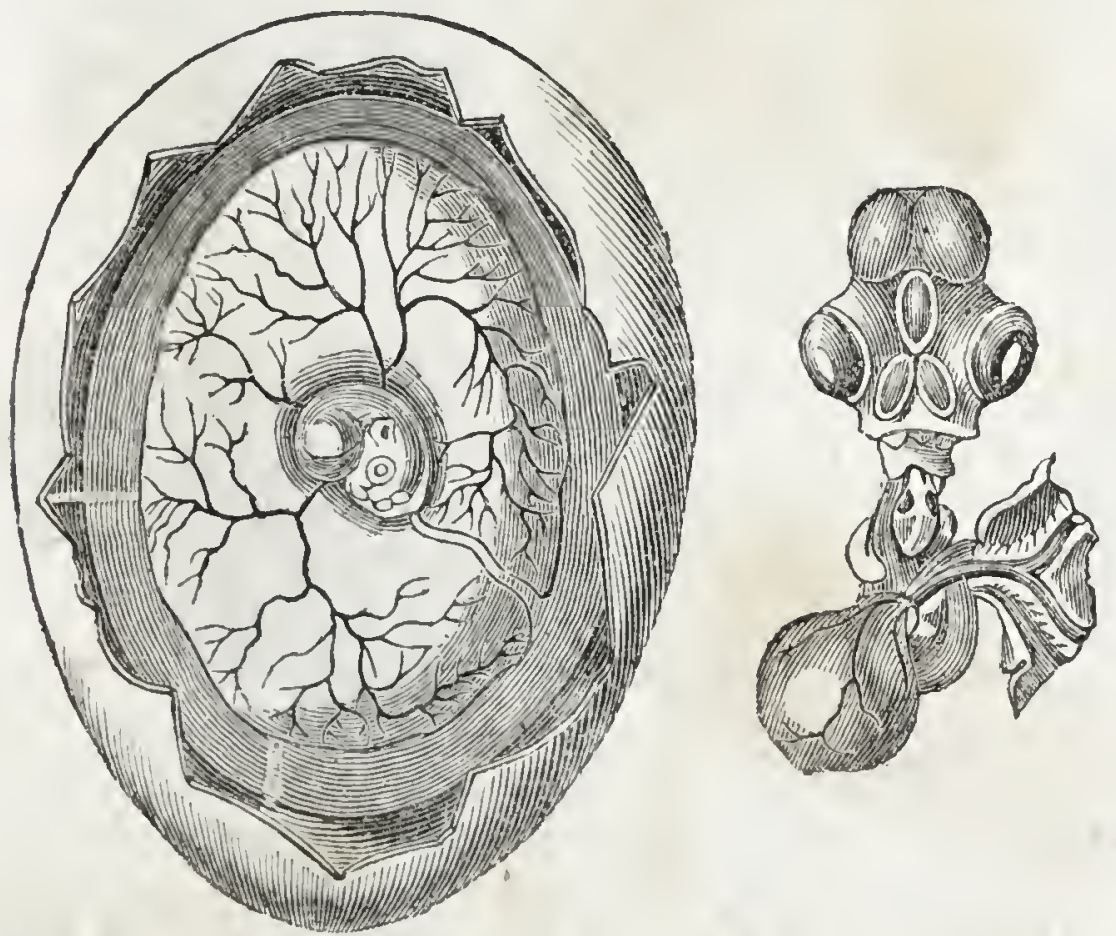

An Egg opened four days after incubation, with a magnified riew of the Chick. 
to appear, and the body extends to one-third of an inch in length. Several other important organs now become visible, as the stomach, the intestines, and the liver. A vascular membrane begins to form about the navel, and grows during the succeeding days so rapidly that it covers almost the whole inner surface of the shell, apparently performing the office of lungs in carrying on the process of respiration.

On the fifth day the lungrs begin to be formed, but cannot, of course, perform their functions, on account of the circumambient fluid. The vessels of the navel rise out of the abdomen; the heart is confined in a very thin membrane that covers the chest; and the muscles appear over the body in the form of an unctuous envelope.

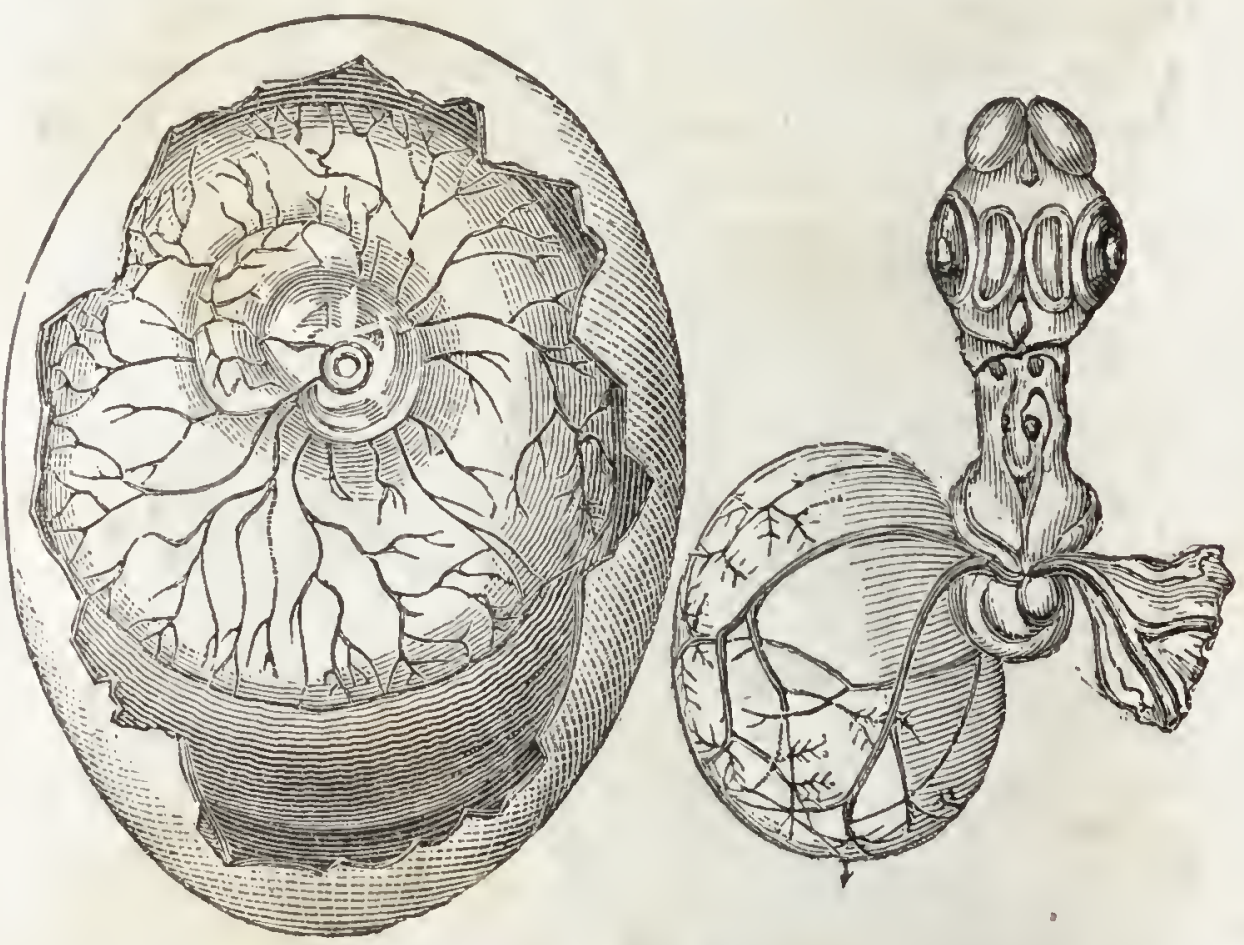

An Egg as it appears five days after incubation, with a magnified view of the Chick.

On the sixth day the gall-bladder is first perceptible, and the first indications of voluntary motion 
may be remarked. The spinal marrow, divided into two parts, is extended along the trunk; the liver, previously whitish, becomes of a darker dusky colour. It is now seven lines* in length.
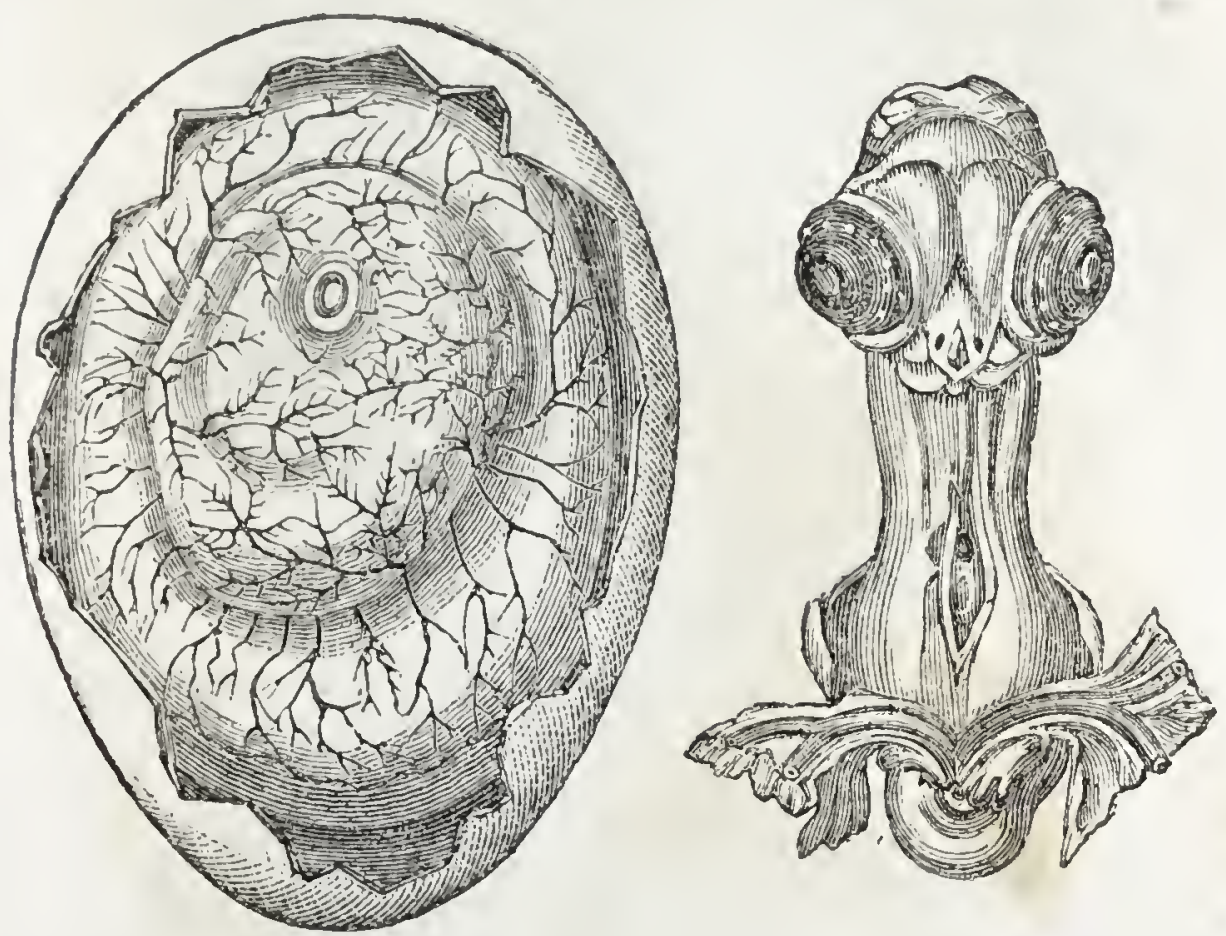

An Egg as it appears six days after incubation, with a magnified view of the Chick.

On the seventh day it is easy to distinguish the bill; and the skin, with the germs of the feathers, becomes obvious.

On the eighth day the brain, the wings, thighs, and legs, have taken nearly their ultimate form; but, according to Scarpa, are still soft, flexible, and pellucid + . The two ventricles of the heart also appear like two bubbles, contiguous and joined above to the substance of the auricles; while two successive motions are now observed in them, as well as in the auricles, which resemble two separate hearts.

* A line is the twelith part of a French, or rather less than the eleventh of an English inch.

†. De Penit. Ossium Structura Comment. 4to. Lips, 1799. 

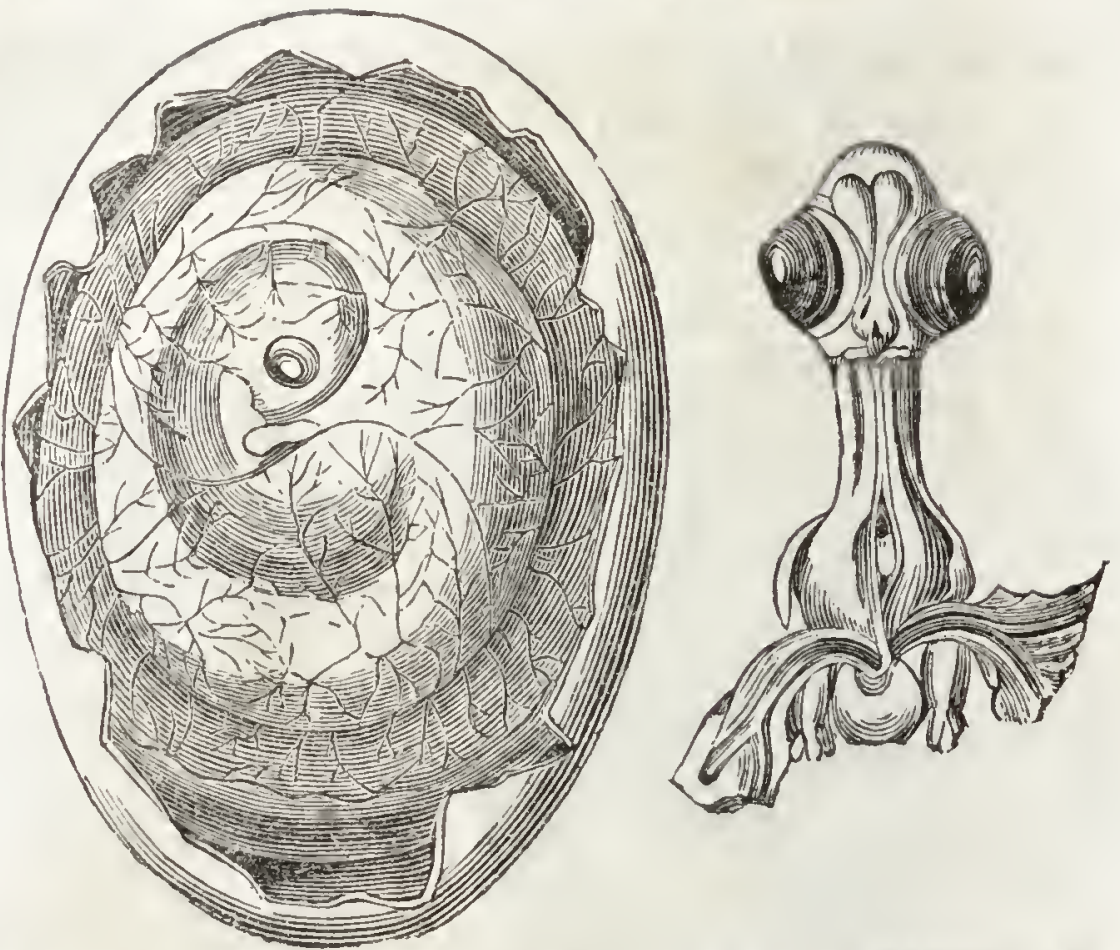

An $\mathrm{E}_{g \mathrm{~g}}$ as it appears seven days after incubation, with a magnified viow of the Chick.
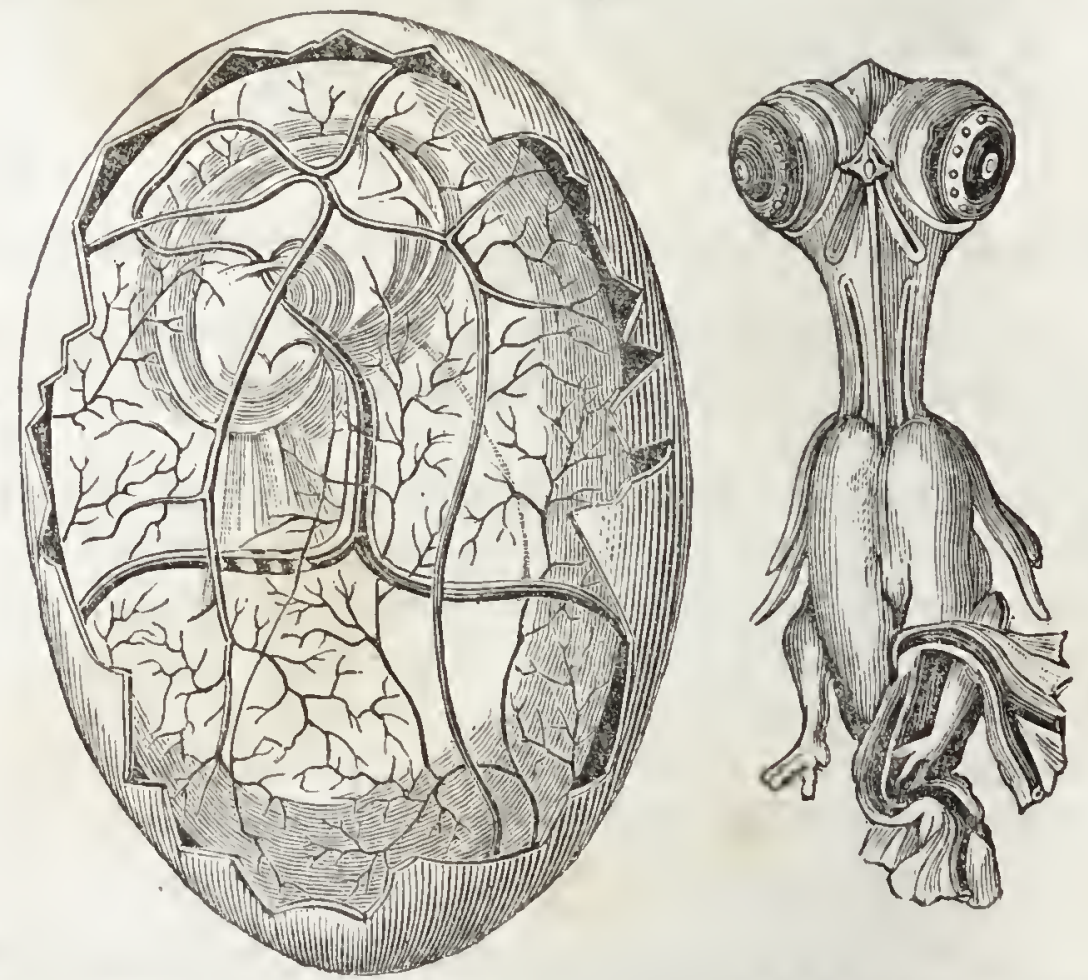

An Egg as it appears eight days after incubation, with a magnified view of the Chich. 


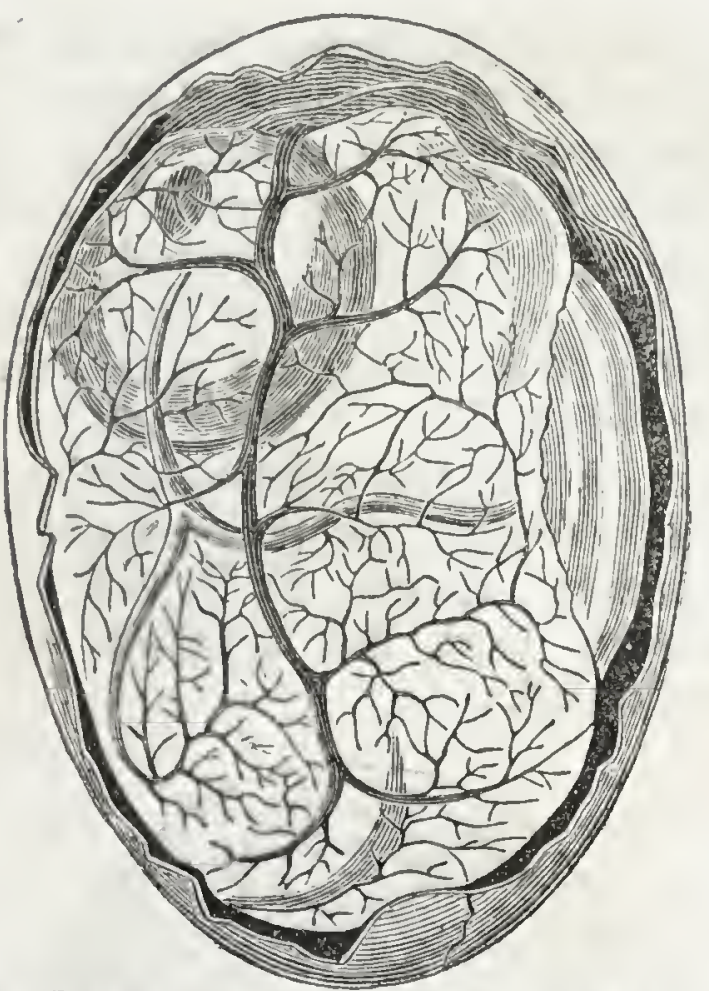

An Egg as it appears nine days after incubation.

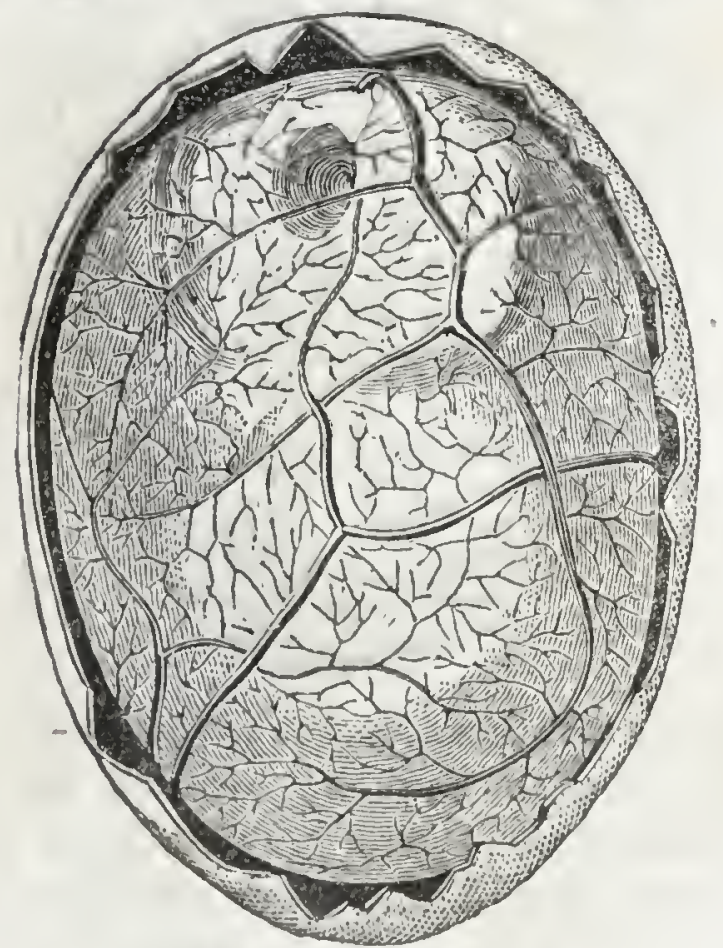

The same Egg turned more to its right side. 
On the ninth day the bones begin to be formed, appearing in the form of hard bony joints, the middle of the thigh and leg-bones, according to Scarpa, becoming yellowish. These form the rudiments of the bony ring of the sclerotic, resembling a circular row of the most delicate pearls. At the same period the marks of the beautiful yellow vessels on the yolkbag begin to be visible.

On the tenth day the muscles of the wings are seen completely formed, and the germs of the feathers appear enlarging. Scarpa up to this period could observe nothing hard, but a yellow wrinkling of beautiful network *

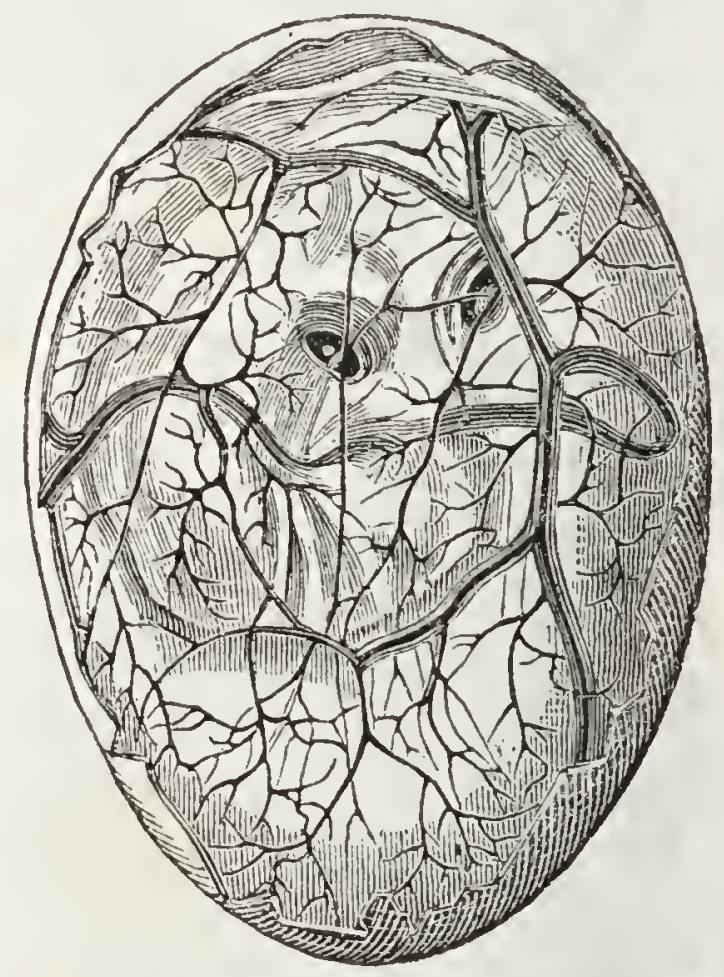

An Egg as it appears ten days after incubation.

On the eleventh day the arteries begin to be distinct, those which were previously at a distance from the heart now joining and cohering to it. It * Zool, Journ, ii. 433. 


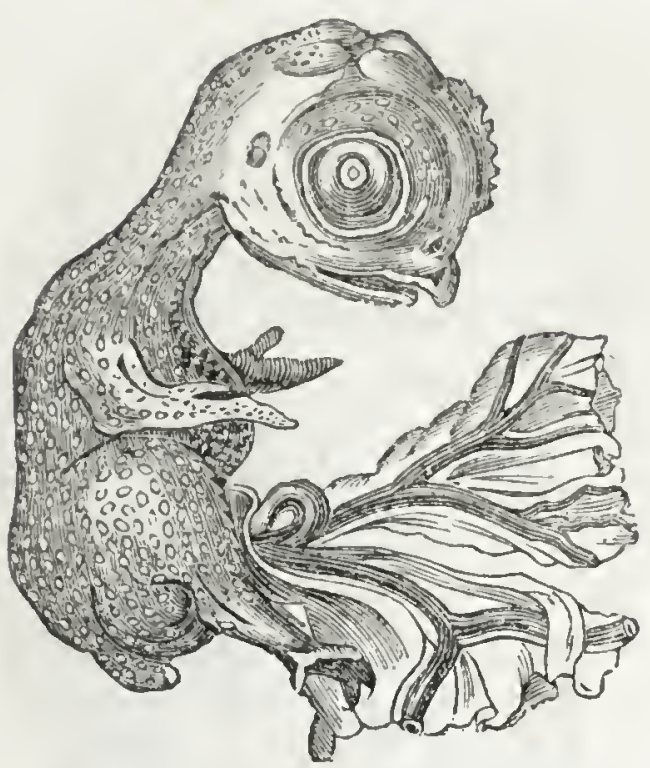

The Embryo Chick taken from the preceding Egg, with the amnion and vesicle removed.

was now that Scarpa first observed the wrinkles in the leg and thigh-bones to become rough and hard, and red spots to appear.

On the twelfth or thirteenth day, if the membrane (chorion) enveloping the white of the egg be examined by very cautiously opening the shell, it will present, Blumenbach says, without any artificial injection, one of the most splendid spectacles that occurs in the whole organic creation,- the most simple, yet the most perfect substitute for the lungs. It exhibits a surface covered with countless bloodvessels, venous and arterial, branching through its texture. The veins are of a bright scarlet colour, carrying oxygenated blood to the chick; while the arteries, on the other hand, are of a deep crimson or livid red, bringing the carbonated blood from the body of the embryo. The functions of the two are thus the reverse of those they perform after the chick respires. From the trunks of these arteries being connected with the iliac vessels, and on account of 


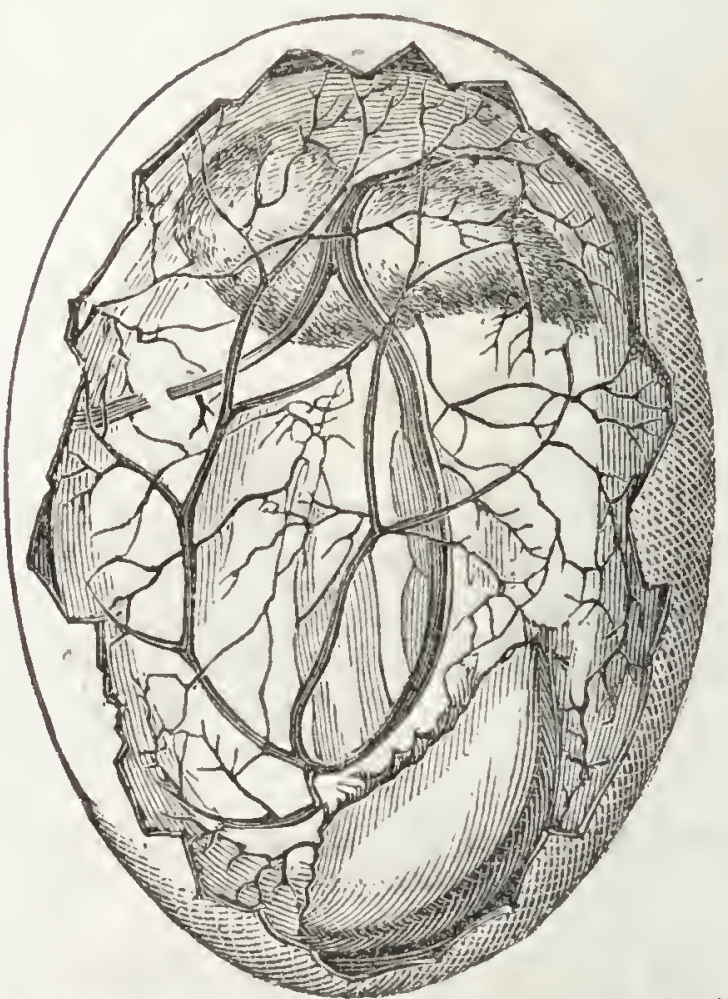

An Egg as it appears fourteen days after incubation.

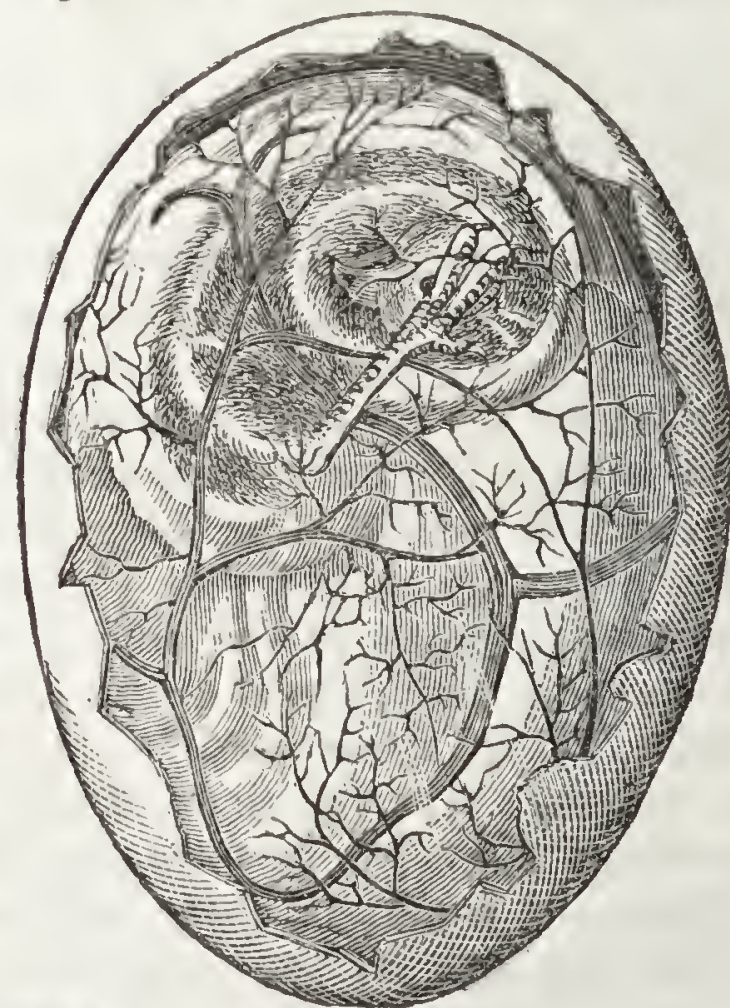

The same Egg as the preceding, with the external half of the vesicle removed. 


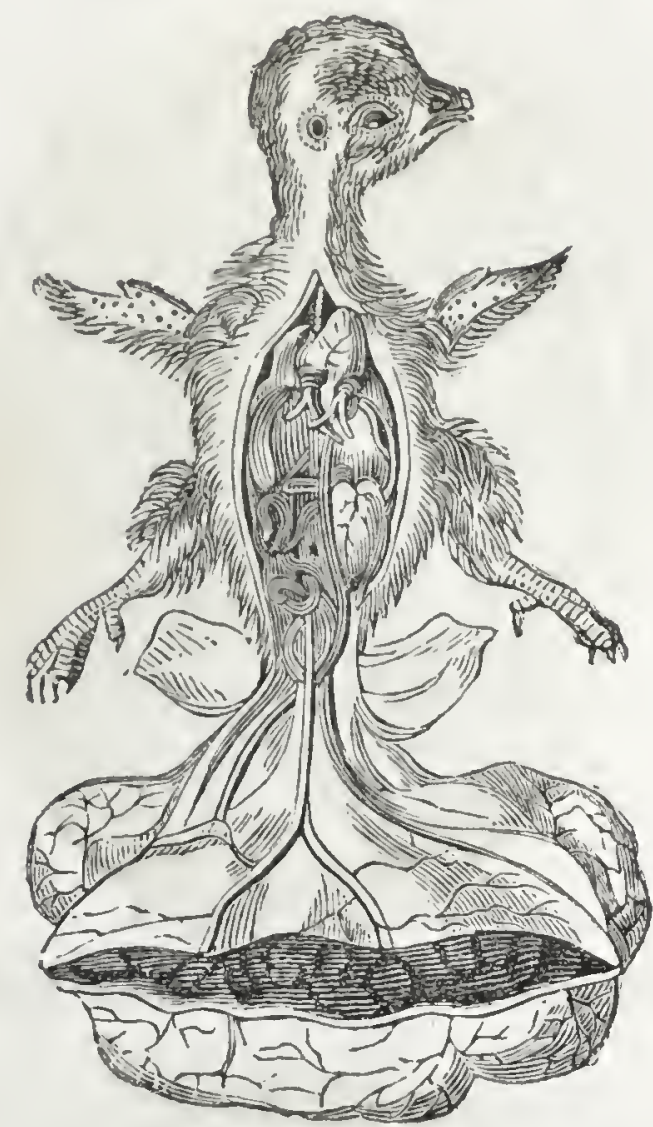

The Embryo of the preceding Figg, onened to show the conrse of the principal blood-vessels which go to the vesicle and to the areolar membrane.

the thinness of their coats, they furnish the best object for demonstrating the circulation of the blood in a warm-blooded animal. According to Scarpa, the thigh-bones, when dried, now preserve their shape.

On the fourteenth day the feathers appear well developed; and if the embryo be taken out of the egrg, it can open its beak for the purpose of breathing:

During the remaining part of the process, the yolk becomes gradually thinner and paler by the intermixture of the inner white; while an immense number of fringe-like vessels, with flaky terminations of a singularly peculiar structure, are formed on the inner surface of the yolk-bag, and hang into the 


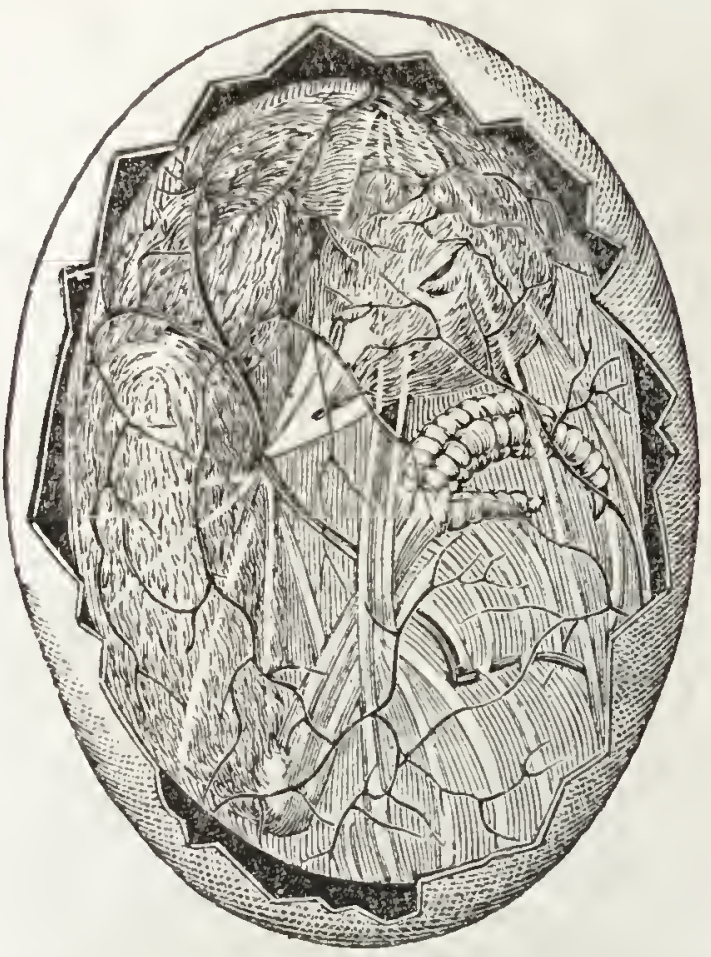

An Egg as it appears eighteen days after incubation.

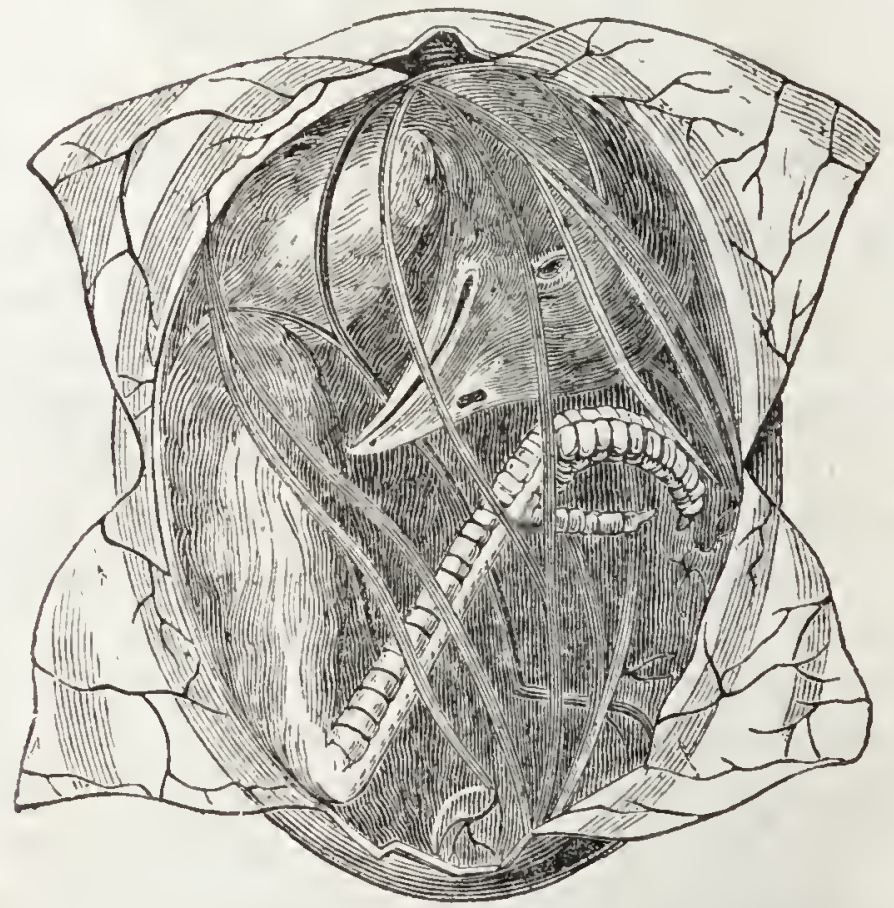

The same Egg as the preceding. with part of the vesicle remored, to show the Embryo Chich more clearly. 


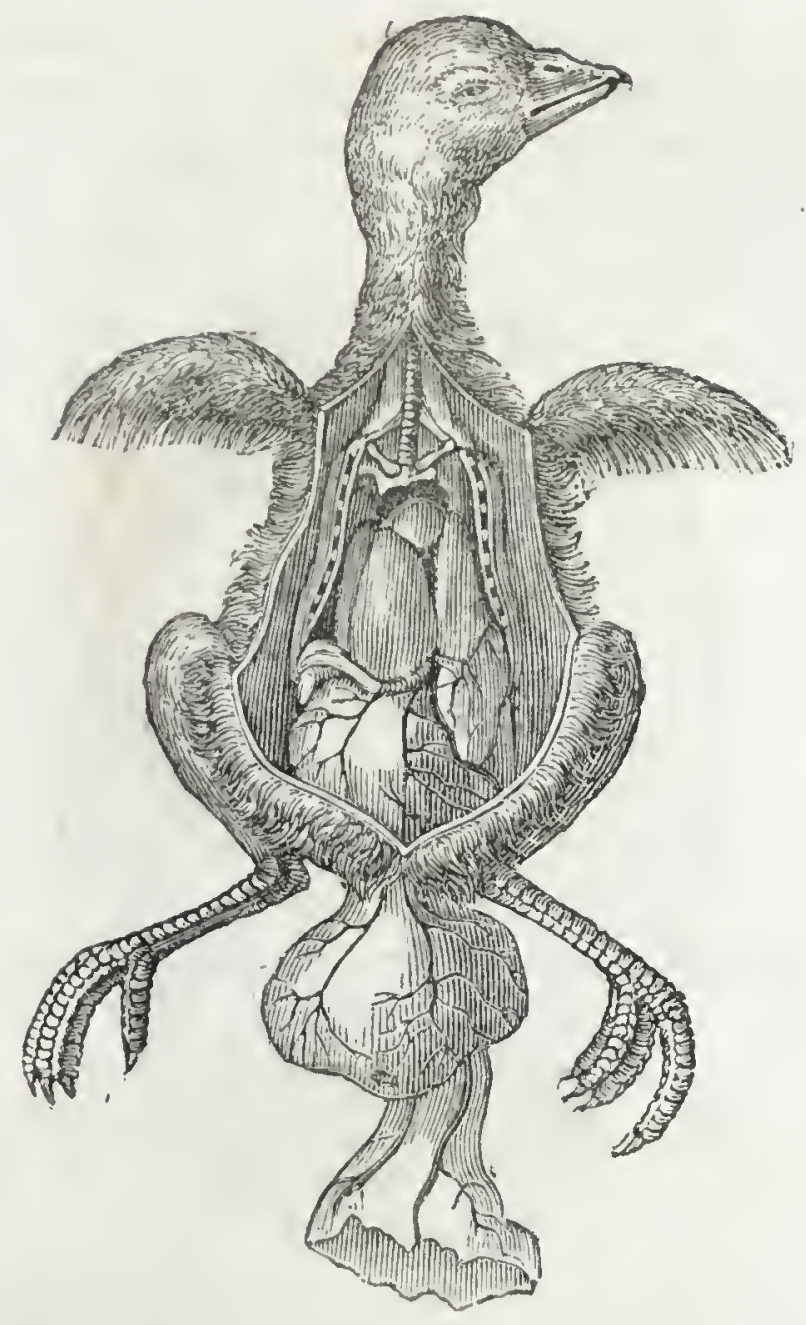

The Embryo Chick opened to show the absorption of the yolk into the body.

yolk, evidently for the purpose of absorbing it and conveying it to the veins, where it is assimilated to the blood and applied to the nutrition of the chick. Blumenbach persuaded himself of the actual passage of the yolk from the floating vessels of the inner surface of the bag into the blood-vessels which go to the chicken; at least, he could distinguish yellow streals in the red blood contained in the veins*.

On the ninetcenth day the embryo can utter sounds, and may be heard doing so through the shell. 
It breaks and escapes from the shell usually on the twenty-first day, but sometimes as early as the eighteenth, and at other times not till the twentyseventh.

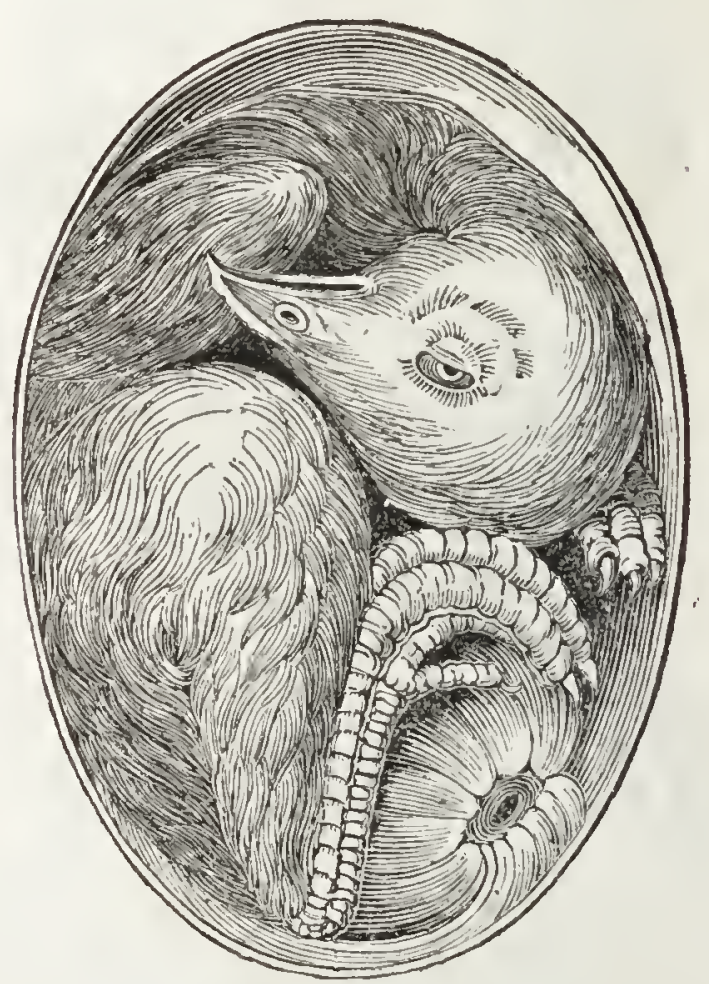

An Egg as it appears twenty days after incubation. The vesicle and amnion are removed, to show the position of the perfeet Chick.

The exit of the chick from the shell appears to us to be one of the most interesting processes of animated nature ever investigated by naturalists. We are indebted to Réaumur for a most minutely accurate account of this process*; and recently Mr. Yarrel has given a brief detail of his own observations upon several species of birds. It is the popular opinion, that the mother-bird breaks the shell of the egg to free the chick from imprisonment,-an opinion which must have originated from the circum-

* Oiseaux Domestiques, Mém. vi. 
stance, that pieces of the shell are often broken and driven off to some distance, while the membrane within remains unruptured, which it is supposed could not happen if the fracture were made on the inside by the chick. But it might on the same principle be argued, that a wine-glass covered with parchment could not be broken by the stroke of a hammer without rupturing the parchment; for the membrane of the egg is elastic and yielding, while the shell is not. That the chicken, however, and not the mother, performs this office, has been proved by direct observations, which may be readily verified. It is worthy of remark, that the fact was correctly stated so long ago as the thirteenth century, by Albertus Magnus, the great naturalist of the dark ages*.

It might be supposed that this task was much above the strength of the yet feeble chick, did we not reflect that the anxiety it must feel to escape must add greatly to its energy, which is farther aided both by its peculiar structure, and by the position it assumes. The bill is still soft, indeed, and to a careless observer would seem ill fitted for breaking the shell; but, superadded to the bill, " upon the curved part of the upper mandible," to use the words of Mr. Yarrel, "just above the point there will be seen a small horny scale, nearly circular, having at its centre a hard and sharp projecting point, and by the particular position of the liead, this sharp point is brought into constant contact with the inner surface of the shell." It is worthy of remark, that the only use of this liorny point seems to be to break through the shell, for when the chick escapes, and the beak hardens by exposure to the air, it soon falls off, and on the second or third day, only a light-coloured mark is observable on the spot which it had occupied. It may, indeed, be easily separated by the thumb-nail

* Apud Aldrovand, Ornith. iii. 184, ed. Francofurti. 
when the chick comes forth. In pigeons, and probably in other birds which do not run about and feed the instant they are hatched, the bill-scale does not fall off for more than a week. Mr. Yarrel thinks the hardness of the bill-scale may be proportioned to the thickness of the shell, from its being very prominent, hard, and sharp in a preserved chick of the Egyptian goose (Anser Gambensis).

The position of the chick in the egg appears no less unfavourable to its breaking through the shell than the softness of the bill ; for it is rolled up almost like a ball, the neck sloping towards the belly, with the head in the middle, and the bill thrust under the right wing, as in birds when asleep. The feet also are bent up under the belly, as chickens and pigeons sometimes are when trussed for the spit, the claws being so bent back that their convex part almost touches the head. The forepart of the chick, as

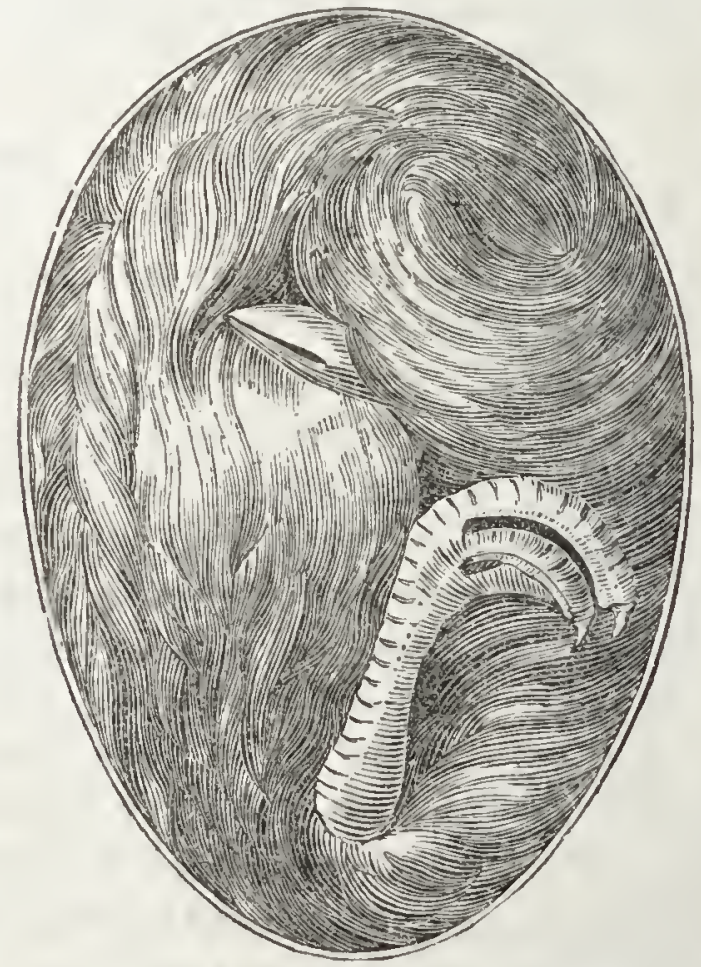

Position of the Chick in the Egg. 


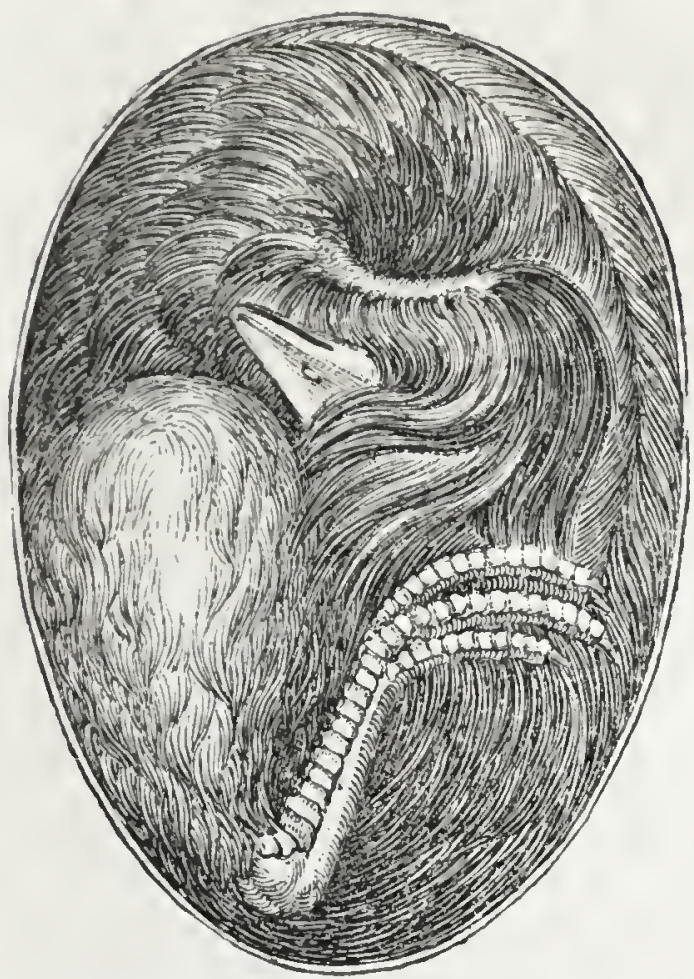

Position of the Chick in the Egg.

Réaumur observed, is towards the biggest end; and Dr. Prout adds, that it "is so situated in the egg, as, by its superior weight on one side, to assume such a position that the beak shall be uppermost *." It is surrounded by a thick strong membrane, which retains it in the attitude just described, and is apparently unfavourable to its requisite movements. But closer inspection shows that all these circumstances tend to facilitate rather than retard its operations on the shell, which it must break before it can escape.

The bill, indeed, though placed under the wing, as in the case of a sleeping bird, is thrust so far as to project beyond it towards the back, and the head, by moving backwards and forwards alternately, causes the bill to strike upon the shell, the action being partly guided by the wing and the body. It is to be * Phil. Trans. for 1822. 
remarked, that the head, compared with the bulk of the body, is very heavy; and it makes, together with the neck, a load which the chick, even for several days after its exclusion, can with difficulty support. But in the egg, let the position be what it may, the head is supported either by the body or by the wing, or by both together; and the greater the size of the head, the more efficient of course are the blows of the bill. 'The length of the neck causes it to be bent at this time, though after the first fourteen days it becomes nearly straight; but what seems to be done out of necessity to procure room, is here, as in many other operations of nature, the best thing that possibly could have been done out of choice.

By watching at the proper time, Réaumur frequently heard chicks hammering upon the shell with their beaks; and in the more advanced stages of the operation he could actually see them at work, through the translucent membrane. The result of the first strokes is a small crack, commonly situated nearer the larger than the smaller end of the egg. When this crack is perceptible, the egg is said to be chipped. The membrane is seldom ruptured in the first instance, even when the hard part of the shell over it is detached; but in one instance, while Réaumur was observing the operations of a chick by candle-light, it was hard at work pecking at the membrane divested of its shell. It did not strike, however, but seemed as if endeavouring to wear it out, and make it thinner by continued friction.

The continued blows extend the first cracks, and new pieces of shell are driven off almost all in the same circle, the blows running round nearly the whole circumference of a circle which never cuts the egg. obliquely, but always directly across; yet the bill all the while remains under the wing, and always in the same position. In order to accomplish this, 
it is indispensable for the chick to turn gradually round, till it has completed an entire revolution; though this circumstance camnot, in consequence of the opacity of the shell, be actially observed. The demonstration of the inference, however, is completed by the several places at which the point of the bill appears, whilst the head is liept constantly under the same wing; a position so strictly preserved, that it is persisted in even for some time after the separation of the shell into two portions, leaves the chick a door almost as large as the dimensions of his prison. The revolution which the chick thus makes on his own body is invariably from left to right, and it is probably performed by means of the feet; for the claws, on pressing the shell through the membrane that separates them from it, must find in that shell the resistance necessary to effect the required circular motion. This notion is corroborafed by the circumstance of the feet alone enabling the chick to effect its exit; for the wings and other members, with the exception of the neck and bill, are incapable of any action so long as the chick is in the shell. Réaumur, being curious to ascertain the mode of the circular movement of the chick, was not contented with mere probability, but had recourse to experiment.

"Is it," he asks, "contrary to probability that the strokes of the bill upon the shell exert a reaction on the body of the chick sufficient to alter its position, and turn it by little and little round the circle? A plain experiment seemed to me well adapted to determine this; founded on the principle, that if the notion was correct, the chick could not turn itself if the bill were so placed as to have nothing solid to press against, a condition easily produced, by taking from the bill that solid support against which it was supposed necessary for it to act, or protracting the 
fracture towards the right, so that the bill might have lothing to strike against.

"Accordingly, I protracted considerably the small fracture made in two different eggs, taking off pieces both of the shell and the membrane as far as I went, purposely to see what would happen to the chicks. Unfortunately for the theory, the consequence was, that each chick was sooner released from confinement than if it had had to effect its own exit. I had saved it part of the work, and it very well knew how to change its place, so as to be able to break the remaining part of the shell *."

The fracture may be observed to be broader in some eggs and narrower in others, and even of different. breadths in the same egg; while only a few pieces are broken off in some and a great number in others, the latter case exhibiting all the irregularities of a glass bottle broken by the repeated gentle blows of a hammer. The effect required to be produced is, the entire separation of the two portions, first of the hard shell, and then of the membrane, which is torn by repeatedly pecking it with the bill. All chicks do not succeed in producing this result in the same period of time, some being able to perform the task within an hour, others taking two or three hours, while half a day is most usually employed, and some require twenty-four hours. "I have seen chicks," says Réaumur, "continue at work for two days together. Some again work incessantly; others take rest at intervals according to their physical strength. I have observed some, in consequence of their impatience to see the light, begin to break the shell a great deal too soon; for they ought, before they make their exit, to have within them provision enough to serve for twenty-four hours without taking * Oiseaux Domestiques, Mém. tom. vi. 
food, and for this purpose the unconsumed portion of the yolk enters through the navel. The chick, indeed, which comes out of the shell before taking up all the yolk is certain to droop and die a few days after it is hatched. The help which I have occasionally tried to give to several of them towards their deliverance, has afforded me an opportunity of observing those which had begun to break their shells before this was accomplished; and I have opened many eggs much fractured, in each of which the chick had as yet much of the yolk not absorbed. Besides, some chicks have greater obstacles to overcome than others, since all shells are not of an equal thickness nor of an equal consistence; and I think it probable that the same inequality takes place in the lining membrane. The shells of the eggs of birds of various species are of a thickness proportional to the strength of the chick that is obliged to break through them. The canary-bird would never be able to break the shell it is enclosed in if that were as thick as the egg of a barn-door fowl; and the latter would crush all the eggs she might attempt to sit upon, if their shells were as thin as those of a canary-bird. The chick of a barn-door fowl, again, would in vain try to break its shell if it were as thick and hard as that of an ostrich; and even though an ostrich ready to be hatched is perhaps thrice as large as the common chick, it is not easy to conceive how the strokes of its bill can be strong enough to break a shell thicker than a china cup, and whose smoothness and gloss indicate that it is nearly as hard, sufficiently so indeed to form, as I have often seen, a solid drinkingcup. It is the practice in some countries to dip the eggs into warm water at the time they are expected to chip, on the supposition that the shell is thereby rendered more fragile and the labour of the chick 
lightened. But even boiling water does not render the shell more fragile; and though the water should soften it, upon drying in the air it would become as hard as at first." It is well remarked by 'Mr. Yarrel, that the shell is rendered more brittle by the process of hatching, during which the egg of the common fowl loses on an average eight grains a day, the moisture being partly evaporated and partly absorbed, and the lining membrane at the same time becoming partially separated $\dagger$.
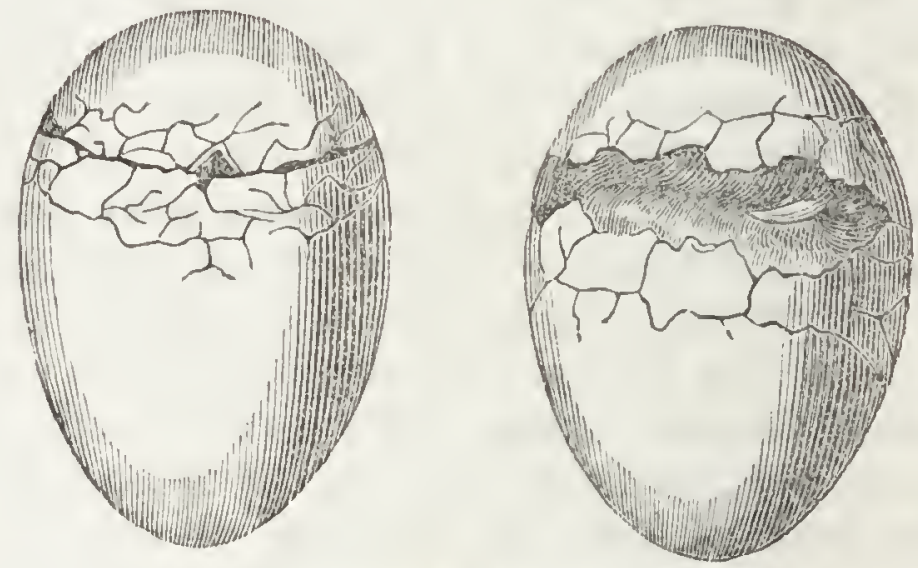

Eggs fractured by the included Chick.

Though the fracture of the shell usually extends round the whole circumference, yet the chick is sometimes contented with performing only about three-fourths of the task. When this has been done, the bill is not required to complete the separation, which is effected more easily and speedily by pushing with the whole mass of its body, using the feet as a lever. By thus continuing to push the body forwards, a movement which is frequently repeated, the chick gradually raises the upper portion of the shell, and at length tears all the fastenings; and if any part hold out, that becomes a sort of hinge which permits the lid, as we may call it, to be thrown on one

* Réaumur, as before. i Zool, Journ. ii, 436. 
side. When the upper portion is wholly detached, it is sometimes thrown to a considerable distance; but it often happens also that it is thrown into a very singular position, and is found placed within the other portion, as one cup may be set within another. This circumstance has been observed to arise from the chick, just escaped, having the upper portion of the shell immediately before him, and pushing it back with his feet into the under portion without any necessity or design. "A young duckling," says Réaumur, "which I observed just as it was striving to separate the two parts of the shell entirely, showed me that it had recourse, in order to this, to methods like those used by chickens and probably by all other birds for the same purpose. 'The duckling's shell was at most fractured in twothirds of its circumference, but the fracture being wide suffered me to see that the bill was under the right wing, while the little creature was lifting at the forepart of the shell on the side where it did not resist, because there all its fastenings were broken, and by these means it forced the shell to break on the side where it was yet entire."

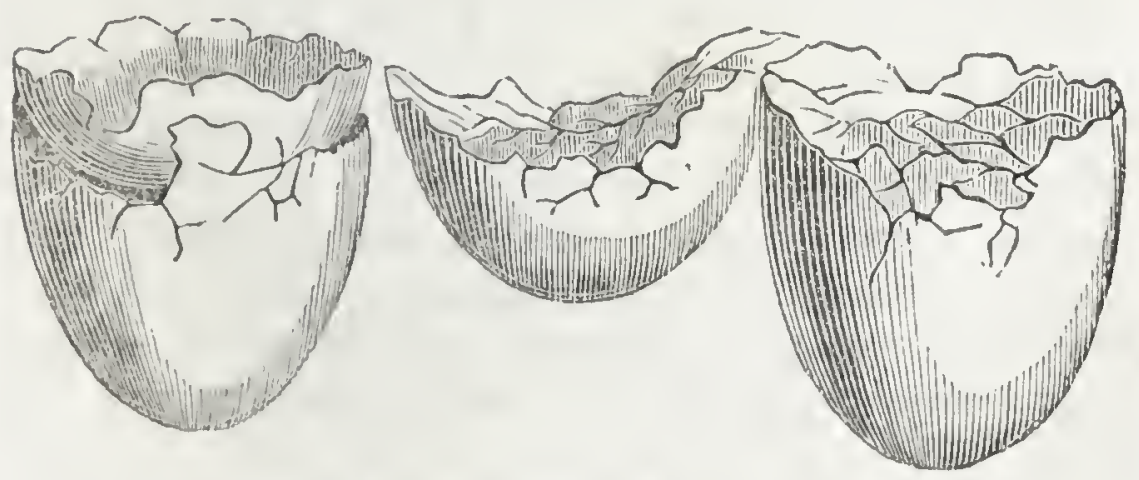

Positions of the Shell after the escape of the Chich.

"When the chick," Réaumu" continues, "has at length been able to turn up or heave off sufficiently the forepart of the shell to procure itself a door, it 
stretches out its feeble legs, which are yet insufficient to carry it. Being then entirely or almost out of the shell, it draws its head from under the wing where it had hitherto been thrust, stretches out its neck, and directs it forward, but is not strong enough for several minutes to raise it. Upon seeing for the first time a chick in this condition we are led to infer that its strength is exhausted, and that it is ready to expire; but in most cases it recruits rapidly, all its organs gather strength, and in a very short time it appears quite another creature. After having dragged itself on its legs for a little while, it becomes able to stand on them, to lift up its neck, to bend it in various directions, and finally, to hold up its head. 'The feathers are at this period only fine down; and as they are wet with the fluid matter of the egg, the chick appears almost naked. By the multitude of their branches these rlown feathers look like so many minute shrubs; yet when those branches are wet and sticking to each other, they take up very little room, but as they dry they become disentangled and separated. The branchlets, plumules, or beards of each feather are at first enclosed in a membranous tube, by which they are pressed and kept close together; but as soon as this dries it splits asunder, an effect which is also aided by the elastic springs of the beards themselves causing them to recede and spread about. When this is accomplished, each feather extends over a considerable space, and when they all become dry and straight, the chick appears completely clothed in a warm vestment of soft down*."

It would not be according to the usual course of nature unless the greater number of eggrs sat upon proved fertile ; but circumstances, many of them unintelligible to us, occur during hatching, which render * Oiseanx Domestiques, as befurc. 
the egres abortive : and there is scarcely an instance of a hatch of eggs that will not afford a greater number of chickens, if a little artificial assistance be afforded. Some of the chicks, for instance, are weak; while others, though not wanting in strength, still meet with more resistance than they can overcome from the shell or its membrane; and others again, though sufficiently strong, and enclosed in a shell and membrane of the usual thickness and consistence, are unable to effect an exit, even when an aperture is made for them, in consequence, it wonld appear, of some unknown cause depriving them of the power of making the circular revolution on their own bodies, which, remaining in the same position, stick to the shell.

In order to understand how a chick may be thus glued to its shell it will be necessary to recollect, that between its body and the lining membrane is the white of the egro, or glairy adhesive fluid, which, by drying, becomes a sort of cement, very apt to cause the feathers to adhere to the membrane with which they are in contact. The chick of an egro which has been subjected in artificial hatching to a temperature too high is in the most danger of such an accident; though it seldom happens before it has made a pretty large breach in the place first chipt, and has also rent the membrane, after which operations it remains a good while at rest. The air introduced through this rent soon changes into a hard tenacious glue the fluid white next the margin of the aperture, as well as to some distance inward; so that when the chick is desirous of returning to its task it can only peck at the same place, being held fast from moving its body by the gluc. Its attempts pull the feathers, and make it squeak; and from its efforts being more and more painful, the desire to move is abandoned. Under such circumstances the chick, if un- 
assisted, must die, and hence it may not be useless to point out the indications by which this state of things may be recognised. Whenever, then, a considerable fracture of both the shell and the membrane is observed to remain for five or six hours without enlargement, and at the same time the margin of the membrane is perceived to be hard and dry, with perhaps some feathers sticking to it, it will be indispensable to liberate the chick by breaking the shell very gently with a key or some such instrument, and by cutting the membrane with the points of a pair of scissors. The operation, though painful to the chick, does not prove mortal, for it is no sooner freed than it exhibits as much vigour as any other chick of its age.

In the case of a chick not having sufficient strength to break through the shell, the indication will be a slight chip appearing and continuing for several hours without either being extended or the membrane rent. Here it will be requisite to lend assistance, as in the former case; and if it come not too late, as soon as the chick is exposed to the air, it will pull out its head, stretch its neck, and endeavour to get out of the shell. 
Is rearing tender song birds taken from their mothers, as is frequently done, before they are fledged, experience proves that warmth is no less indispensable than food; exposure to cold during the night frequently killing the most healthy nestlings. 'The mother-birds, well aware of this, are equally assiduous in covering their chicks after they are hatched as they had previously been while sitting on the eggs. Among small birds (Sylvicola, VIE1LLot), accordingly, for several days after her brood has been hatched, the mother seldom quits the nest, the male providing the food necessary for her and the little ones, who as yet require but a very small portion. The wren, and other birds which build domed nests, have this additional protection to prevent the dissipation of their animal heat; and birds of prey, pigeons, and crows have but a small number of nestlings to shelter.

In the case again of poultry, when the newlyhatched birds can run about, the mothers have no little trouble in sheltering them from cold, and, even during the hottest weather, from rain, which proves very injurious in consequence of the cold produced by its evaporation. However much, also, we may admire the ingenuity of birds in some things, and their anxious affection for their young, yet they exhibit in other instance's great apparent stupidity; and maternal affection, so far from sliarpening their faculties, seems at first rather to blind them, and to cause them to 
injure and even to kill some of their chickens through awkwardness or inconsideration. A hen, for example, out of over anxiety to have her chickens near her, will not unfrequently set her foot upon some of them so as to crush or mortally injure them; and the same accirlent often happens by her sitting over them with her body to keep them warm. Again, in scratching to procure them food, she seems quite heedless where she strikes with lier foot; and we have observed in several instances that she kicked the chickens behind her, and laid them sprawling on the ground. But independently of such accidents as these, no hen, whatever may be her care, can prevent her brood from often passing through sudden changes of temperature. She neither can nor ought to sit on them constantly, as they must eat and rum about; and in cold or rainy weather, the damp ground must prove very injurious even when she has them under her warm wings. Hence it is that we frequently see a mother not able to rear above three or four, out of a dozen or more that she may have hatched.

It has been recorded that cocks have sometimes performed all these duties of the mother, when she has been accidentally killed, or has abandoned her brood. Aristotle tells us that he witnessed an instance of this kind*; and Pliny says, "We have heard that when a brood hen chanced to die, the cocks were seen to go about with the chickens one after another by turns, and to do every thing like to the very hen that hatched them, and all that while to forbear once to ćrow.$+ "$ Albertus Magnus witnessed a similar case; and Elian even mentions a cock which, on the death of the hen while hatching, sat on the eggss and brought up the chicks $\ddagger$. Willughby says, "We have beheld * Hist. Anim. ix. 49. + Holland's Transl. i. 299. Hist. iv. 29. Apnd Aldrovandi, ii. 107. 
more than once, not without pleasure and admiration, a capon bringing up a brood of chickens like a hen, clucking of them, feeding them, and brooding them under his wings, with as much care and tenderness as their dams are wont to do ${ }^{*}$ "' This leads us to the very curious subject of training capons to perform the office of a mother, which was practised as early as the sixteenth century.

In order to train a capon for this purpose we are instructed by Baptista Porta, in his curious book on Natural Magic, to make him so tame that he will take food out of the hand, then about even-tide to pluck the feathers off his breast, to irritate the bare skin by rubbing it with nettles, and then to put the chickens to him. 'They will naturally huddle under him, and by rubbing with their heads allay the itching caused by the nettles; and upon repeating this for two or three nights, he will gradually take an affection for the chickens and attend to them like a mother. The author thinks it may probably be on the principle of mutual distress producing mutual sympathy, that the querulous chirp of the chickens may make him, while in pain himself, desirous of allaying their misery. A capon, once accustomed to this office, will not abandon it, but, when one brood is grown up, another of newly-hatched chickens may be put to him, and he will be as kind to them and take as much care of them as of the first, and so in succession $\dagger$.

The feeling of tenderness for the young broods of other birds, in whatever way it may be supposed to originate, has been exemplified in several very striking instances, botl among birds and other animals. "In the month of May," says M. de Buffon, "a young hen-bird was brought to me, which was not

* Ray's Willughby, p. 156.

+ Magia Naturalis, ir. 26. 
able to feed without assistance. I caused her to be educated; and she was hardly fledged, when I received from another place a nest of three or four unfledged sky-larks. She took a strong liking to these new-comer's, which were scarcely younger than herself; she attended them night and day, cherished them beneath her wings, and fed them with her bill. Nothing could interrupt her tender offices. If the young ones were torn from her, she flew to them as soon as she was liberated, and would not think of effecting her own escape, which she might have done a hundred times. - Her affection grew upon her; she neglected food and drink; she now required the same support as her adopted offspring; and expired at last, consumed with maternal anxiety. None of the young ones survived her. They died one after another; so essential were her cares, which were equally tender and judicious.".

A more singular instance still is related by $\mathrm{Mr}$. Broderip. "On the 27th of April, 1820, I saw a cat giving suck to five young rats and a kitten; the rats were about one-third grown. It was diverting to observe the complacency with which the young creatures sucked in the liberal stream, which the teats of their foster-mother supplied; and curious to see the prey cherished by the milk of the destroyer. 'The cat paid the same maternal attentions to the young rats, in licking them and dressing their fur, as she did to her kitten, notwithstanding the great disparity of size. The man, who exhibited this phenomenon in the Strand, near Essex-street, said, that the cat had kittened fourteen days, and at that time had three littens at hel tcats, when he found this nest of young rats, which seemed a few days old, and turned them in at night to the cat for her prey; in the morning he found the kittens sharing the * Oiseaux, Art. L'Alouette. 
milk of their mother with the rats. Two of the kittens were afterwards destroyed, for fear of exhausting the cat, by so numerous a family. The man said that the cat was a good mouser; but admitted that he had tanght lier to abstain from white mice, which he had been in the habit of lieeping'.

"As the cat had kittens," Mr. Broderip adds, " on which to exercise her maternal tenderness, and which must have sucked sufficiently to prevent any thing like bodily inconvenience, it is hard to account for this perversion of instinct. Is it that, at such times, the all-powerful and uncontrollable $\sigma \tau o p \gamma \eta$ is exercised indiscriminately upon every young living creature which is thrown upon the mercy of the new mother for protection and nourishment, and is capable of enjoying her care? The cases of the hedge-sparrow or wagtail and the young cuckoo, of young ducks which are hatched by hens, and even substituted for their own broods on their loss or failure,-nay, the very assiduity with which a hen will sit upon a ball or two of whitening, would all seem to point this way*."

The similar account in White's Selborne, which the precerling is given by $\mathrm{Mr}$. Broderip to illustrate, is too striking to be omitted. "My friend," says White, "had a little helpless leveret bronght to him, which the servants fed with milk in a spoon, and about the same time his cat kittened, and the young were despatched and buried. The hare was soon lost and supposed to be gone the way of most fondlings, to be killed by some dog or cat. However, in about a fortnight, as the master was sitting in lis garden in the dusk of the evening, he observed his cat, with tail erect, trotting towards him, and calling with little short inward notes of complacency, such * Zool. Journ. ii. 21. 
as they use towards their kittens, and something gamboling after, which proved to be the leveret, that the cat had supported with her milk, and continued to support with great affection."

Sir William Jardine adds, "About two years since at a cotter's house in Annandale, Dumfries-shire, a litter of pigs by some accident lost their mother; at the same time, a pointer bitch happening to pup, and the puppies suffering the lot common to most such, their place was supplied by the pigs, which were well and affectionately nursed by their foster parent*". A similar anecdote has been recorded of a cat suckling puppies $†$.

It is not improbable that some such incidents as these gave rise to the relations of exposed children being suckled by wild beasts, such as the celebrated Roman story of the twin brothers, Romulus and Remus, alleged to have been suckled by a wolf.

The cave of Mars was dressed with mossy greens;

There, by the wolf, was laid the martial twins :

Intrepid on her swelling dugs they hung,

The fuster dam loll'd out her fawning tongue-

They suck'd secure, while bending back her head

She lick'd their tender limbs t.

To return to the accounts of chickens nursed by cocks. "I have had repeated opportunities," says Réaumur, "of convincing myself with my own eyes that capons perform the office of a mother very well.

* White's Selborne, Sir W. Jardine's edit. p. 231.

+ See Menageries, i. 215.

+ Dryden's Virgil. The original is :

Viridi foetam Mavortis in antro

Procubuisse lupam; geminos huic ubera circum Ludere pendentes pueros, et lambere matrem Impavidos; illam tereti cervice reflexam Mulcere alternos.- Eneid, viii. 
$\Lambda$ lady related to me has a vast number of chickens, brought up every year with no other murses than capons; and I have seen frequently at her Château of Vanjour, near Livry, above two hundred chickens that had only three or fonr capons for their leaders; it being one of the advantages of this meihod, that a capon may be trusted with two or three times as many chickens as a hen can properly manage. Another advantage is, that a capon may be set to nurse at any given time, as he is always ready to undertake the task, and he even seems to become proud of his family in proportion as the number increases; whereas hens will persecute and drive away the chickens which are offered to them after a certain age, and which are of course different in size from those they have themselves hatched. Another advantage consists in saving the hens from the trouble of nursing, as in that case thcy will either continue longer, or begin much sooner to lay; while the chance will be avoided of any disaster happening to the chickens from being abandoned before they can provide for themselves, by a mother in whom, as often happens, laying is prematurely renewed *."

The education of the capon for the maternal office has been considered a matter of great difficulty. Besides Baptista Porta's method of stinging the capon with nettles, others advise making him tipsy with wine or brandy when the chickens are put to him, in order, as they profess, to make him fancy himself a hen, when he sees them crowding round him. Réaumur, upon trying this, found that in a number of instances, the capon, instead of attending to the chickens, trod upon and crushed several of them to death, and gave others a drubbing with

* Oiscaux Domestiques, Mém. vii. 
his beak. Having been convinced that such empirical practices were useless, he put three capons under the care of the woman who had the charge of the poultry-yard at the Châtean de Vaujour; and as she proceeded on a regular and rational plan of tuition, put in force not for a single night or day, but continued for several days in succession, they came out of her school very well instructed in the space of ten or twelve days. Her method was, neither to pluck their feathers, to sting them with nettles, nor to make them drunk. She kept them alone for a day or two in pretty deep and rather narrow buckets darkened by a covering of boards, taking them out two or three times a day to feed. After making the capon in this manner wearied of solitude, she placed with him for companions two or three chickens somewhat anvanced in growth, and gave them all their food in common. If he ill used them, they were removed for a day or more, and then others were put to him. By such means, varied as circumstances indicate, the capon will contract a habit of living amicably with two or three chickens, and the number being increased by degrees, he will at last begin to take pride in his flock, so that it may be enlarged to any extent. Upon receiving his liberty in these circumstances, he will sit upon the chicks as a lien does, whenever they require to be protected from cold, and will lead them to places where they may find food, clucking like a hen to call them together when they straggle. He will likewise redouble his clucking when he finds such dainties as a piece of bread or an earthworm, which he will divide in to several smatl portions to share it amongst them alt, and will seem delighted to see them eat heartily of what he deprives himself of for their sake. After the few first days of training a capon, during which he may probably injure or lill two or three chickens, 
the task becomes casy ; and when once he is taught he will retain the habit to the end of his life, nor ever beeome tired of the task; for even when unemployed for sereral months during winter, he will take to it adgain in spring nearly as well as before.

Though capons probably make the best nurses, it appears to be equally possible to instruct eoeks in the art of nursing. "I thought," says Réaunur, "I had sent to school three capons, but one of them proved to be a cock, though he came home as well instructed as his two eompanions *."

But in the case of artificial liatching by means of ovens, it must frequently be found in possible to procure a sufficient number of nurses either of hens or capons; and in that case, in order to rear the ehickens suceessfully, artificial methods must be eontinued. Were all the assiduities indeed of the hen required, it would be next to impossible to find an artifieial substitute; but as her ehief objeet is to proeure food and seeure warmth, these with a little attention may be supplied as well or even better by art than by the most assiduous mother. Réanmur, in the course of his interesting experiments, tried several plans for the substitution of what he aptly denominates an artifieial mother. By bringing the ehickens up in a hot-bed, indeed, it will be easy to make them enjoy a perpetual summer, exempt from exposure to rain or cold nights. They may even be advantageously reared for the first fortnight or three weeks in the oven where they have been hatched, taking them out about five or six times a day for food and water. This, however, is a more troublesome plan than is necessary. Réaumur's statement of some of the difficulties whieh he met with is so illustrative of the subject that we shall quote the passage.

* Oiseaux Domestiqucs. 
"My apparatus," he says, " did not at first seem sufficiently perfect; for, though the chickens were kept in warm air, they had no equivalent for the gentle pressure of the belly of the mother upon their backs when she sits over them. Their back is, in fact, necessarily more warmed than the other parts of the body while huddling under their mother's wings; whereas their belly often rests on the cold moist earth, the reverse of what took place in the apparatus, where their feet were the best warmed. The chickens themselves indicated that they were more in want of having their backs warmed than any other part of their body; for, after all of them had repaired to the warmest end of the apparatus, instead of squatting as they naturally do when they rest, they remained motionless, standing bolt upright upon their legs, with their backs turned towards the sides or end of the apartment in order to procure the necessary warmth. I therefore judged that they wanted an apparatus that might, by resting on them, determine them to take the same attitude as they naturally assume under the hens, and I contrived an inanimate mother that might supply, in this respect, the want of a living one *."

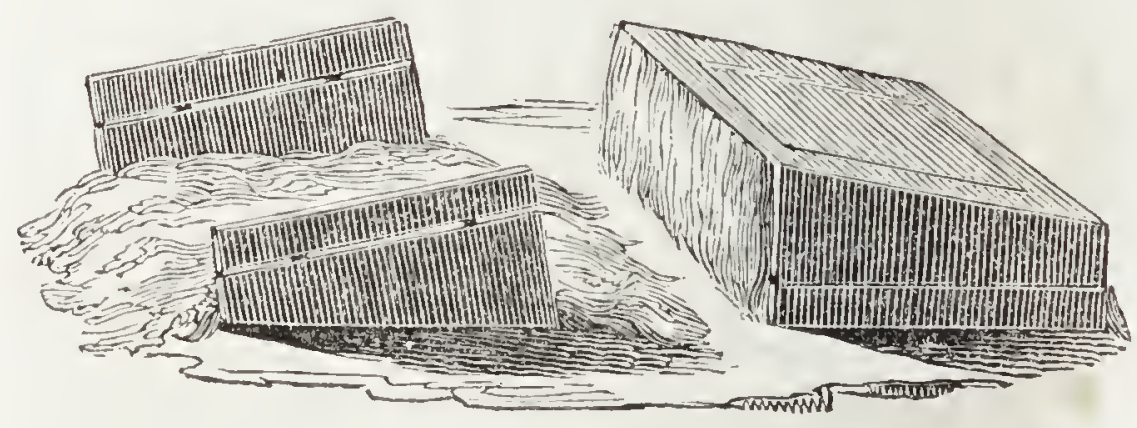

Artificial Mothers.

The artificial mother contrived upon these prin* Oiseaux Domestiques. 
ciples, consists of a box lined with sheep-skin, with the wool on it, the bottom being of a square form, and the upper part sloped like a writing-desk. 'This box is placed at the end of a crib or cage, shut with a grating of willow, net, or wire, and closed above with a hinged lid, the whole being so formed that the chickens can walk round the sides. The slope of the cover permits the chickens to arrange themselves according to their sizes; but as it is their practice, as well as that of all other young birds, to press very closely together, and even to climb upon one another, the small and the weak being thereby in danger of being crushed or smothered, Réaumur constructed his artificial mother open at both ends, or, at most, with only a loose netting hanging over it. 'Through this the weakest chicken can escape when it feels itself too much squeezed, and then, by going romd to the other opening, it may find a less dangerous neighbourhood. The ingenious author even made improvements upon this contrivance, one of which consisted in keeping the cover sloped so low as to prevent the chickens from climbing on each other, and raising it as they increased in growth. Another was, the dividing the

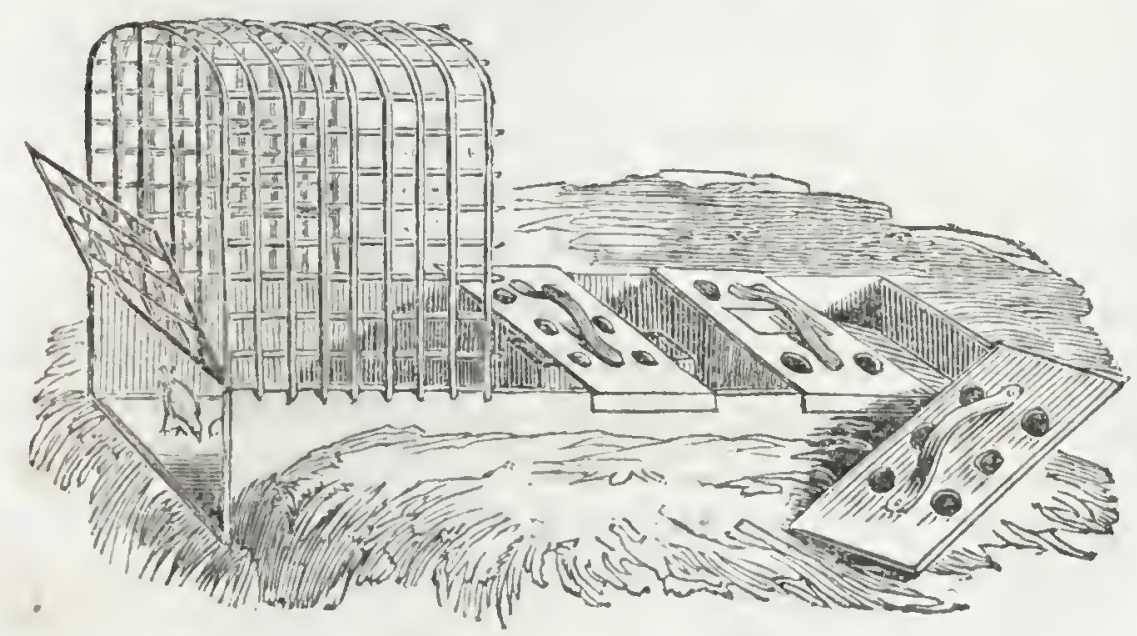

Improved Artificial Mother.

R 3 
large cribs into two by means of a transverse partition, so as to separate the chickens of different sizes.

"They soon showed me," says Réaumur, "how sensible they were of the advantage of my artificial mother, by their delight in remaining under it and pressing it very close. When they had taken their little meals they jumped and capered about, and when they began to be tired, they repaired to this mother, going so deep into it that they were compelled to squat, so that when the roof was turned up, I perceived the impression of the backs of several chickens upon the fur-lining. There is, indeed, no natural mother that can be so good for the chickens as the artificial one, and they are not long in discovering this, instinct being a quick and sure director. Chickens, direct from the hatching oven, from twelve to twenty-four hours aftcr their escape from the shell, will begin to pick up and swallow small grains or crumbs of bread; and, after having eaten and walked about a little, they soon find their way to the fleecy lodge, where they can rest and warm themselves, remaining till hunger puts them again in motion. They all betake themselves to the artificial mother at night, and leave it exactly at day-break, or when a lamp is brought into the place, producing an artificial day-break, with which, it is worthy of remark, old hens are not affected but remain immoveable on their roosts *."

A still more elegant and ingenious artificial mother consists of a stove with an apartment round it for the chickens, and an net-work over it, to prevent their escape or their getting too near the stove. This Réaunur found to be an excellent plan for keeping

* Oiseaux Domestiques, as before. 
the chickens in good health, while he took advantage of the same heat to hatch fresh broods by hanging egris in baskets over the stove.

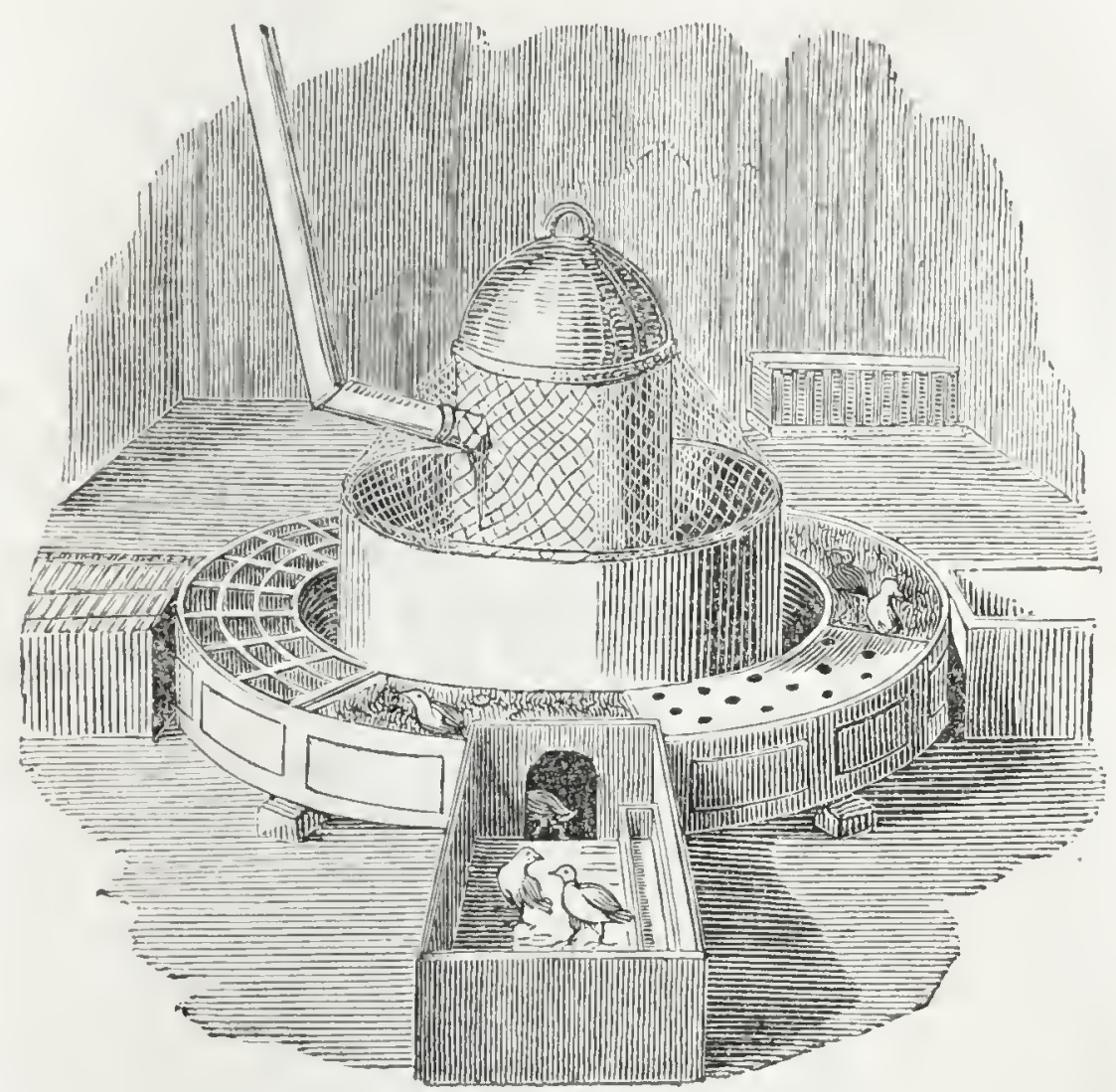

Réaumur's Stove Hatching-house.

These methods of constructing artificial mothers are applicable to all birds that do not require to be fed by putting food into their bills, or do not go into the water, such as partridges, pheasants, turkeys, and peacocks. But for ducklings and goslings, which require water to swim in, provision must be made accordingly; and Réaumur, proceeding on the principle of following nature, constructed, in the crib comnected with an artificial mother, a small pond 
for his water-fowls, with a gentle slope for an approach, surrounded with green turf, of which these birds are fonder than young chickens.

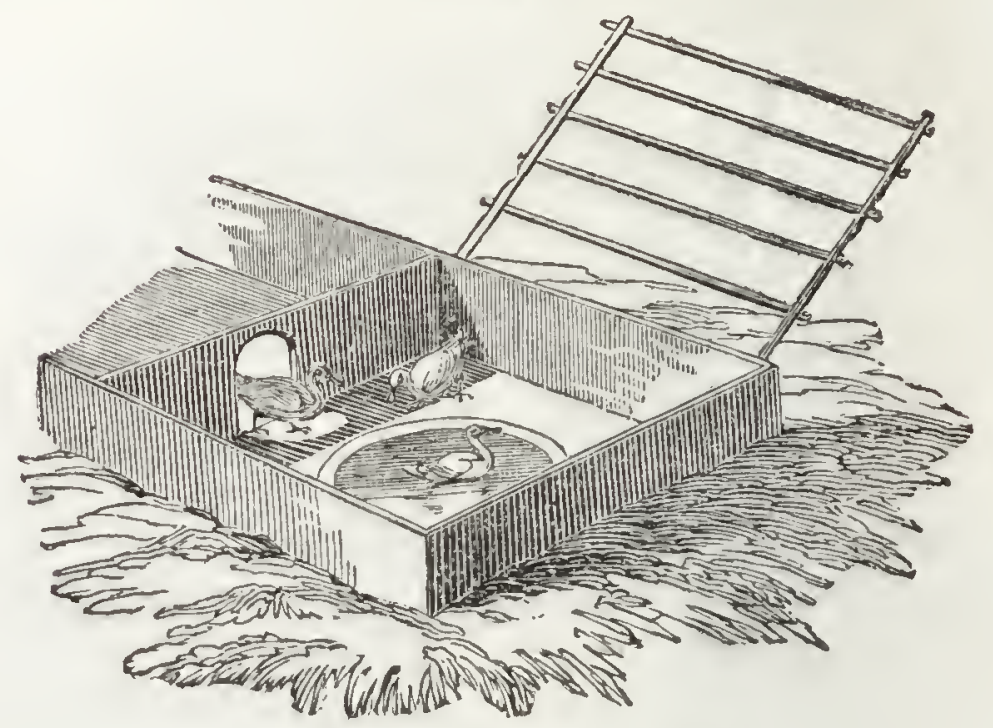

Artificial Mother for Water-fowls 


\section{Chapter XT.}

FEEDING OF THL YOUNG.

Bıros difler essentially from quadrupeds in their mode of providing food for their young. Among the latter, Providence has furnished the mother with a supply of food for her off'spring within herself till the teeth arrive at sufficient growth for manducation; and hence even animals of prey do not, for several weels, bring food to their cubs, but nourish them solely with milk. Birds, on the other hand, have to provide food for their young from the second day after they are hatched. During the first day they have, in general, sufficient nutriment in the last portions of the yolk of the egg, which they have absorbed, as we have already seen, through the umbilical vessels.

We may follow John Hunter in dividing animal life into three stages or periods, the first comprehending the foetal or embryo state; the second the perior inmediately after birth, when the parent must, in most cases, supply food; and the third dating from the time when the animal begins to act for itself without parental care. 'The first and third of these stages are perhaps common to all animals; but some appear to pass immediately from the first to the third stage. 'The nourishment which is provided in the second stage varies to infinity. In most insects it is effected by the mother instinctively depositing her eg' or cocoon upon or near something that will form appropriate food for the young when hatched. Most birds again collect food for their 
young; though, in the instance of pigeons and some others, there exists a provision very similar to that of milk in quadrupeds.

" I have," says John Hunter, " in my inquiries concerning the various modes in which young animals are nourished, discovered that all the dove kind are endowed with a similar power. The young pigeon, like the young quadruped, till it is capable of digesting the common food of its kind, is fed with a substance secreted for that purpose by the parent animal; not as in the mammalia, by the female alone, but also by the male, which perhaps furnishes this nutriment in a degree still more abundant. It is a common property of birds, that both male and female are equally employed in hatching and in feeding their young in the second stage; but this particular mode of nourishment, by means of a substance secreted in their own bodies, is peculiar to certain kinds, and is carried on in the crop.

"Besides the dove-kind, I have some reason to suppose parrots to be endowed with the same faculty, as they have the power of throwing up the contents of the crop and feeding one another. I have seen the cock paroquet regularly feed the hen, by first filling his own crop, and then supplying her from his beak. Parrots, macaws, cockatoos, \&c., when they are very fond of the person who feeds them, may likewise be observed to have the action of throwing up the food and often do it. 'The cock pigeon when he caresses the hen, performs the same kind of action as when he feeds his young; but $I$ do not know if at this time he throws up any thing from the crop.

"During incubation, the coats of the crop in the pigreon are gradually enlarged and thickened, like what happens to the udder of females of the class mammalia, in the term of uterine gestation. On 
comparing the state of the crop when the bird is not sitting with its appearance during incubation, the difference is very remarkable. In the first case it is thin and membranous; but by the time the young are about to be hatched, the whole, except what lies on the trachea (wind-pipe) becomes thickened and takes on a glandular appearance, having its internal surface very irregulal. It is likewise evidently more vascular than in its former state, that it may convey a quantity of blood sufficient for the secretion of this substance, which is to nourish the young brood for some days after they are hatched.

"Whatever may be the consistence of this sub-
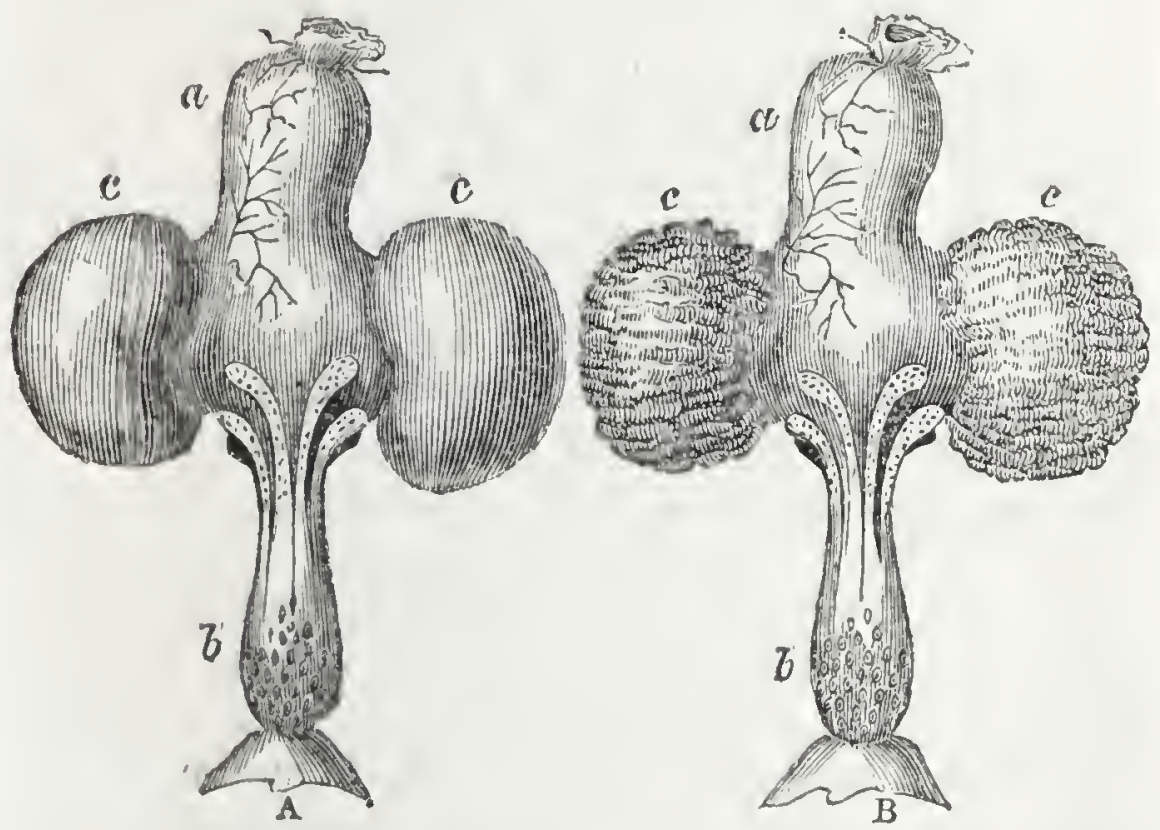

A. Crop of a Pigeon when it had no young.

('l'he figures $A$ and $B$ represent the crops turned inside outwards and distended with spirits.)

B. Crop of a male ligeon while the female was breeding.

a. Inner surface of the upper esophagus.

b. Ditto lower csophagus, leading from the crop to the gizzard.

c. c. Inner surface of the two bags of the crop.

The difference consists in the glandular structure on the inner surface of the crop, which is not seen except in the breeding seasnu. 
stance, when just secreted it most probably very soon coagulates into a granulated white curd; for in such a form, I have always found it in the crop, and if an old pigeon is killed just as the young ones are hatching, the crop will be found as above described, and in its cavity pieces of white curd mixed with some of the common food of the pigeon, such as barley, beans, acc. If we allow either of the parents to feed the young, its crop, when examined, will be discovered to contain the same curdled substance, which passes thence into the stomach, where it is to be digested.

"The young pigeon is fed for some time with this substance only, and about the third day, some of the common food is found mingled with it; and as the pigeon grows older, the proportion of common food is increased; so that by the time it is seven, eight, or nine lays old, the secretion of the curd ceases in the old ones, and of course no more will be found in the crop of the young. It is a curious fact, that the parent pigeon has at first the power to throw up this curd without any mixture of common food, although afterwards both are thrown up according to the proportion required for the young ones. I have called this substance curd, not as being literally so, but as resembling that more than any thing 1 know : it may, however, have a greater resemblance to curd, than we are perhaps aware of ; for neither this secretion, nor curd from which the whey has been pressed, seem to contain any sugar, and do not run into the acetous fermentation. 'The property of coagulating is confined to the substance itself, as it produces no such effect when mixed with milk. This secretion in the pigeon, like all other animal substances, becomes putrid by standing, though not so readily as either blood or meat, it 
resisting putrefaction for a considerable time; neither will curd, much pressed, beeome putrid so soon as either blood or meat ":"

We have been more particular in giving these statements of an admirable observer at length, because even in works of high eharacter, most vague and erroneous accounts of the facts are promulgated. We are told, for example, by M. Vieillot, that "the male and female are equally attentive to the young, and both feed them with aliment half digested, like broth (alimens à demi-digérés comme de la boullie); but by degrees they give them more solid food; grain, namely, which they have swallowed more hastily, and which they disgorge after it is somewhat softered, according to the age of the young pigeons $\uparrow "$ We find the same statement, word for work, in Temminck's General History of Pigeons + ; Griffiths says "the parents disgorge the food which they have amassed and placed in reserve in their crop \$;" and Selby says " the young remain in the nest till they are able to fly, and are fed by the parent birds who disgorge into their mouths the food that has undergone a maceration, or semidigestive process in that part of the cesophagus, usually ealled the crop or craw \|."

We have not been able to trace the origin of this error in physiology, which seems to be so generally diffused in books of natural history. Colonel Montagu appears to be the only original observer who confirms the account given by Hunter. "Tire rook," he says, "has a small pouch under the tongue, in which it earries food to its young. It is

* On the Animal Economy, p. 194.

+ Dict. l'Histoire Nat. xxvi. 329.

\pm Vol.i. p. 160.

\$ Curier's Arimal Kingdom, Birds, viii, 272.

|l Illustrations, p. 287. 
probable the use of the craw may be extended further than is generally imagined; for, besides the common preparation of the food to assist its digestion in the stomach, there are some species that actually secrete a lacteal substance in the breeding season, which, mixing with the half-digested food, is ejected to feed and nourish the young. The mainmæ from which this milky liquor is produced, are situated on each side of the upjer part of the breast, immediately under the craw. In the female turtledove we have met with these glands tumid with milky secretion, and we believe it common to both sexes of the dove genus. The cormorant or pelican genus possess no craw; but, to supply its place, they have a loose skin at the base of the under mandibles, capable of great distention, in which they carry fish to their young ${ }^{*}$."

The latter, there can be no doubt, is the fact with regard to the manner in which the pelican feeds its young; but it was universally believed in former ages that this bird nourished its young with its own blood, - a legend vulgarly credited even in our own times, for M. Larnini says it is a common practice with the people at Barcelona to go every Sunday to the cloisters in the cathedral, where there is a menagerie kept for pelicans, in the expectation of seeing them distribute their blood to their youngt. This story, it would appear, was also related of the vulture by the Egyptians, who thence made that bird an emblem of maternal tenderness ${ }_{\ddagger}^{\star}$

It does not appear to be ascertained with whom the fable respecting the pelican originated, but our readers may like to see the statements of some of the early authors. We shall content ourselves with

* Ornith. Dict. Pref, first edit.

$\uparrow$ Buffon, Oiseaux, 1x. 5.

+ Horus Apollo, Hieroglyph. 
giving two. Albertus Magnus says, "The pelican derives its name (pelle cana) from the white colour of its feathers. It is said to be indigenous to the banks of the Nile. Two species are described: one the water-pelican, which feeds on fishes; and the other the land-pelican, which preys on serpents and vermin. It is said, also, to be fond of the milk of crocodiles, which is left on the mud of marshes; on which accomnt, also, the pelican follows the crocodile. Some writers assert, that this bird destroys such of its own young as offend it, but after lamenting them, for a time, again brings them to life by means of blood drawn from its own breast by a wound, From this wound, and the loss of blood, the bird becomes so weak as to be unable to leave its nest, and the young ones are therefore compelled to provide food both for themselves and their dam. And if there should be any of them which, either through inertness or want of filial affection, refuse to procure fool for her, as soon as she acquires vigour she drives them away, but permits those who have been attentive to her to follow her wherever she goes." He adds with great simplicity, "but these things are rather to be found in history, than proved by philosophical experience*".

We find the same legend in a passage of the curious old writer Bartholomaus, which Berthlet thus renders:-" Plinius saith in this manner: 'The pelican loveth to mocke her children; for when the children been laught [arown] and begin to wax hoar, they smite the father and the mother in the face, wherefore the mother smiteth them again and fleeth them [drives them away]. And the third day she striketh herself on the side that the blood runneth out, and sheddeth that lot blood upon the bodies of her children. And by virtne of the blood the birds that were before dead quicken again." * Alberlus Magnus, De Animal, lib. 23. 
The learned author of the 'Physicæ Curiosæ,' however, could not find any such passage as this in Pliny, and we also have searched for it in vain. Bartholomæus goes on to say that "Master Jacobus de Vitriaco, in his hook on the Wonders of the Eastern World, telleth another cause of the death of the pelican's birds. He saith, that in Egypt is a bird hight [named] Pelly canus, a bird with great wings and most lean; for all that he swalloweth passeth forth anon behind: for he hath a right flipper gut. And, therefore, he may not hold meat till it be incorporate. And the serpent hateth kindly [sincerely] this bird. Wherefore when the mother passeth out of the nest to get meat, the serpent climbeth on the tree and stingeth or infecteth the birds. And when the mother cometh again, she maketh sorrow three days for her birds, as it is said. Then (he saith) she smiteth herself in the breast and springeth blood upon them and reareth them fro death to life, and then for greater bleeding the mother wareth feeble and the birds been compelled to pass out of the nest to get themselves meat. And some of them for kind love feed the mother that is feeble, and some been unkind and care not for the mother, and the mother taketh good heed thereto, and when she cometh to her strength, she nourisheth and loveth those birds that fed her in her need, and putteth away her other birds as unworthy and unkind, and suffereth them not to dwell or live with her*."

The origin of the fable is plausibly explained by M. Perranet, who says "there is nothing in the structure of the pelican but enters into the general plan of the organization of birds; all of them have a craw in which their food is lodged; in the pelican it lies without and under the bill, instead of being concealed within, and placed at the bottom of the asophagus. But this exterior craw has not the * Berthlet, Barthol, de Prop. Rer. fol, Lond. 1498. 
digestive heat of that of other birds, and in this bag the pelican carries the fish entire to its young. 'To disgorge them it presses the pouch against its breast; and this very natural act may have given rise to the fable so generally related, that the pelican opens its breast to nourish its off'spring with its blood *."

The fact of the pelican feeding its young with fish and not with its own blood, was settled by Labat, who made the following experiment, apparently to satisfy himself on the point. "I took," he says, "two young ones, which I fastened to a stake, and I had the pleasure, for some days, of seeing the mother, which fed them, and remained the whole of the day with them, passing the night on a tree above their heads: all the three were grown so familiar, that they allowed me to touch them, and the young ones took very graciously the little fish which I offered them, and which they put first into their ponch. I believe that I should have brought them away, if their dirtiness had not hindered me; they are filthier than geese or ducks; and we may say that their life is divided into three acts, seeking food, sleeping, and ejecting every moment heaps of excrements as large as one's hand †.'

It may be remarked that the early translators of the ancient naturalists have confounded the pelican with the spoonbill (Platalea leucorodia, Linn.), which indeed is the bird called pelican $(\pi \epsilon \lambda \epsilon \kappa a \nu)$ by Aristotle, as he tells us that it devours the large smooth river shells, and when it has partly macerated the contents, brings them up now opened, and then picks out and eats the contentsł. Pliny again, copying Cicero $\S$, says, "Their manner is to fly at those fowl that use to dive under the water for fish;

* Qunted by Buffon.

+ Nouv. Voy. aux Iles de l'Amerique, viii. 296. $\ddagger$ Hist. Animal, ix。 10 .

\& De Nat. Deor. ii. 124: 
and so long will they peek and bite them by the heads, until they let go their hold of the fish they have gottell, and so they wring it perforce from them. 'This bird, when his belly is full of shell-fishes, that he hath greedily devoured, and hath by the natural heat of his craw and gorge in some solt concocted them, casteth all up again; and at leisure picketh out the meat and eateth it again, leaving the shells behind*." As Elian and Appiant give a similar account of herons, gulls, and other water-fowl, it is probable the observation has been hastily applied to the pelican, whose craw or bag does not seem to possess any digestive power. Even the stork, which has been compared in this respect with ruminating animals, does not appear to possess much, if any, power of digestion in the craw, as has been shown by Pever + and Schelhammer $\$$.

The quantities of food brought for their young by the parents of birds which feed upon fish, has attracted the attention of every naturalist who has observed their nests. " So much fish," says Audubon, " is at times carried to the nest of the fish-hawk (Pandion Halicetus, SAvigNy), that a quantity of it falls to the ground, and is left there to putrefy around the foot of the tree\|l;" and of the white-headed eagle, he says, the young " are fed most abundantly while under the care of the parents, which procure for them ample supplies of fish, either accidentally cast ashore, or taken from the fish-hawk, together with rabbits, squirrels, young lambs, pigs, opossums, or racoons 9 ."

The various species of eagles are all recorded to be equally assiduous in supplying extraordinary quan-

* Holland, x. 40.

$\uparrow$ In Aucupio, Phys. Cur.p. 1220.

† Ephem. Nat. Cur. ii. 2, 97. \$ Collect. Acad. Etrang. iv. 109. |l Ornith. Biogr. p. 419.

I Ibid. p. 162. 
tities of food for their young, frequently carrying off for that purpose animals of considerable size, and even children. The latter circumstance appears to be well authenticated by a variety of independent testimony. Amongst other instances, Sir Robert Sibbald gives the following, which occurred in the Orkneys.

"An eagle seized a child a year old, which its mother had left, wrapped up in some clothes, at a place called Houton-Head, while she went for a few moments to gather sticks for firewood, and carried it a distance of four miles to Hoia; which circumstance being known from the cries of the mother, four men went there in a boat; and, knowing where the nest was, found the child unhurt and untouched *." This story, which all the compilers attribute to Ray, though he does not even allude to it, seems to have furnished the groundwork of the intensely-affecting tale of ' Hammah Lamond's Bairnt.' Anderson, also, in his 'History of Iceland,' says, that there have been instances of children, four or five years of age, being carried ofl' by eagles.

It is highly probable, we think, that some incident of this kind gave origin to the classic fable of Ganymede, said by Homer and Ovid + to have been carried off' by Jupiter, under the form of an eagle, to replace Hebe as cup-bearer to the Olympian gods. That the story was founded upon some real occurrence, may be inferred from the spot being referred to by Strabo $\S$, and from Herodian's allusion to it, though he says "Ganymede was torn in pieces by lis brother, and disappeared, which gave occasion to the report of Jupiter's carrying him into heaven \|;" while Lac-

\footnotetext{
* Prodromus, Nat. Hist. Scotix, vol. iii. part 2, p. 14. † Blackwood's Magaziuc.

+ Metam. x. $\$$ Apud Aldrovand. Ornith. i. 42. If Hist, Vit, Commod.i.
} 
tantius, refining upon this notion, thinks the youth was either captured by a legion, whose insignia was an eagle, or carried off in a ship luaving an eagle carved on the prow*. Cicero justly condemns the morality of the legend, which, however, he gives very inaccurately + from memory.

Gesher, on the authority of Fabricius ab Aquapendente, says, that some peasants between Meissen and Brisa, in Germany, losing every day some of their cattle, which they sought for in the forests in vain, observed by chance a very large nest, in which were found several slins of calves and sheep. 'This nest, which is described as being as large as the body of a cart, rested on three oaks. It is very doubtful, however, whether any species of eagle, with all its power of talon and of wing, could carry off an animal so large as a calf, which must be more weighty than itself. Hares, rabbits, and lambs, may indeed be easily managed; and when larger animals are encountered they may be carried off piecemeal, as is probably done with deer, which, Pennant says, are frequently in Scotland attacked by the erme (Haliatus albicilla, SAvignv). It seizes the deer between the horms, and incessantly beating it about the eyes with its wings, soon makes prey of the harassed animal +.

Owls, it would appear, are equally provident of prey for their young. Bingley tells us that, on examining a nest of the hawk-owl (Otus brachyotus, Fleming), "that had in it two young ones, several pieces of rabbits, leverets, and other small animals were found. 'The hen and one of the young ones were taken away; the other was left to entice the cock, which was absent when the nest was discovered. On the following morning there were

* De Falsa Religione, i. † Tusc. Quæst. i.

t. Brit. Zool. vol. i. No. 43. 
found in the nest three young rabbits that had been brought to this young one by the cock during the night*."

M. Cronstedt, the mineralogist, "resided several years at a farm in Sudermania, near a steep monntain, on the summit of which two eagle-owls had their nest. One day in the month of July, a young owl, having quitted the nest, was seized by some of his servants. 'This bird, after it was caught, was shut up in a large hen-coop; and the next morning M. Cronstedt found a young partridge lying dead before the door of the coop. He immediately concluded that this provision had been brought thither by the parent birds; which, he supposed, had been making search in the night-time for their lost young one, and had been led to the place of its confinement by its cry. 'This proved to have been the case by the same mark of attention being repeated for fourteen successive nights. The game which the old ones carried to it consisted principally of young partridges, for the most part newly-killed, but sometimes a little spoiled. One day a moor-fowl was brought, so fresh that it was still warm under the wingss. A putrid lamb was found at another time. M. Cronstedt and his servant watched at a window several nights, that they might observe, if possible, when this supply was deposited. 'Their plan did not succeed; but it appeared that the owls, which are very sharp-sighted, had discovered the moment when the window was not watched, as food was found to have been deposited before the coop one night when this had been the case. In the month of $A$ ugust the parents discontimned this attention; but at that period all birds of prey abandon their offspring to their own exertions. From this instance some idea may be formed of the great quantity of game that * Anim."Biogr. ii. 216 , sisth edit. 
must be destroyed by a pair of these owls during the time they are employed rearing their young*."

So anxious are the parent birds to provide food for their young, that several of them exhibit, during the breeding season, more omnivorous propensities than at any other. We may indeed occasionally see a chaffincli (Fringilla spiza), or a green-bird ( $E$. chloris), catch a fly or a beetle, but never we believe except when seeds are scarce. On the contrary, in feeding their young, insects constitute probably their sole provision, the seeds upon which the old birds live being too indigestible at least for the unfledged young. In the same way some of the larger birds, which are at all times omnivorous, such as the magpie (Pica caudata, $\mathrm{R}_{\mathrm{AY}}$ ), exhibit more carnivorous propensities than usual. Spealing of the magpie, Mr. Knapp says, "When a hatch is effected, the number of young demand a larger quantity of food than is easily obtained, and whole broods of our ducklings, whenever they stray from the yard, are conveyed to the nest.$+ "$

The same delightful writer gives an account of the rearing of a brood of tom-tits, which shows that smaller birds are no less provident with regard to the quantity of food furnished to their young than the eagle or the magpie. "I was lately," says he, " exceedingly pleased in witnessing the maternal care and intelligence of this bird; for the poor thing. had its young ones in the hole of a wall, and the nest had been nearly all drawn out of the crevice by the paw of a cat, and part of its brood devoured. In revisiting its family, the bird discovered a portion of it remaining, though wrapped up and hidden in the tangled moss and featlers of their bed, and it then drew the whole of the nest back into the place from

* Cronstedt, quoted by Bingley, ii. 212, 5th edit. + Journal of a Naturalist, p. 183, third edition. 
whence it had been taken, unrolled and resettled the remaining little ones, fert them with the usual attentions, and finally sncceeder in rearing them. The parents of even this rerlucer family laboured with great persererance to supply its wants, one or the other of them bringing a grub, caterpillar, or some insect, at intervals of less than a minnte, through the day, and probably in the earlier part of the morning more frequently; bnt if we allow that they brought food on the whole every minute for fonrteen hours, and provided for their own wants also, it will admit of perhaps a thousand grubs a day for the requirements of one, and that a diminished, brood; and give us some comprehension of the infinite number requisite for the summer nutriment of our soft-billed birds, and the great distances gone over by such as have yonng ones, in their numerous trips from hedge to tree in the hours specified, when they have full broods to support. A climate of moisture and temperature like ours is peculiarly favourable for the production of insect food, which would in some seasons be particularly injurious, were we not visited by such numbers of active little friends to consume it *".

From similar observations, Mr. Bradley, in his ' Treatise on Husbandry,' calculated that a pair of sparrows, during the time they have their young to feed, destroy every week about 3360 caterpillars. 'The basis of this calculation was, that he had observed the two sparrows carry to their young 40 caterpillars within an hour, and thence making a supposition that they are employed in this manner during twelve hours in the day, he finds the daily consumption to be 480 caterpillars, which, multiplied by 7 , the days in a week, gives 3360 . We should be disposed, however, to consider this perhaps double the real number, for, in a case so uncertain, the result * Journ. of a Naturalist, p. 171, 3d edit. 
of one hour cannot be accurately predicated of twelve successive hours, inasmuch as the sparrows could not be certain of meeting with the requisite supply of caterpillars in their immediate vicinity, and if they did one day, they would probably have afterwards to forage at some distance.

A more recent observer has with due caution considered such calculations too vague, though they are literally copied not only by all the compilers, but by Bonnet and Smellie. "I have observed," says Mr. Knapp, "a pair of starlings for several days in constant progress before me, having young ones in the hole of a neighbouring poplar tree, and they have been probably this way in action from the opening of the morning-thus persisting in this labour of love for twelve or thirteen hours in the day! The space they pass over in their various transits and returns must be very great, and the calculation vague; yet from some rude observations, it appears probable that this pair in conjunction do not travel less than fifty miles in the day, visiting and feeding their young about a hundred and forty times, which consisting of five in number, and admitting only one to be fed each time, every bird must receive in this period eight and twenty portions of food or water! This excessive labour seems entailed upon most of the land birds, except the gallinaceous tribes, and some of the marine birds, which toil with infinite perseverance in fishing for their broods; but the very precarions supply of food to be obtained in dry seasons by the terrestrial birds, renders theirs a labour of more unremitting hardship, than that experienced by the piscivorous tribes, the food of which is probably little influenced by season, while our poor land birds find theirs to be nearly annihilated in some cases *."

There camnot be any question of the immense num* Journ. of a Naturalist, p. 198, 3d edit. 
bers of insects required during the breeding season. An instance of this is mentioned by Bingley, with regard to some small Amcrican bird, which he calls a crecper (Certhia), but which we suspect to be more probably the house-wren (Anorthura EEdon). "From observing," he says, "its ntility in destroying insects, it has long been a custom, with the inhabitants of many parts of the United States, to fix a small box at the end of a pole, in gardens and about houses, as a place for it to build in. In these boxes the animals form their nests and hatch their young ones; which the parent birds feed with a variety of different insects, particularly those species that are injurious in gardens. A gentleman, who was at the trouble of watching these birds, observed that the parcnts generally went from the nest and returned with insects from forty to sixty times in an hour, and that in one particular hour, they carried food no fewer than sevcnty-one times. In this business they were engaged during the grreatest part of the day. Allowing twclve hours to be thus occupied, a single pair of these birds would destroy at least 600 insects in the conrse of one day; on the supposition that the two birds took only a single insect each time. But it is highly probablc that they often took more*."

Looking at the matter in this point of view, the destruction of insectivorous birds has in some cases been considered as productive of serious mischief. One striking instance we distinctly recollect, though we cannot at this moment turn to the book in which it is recorded t. The numbers of the crows or rooks of North Amcrica were, in consequence of state rewards for their destruction, so much diminished, and the increase of insccts so great, as to induce the state to ammounce a counter reward for the protec* Anim. Biogr. ii. 282, Gth edit.

中 Belknap, Hist. of New Hampshire. 
tion of the crows. Such rewards are common in America, and from a document given by Wilson, respecting a proposal made in Delaware "for banishing or destroying the crows," it appears that the money thus expended sometimes amounts to no inconsiderable sum. The document concludes by saying, "The sum of five hundred dollars being thus required, the committee beg leave to address the farmers and others of Newcastle county and elsewhere on the subject ${ }^{*}$."

From its sometimes eating grain and other seeds, "the rook," says Selby, " has erroneously been viewed in the light of an enemy by most husbandmen; and in several districts, attempts lave been made either to banish it, or to extirpate the breed. But wherever this measure has been carried into effect, the most serious injury to the corn and other crops has invariably followed, from the unchecked devastations of the grub and caterpillar. As experience is the sure test of utility, a change of conduct has in consequence been partially adopted; and some farmers now find the encouragement of the breed of rooks to be greatly to their interest, in freeing their lands from the grub of the cockchafer (Melolontha vulgaris), an insect very abundant in many of the southern counties. In Northumberland I have witnessed its usefulness in feeding on the larva of the insect commonly known by the name of Harry Longlegs (Tipula oleracea), which is particularly destructive to the roots of graim and young clovers + .'

It has on similar grounds been contended, that the great number of birds caught by hird-catchers, particularly in the vicinity of London, has been productive of much injury to gardens and orchards. So serious has this evil appeared to some, that it has

* Am. Ornith. iv. 84, note. $\uparrow$ Illustrations, p. 73 . 
even been proposed to have an act of parliament prohibiting bird-catchers from exereising their art within twenty miles of the metropolis ; and also prohibiting wild birds of any kind from being shot or otherwise caught or destroyed within this distance, under certain penalties. It is very clear, however, that such an act could never be carried; and though it might be advantageous to gardens, orchards, and farms, yet the attacks which the same birds make on fruit would probably be an equivalent counterbalance.

In the case of swallows, on the other hand, it has been well remarlied by an excellent naturalist, that they are to us quite inoffensive, while "the beneficial services they perform for us, by clearing the air of innumerable insects, ought to render them sacred and secure them from our molestation. Without their friendly aid the atmosphere we live in would scarcely be lrabitable by man: they feed entirely on insects, which, if not kept under by their means, would swarm and torment us like another Egyptian plague. The immense quantity of flies destroyed in a short space of time by one individual bird is scarcely to be credited by those who have not had actual experience of the fact." He goes on to illustrate this from a swift (Cypselus murarius, Temmanck), which was shot, "It was in the breeding season when the young were hatched; at which time the parent birds, it is well known, are in the habit of making little excursions into the country to a considerable distance from their breeding places, for the purpose of collecting flies which they bring home to their infant progeny. On picking up my hapless and ill-gotten prey, I observed a number of flies, some mutilated, others scarcely injured, crawling out of the bird's mouth; the throat and pouch seemed absolutely stufted with them, and an incredible number was at length disgorged. I am sure I speak within compass 
when I state that there was a mass of fies, just cauglit by this single swift, larger than when pressed close, could conveniently be contained in the bowl of an ordinary tablespoon *",

The extraordinary affection exhibited by the parent birds for their young is strikingly, exemplified in the instances recorded of their risking their own freedom and safety by venturing into houses whither their nestling's have been carried. We once rvitnessed an instance of this in a pair of goldfinches, who were, however, enticed by hanging the cage containing the nestlings upon their native tree in an orchard, from which it was gradually removed to the outside of a window, and afterwards taken indoors, whither the parent goldfinches followed and assiduously supplied their young with food. No attempt was made to catch the old ones; yet with all their anxiety to supply the young with food, they took care, although the window was left open for them, never to remain in the room during the night, roosting always in an adjacent tree in the orchard $t$. An interesting story of a similar kind is told by Colonel Montag'u respecting the gold-crested wren (Regulus cristatus, $\mathrm{R}_{\mathrm{AY}}$ ).

"A pair," says he, "of these birds, who took possession of a fir-tree in my garden, ceased their notes as soon as the young were hatched; and as this beautiful little family caused me much delight and amusement, some observations thereon may not be unacceptable to the curious reader. When first I discovered the nest, I thought it a favourable opportunity to become acquainted with some of the manners of this minute species, and to endeavour to discover whether the male ever sung by way of instructing the young ones. Accordingly I took the nest, when the young were about six days old, placed it in a small

* Rev, W. T. Bree, Mag. Nat. Hist, iii. 37. t J.R. 
basket, and by degrees enticed the old ones to my study window : and after they became familiar with that situation, the basket was placed within the window; then at the opposite side of the room. It is remarkable that although the female seemed regardless of danger, from her aflection to her young, the male never once ventured within the room; and yet would constantly feed them while they remained at the outside of the window: on the contrary, the female would feed them at the table at which I sat, and even when I held the nest in my hand, provided I remained motionless. But on moving my head one day, while she was on the edge of the nest, which I held in $\mathrm{my}$.hand, she made a precipitate retreat, mistook the open part of the window, knocked herself against the grlass, and laid [lay] breathless on the floor for some time. It is probable the focal distance of such minute animals' eyes is very near, and that large objects are not represented perfect on the retina; that they do not seem to see such distinctly is certain, unless in motion. However, recovering a lit:le, she made her escape, and in abont an hour after I was agreeably surprised by her return; and she would afterwards frequently feed the young while I held the nest in my hand. 'The male bird constantly attended the female in her flight to and fro, but never ventured beyond the window-frame; nor did he latterly ever appear with food in his bill. He never uttered any note but when the female was out of sight, and then only is small chirp. At first there were ten young in the nest, but probably for want of the male's assistance in procuring food, two died. The visits of the female were grenerally repeated in the space of a minute and a half or two minntes, or upon an average thirty-six times in an hour; and this continued full sixteen hours in a day, which, if equally divided between the eight young ones, each 
would receive seventy-two feeds in the day; the whole amounting to five hundred and seventy-six. From examination of the food, which by accident now and then dropped into the nest, I judged from those weighed that each feed was a quarter of a grain upon an average; so that each young one was supplied with eighteen grains weight in a day; and as the young ones weighed about seventy-seven grains at the time they began to perch, they consumed nearly their weight of food in four days' time at that time. This extraordinary consumption seems absolutely requisite in animals of such rapid growth. The old birds of this species weigh from eighty to ninety grains. I could always perceive by the animation of the young. brood when the old one was coming; probably some low note indicated her approach, and in an instant every mouth was open to receive the insect morsel. But there appeared no regularity in the supply given by the parent bird: sometimes the same was fed two or three times successively; and I generally observed that the strongest got most, being able to reach farthest, the old one delivering it to the mouth nearest to her*".

It would be easy for us to extend this chapter to a much greater length by similar anecdotes; but we shall only add one more respecting one of the humming birds (Trochilidce), mentioned by M. Labat, premising that we have no means of ascertaining the particular species meant. It being found extremely difficult, if not impossible, to breed the young humming birds, endeavours have been made to rear them by taking advantage of the natural affection of the parents for their offspring. Our author records an instance of such an experiment: "I showed," says he, "a nest of humming-birds to Father Montdidier, which was placed on a shed near the house. He * Ornith. Dict. Introd. 1st ed, and p. 204, 2nd ed. 
carried it off with the young, when they were about fifteen or twenty days old, and put them in a cage at his room window, where the cock and hen con. tinued to feed tirem, and grew so tame, that they scarcely ever left the room; and though not shut in the cage, nor subjected to any restraint, they used to eat and sleep with their brood. I have often seen ail the four sitting upon Father Montdidier's finger, singing as if they had been perched upon a branch. He fed them with a very fine and ahmost himpid paste, made with biscuit, Spanish wine, and sugar. They dipped their tongue in it, and when their appetite was satisfied they fluttered and chanted. I never saw any thing more lovely than these four pretty little birds, which flew about the house, and attenched the call of their foster-father. He preserved them in this way five or six months, and we hoped soon to see them breed, when Father Montdidier, having forgotten one night to tie the cage in which they were roosted by a cord, that hung from the ceiling, to keep them from the rats, had the vexation in the morning to find that they had disappeared; they had been devoured*."

* Nourcau Voyage aux Iles de l'Amerique, iv. 14. 


\section{Chapter XII.}

TRAINING OF YOUNG BIRDS BY THEIR PARENTS.

By far the greater number of the actions of animals appear to be performed without previous instruction, in a manner which being inexplicable in the present state of knowledge, is designated by the terms instinct and instinctive, meaning that the motives to any particular movement or action, as well as the mode of execution, originate in the animal spontaneously, without the series of reasoning, or thinking and determining, which we employ in similar cases. Thus a frog is said to swim instinctively in water; that is, it requires no training, no instruction in the art of swimming, no more than we do in the process of breathing; and the same may be said with regard to the swimming of most other animals, even those least accustomed to water, few being unable to swim except man, who requires training and instruction for that purpose. It is not our design to enter here upon the difficult subject of instinct, farther than to point out a few of the acquired actions of birds, originating either in the express instruction or imitation of their parents.

With respect to the eagle, which is the most celebrated from the remotest antiquity for instructing its young, we are told by Moses, that she "stirreth up her nest, fluttereth over her young, spreadeth abroad her wings, and taketh them and beareth them on her wings *." A ristotle adds, that the young are not permitted to leave the nest prematurely, and

* Deuteronomy, xxxii. 11. 
if they make the attempt, their parents beat them with their wings and tear them with their claws*. Be this as it may, we are assured that eagles will feed their young for a considerable period, if the latter are disabled from flying by clipping their wings; and it is recorded that a countryman once obtained a comfortable subsistence for his family out of an eagle's nest, by clipping the wings of the eagtets and tying them so as to increase their cries, a plan which was fonnd to stimulate the exertions of the old birds in bringing prey to the nest. It was of course necessary for lim to make his visits when the old birds were absent, otherwise he might have been made to pay dearly for his plunder. After instructing their young in flying and hunting, the parent eagles, like other birds of prey, drive them from their territory, though not, we believe, as Aristotle says, from the nest. Bonnet says, "The eagle instructs its young in flying, but does not, like the stork, prolong their education, for it mercilessly drives them away before they are thoroughly taught and forces them to provide for their own wants. All the tyrants of the air aet in the same manner, yet though this seems cruel and shocking, when we consider their close relationship, it takes a different aspect when we consider the lind of life led by those voracions birds. Destined to subsist by rapine and carnage, they would soon produce a famine amongst their race did many of them dwell in the same district. For which reason, they hasten to drive away their young at a certain age from their boundaries, and then if a scarcity of provision occur, the nale and female put one another to death.$+ "$ The poet Thomson, without going' quite so far as this, gives a very good account of the circumstance.

* Hist. Anim. ix. 3:2.

if Contemplo de la Nature, vi. note 5. 
"High from the summit of a craggy cliff Hung o'er the deep, such as amazing frowns On utmost Kilda's shore, whose lunely race Resign the setting sun to Indian worlds, The royal eagle draws his vigorous young, Strong-pounced, and ardent with paternal fire.

Now fit to raise a kingdom of their own, He drives them from his fort, tise tow'ring seat For ages, of his empire; which in peace, Unstain'd he holds, while many a league to sea He wings his course and preys in distant isles."

Another bird celebrated for instructing its young is the stork. When the wings of the young storks begin to grow, they are said to try their strength in fluttering about the nest, though it often happens that, in this exercise, some of them fall and are unable to regain their place. When they first venture to commit themselves to the air, the mother leads them in small circumvolutions about the nest, whither she conducts them back, and about the end of August, the young ones having acquired strength, unite with the old ones for the purpose of migration*." "When the young storks," says Bonnet, as if speaking from observation, "begin to try their wings, the mother fails not to watch over and conduct them. She exercises them by little and little in short flights around the nest, to which she soon conducts them again. She continues her attention for a long time, and does not abandon them till their education is completed †."

We are disposed, however, to look upon much that has been written respecting parent birds instructing their young as merely fanciful, and whether we are right in this may be readily verified by observing and comparing facts of daily occurrence. In the case of

* Buffon, Oiseaux, vol, viii.

+ Contempl. de la Nature, pl. xi, c. vi, note 5 . 
a brood of dncklings, for example, it might be plausibly alleged, that their'parents taught them to swim, because the mother may be seen swimming before them as their leader, and the little things all paddling after her according to their strength or their agility. But, in order to prove this view to be correct, it would be indispensable to show that the ducklings could not swim till they were instructed by their mother, which elearly appears not to be the case, for a duckling, as soon as it acquires the requisite strength of foot, which occurs a very short time after it is hatched, takes to the water and swims as dexterously as its mother herself can do. Nay, it can not only swim so as merely to keep itself afloat, but it knows, without any instruction, how to proportion the frequency and force of the strokes of either foot so as to carry it to any part of the pond it chooses, as acurately as if it were profoundly acquainted with the mathematieal problems of the composition and resolution of forces. No instruction nor imitation of the parent will account for this, inasmuch as duclilings hatehed in an oven will take to the water as readily as those tended by a female duck; and, in the common occurrence of their being hatched under a hen, they will swim away and leave their foster-mother on the bank of the pond in utter despair for their safety. This proves not only that they can swim without instruction, but in opposition to the most earnest solicitude of their sole instructress. We have witnessed a similar case, no less in point, in a brood of turkeys hatched by a goose, which their foster-mother, as was natural, was desirous of leading into the water; but this they refused as obstinately as ducklings do to quit the water when recalled by a hen*.

As to what is alleged about the old birds warning the young ones of dinger from their natural enemies, *J.R. 
or teaching them of what animals to be afraid, the same remarks will apply. We have seen, for example, a young brood of the gallinule (Gallinula chloropus, LinN.), evidently not above two days old, dive instantancously, even before the watchful mother seemed to have time to warn them of our approach, and certainly before she followed them under water. The same thing occurs in other parts of nature: this we have observed a shoal of salmon fry, whose size was less than that of minnows, and whose age we knew could be only a few days, as we had witnessed the deposition of the spawn whence they were hatched, all simultaneously exhibiting alarm, and ruming under the over-hanging brow of a stream for protection; yet this could not be the consequence of the instruction of their mother, whom they had never seen, and who was far on her way to the sea, thirty miles off, before they had been hatched ${ }^{*}$.

We think it highly probable that the instances of the eagle and the stork, above quoted, admit of a similar solution into instinctive motives independent of instruction. Even the case of the hen who leads her chickens so assiduously to where they may find food, though it appears to be more like instruction than the instances of the eagle and the stork, is far from being conclusive; for chickens which are hatcher artificially seem to be at no loss in learning to feed, though they have no mother; and duclis hatched under a hen will take the water in spite of her most anxious warnings.

The swallows and sparrows, which, from building in our houses, are more under common observation than most wild birds, may readily be fancied to be scen instructing their young to fly. The whole family may have got ont of the nest and have perched * J. R. 
on the tiles, orr a window-ledge, or on the projecting. bricks of a neighbouring chimney, basking themselves in the sunshine, and enjoying the freshness of the summer air, and the parents, in their exuberance of joy at having reared their young ones so far without accident, may be seen flitting about from one to another, and sometimes making short excursions to the nearest tree as if to survey their young from a diflerent point of view, chuckling all the while with buoyant delight, in tones which many observers would not hesitate to interpret as invitations to the little things to try their wings. We are more inclined, however, to consider the conduct of the parent bircls on such occasions as simply expressive of pleasurable feeling; and if an anxious movement or the tremulous tone of fear be heard to intermingle, it may usually, we think, be traced to the attempts made by the young birds to fly, the old ones naturally anticipating the possibility of danger, from the known weakness of wing as well as the inexperience of the young ones, placed as they usually are in such cases, at a considerable height. It appears, indeed, to be the chief recommendation of a nestling place, both for sparrows and swallows, that it should have a good fall, to aid their flight in starting on a journey. "I have known window-swallows," says Mr. Couch, "forsake a situation in which they had long been accustomed to build, only because a low wall had been erected in a situation that interfered with their comfortably taking flight*." In other respects it appears to us that the supposed instructions given by the parent birds to the young, in the art of flying, are exactly parallel with those given by ducks in the art of swimming. We may in all faimess, indeed, ask those who adlopt the opinion of Bonnet above quoted, how they suppose young frogs and young "Mag. Nat. Hist, i\%. 521. 
fish to learn to swim, or young bees and butterflies to learn to $\mathrm{fly}$, since in these cases the parents are either far distant or dead before the young are hatched from the egrgs

In this manner we should explain such observations as the following, which are coloured in conformity with Bonnet's theory: "The progressive method by which the young swallows are introduced to their proper habits is very curious. They first, but not without some difficulty, emerge from the shaft; for a day or two they are fed on the chimney top, and then are conducted to the dead leafless bough of some neighbouring tree, where, sitting in a row, they are attended by the parents with great assiduity. In a day or two after this they are strong enough to fly, but they continue still unable to take their own food. 'They, therefore, play about near the place where the dams are watching for flies; and when a mouthful is collected, at a certain signal, the dam and the nestling advance, rising towards each other, and meeting at an angle, the young one all the while uttering such a short quick note of gratitude and complacency that a person must have paid very little regard to the wonders of nature who has not remarked this scene $\uparrow . "$ On the same principle it is said that the male assists the female stone-curlew (QEdicnemus cregitans, Tenminck) " in conducting the young, whose education, notwithstanding, appears to be rather slow †"

In the instance, again, of impending danger, or on the approach of an enemy, the parent birds eagerly express their feelings of solicitude, though it is questionable, we think, whether the cries they utter are meant or understood by the young as invitations to fly to a place of greater security. We have in this way observed, in the case of a brood of young

* J. R. + Bingley, ii. 341, 6th cdit. * Griffith's Cuvier, viii. 457. 
goldfinches (Carduclis elegans, Stephens), perched on an apple-tree and chirruping in chorus, that, when the watchful parents warned them of our approach, they did not fly towards them for protection, but instantly ceased to chirup, squatting close to the branches where they were sitting. Yet we can imagine, and have seen, cases in which young birds, being in confinement or in danger, have been solicited to shift their quarters with all the varied tones and movements of invitation, which are in fact identical with the tones used in feeding, and, to all appearance, instinctively understood $*$. It is thus we would explain the following interesting narrative, which proves that had the author had opportunities for observation he might have accomplished something much superior to his very imperfect though well-planned compilation.

"When I was a boy," says Smellie, "I carried off a nest of young sparrows, about a mile from my place of residence. After the nest was completely removed, and while I was marching home with them in triumph, I perceived with some degree of astonishment, both the parents following me at some distance, and observing my motions in perfect silence. A thought then struck me that they might follow me home, and feed the young according to their usual manner. When just entering the door I held up the nest, and made the young ones utter the cry expressive of the desire of foot. I immediately put the nest and the young in the corner of a wire cage, and placed it on the outside of a window. I chose a situation in the room where I could perceive all that should happen without being myself seen. 'The young animals soon cried for food. In a short time both parents, having their bills filled with small caterpillars, canne to the cage; and after chatting a * J.R. 
little, as we do with a friend through the lattice of a prison, gave a small worm to each. This parental intercourse continued regularly for some time, till the young ones were completely fledged, and had acquired a considerable degree of strength. I then took one of the strongest of them and placed him on the outside of the cage, in order to observe the conduct of the parents after one of their offspring was emancipated. In a few minutes both parents arrived, loaded, as usual, with food. 'They no sooner perceived that one of their children had escaped from prison, than they fluttered about and made a thousand demonstrations of joy, both with their wings and with their voices. 'These tumultuous expressions of unexpected happiness at last gave place to a more calm and soothing conversation. By their voices and their movements it was evident that they earnestly entreated him to follow them, and to fly from his present dangerous state. He seemed to be impatient to obey their mandates; but, by his gestures and the feeble sounds he uttered, he plainly expressed that he was afraid to try an exertion he had never before attempted. 'They, however, incessantly repeated their solicitations; by flying alternately from the cage to a neighbouring chimney-top, they endeavoured to show him how easily the journey was to be accomplished. He, at last, committed himself to the air, and alighted in safety. On his arrival another scene of clamorous and active joy was exhibited. Next day I repeated the same experiment, by exposing another of the young ones on the top of the cage. I observed the same conduct with the remainder of the brood, which consisted of four. I need hardly add, that not one either of the parents or children ever afterwards revisited the execrated cage*."

It does not appear to us that, in the instance of * Philosophy of Natural History. 
carnivorous birds, the bringing of live prey to the young, and of inviting them to kill and devour it, is capable of being interpreted as it nsually has been as an instance of training them to hunt. We have seen a kitten bronght up by hand from the day it could see, and, of course, before the mother had any opportmity of instructing it to mouse, exhibit all the cumning devices of a practised veteran in lying in wait for a mouse, which it succeeded in capturing, though, so far as we were aware, it had never before seen a mouse*; and we have not a doubt, though we never witnessed an instance, that a young hawk wonld pounce upon the first live bird presented to it, independently of all experience and instruction. But though we look upon this as the correct view of the matter, it may be well to give some of the statements of those who adopt a different opinion.

Albertus Magnus tells us, that " hawks feed their young on the wing, generally for the space of a month, and then abandon them. They instruct them to catch such birds as they carry to the nest, and let go again in their presence. But when the nestlings are able to fly quite well, and to provide for themselves, they drive them away or forsake them + ." The priests of Egypt, on that account, when they wanted to represent a person who banished his children, were accustomed to express the idea by the figure of a brooding hawk. The same figure was also understood to signify want. Want, indeed, is said to be the reason of this conduct in the hawk, while the eagie rears only one young one, from pride and not from indigence. Such at least is the acconit of Elian. But other writers of not less repute think, perinaps with more truth, that this severity on the part of the hawk is occi-

$$
\text { J.R. † Hist. Anim. vii.9. }
$$


sioned not through the want of food, which would be unworthy of the prince of the hawk tribe, but through the ingratitude of the offspring. St. Basil also remarks, that "hawks act with cruelty towards their young, and when they are able to fly keep them without food, and, as eagles do, drive them from their nest with their beaks and talons: they teach them, also, to be daring, and excite them to pursue prey, lest, when full grown, their nature should be dulled by sluggishness, and they should seek food rather from habit than a ferocious disposition *" Cassiodorus coincides with this opinion. "Hawks," says he, "who live on prey, famish their young, expel them from their nest, lest indolence should render them tame and dull, strike them with their wings, if they are unwilling to depart, and, at last, compel them to flight that they may subsist, as their fond parents anticipate.$+ "$ Elian also relates, that " in spring, hawks select two out of their whole tribe, and despatch them into Egypt to examine those desert islands, which are adjacent to Africa, and these, after their return, become the leaders of the rest to those places. The Lybians, moreover, observe their peregrination with festal celebration. When they arrive at those islands which the precursors had considered most proper for their habitation, they pair and incubate, and hunt pigeons and sparrows, redundantly supply their offispring with food, and when they are strong enough to undertake the flight, conduct them into Egypt, as their native settlement + ."

But leaving these antique accounts of mingled truth and fable, we are told by a recent observer, that "the rook entices the young from the breeding trees as soon as they can flutter to any other. These * In Hexam. to De Anim. ii. 43. 
young, for a few evenings after their flight, will return to their parents, and roost where they were bred; but they soon quit their abode, and remain absent the whole summer months *." Now we think this is putting the matter in its true light; for the rooks are here represented under very different circumstances from the swallows and sparrows, whose supposed training we have above endeavoured to explain, their prey not being usmally at hand, but in some distant field. 'To continue therefore to supply their young as they had done while unable to quit the nest would be in many cases impossible, for their inmediate vicinity is for the most part exhansted, and the increasing dryness of the season renders it more difficult to obtain worms, slugs, and the grubs of chafers. This is not a mere hypothetical view, but is proved by facts. "In the hot summer of 1825 , many of the young brood of rooks of the season perished for want; the mornings were without dew, and consequently few or no worms were to be obtained; and we found them dead under the trees, having expired on their roostings. It was particularly distressing, for no relief could be given, to hear the constant clamour and importunity of the young for food. The old birds seemed to suffer without complaint ; but the wants of their offspring were expressed by the unceasing cry of hunger, and pursuit of their parents for supply, and our fields were scenes of daily restlessness and lament. Yet, amid all this distress, it was pleasing to observe the perseverance of the old birds in the endeavour to relieve their famishing fanilies, as many of them remained out searching for food quite in the dusk, and returned to their roosts long after the usual period for retiringt."

* Journal of a Naturalist, p. 181.

+ Jeurnal of a Naturalist, p.178, 3d edit. 
Under such circumstances, it is surely not wonderful, that the parent birds should endeavour to entice their young as soon as they can fly, to take excursions to the particular fields where they expect to find a supply of food; yet such enticenent does not appear to us to constitute training in the proper meaning of the term. 


\section{Chapter XIII.}

VOCAL ORGANS OF BIRDS.

As the peculiar calls of birds expressive of fear, alarm, invitation, and the like, as well as the songs of many of the smaller species, are amongst the most obvious of their habits, even to those who otherwise pay little attention to their economy,-it will be requisite, before we consider snch call-notes, to give some account of their vocal organs, as they have been described by comparative anatomists, of whom Fabricius and Kircher are amongst the earliest, and Colonel Montagu and Mr. Yarrell the most recent.

The views which have been taken by physiologists of the mechanism of the voice in man as well in birds are so different, that it is by no means easy to reconcile them. Galen, the celebrated Greek physician, compared this mechanism to a flute, very naturally supposing it to be altogether of the nature of a wind instrument * ; and in modern times M. Dodart $\uparrow$ has adrocated the same opinion, maintaining that the tones vary according to the expansion or contraction of the orifice of the windpipe (Glottis). M. Ferrein and Dr. Young, on the contrary, have compared it to a violin or a harpsichord, the rocal cords formed by the sinews or ligaments constituting. the orifice of the windpipe, being supposed to perform the office of strings, upon which the air acts

* De Usu Partium. † Mém. Academic, for 1700, p. 244, and 1707, p. 66 . 
like a bow*. In man, when this orifice is brought into its narrowest compass, the opening is diminished about one-third of its length, and is then not more than from one-twenty-fourth to one-twelfth of an inch in width, and about half an inch in length, the sides or lips presenting a sharp edge, directed upwards and inwards, which has with considerable propriety been termed the vocal chords.

Other physiologists take different views from both Dodart $\dagger$ and Ferrein, and amongst those M. Kratzenstein imagined the opening of the windpipe to resemble a drum, with the head divided + ; and Blumenbach and Sümmering think it is more analogous to a flute, a pipe, or an Eolian harpa stringed instrument played upon by the wind $\S$. M. Majendie, again, who has given a very elaborate description of the organs of the voice, refers us to those instruments whose sound is produced by a reed, such as the hantboy and the clarionet $\|$. We may remark, however, respecting this hypothesis, ingenious as it is, that the varions tones of the voice are produced, not by stopping the holes at different distances, as in those reed instruments, but by varying the width of the windpipe at its orifice or out-going, where the principal organs are situated, and also by varying the length of the tube of the windpipe.

Another well-known physiologist, M. Richerand \%, questions the fact of the voice being similar to a reed instrument, and goes into a learned argument

* Mém. Acad. pour 1741, pp. 409-22 ; and Haller, Element. Physiologiæ, ix. 31, 17; and Young, sect. i. 400; and Phil. Trans. for 1800, 141-2.

+ Mém. de l'Acad pour 1700 .

+ Tentamen Sonorum Vocalium, 4to. 1781.

Blumenlach, Instit. Physiol. by Dr. Elliotson, ix. 87, and Söinmering, Comp. Human. Fabric. vi. 93.

|l Pnysiologie, i. 2078.

q) Physiology, by de Lys. 
to prove that it is both a wind and a stringed instrument at the same time. 'The voice, he remarks, becomes stronger, fuller, and passes from the acute to the grave, as the orifice of the windpipe enlarges with the progress of age; and it remains always weaker and slarper in women, who have the orifice nearly a third smaller than men. The tension or reJaxation, however, of the vocal chords may perhaps enable them to execute in a given time vibrations nore or less rapid, in such a manner that if the air, expelled from the lungs in breathing, strike upon them in a state of tension, produced by the action of the muscles, the voice will be shrill, clear, and piercing; whereas it would be grave, if the vocal chords were relaxed.

M. Ferrein's comparison of the voice to a violin has been objected to from the consideration, that in order to perform the office of vibrating strings, the rocal chords ought to be dry, tense, and insulated, the three-fold condition required for the production of sound in stringed instruments. But notwithstanding the incompleteness of their resemblance to strings, the vocal chords, like the vibrating bodies, serving as mouth-pieces to wind instruments, such as the reed and oboe, the mouth-hole of flutes, and the lips themselves in the horn, do not the less contribute to the formation and varied inflexions of vocal sound.

So far as we are able to judge, the organ in question (larynx) represents a reeded wind-instrument with a double plate, the tones of which are more acute as the plates are shortener, and more grave the longer they become. Although this analogy, however, is generally correct, it does not necessarily follow that it is in every part complete. The common reeds of instruments, in fact, are composed of rectangular plates fixed on one side, and free on the other three. In the vocal organ, on the other 
hand, the chords or reeds are indeed rectangular, but they are fixed by three sides instead of one. In the common reeded instrument, again, we raise or lower the notes by varying its length; while, in the plates of the vocal reeds, it is the size which is varied. In musical instruments, besides, we cannot employ nor procure reeds, the plates of which can every instant alter their thickness and elasticity as happens in the vocal chords. It can easily be conceived, then, from these circumstances, that the vocal chords may produce and vary the tones of the voice somewhat after the manner of reeded instruments, though we cannot make out the analogy in every particular.

M. Majendie partly proved these views by actual observation; and, in the instance of dogs, he found that, when the sound uttered was grave, the vocal chords vibrated through their whole length, and the expired air passed through the whole extent of the orifice (glottis). 'When the sounds were acute, on the other hand, the vocal chords did not vibrate in the front, but only in the back part; and, as the orifice was of course diminished, the air only passed through the vibrating portion. When the sounds, again, became very acute, the vocal chords no longer vibrated, except at the very extremity, and the expired air then passed out only at this part. So far as he was able to ascertain, the sound increased in acuteness till the orifice became entirely closed. When the air could no longer pass, the sound ceased.

That it is the vocal chords whose vibration produces the sound, may also be fairly inferred from experiments made after death; for by taking the windpipe of any quadruped and blowing strongly from below upwards, no sound will be produced so long as the orifice remains expanded: but if, while continuing to blow, the orifice is compressed so much 
as to bring the inner surfaces into contact, a sound will be produced somewhat resembling the voice of the animal from which the windpipe has been taken. 'The sound, also, will be more or less acute or grave, according as the lips of the orifice approach each other, and will be most intense when we blow with most force. Again, when an opening is made into the windpipe, either in man or other animals, below the orifice, the voice is destroyed; but will be restored if the opening be mechanically stopped. M. Majendie says, he knows a man who has been in this situation for many years, and who cannot speak except when his cravat, which closes a fistulous opening in the windpipe, is drawn tight.

Although Linnæus has given the general character of "speaking" animals to his class Mammalia, there are several, such as the ant-eaters (Myrmecophagæe) and the pangolins (Manes), even according to his own description, altogether dumb is said to lose its voice in the West Indies; and the same is reported of quails in Siberiat. 'The greater or less perfection of the voice seems, indeed, to depend upon the degree of perfection with which the oritice of the windpipe is formed in the classes of animals possessing that organ; and it is by the varying number of membranes or muscles in its general structure, or by variations in their sliape, position, or elasticity that quadrupeds and most other animals are rendered capable of making those peculiar sounds by which their different kinds are respectively characterized, and are enabled to neigh, bray, bark, or roar; to purr, as the cat and the tiger; to bleat, as the sheep; and to croak, as the frog. 'The frog, however, has a sack or bagr of

* Systema Naturx, in loco.

+ Pennant, Arct. Zool. ii. 320. 
a singular character in the throat or cheek, directly communicating with the orifice of the windpipe, on which the croaking principally depends*

In birds, again, the windpipe is very different in structure from that of other animals, and in songbirds is peculiarly and admirably adapted to that sweet and varied music with which we are so often delighted in the woodlands. The whole extent, indeed, of the windpipe in such birds, may be regarded as one vocal apparatus; the upper part (larynx) being divided into two sections, or, as they may rather, perhaps, be considered, into two distinct organs. That which is more complicated, or in which the parts are more numerous and elaborate, is placed at the lower end of the windpipe, at the place where it divides, in order to be distributed through the lung's: the more simple, or that in which the parts are fewer, occupies its usual situation at the upper end of the windpipe, which, however, is destitute of the valve or lid (epiglottis) which is found in man. From this view of the vocal organs in birds, we may consider their lungs and windpipe as forming a natural bag-pipe, in which the lungs constitute the pouch and supply the wind,-- the windpipe itself forming. the chanter or pipe; the lower or more complicated part (glottis inferior) being the reed or monthpiece which produces the simple sound; and the upper part (glottis superior) the finger-holes, which modify the simple sound into an intinite variety of distinct notes + .

Dr. Macartney has justly remarked, that "a very little comparison of the mechanism of wind musical instruments with the organs of the voice in birrls, will show how nearly they are allied to each other; and * Good's Study of Medicine, i. 429, second edit. + luem, i. 461 . 
it may be observed, that the sound produced by some of the larger birds is exactly similar to the notes that proceed from a clarionet or lautboy in the hands of an mitntored musician. 'The inferior nlottis exactly corresponds to the reed, and produces the tone or simple somid. The superior larynx gives it utterance, as the holes of the instrument; but the strength and body of the note depend upon the extent and capacity of the trachea, and the hard. ness and elasticity of its parts. The convolution and bony cells of the windpipe, therefore, may be compared with the turns of a French horn, and the divisions of a bassoon; and they produce the proper effects of these parts in the voices of those birds in which they are found"." The Abbe Armaud compares the voice of the hooping swan (Cygnus ferus, $R_{A y}$ ) to the sound of a clarionet, winded by a person unacquainted with the instrument ${ }^{\circ}$.

In birds, however, we meet with a very considerable diversity in the structure of the vocal organs, particularly in the length and thickness of the tube of the windpipe; and that not only in different species, but often in different sexes of the same species, and especially among water-fowl. This was observed even by the earlier naturalists. Aldrovand, for example, whom it las been the fashion to consider as a mere fabulist, has given a very excellent account of the windpipe of the wild swan (Cygmus ferus, $\mathrm{R}_{\mathrm{Ar}}$ ) from his own observation, which we shall here translate.

"'The structure of this windpipe," he says, " is worthy of high admiration; for in descending along with the gullet, when it arrives at the throal, it does not, as in other animals, enter the lungs in a straight line, but rising over the shoulder-blade (claviculus),

$$
\begin{aligned}
& \text { * Rees' Cyclopxdia, Art. Birds. } \\
& + \text { Buffon, Oiseaux, Art. Cygne. }
\end{aligned}
$$


it passes into the keel of the breast-bone, which keel is seldom composed of a single bone, but consists of two sides, with a third resting upon them by way of cover, the whole forming a sort of sheath or tunnel. When the windpipe arrives at the extremity of this sheath, it bends downwards in a serpentine form resembling the letter $\mathrm{S}$, and again, beneath the portion just described, it emerges from the sheath, and rising upwards over the middle bend of the shoulderblade, it winds, thus supported, in the manner of a trumpet. Upon its passing under the cavity of the chest, and just before it reaches the lunigs, as if to form another vocal organ (larynx), it is transver'sely cut (being as broad as the small bone is long), and a

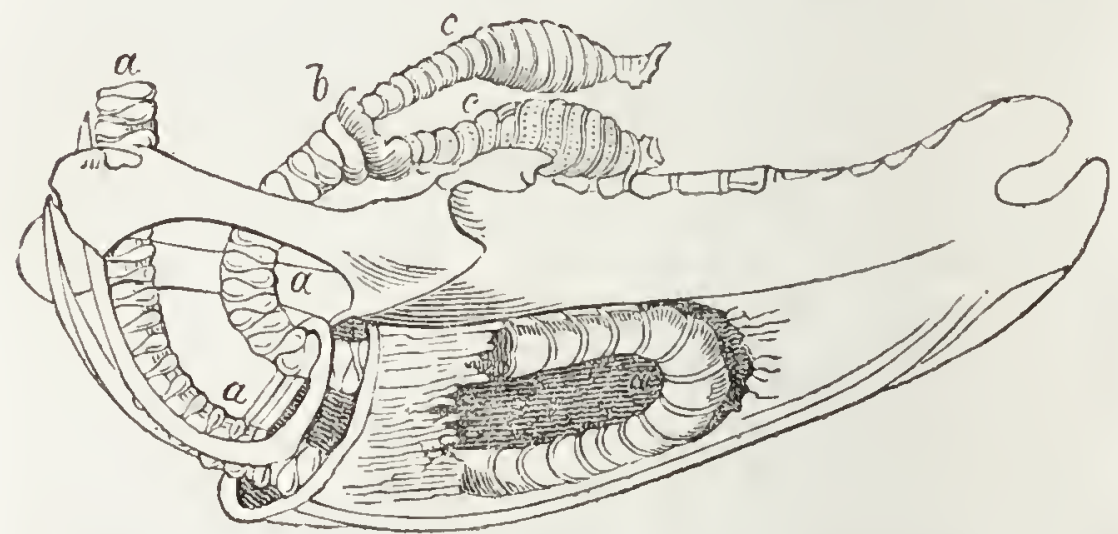

The breast-bone of a wild Swan, with part of the keel removed to show the convolution of the trachea withiu it.

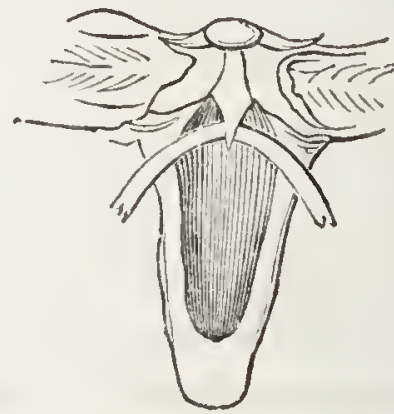

The point of the keel-bone, showing the opening through which the trachea enters and returas. 
thin membrane stretched over the opening, the whole resembling in figure and texture the split reed of those musical instruments, conmonly called trombones, so much esteemed in church service, and which are widest at the lower end, with a similar fissure. lelow this the windpipe divaricates into two branches, both of which enlarge towards the middle, or are directly ranified through the lungs* Dr. Latham's description is, that "the windpipe in the wild swan passes lown the neck the whole of its length, after which it enters the licel of the stermum [breast-bone], passing backwards therein nearly the whole of its length, when it bends upwards and forwards, and then enters the cavity of the breast to communicate with the lungst."

As this curious structure is not found in the tame swan (Cygnus mansuetus, RAy), Willughby very justly remarks, that "Aldrovand doth not rightly infer that Aristotle never dissected this fowl, because he malies $n o$ mention of this ingress, and of the: strange figure of the windpipe." He ards, "of tame swans, we have anatomized many, and in all have observed the windpipe to descend straight dow a into the lungs, without any such digression or deflection t." Buffon, however, in conformity to the theory which vitiates so many of his details, maintains that this difference of structure " is insufficient to constitute two distinct species, for the variation exceeds not the sum of the impressions, both internal and external, which the domestic habits may in time produce §."

liecently, Mr. Wingate has discovered that there are two species of wild swan, differing remarkably in

* Aldrovandi Orrithologia, iii, fo edit. Francf.

t Linn. Trans. iv. 106.

t. Willughby, Ornith. by Ray, p. 356.

$\S$ Oiseaux, Art. Le Cygne. 
the conformation of the windpipe. In Bewick's swan (Cygnus Bewickii, Yarrel), in the adult state, the windpipe, which is of equal diameter throughout, enters the keel of the breast-bone, through which it makes its way to the end, where, inclining upwards and outwards, it passes into a cavity formed in the body of the bone by the separation of the bony plates, and producing a convex protuberance on the inner surface of the breast-bone. In this cavity the windpipe assumes a horizontal direction, and makes a considerable curve, reaching within half an inch of the posterior edge of the breast-bone. It then returns to the keel, along the upper part of which it passes to the exterior edge of the bone, over which it is reflected so as to enter the body of the bird, and become attached to the lungs. On the other hand, in the wild or hooping swan ( $C$. ferus), the windpipe never assumes a horizontal direction, and does not even penetrate within the keel to the extent of one half of the breast-bone*.

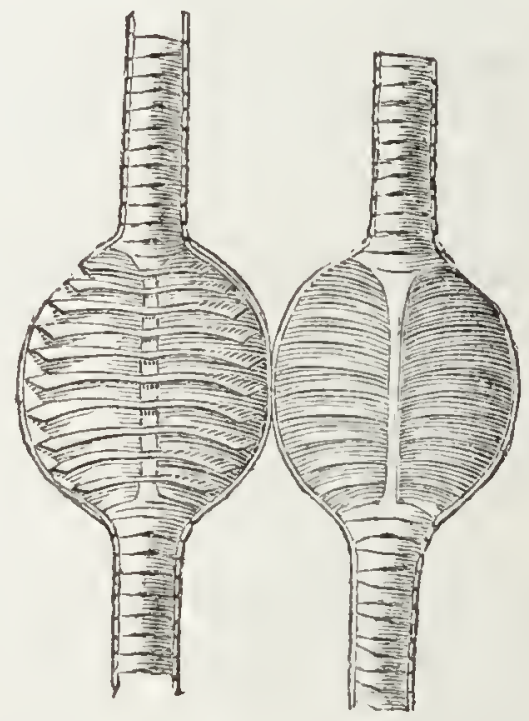

Trachea of C. Bewichii.

* Trans. of the Nat. Hist. Society of Newcastle, for 1831, and Zool. Journ. v. 258. 
One of the best accounts we have met with of the rocal organs of birds is by M. Herissant, aceording to whom the prineipal apparatus consists of membranes varying in thinness and expansion in different species. In such birds as the goose, which is admirably deseribed by Haller*, there are four such membranes, resembling in figure and disposition the reeds of a hautbois, and disposed in twos. But though these membranes, which are more or less distinet according to the species, are the prineipal rocal organs, they are not the only ones, for M. Herissant discovered many others in the interior parts of the lungs. They are placed transversely upon one another, and their texture and disposition resemble spiders' webs. 'These membranes, so delieate, placed one above the other, and all ready to vibrate, present a spectaele which no naturalist can fail to admire. Each of them is somewhat of a erescent shape, and attaehed by the eireular eireumference to the sides of the tube. Eaeh inclines a little towards the end whence the air passes which eomes from the lungs, and whieh cannot pass without exciting them more or less to vibrate.

Besides the membranes just described, and which are met with in all the birds M. Herissant examined, there are other's, of different forms, variously placed over certain bones and cartilages, some being situated towards the middle part of the windpipe, and others lower down. These are also met with in eertain water-fowl of the duck tribe. There is found, moreover, in all birds, another membrane varying in thiekness, and so essential, that without it no vocal sound eould be produeed. This is situated almost transversely between the two homs of the ereseentshaped bone (furcula), and there forms the termination of the cavity in the upper and inner part of the * Element. Physiol. 
chest. All these organs being put in play by the air in the lungs, they jerk and vibrate more rapidly according to the rapidity with which the air passes*.

At the request of Mr. Pennant, the celebrated John Hunter examined the vocal organs of many singingbirds, and found that the loudest songsters have the strongest muscles in those parts. The sky-lark, whose clear and vigorous note is often heard when he can no longer be followed in his ascent by the most penetrating eye, had the muscles bere stronger than any other bird that was examined. Mr. Hunter also observed that, among singing-birds, the muscles of the male, following the same rule, are stronger than those of the female, whose voice is always less powerful; and it is worthy of remark that he could discover no difference in the vocal organs of the male and female in birds which do not sing.

Baron Cuvier aggain found in all singing-birds five pairs of constrictor muscles, namely, two pairs before, two behind, two small, two oblique, and two transverse, while in most birds which do not sing there is in general only one pair $\dagger$. 'The most minute account of the action of these muscles has been given by $M$. Meckel in his work on comparative anatomy, and by Dr. Bennati ; but it would be difficult to present any intelligible statement of their details in an abridged form.

All these observations, however, are by no means new, for the famous Jesuit, Athanasius Kircher, gives the following minute and surprisingly accurate account of the vocal organs of the nightingale. "In the first place," says he, "we find its tongue very short, but the other vocal organs (larynx) fibrous and muscular in an astonishing manner, though in other respects it

2: Mém. Acad. des Sciences. pour 1753, p. 229.

† Leçons d'Anat. Comparée.

+ Annales des Sciences Naturelles, xxiii. 32, \&c. 
does not differ from other birds. We therefore conclude that all the power and variety of its notes are produced from innumerable fibres by which the rocal chord (glottis) is either tightened or relaxed, projected forwards or drawn inwards, and bent in every direction, the tongne performing the ofice of a bow (plectrum) in eliciting the several notes. I further infer that those guttural warblings ealled trills, which professional singers make in the throat, are not formed by the tongue, but immediately by the vocal chords, and that this trilling is produced solely by the exspiration of air striking on the vocal chords:"

From the inquiries of those of the more modern physiologists whose works we have examined, it does not appear that they have paid sufficient attention to the influence of the tongue in modifying the sound of the voice, though it will appear from some of the facts which we shall presently state, that this infuence is probably considerable, even if we should not go so far as Kireher, in representing it as the bow or quill by which at least in the nightingale the sound is produced. Aristotle had observed the shortness of the nightingale's tongue, which he says "wants the tip + ;" and Pliny remarks that "in common with the blackcap (Atricapilla) it has not the slender tip possessed by other birds +." F. Sanctius says, "I can positively aver, that the nightingale has no tongue, unless my eyes deceive me§." Aldrovand, on quoting the above passage, remarks, "A few days since, one of my friends brought me a nightingale in a care, and when we had taken it out, we could hardly observe the smallest vestige of a tongue; which circumstance excited in me considerable wonder, that the little bird

* Fircher, Musurgia, lib. i.

$\dagger$ Hist. Anim. ix. 15.

$\ddagger$ Hist. Nat. x, 29.

is Commen. in Al, Emb.701. 
should have such sweetness of song and such vibration of voice, and yet be without a tongue, unless it were perhaps concealed in its throat. Poets, therefore, were not far from the truth when they sung, that the nightingale's tongue had been cut out. But whether their story be correct, I leave to be decided by others. As many, however, as I have seen (and I have seen a great many) had all a very distinct tongue. Some assert that the story among poets of the nightingale's wanting a tongue originated in the circumstance of Philomela having her tongue cut out by Thereus, and thence deduce a plausible reason for believing that the nightingale is in reality deprived of the tip of the tongue*."

Now, recurring to the comparison of the organs of the voice to a reeded wind instrument, it has been maintained by Dutrochet and Cuvier, that the tube which conveys the air to the reed has no influence whatever on the sound produced. M. Biot, however, relates an experiment by $\mathbf{M}$. Grenié, which proves that this opinion is not correct. It is not impossible, that the lengthening or shortening the windpipe, which is the tube for conveying the air to the vocal chords, may have some influence in the production of the voice and in occasioning its different tones. This tube, indeed, is formed so as to be lengthened or shortened, enlarged or diminished in diameter; and being susceptible of assuming an indefinite number of different forms, it may fulfil very well the office of the body of a reed instrument; that is, it may possess the power of adjusting itself so as to harmonize with the vocal chords, and thus favour the production of any among the numerous tones of which the voice is susceptible. It will increase the intensity of the vocal sounds, by assuming a conical form ; by enlarging externally, it will give them an agreeable rotundity; * Aldrovandi Ornithologia, ii. 339. 
or, by a suitable disposition of the external opening, it will nearly suppress them. Bnt till natural philosophy shall have determined with precision the influence of the tube in reeded instruments, we can, at best, only form probable conjectures upon this subject. Through its various peculiarities, however, of form, position, elasticity, and movement, the tongue in the nightingale, like the value or lid (epriglottis) of the orifice in man, scems to constitute an essential part of the apparatus of the voice, independently of its office of contracting the vocal tube. M. Grenie, who has invented so many ingenious and useful modifications of reeded instruments, at one period of his investigations, attempted to angment the in. tensity of the sound without changing the reed. To effect that object, he was obliged to augment, gradually, the intensity of the current of air ; but this, though it rendered the sounds stronger, had likewise the effect of elevating the note. 'The only remedy for this inconvenience, which M. Grenié could discover, was to place obliquely, in the tube, immediately above the reed, a flexible elastic tongue, resembling very much the similar apparatus in animals.

Among the call-notes of birds, that of the bittern (Ardea stellaris), has excited attention from the earliest times, anrl varions attempts have been made to account for its formation. The sound itself has been likened to the lowing of a bull, and hence the bird was called the bull (Botaumus), by old writers; but Willughlyy, from his own observation, asserts that the somick is "nothing like to lowing," \&c., but "to say the truth, seems muchl more to imitate the braying of an ass than the bellowing of a bull*." Goldsmith's description, also, from his own observation, seems more minute, though it may possibly * Ornith. lyy Ray, p. 283. 
be somewhat tinged with poetry. "Those," says he, "who have walked in an evening by the sedgy sides of unfrequented rivers, must remember a variety of notes from different water-fowl ; the loud scream of the wild groose, the croaking of the mallard, the whining of the lap-wing, and the tremulous neighing of the jack-snipe. But of all those sounds there is none so dismally hollow as the booming of the bittern. It is impossible for words to give those who have not heard this evening call, an adequate idea of its solemnity. It is like the interrupted bellowing of a bull, but hollower and louder, and is heard at a mile's distance, as if issuing from some formidable being that resided at the bottom of the waters." Southey represents this sound as being heard at a distance :

"s At evening o'er the swampy plain

The bittern's boom came fart."

The earliest explanation we have met with of the manner in which this sound is produced, is by Aristotle, who introduces it amongst his Problems. "Why," says he, " do those, which are called Bomugi, and which are fabulously reported to be bulls, consecrated to some deity, usually divell among marshes, which are situate near rivers? Is the sound really so like the bellowing of a bull, that, if it is heard by oxen, they are as much affected by it, as if they felt sensible some bull was bellowing? Is not such a sound produced when rivers inundate marshes, or marshes overflow their boundaries, and are either roughly checked in their impetuous course by the sea, and thence send forth a rushing sound? Similar sounds are produced in caverns under ground, into which currents of water rush and dispel the air through small apertures; and also when a man
* Auimated Nature, iii. 263.
+ Thalaba. 
applies his mouth to an empty barrel, and makes a murmuring noise therein, it will resemble the lowing of an ox. Varions forms of things which are hollow produce sounds of astonishing variety. If any one, for instance, remove the lid of a cask and draw the bottom of it upwards and downwards, shouting in it at the same time, a sound will, by such a contrivance, be produced, that would frighten wild animals in a similar manner to that which is practised by orchard keepers*."

Old Belon does not seem to be aware of this pas. sage when he says, "It is not a little marvellous that Aristotle, who has written the history of animals with so much care, should have left it to us to record, that when the bittern comes to the bank of a pond or marsh, putting its bill under the water, it produces so loud a sound that a bull could not bellow so loud; for it so manages the utterance of this sound that it can be heard at the distance of half a leaguet." Gesner, from his own observation, says it may be heard at the distance of half a German mile $\ddagger$; or, as another author gives it, a grond lıour's walk $\$$.

The remarks of Buffon on the loudness of the roices of birds are more correct than is usual with him when he lanncles into speculation. "In birds," he says, "the formation of the thorax, of the lungs, and of all the organs connected with these, secms expressly calculated to give force and duration to their utterance, and the effect must be proportionally

* Aristutle, Problem, ii. 35.

† Oyseaux, p. 193, fol. Paris, 1555. The original is, "C'est bien is s'csmerueiller qu'Aristote, qui it escrit l'histuire des animaux saigneusement, à laissé ce que dirons du Butor, c'est que quand il se trouve à la rive de quelque estang au marais, mettant son lec en l'eau, il fait un si gros son, qu'il n'y à beuf qui peust crier si hant."

I De Avibus, iii. Ardea Stellaris.

\$ Physica Curiosx; p. $\$ 100$. 
greater. There is another circumstance which evinces that birds have a prodigious power of voice; the cries of many species are uttered in the higher regions of the atmosphere, where the rarity of the medium inust consequently weaken the effect. That the rarefaction of the air diminishes sounds is well ascertained from pneumatical experiments; and I can add from my own observation, that, even in the open air, a sensible difference in this respect may be perceived. I have often spent whole days in the forests, where I was obliged to listen closely to the cries of the dogs or shouts of the hunters; I uniformly found that the same noises, were much less audible during the heat of the day, between ten and four o'clock, than in the evening, and particularly in the night, whose stillness would make hardly any alteration, since in these sequestered scenes there is nothing to disturb the harmony but the slight buzz of insects, and the chirping of some birds. I have observed a similar difference between the frosty days in winter and the heats of summer. This can be imputed only to the variation in the density of the air. Indeed, the difference seems to be so great, that I have often been unable to distinguish, in mid-day, at the distance of six hundred paces, the same voice which I could, at six o'clock in the morning or evening, hear at that of twelve or fifteen hundred paces. A bird may rise at least to the height of seventeen thousand feet, for it is there just visible. A flock of several hundred storks, geese, or ducks, must mount still higher, since, notwithstanding the space which they occupy, they soar almost out of sight. If the cry of birds, therefore, may be heard from an altitude of above a league, we may reckon it at least four times as powerful as that of inen or quadrupeds, which is not audible at more than half a league's distance on the surface. But this estimation is even too low; for, besides the dis- 
sipation of force to be attributed to the cause already assigned, the sound is propagated in the higher regions as from a centre in all directions, and only a part of it reaches the ground; bnt, when made at the surface, the aerrial waves are reflected as they roll along, and the lateral and vertical effect is augmented. It is hence that a person on the top of a tower hears one better at the bottom than the person below hears from above *."

With respect to the bittern, an opinion is popularly held, that this bird "thrusts its bill into a reed that serves it as a pipe for sweiling the note above its natural pitch;" the supposition of some being, "from the londness and solemnity of the note, that the bird made use of external instruments to produce it, and that so small a body could never eject such a quantity of tone; while others, and in this number we find 'Thomson, the poet, imagine that the bird puts its head under water, and then, violently blowing, produces its boomingst." Thomson says-

"4 So that scarce

The bittern knows his time, with bill ingulph'd, Tu shake the sounding marsh +."

Had 'Thomson, however, been acquainted with the Omithology of Aldrovand, he might there have found a correct account of the vocal organs by which the bird produces the sound, and which we shall now translate. "It has not," he says, "like the wild swan and many others, a double larynx, namely, one at the base of the tongue, and another where the windpipe begins to divaricate. In the bittern the windpipe is continuous, having no larynx nor anything analogous to one. But Nature appears to have wished to compensate for this deficiency, by constructing two canals

* Wood's Buffon, xi. 12.

† Goldsmith, Anim. Nat. iii. 263.

小 Seasons,-Spring. 
from the windpipe, one going to the right and another to the left lung. The cartilaginous rings of the windpipe, moreover, do not go entirely, but only half round the tube, the circle being completed by a thin, loose, and elastic membrane, which is capable of being greatly inflated. Two sacks being thus formed, when they are inflated, the imprisoned air escapes with violence in bellowing.". So far the account is perspicuous and accurate; but he adds, "When the inspired air inflates the sacks, the bird, thrusting its bill under water, and opening it, allows the air to rush out with such impetus as to rival the bellowing of a bullt." We must consider this statement as purely conjectural; and, as Buffon well remarks, it would not be easy either to verify or disprove the fact from observation $\ddagger$, since the bird lurks always so close as to escape the sight, and the fowlers camnot reach the spots where it lurks without wading through the reeds into deep water. Goldsmith, who seems to liave been faniliar with the sound, says, "It is often heard where there are neither reeds nor waters to assist its sonorous invitations." He adds, "It cannot be, therefore, from its voracious appetites, but its hollow boom, that the bittern is held in such detestation by the vulgar. I remember, in the place where I was a boy, with what terror this bird's note affected the whole village; they considered it as the presare of some sad event, and generally found or made one to succeed it. I do not speak ludicrously; but if any person in the neighbourhood died, they supposed it could not be otherwise, for the night raven had foretold it; but if nobody happened to die, the deatl of a cow or a sheep gave completion to the prophecy $\$$."

"The bellowing noise," says Dr. Latham, "is supposed to arise from a loose membrane which can

* Ornithologia, iii. 166.

+. Oiseaux, Art. Le Butor. t Ibid.

§ Anim. Nat, iii, 264. 
be filled with air and exploded at pleasure; and the situation of it is at the divarication of the windpipe; it is capable of great distension, and is probably the cause of this singular phenomenon, observed, we believe, in no other bird, at least in the same degree. We have had no opportmity ourselves of witnessing this, but are inforned by Dr. Lamb, that, on dissecting a female, he observed that after the windpipe (trachea) had passed into the chest (thorar) to the lower part of the breast-bone (sternum), it was reflected to the superior portion of the latter, and then, on a second reflection, divided and passed into the lungs." He adds, "I have been assured, that by filling the windpipe with air after death and exploding. it again suddenly, a similar noise will be produced *."

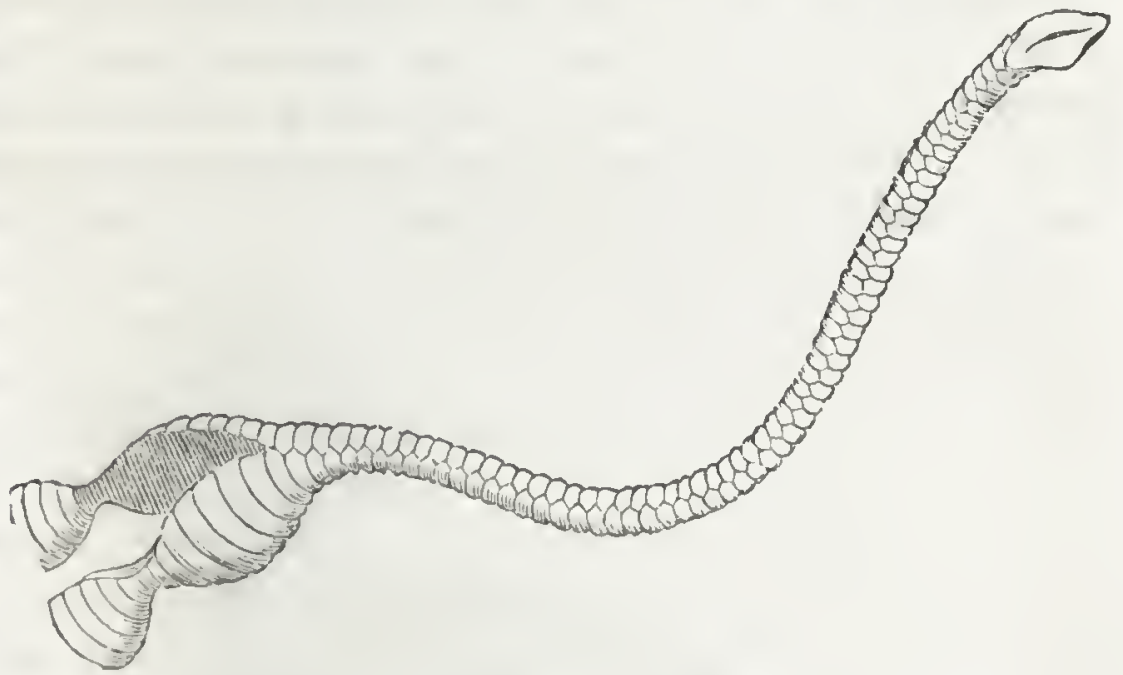

Singularly formed Windpipe of the Butor.

The cry of the bittern has been sometimes confounded with that of the snipe, though there is little if any resemblance between the twot. It is, on the contrary, so like the bleating of a goat, that Klein and Rzac:zynski have named it the celestial goat (Capella * General Hist. of Birds, ix.98. See also Ward, Nat. Hist. of Birds, iii. 150 .

+ J. Rennic, Mag. Nat. Hist. i. 495. 
cœlestis) ; and, in the North, it is well known under the name of Heather-bleat. The snipe, however, like most other birds, can vary its calls. "One note," it has been said, "may be compared to the words "tinker, tinker,' uttered in a sharp shrill tone, as the bird ascends in his flight; the other, uttered as he descends, is somewhat similar to the bleating of a lamb, only in a deeper tone, and accompanied with a violent vibration of the wings *."

It is probable, as M. Temminck plausibly conjectures, that some unexamined peculiarity of construction in the vocal organs of the Indian-crowned pigeon (Lophyrus cristatus, Vifrilot) enables it to produce the loud cooing, or rather bellowing, which so much alarmed M. Bougainville's sailors when they landed on a wild and unfrequented spot in some of the New Guinea islands, that they supposed it to proceed from the cries of hostile and concealed natives $\uparrow$. Temminck compares the sound to the gobbling ventriloquism of the turkey.

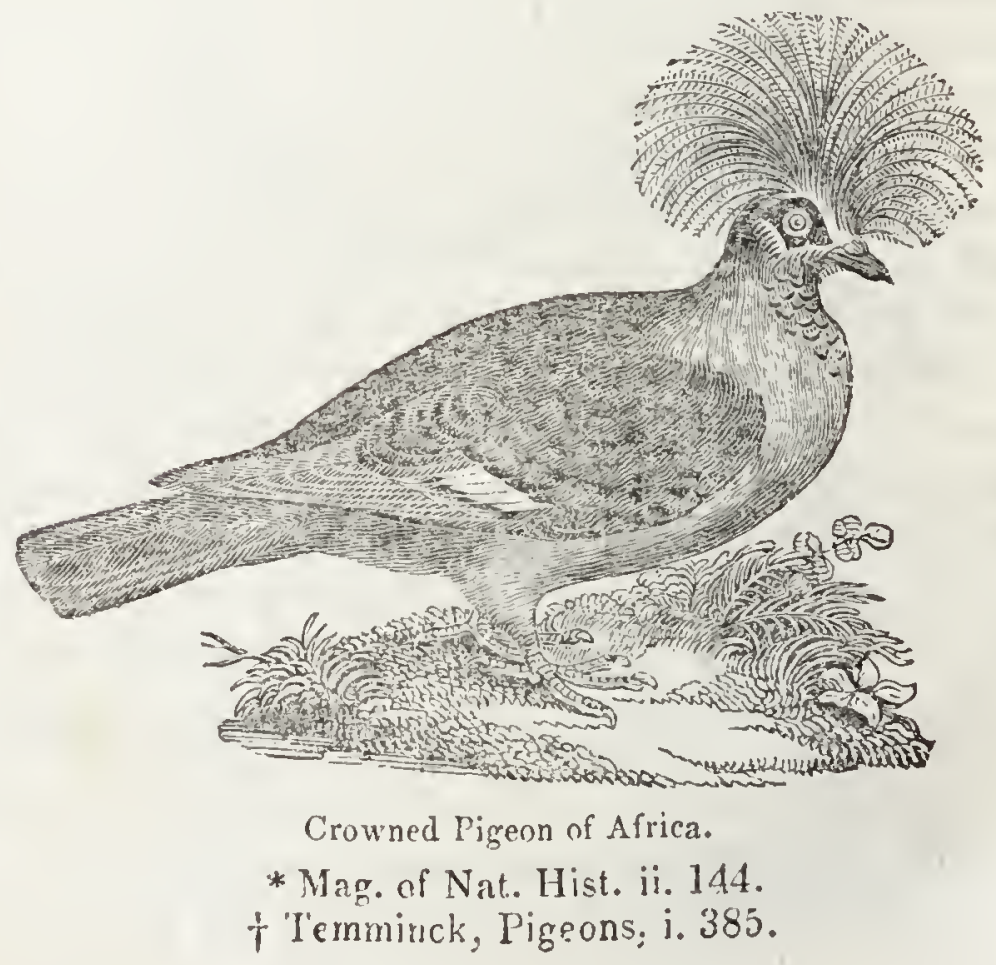




\section{Chapter XIV.}

\section{LANGUAGE OF BIRDS.}

$\mathrm{Br}$ the term language, in reference to birds, we mean sounds which can be mutually understood, excluding the words and phrases which parrots and starlings may be tauglit by imitation, but to which the birds that repeat them can attach no meaning. An example will best illustrate this, and we do not recollect one more apposite than a circumstance mentioned by Wilson when speaking of the richel bird (Sterna mimuta). "I lately," he says, "visited those parts of the beach on Cape May, where this little bird breeds. During my whole stay, these birds flew in crowds around ine, and often within a few yards of my head, squeaking like so many young pigs, which noise their voice strikingly resembles. A humming-bird, that had accidentally strayed to the place, appeared suddenly among this outrageous troop, several of whom darted angrily at him; but he shot like an arrow from them, directing his flight straight towards the ocean. I have no doubt but the distressing cries of the terus had drawn this little creature to the scene, having frequently witnessed his anxions curiosity on similar occasions in the woods*." The humming-bird indeed is not alone in the exhibition of curiosity to see what is going forward when other birds are vociferous. We recollect having our attention once drawn to the loud scolding of a pair of chaffinches in a copse, a circumstance of very frequent occurrence during summer, but rendered peculiar in the instance in * Wilson, Am. Ornith, vii. 85. 
question, by the birds darting down almost to the roots of the bushes at some distance from where we stood, from which we concluded their scolding was not directed to us. The loud pink, pink, of the chaffinches soon attracted to the spot a crowd of their woodland neighbours, among whom a red-breast took the lead, followed by a green-bird, a songthrush, and about a dozen of the small summer birds (Sylviada), all brought together by curiosity to learn what the chaffinches were scolding about. From all of these curiosity-hunters giving vent to the same expression of feeling, we concluded that some common enemy had made his appearance among them; and upon looking narrowly into the bushes we perceived a pine martin (Martes abietum, $\mathrm{R}_{\mathrm{AY}}$ ) stealing along, occasionally throwing a sly, or rather contemptuous look at his vociferous railers, but otherwise continuing a careful prying search into every hole and bush for a nest of egges or young, of which he might make a breakfast *

It appears, however, to be a shrewd and correct observation of Mr. Knapp, that the voice of one species of birds, except in particular cases, is not attended to by another species; and he instances the peculiar call of the female cuckoo which assembles so many contending rivals, but excites no attention generally, inasmuch as the dialect seems to be unknown to all but its own species. He adds, "I know but one note which animals make use of, that seems of universal comprehension, and this is the signal of danger: the instant it is uttered, we hear the whole flock, thongh composed of various species, repeat a separate inoan, and away they all scuttle into the bushes for safety + ."

The latter circumstance, however, is contrary to all * .J. R.

† Journ, of a Naturalist, p. 268, third edit. 
that we have ever observed; for instead of flying or hiding from danger, the alarm-call seems to $\mathrm{em}$ bolden even the most timid to run every hazard; and accordingly, it is matter of common observation that whenever a hawk makes his appearance, the first swallow which descries him, sounds the tocsin, when not only all the swallows in the vicinity muster their forces, but many other small birds liurry to the spot, and so far from sculking away out of danger, they boldly face their powerful foe, attacking lim fearlessly with beak and wing, till some individual pays the penalty of his temerity. With this exception we can bear testimony to the description of Mr. Knapp being minutely correct. "Some," he adds, " give the maternal hush to their young, and mount to inquire into the jeopardy announced. The wren, that tells of perils from the hedge, soon collects about her all the various inquisitive species within hearing to survey and ascertain the object and add their separate fears. 'The swallow, that shrieking darts in devious flight through the air when a hawk appears, not only calls up all the hirundines of the village, but is instantly understood by every finch and sparrow, and its warning attended to *."

Dr. Darwin, in his usual ingenious but fanciful manner, endeavours to show that this language of fear and alarm is (like other sounds usually considered natural) acquired and conventional like human speech. His facts will amuse the reader, while lis inferences inust appear quite hypothetical and strained. "All other animals," lie says, "as well as man, are possessed of the natural language of the passions, expressed in signs or tones; and we shall endeavour to evince, that those animals which have preserved themselves from being enslaved by mankind, and are associated in floclis, are also possessed of some * Jouru. of a Naturalist, p. 268, third edit. 
artificial language and of some traditional know. ledge.

"The mother-turkey, when she eyes a kite hovering high in air, has either seen her own parents thrown into fear at his presence, or has by observation been acquainted with his dangerous designs upon her young: She becomes agitated with fear, and uses the natural language of that passion; her young ones catch the fear by imitation, and in an instant conceal themselves in the grass.

"At the same time that she shows her fears by her gesture and deportment, she uses a certain exclamation, Koe-ut, Koe-ut, and the young ones afterwards know that the presence of their adversary is denounced and hide themselves as before.

"The wild tribes of birds have very frequent opportunities of knowing their enemies by observing the destruction they make amoug their progeny, of which every year but a small part escapes to maturity; but to our domestic birds these opportunities so rarely occur, that their knowledge of their distant enemies must frequently be delivered by tradition in the mamer above explained, through many generations.

"'l'his note of danger, as well as the other notes of the mother-turkey, when she calls her flock to their food, or to sleep under her wings, appears to be an artificial language, both as expressed by the mother, and as understood by the progeny. For a hen teaches this language with equal ease to the ducklings she has hatched from supposititious eggrs, and educates as her own offspring; and the wagtails or herdge-sparrows learn it from the young cuckoo, their foster-nursling, and supply him with food long after he can fly about, whenever they hear his cuckooing, which Limnæus tells us, is his call of hunger*. And * Syst. Nat. 
all our domestic animals are readily taught to come to us for food when we use one tone of voice, and to fly from our anger when we use another.

"Rabbits, as they canmot easily articulate somuds, and are formed into societies that live muder ground, have a very different method of giving alarm. When danger is threatened, they thump on the ground with one of their hinder feet, and produce a sound that can be heard a great way by animals near the surface of the earth, which would seem to be an artificial sign both from its singularity and its aptness to the situation of the animal.

"The rabbits on the island of Lor near Senegal have white flesh and are well-tasted, but do not burrow in the earth, so that we may suspect their digging themselves houses in this cold climate is an acquired art, as well as their note of alarm $*$

"The barking of dogs is another curious note of alarm, and would seem to be an acquired language, rather than a natural sign; for 'in the island of Juan Fermandez, the dogs did not attempt to bark, till some Enropean dogs were put anong them; and then they gradually begun to imitate them, but in a strange manner at first, as if they were learning a thing that was not natural to them $t^{\prime}$ '

"Limnæus also observes that the dogs of America do not bark at strangers + ; and the Luropean dogs which have been earried to Guinea are said, in three or fonr generations, to cease to bark, and only howl, like the dogs that are natives of that coast $\$$."

In reference to the thumping of the rabbit mentioned by Dr. Darwin, we may state that the act

* Adansou's Voyage to Senegal.

† Voyage to S. America, by Dou G. Juin and Don Ant. de. Ulloa, B. 1i. c. 4.

+ Syst. Nat.

World Displayed, xvii. 26, and 'Loonomia, \& xvi.10,1. 
is by no means peculiar to that species, several other animals exhibiting it still more strikingly, and amongst others the porcupine (Hystrix, BRisson), which we have in numerous instances observed when in confinement to beat the floor of its cage with one of its hind feet so violently as to make us apprehend it might fracture the bone. We are not sufficiently acquainted with the economy of the porcupine in a wild state to assign a cause for this thumping; but it appeared to us to mean defiance as plainly as the hissing of an owl or of a gander, or the crowing of a cock .

Those who have attended minutely to the language of fear, alarm, or defiance among birds, cannot fail to have remarked the considerable variety both of notes and intonation in the same species. 'Thus, as White of Selborne remarks, "when the hen turkey leads forth her young brood, she keeps a watchful eye, and if a bird of prey appear, though ever so high in the air, the careful mother announces the enemy with a little inward moan and watches him with a steady and attentive look; but if he approach, her note becomes earnest and alarming, and her outcries are redoubled $\uparrow . "$ In the instance of a cock bird expressing fear or giving an alarm to the hen of the approach of langer near the nest, the tones seem to be varied so as to give her due notice either to keep close and still, or to make her escape with as much caution as she can. "This note," observes Mr. Syme, "is only comprehended by birds of the sane species, though we have certainly seen birds of different genera appear as if alarmed by this note of fear sounded by a bird of a different species or genus; but whether it was the note that alarmed them, or our presence, we cannot say. But we are pretty sure the notes of parent birds and the chirp of their young, * J, R. + Letter 85. 
are only understood by birds of the same species, or rather we should say same family, for it appears to be a family language, understood reciprocally by parent bircs and their young: for the young know the notes of the parents, and the parents those of their own brood, amongst all the young broods of other birls of the same species in the neighbourhood; and this they do as distinctly as the ewe knows the bleat of her own lamb, or the lamb the cry of its own mother, amongst a large flock. With regard to the note of alarm birds send forth on the approach of their natural enemies, whether a hawk, an owl, or a cat, we consider it to be a general langruage perfectly understood by all small birds, though each species has a note peculiar to itself. This note differs in sound from the note of fear or alarm given by them when man approaches near their nests. This last seems confined to particular species; but this general alarm note (which is understood by all small birds), we should call their war.whoop or gathering cry, for it is a true natural slogan *"

'The noisy cackle of jays, the cawing of rooks, and the incessant yelp of sparrows, appear, so far as we can judge, to be partly so many social signals for congregating in a particular place, and to be continued after the flock has assembled, either to warn stragglers to what point they ought to wing their way, or, in the spirit of rivalry which prevails so extensively amongst birds, with the object of outvying each other in loudness of tone. It is remarkable, indeed, that most, if not all, gregarious birds are thus noisy, and difler much in this respect from solitary or sub-solitary birds. If a rook or a sea-gull, therefore, is by accident separated from its companions, it will keep up 
an incessant vociferous call, till a response is returned either from some other straggler, or from the colony to which it belongs. The necessity of such a habit as this is still more obvious in the case of those birds which migrate together at night. "Aquatic and gregarious birds," says White, "especially the nocturnal, that shift their quarters in the dark, are very noisy and loquacious; as cranes, wild-geese, wildducks, and the like; their perpetual clamour prevents them from dispersing and losing their companions*;" and accordingly, when residing near the sea or a large river, we have often heard the scream of these night-fliers "startle the dull ear of night."

There appears, however, to be a decided and wellunderstood distinction between the call of such stragglers as we have just alluded to, and the gathering-cry when an individual has discovered abundarice of food. A sea-mew, or what is more common, a pair of sea-mews, may thus be seen far inland, whither they have probably been driven by blowing weather, coursing about high in the air, sometimes flying in one direction and sometimes tacking about, and all the while uttering at intervals a peculiar call-note; but even should this occur near the beach, no other sea-mew would think of coming at the signal. But, on the other hand, the note of intimation proceeding from an individual who has discovered a good fishing-station over a sand-bank, is so well understood and so quickly obeyed, that we have repeatedly seen some hundreds of birds hurry to the place in a few minutes, though none were previously observable.

There are instances, however, of birds thus calling when on the wing, which it does not seem so natural to account for on either of these suppositions. 
We may mention the shrilt harsh scream of the ling-fisher and of the dipper (Cinclus aquaticus, Becistern), which, so far as our observation goes, is repeated every time these birds take wing. It may, perhaps, as they are almost always seen in pairs, bc meant as a signal-note to the mate,-an explanation rendered more probable by the rapidity of their flight, which carries them in an instant to a great distance along a stream, so that without some such watch-call they might soon be separated. 'This calt is not unlike the sound of a stick drawn rapidly across the uprights of an iron railing, and comes on the ear so quick and transient, that it is impossible to catch a view of the bird by trying to follow the sound *.

It is ingeniously, and, as we think, correctly, remarked by Mr. Knapp, that "as Nature, in all her ordinations, had a fixed design and fore-knowledge, it may be that each species had a separate voice assigned it, that each might continue as created, distinct and mmixed; and the very few deviations and admixtures that have taken place, considering the lapse of time, association, and opportunity, united with the prohibition of continuing accidental deviations, are very remarkable, and indicate a cause and original motive. That some of the notes of birds arc a language designed to convey a meaning, is obvious from the very different sounds uttered by these creatures at particular periods; the spring voices become changed as summer advances, and the requirements of the early season have ceased: the summer excitements, monitions, informations, are not needed in autumn, and the notes conreying such intclligence are no longer heard. The periodical calls of animals, croaking of frogs, \&c., afford the 
same reason for concluding that the sound of their voices, by elevation, depression, or modulation, conveys intelligence equivalent to an uttered sentence. 'The voices of birds seem applicable, in most instances, to the immediate necessities of their condition; such as the sexual call, the invitation to unite when dispersed, the moan of danger, the shriek of alarm, the notice of food *."

It was, no doubt, from such views as these that the notion originated of birds being possessed of a language, and of a knowledge of it having heen obtained by certain individuals. The faculty of interpreting the language of birds is attributed, in classic fable, to various of the ancient diviners. Apollodorus, in his Bibliotheca, relates of Melampus, that he acquired this gift by having had his ears licked by serpents; and that one of the ways by which he chiefly gained a knowledge of futurity, was by listening to what he heard uttered by the birds as they flew over his head. Porphyry, in his book on abstinence from animal food, refers to Empedocles, Plato, and Aristotle, in support of the opinion that all the inferior animals are possessed both of reason and language; and, in addition to Melampus, he mentions 'Tiresias, Thales, and Apollonius of 'Tyanaa, as having been able to interpret what they said. This is affirmed to have been one of the gifts bestowed upon Tiresias in compensation for his blindness by Minerva. Some of the Jewish rabbies have attributed a similar power to King Solomon. Even as late as the seventeenth century we find the Irish monk, Bonaventure Baron, in his work in defence of Scotus, speaking of a brother Franciscan, who, he says, understood the language of beasts, and was enabled by that means to foretell

* Journ. of a Naturalist, p. 269, 3d edit. 
coming events. The belief that birds are possessed of a knowledge of futurity, is part of the same notion which has led men to seek indications of what is about to happen in their flight and other movements, and which has given rise both to the ancient vaticination by augury, and to various popular superstitions which still survive. The power of communicating the gift of prophecy inherent in the serpent, was also a prominent article of the mystic creed of antiquity. 'The Trojan prophetess, Cassandra, is said to have acquired her art by having been left one night, when a child, together with her twin brother Helenus, in the temple of Apollo, when the two were found next morning with some serpents coiled round them and licking their ears. And Pliny, in his Natural History, tells us that Democritus had mentioned the names of certain birds, whose blood being mixed together would produce a serpent of such virtue, that any one who ate of it should understand whatever was said by birds when they conversed together. 'This story is alluded to by Addison in one of his Spectators *

It were to be wished that all fables in natural history were as obvious to an ordinary reader as this; for we meet with others in books wearing the air of well-ascertained facts, which could only originate in the fancy of the writers. This is exemplified in the story told of the butcher-bird (Lanius excubitor), which is said to imitate the voices of other birds, by way of decoying them within his reach, that he may devour them " excepting this," it is added, "his natural note is the same throughout

* Vol. vii. No.512. See upon this subject Barle, Dictionnaire, in articles Carsindra, Melampus, Pereira, and Tiresia:. See also sume remarts on the language of hirds in Muntaigne, Essais, Lir. ii. Es. 12, Apologie pour Raymonde de Sebonde. 
all seasons: when kept in a cagre, even when he seems perfectly contented, he is always mute*." We venture to say, however, that nobody will ever be able to authenticate this statement, for the organs of the bird, were there no other obstacle, seem altogether incapable of the variety of modulation which the habit imputed to it would require, though, like most, if not all other birds, this species ean express more than one sort of feeling. Father Kircher, who attended minutely to this curious subject, has expressed the various notes of poultry by musical characters of which the following is a copy.

Cock's notes.

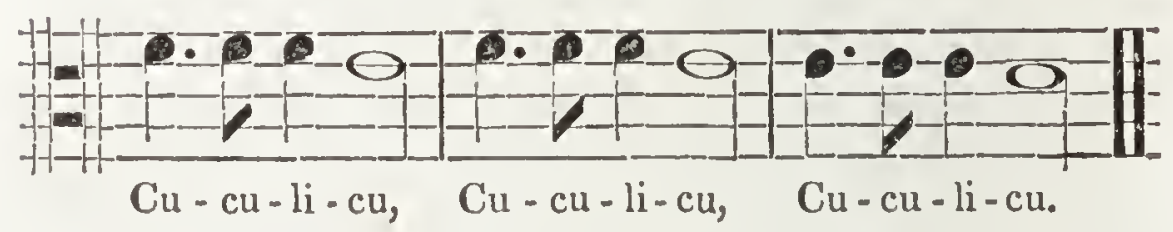

Hen after laying.
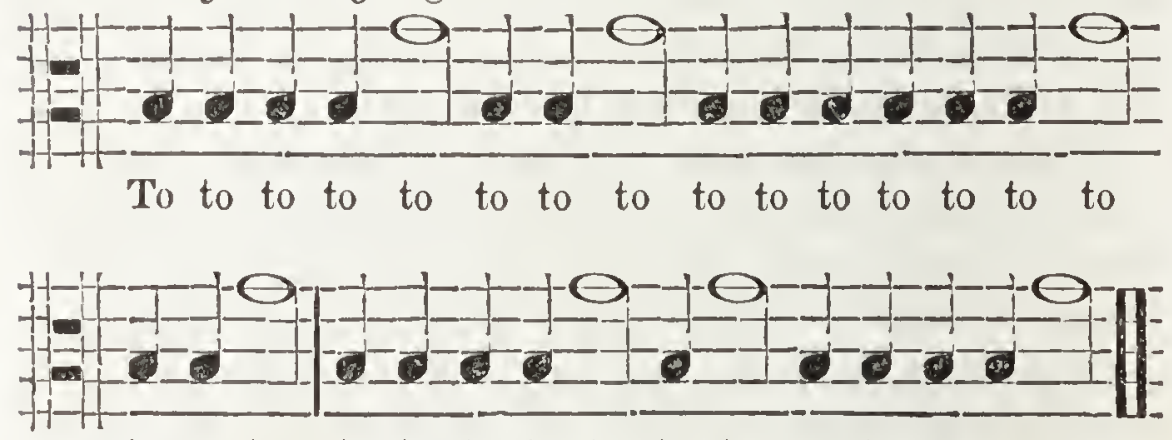

to to to to to to to to to to to to to to to

Hen calling her chickens.

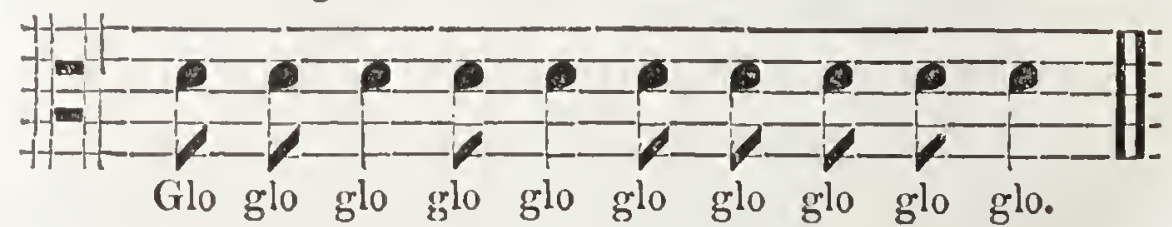

* Anim. Biog. ii. 219. 
Call of the Quail.

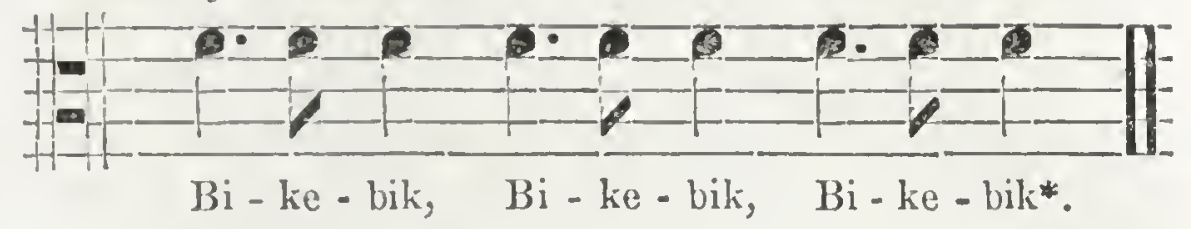

M. Vaillant has alco noted in a similar manuer the peculiar calls of many of the birds which he observed in Southern Africa.

* Kircher's Musurgia, i. 


\section{Chapter XV.}

SONGS OF BIRDS.

THE songs of birds have given rise to several curious inquiries of no small interest to naturalists, sonre of which it may prove both amusing and instructive to detail. We may, however, begin by stating, that, after investigating the subject with considerable attention for many years, we have come to the conclusion that the notes of birds which are denominated singing, may all be referred to hilarity and joy, or to rivalry and defiance, rather than to imitation or to love, as has been maintained by some maturalists of celebrity. Mr. Pennant gives the fol-. lowing view of the matter:-

"It may be worthy," he says, "of observation, that the female of no species of birds ever sings: with birds it is the reverse of what occurs in human kind: among the feathered tribe, all the cares of life fall to the lot of the tender sex: theirs is the fatigue of incubation; and the principal share in nursing the helpless brood: to alleviate these fatigues, and to support her under them, nature hath given to the male the song, with all the little blandishments and soothing arts; these he fondly exerts (even after courtship) on some spray contiguous to the nest, during the time his mate is performing her parental duties. To these we may add a few particulars, that fell within our notice during our inquiries among the bird-catchers, such as, that thev immediately kill 
the hens of every species of birds they take, being incapable of singing

Bufion makes the qualified statement that "the females are much more silent than the males, song being generally withheld from thent + ;" probably resting on the authority of Lord Bacon, who says "that cock birds, among singing birds, are ever the better singers.." The latter again most likely followed A ristotle, who says, "some males sing like their females, as appear's anong nightingales, but the female gives over song when she liatches §." Daines Barrington, assuming it as a fact that females never sing, proceeds to divine the reason thereof, inferring it to be because it might betray their nest should they sing while sitting on their eggrs $\|$. But before drawing such a conclusion, it would have been well to make sure of the fact. It is certainly true as a general position, that female birds do not sing; yet many exceptions have been recorded. We possess, at present, in the same aviary with two green-birds and an aberdevine (Carduelis spinus), a female canary who sings a great deal. Her notes indeed are harsh and unmusical, but are both loud and uttered in a full and sustained tone of voice, though altogether unlike the notes either of the male canary or of any other bird with which we are acquainted. It is no less worthy of remark that this female canary is never excited to rivalry by the songs of a number of other birds in the same apartment, as the cocks of every species commonly are; for she usually remains silent during the attempts of the others to sing each other down, and prefers singing at night when the others are for the most part silent. We have also re-

"Brit. Zool. ii. 335.
+ + Sylva Sylvarum, p. 56, ed. fol. 1664 .
$\begin{aligned} & \text { \$ Hist. Anim. iv. 9. } \\ & \text { H Phil. Trans. Ixii. }\end{aligned}$ 
marked in birds reared from the nest, that the females will record, as it is termed, the first rehearsal (inexpertum carmen, as Statius gives it in his 'Sylvæ,') warbling in the low preluding manner peculiar to all birds some time before coming into full song. This was particularly the case with the green-birds just mentioned, and one female green-bird will at present record in a similar manner, while her brother of the same age begins to sing in good earnest *

Mr. Sweet, the well-known botanical writer, and author of the "British Warblers,' says that "females seldom sing: I had a female red-start, which sang a little; and female bulfinches sing as frequently as the males." Again, Mr. Sweet says, "I have had several female birds, which never attempted to sing; but now I have two that sing frequently; one is a female black-cap; she sings a note peculiar to herself, and not the least like the male, or any other bird with which I am acquainted. I kept her several years before she began to sing. I have also a female willow-wren, that sings nearly as much as the cock; this bird was bred up from the nest, and did not sing at all the first year. Her note is quite different from that of the male, but resembles it sufficiently to indicate that it belongs to the same speciest." "In nightingales," says M. Montbeillard, "as in other species, there are females which enjoy some prerogatives of the male, and particularly participate of his song. I saw a female of that sort which was tame; her warble resembled that of the male, yet neither so full nor so varied; she retained it unti] spring, when resuming the character of the sex, she exchanged it for the occupation of building lier nest and laying her eggs, though she had no mate. It

* J. R.

+ Magazine of Nat. Hist. i. 316. 
would seem that in warm countries, as in Greece, such females are pretty common, both in this species and many others; at least this is implied in a passage of Aristotle*." Aldrovand, in deducing lessons of morality from this bird, thinks the female ought to be imitated in her silence by women, who "in his time," on the coutrary, "were loquacious, babbling, verlose, garrulous, talkative, tonguy, and never kept secrets $t^{\prime \prime}$

With respect, again, to Mr. Barrington's inference that the want of song in the female is for the purpose of concealing the egrgs, Mr. Sweet further says, "I certainly have never heard a thrush sing when sitting:" (as had been asserted by a correspondent in a recent periodical work,) "perliaps for want of attending to it; but I have frequently heard and seen the male black-cap sing while sitting on the eggs, and have found its nest by it more than once; the male of this species sitting nearly as much as the female t." These well-authenticated facts, as well as more that we could adduce, are fatal to the theory.

St. A mbrose, on the other hand, asserts that "the nightingale by the sweetness of her song solaces herself during the long nights in which she is hatching her eggs, watchful and sleepless \$."

Another hypothesis advocated by several naturalists, and adopted by poets, is that the singing of birds is the language of courtship and affection. "The song of male birds," says Buffon, "springs from the emotion of love: the canary in his cage, the green-bird in the fields, the oriole in the woods, chaunt their notes with a fond, sonorous voice, and their mates

* Oiseaux, Art. Le Rosignol ; and Aristotle, ir. 9.

巾 Loquaculæ, argutulæ, verbosæ, dicaculæ, linguaces, garrulæ et arcanorum minime tenaces.-Ornithol. ii. 346.

$\ddagger$ Mag. of Nat. Hist. ii. 113.

$\$$ Quoted by Aldrovand as above. 
reply in more feeble strains." He adds, what is by no means the fact, that "the nightingale, when he first arrives in spring, is silent, begins with faltering, infrequent airs, and it is not till the dam sits on her egg's that he pours out the warm melody of his heart: then he relieves and soothes her tedious incubation; then he redoubles his caresses, and warbles with deeper pathos*." On the contrary, we uniformly observe, among the innumerable nightingales which annually arrive in our neighbourhood in spring, that the males sing out in as full clear notes on their first appearance (usually many days before the arrival of the females) as they ever do afterwards $\dagger$. Buffon concludes that his opinion derives additional support from the circumstance of song-birds becoming silent, or their notes being less sweet, after the breeding season is over $\ddagger$.

Another naturalist of eminence, Colonel Montagu, is more circumstantial in his arguments for the same opinion, and though we do not agree altogether with his explanations, the greater number of his facts are unquestionable. " The males of song-birds," he says, "and many others, do not in general search for the female; bnt, on the contrary, their business in the spring is to perch on some conspicuous spot, breathing out their full notes, which, by instinct, the female knows, and repairs to the spot to choose her mate. This is particularly verified with respect to the summer-birds of passage. The nightingale, and most of its genus, although timid and shy to a great degree, mount aloft, and incessantly pour forth their strains, each seemingly vying in its love-laboured song before the females arrive. No sooner do they make their appearance than dreadful battles ensue, and their

* Oiseaux, Intr.
+ Oiseaux, as abore. 
notes are considerably changed; sometimes their song is hurried through without the usual grace and elegance; at other times modulated into a soothing melorly. 'The first we conceive to be a provocation to battle on the sight of another male; the last an amorous cadence, or courting address. This variety of song lasts no longer than till the female is fixed in her choice, which is, in general, in a few days after her arrival; and if the season is favourable, she soon begins the task allotted to her sex.

"The male now no more exposes himself to sing as before, nor are his songs heard so frequently or so loud; but while she is searching for a secure place to build her nest in, he is no less assiduous in attending her with ridiculous gestures, accompanied with notes peculiarly soft. When the female has chosen a spot for nidification, the male constantly attends her flight to and from the place, and sits upon some branch near, while his mate instinctively places the small portion of material she each time brings to rear a commodious fabric for her intended brood. When the building is complete, and she has laid her portion of eggs, incubation immediately takes place. The male is now heard loud again, but not near so frequently as at first; he never rambles from her hearing, and seldom from her sight; if she leaves her nest, he soon perceives it, and pursues her, sometimes accompanied with soft notes of love. When the callow brood appears, he is instantly apprized of it, either by instinct, or by the female carrying away the fragment shells to some distant place. 'The male is now no more heard in tuneful glee, unless a second brood should force the amorous song again; his whole attention is now taken up in satisfying the nutrimental calls of his tenrler infant race, which he does with no less assiduity than lis mate, carrying them food, and returning frequently with the muting 
of the young in his beak, which is dropped at a distance from the nest $*$."

Plausible as this reasoning seems to be, it will not be difficult to adduce numerous facts with which it will not accord. It is not indeed a correct statement of the fact, to say that birds sing only during the seasons of pairing and breeding, as Buffon and Montagu assume. This is the case with the greater number of the seed-eating song-birds, both wild and tame; but not with the soft-billed birds. We have not many of these resident with us during winter, the greater number migrating to more southern latitudes, where they can find an abundant supply of insects and fruits; but all of those which do winter with us continue more or less in song after having moulted. The most conspicuous and best known of these autumnal and winter song-birds is the red-breast. Both Montagu and White are in error when they say this bird "sings throughout the winter except in severe weather" or "during frost"; for though continued frost or snow, by depriving it of a due supply of food, may render it silent, we can answer for the fact of having, not once, but frequently, heard the red-breast singing as merrily during sharp frost, as in the heyday of summer or in the mild sunshine of autumn. A much smaller and more delicate bird, the wren (Anorthura communis), also sings in all weathers during the autumn and winter, as well as the little dunnock (Accentor modularis); and they are frequently accompanied by the thrush and the blackbird. Though the latter do not sing so long and so frequently as in summer, this appears to be more on account of the physical languor arising from a precarious supply of food than from its not being the pairing season. That what has been stated is not peculiar to the milder weather of the southern coun* Ornithological Dict., Intr. 1st ed.; p. 476,2d ed. 
tries, is proved by the same thing occurring in the north. In notes of observations made at Mussel. burgh in 1818, we find the following: "On the 26 th Ortober, heard a thrush in the morning singing in an orchard in as sprightly a manner as if it had been in April; and again in the evening of the same day, heard another thrush singing on the banks of the Esk at some miles distant from the orchard."-" On the Sth December observed a wren singing in the same orchard at day-break, and it was answered by a hedge-sparrow" (Accentor modularis). While writing this paragraph (Jan. 18, 1832) a song-thrush is singing in a liedge opposite our window as finely as if it were May*.

"We have one little bird," says Mr. Knapp, "the woodlark (Alanda arborea), that in the early parts of the autumnal months delights us with its harmony; and its carols may be heard in the air commonly during the calm sunny mornings of this season. They have a softness and quietness perfectly in unison with the sober, almost melancholy, stillness of the hour. The skylark also sings now, and its song. is very sweet, full of harmony, cheerful as the blue sky and gladdening beam in which it circles and sports, and known and admired by all; but the voice of the woodlark is local, not so generally heard from its softness, must almost be listened for, to be distinguished, and has not any pretensions to the hilarity of the former. This little bird sings likewise in the spring ${ }^{\prime} . "$

In addition, we have not a doubt that all our little summer visitants, from the whitethroat to the nightingale, continue in song during the winter in the comntries to which they migrate. M. Savigny, who observed the whitethroat in Egypt ${ }_{+}^{+}$, mentions

*J. R. p Journ. of a Naturalist, p. 265, 3rd edit. † Grand Ouvrage sur l'Egypt, Part Zoul. p. 276 . 
its singing on the wing, as it does with us during summer. M. Sonnini indeed says that nightingales, which "live during the winter in the verdant and smiling plains of Lower Egypt, and perhaps also on the coasts of Syria and Barbary, during their passagre and their stay on these foreign shores, do not warble those melodious songs, those varied and brilliant modulations, with which they night and day make our woods resound, inasmuch as they do not busy themselves with pairing and breeding: they are silent, because they require not to sing of love*." Yet we cannot help thinking that his observations were partly biassed by the theory with which he follows them up, more particularly as we have the testimony of $\mathrm{M}$. Le Marie to the fact of the nightingale singing in Africat.

When these birds, again, are kept in cages or aviaries in Europe during the winter, they sing as well as the red-breasts and the wrens out of doors; another strong proof of the incorrectness of M. Sonnini's remark. We have for two winters possessed a male black-cap (Sylvia atricapilla), which begins to warble in autumn about the time the red-breasts come into our gardens, and perch upon houses to sing. Towards Christmas it comes into full song, piping so shrilly at times as to be rather too much for our ears to bear with pleasure. This, however, is at least three or four months before the usual time of pairing, and hence it is fair to conclude, that the pairing is not the cause of its singing, no more than the same circumstance will account for the winter songs of the red-breast and other soft-billed birds, which are continued in the fields as well as by those which are tamed + .

Mr. Sweet, who has successfully kept most of our * Voyages, ii. 401.

$\dagger$ Quoted by Montbeillard, Ois, art. Rosignol. $\quad+$ J.R. 
summer visitants for several years, finds that they uniformly $\operatorname{sing}$ during the winter. Of the white-throat (Curruca cinerea. Brisson) he says, "One that I at present possess will sing for hours together against a nightingale, now in the beginning of January, and it will not suffer itself to be outdone." Of the wheatear (Saxicola onculhe, Bechstern), he says, "A pair that I possess at present were caught in September last; began to sing in a fer days, and have continued in song ever since; and now, while writing this, the $22 \mathrm{~d}$ day of December, they are in full song." Of the nightingale, he says, "It will begin singing at the commencement of December, and continue till . June. I had a very fine one that only left off singing the latter end of June; it began again a little in September, and by the 1st of December it was in full song*."

Pennant was of opinion that it is chiefly the young. male red-breasts of the preceding summer which sing during autumn and wintert. This opinion, if true, would certainly be adverse to the theory of Buffon and Colonel Montagu; but the thrushes above stated to have been heard singing in October, were not young ones, these being readily distinguishable, when they first attempt to sing, by particular notes, resembling the following $\ddagger$ :
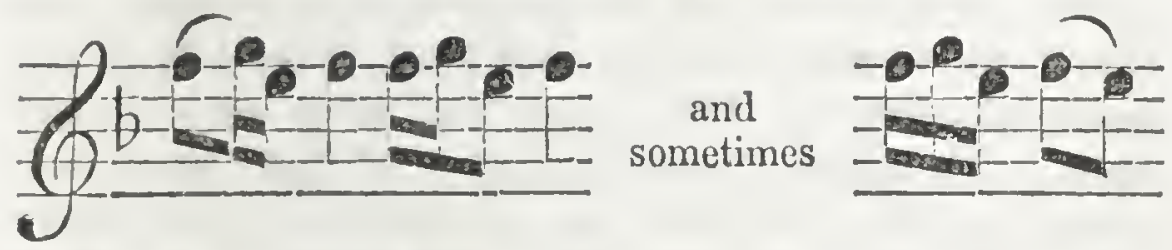

The recording of young birds is indeed always very different from their song, as is also the warble of old birds after moulting, as M. Bechstein has justly remarked. "It is," he says, " a very striking

* British Warblers. + Brit. Zool. ii. 147.

$$
\text { iे J.R. }
$$


circumstance, that birds which continue in song nearly the whole year, such as the red-breast, the siskin, and the goldfinch, are obliged, after their moulting is over, to record, as if they had forgot their song. I am convinced, however, that this exercise is less a study than an endeavour to bring the organs of voice into proper flexibility, what they utter being properly only a sort of warble, of which the notes have almost no resemblance to the perfect song; and, by a little attention, we may perceive how the throat is gradually brought to emit the notes of the usual song. This view, then, leads us to ascribe the circumstance not to defect of memory, but rather to a roughness in the vocal organs, arising from disuse. It is in this way that the chaffinch (Fringilla spiza) makes endeavours during several successive weeks before attaining to its former perfection, and that the nightingale (Sylvic luscinia) tries, for a long time, to model the strophes of its superb song before it can produce the full extent of compass and brilliance *."

It might be alleged, indeed, that the old birds who sing in autumn, are influenced by association, inasmuch as this season resembles the spring; for though spring is all youth and verdure, while autumn wears the aspect of decline, and woods and fields, instead of lively green, display nothing but sombre tints of yellow and brown, yet the temperature of the air has much the same mildness, and food is equally if not more abundant. This, however, is a very partial view, with which the continuance of these autumnal songs during winter is altogether inconsistent. Colonel Montagu, however, endeavours to obviate the objection by some ingenious arguments; and, in support of the general theory, he brings forward experiments tried by himself for that express purpose. " The continuation of song," he says, " in caged * Ornithologisches Taschenbuch, Vor. 
birds, by no means proves it is not occasioned by a stimulus to love; indeed, it is likely the redundancy of animal matter, from plenty of food and artificial heat, may produce it; and this is sufficient for continuing their song longer than birds in their natural wild state, becanse they have a constant stimulus; whereas wild birds have it abated by a commerce with the other sex, by which, and other causes, it is prevented. It is true wild birds are heard to sing sometimes in the middle of winter, when the air is mild, animated by the genial warmth of the sun, which acts as a stimulus. But we shall now proceed to show, by experiments, that birds in their natural state may be forced to continue their song much longer than usual. A male red-start made its appearance near my house early in the spring; and soon commenced his love-tumed song. In two days after, a female arrived, which for several days the male was continually chasing, emitting soft interrupted notes, accompanied by a chattering noise. 'This sort of courting lasted for several days, soon after which the female took possession of a hole in a wall close to my house, where it prepared a nest and deposited six ergs. The male kept at a distance from the nest, and sometimes sang, but not so loud or so frequently as at first, and never when he approached nearer his mate. When the eggs had been sat on a few days, I endeavoured to catch the female on the nest, but she escaped through my hand. However, she soon returned, and I caught her. 'The male did not immediately miss his mate; but on the next day he renewed his vociferous calls, and his song became incessant for a week, when I discovered a second female; his note immediately changed, and all his actions as before returned. This experiment has been repeated with the nightingale with the same success; and a golden-crested 
wren, who never found another mate, continued his song from the month of May till the latter end of August. On the contrary, another of the same species, who took possession of a fir-tree in $\mathrm{my}$ garden, ceased its notes as soon as the young were hatched *".

To us, however, this explanation of the facts appears too partial and contracted, the song of the birds being more naturally accounted for, as we think, from the state of their spirits than by the supposition of its having been meant as the language of courtship; and, accordingly, it does not consist with our observation that the state of the weather has much influence upon them, except in so far as it may affect their supply of food; and hence it is that caged birds remain much longer in song than if they were at large in the fields. We have further remarked, and it agrees with the experience of Mr. Sweet and others who keep tame birds, that the male will sing better, and for a longer period, when there is a female of his own species in the same cage than when he is alone $†$; whereas, according to Colonel Montagu's explanation of his experiments, namely, that the song is uttered chiefly to attract the female to the vicinity, this circumstance ought not to talie place.

The theory in question has been opposed by another which maintains the peculiar notes of various song-birds to be derived from imitation. The Hon. Daines Barrington tried a number of experiments for the purpose of supporting this latter notion, which it may prove interesting to give in his own words:-

" I have educated nestling linnets," says he, " under the three best singing larks, the skylark, woodlark, and titlark, every one of which, instead of

* Ornith. Dict. Intr. first ed.; p. 477, second ed. $\dagger$ J. R. 
the linnet's song, adhered entirely to that of their respective instructors.

"When the note of the titlark linnet was thoroughly fixed, I hung the bird in a room with two common limnets, for a quarter of a year, which were full in song ; the titlark linnet, however, did not borrow any passage from the limnet's song, but adhered stedfastly to that of the titlark.

"I had some curiosity to find out whether a European nestling would equally learn the note of an African bird; I therefore educated a young linnet under a Vengrolina (Linaria Angolensis, Brisson), which imitated its African master so exactly, without any mixture of the linnet's song, that it was impossible to distinguish the one from the other.

"This Vengolina linnet was absolutely perfect without ever uttering a single note by which it could have been known to be a linnet. In some of my other experiments, however, the nestling limet retained the call of its own species, or what the birdcatchers term the linnet's chuckle, from some resemblance to that word when pronounced.

"All my nestling limnets were three weelss old when taken from the nest; and by that time they frequently learn their own call from the parent birds, which consists of only a single note.

"To be certain, therefore, that a nestling will not have even the call of its species, it should be taken from the nest when only a day or two old; because though nestlings cannot see till the seventh day, yet they can hear firom the instant they are hatched, and probably, from that circumstance, attend to sounds more than they do afterwards, especially as the call of the parents announces the arrival of their food.

"I must own that I am not equal myself, nor can I procure any person to take the trouble of breeding. up a bird of this age, as the odds against its being 
reared are almost infinite. The warmth, incleed, of incubation may be, in some measure, supplied by cotton and fires; but these delicate animals require, in this state, being fed almost perpetually, whilst the nourishment they receive should not only be prepared with great attention, but given in very small portions at a time.

"Though I must admit, therefore, that I have not reared myself a bird of so tender an agee, yet I have happened to see both a linnet and a goldfinch which were taken from their nests when only two or three days old.

"The first of these belonged to Mr. Matthews, an apothecary at Kensington, which, from a want of other sounds to imitate, almost articulated the words pretty boy, as well as some other short sentences. I heard the bird myself repeat the words pretty boy; and Mr. Matthews assured me that he had neither the note or call of any bird whatsoever.

"This talking linnet died last year; and many persons went from London to hear him speak.

"The goldfinch I have before mentioned was reared in the town of Knighton, in Radnorshire, which I happened to hear as I was walking by the house where it was kept.

"I thought, indeed, that a wren was singing, and I went into the house to inquire after it, as that little bird seldom lives long in a cage.

" The people of the house, however, told me that they had no bird but a goldfinch, which they conceived to sing its own natural note, as they called it; upon which I stayed a considerable time in the room, whilst its notes were merely those of a wren without the least mixture of goldfinch.

"On further inquiries, I found that the bird had been taken from the nest when only two or three days old, - that it was hung in a window which was 
opposite to a small garden, whence the nestling had undoubtedly acquired the notes of the wren, without having any opportunity of learning even the call of the goldinich.

"These facts which I have stated seem to prove, rery decisively, that birds have not any minute ideas of the notes which are supposed to be peculiar to each species. But it will possibly be asked, why, in a wild state, they adhere so steadily to the sane song, insomuch that it is well known, before the bird is leard, what notes you are to expect from lim.

" 'This, however, arises entirely from the nestling's attending only to the instruction of the parent bird, whilst it disregards the notes of all others which may perhaps be singing round him.

"Young canary birds are frequently reared in a room where there are many other sorts, and yet I have been informed that they only learn the song of the parent cock.

"Every one knows that the common house-sparrow, when in a wild state, never does anything but chirp; this, however, does not arise from want of powers in this bird to imitate others, but because he only attends to the parental note.

“But, to prove this decisively, I took a common sparrow from the nest, when it was fledged, and edncated lim under a linnet; the bird, lowever, by accident, heard a goldinch also ; and his song was, therefore, a mixture of the linnet and goldfinch.

"I have tried several experiments in order to observe from what circumstances birds fix upon any particular note when taken from the parents, but cannot settle this with any sort of precision, any more than at what period of their recording they determine upon the song to which they will adhere.

"I educated a young robin under a very fine nightingale, which, however, began already to be out 
of song, and was perfectly mute in less than a fortnight.

"This robin afterwards sung three parts in four nightingale; and the rest of his song was what the bircl-catehers call rubbish, or 110 particular note whatsoever.

"I hung this robin nearer to the nightingale than to any other bird; from which first experiment I conceived, that the scholar would imitate the master which was at the least distance from him.

"From several experiments, however, which I have since tried, I find it to be very uncertain what notes the nestling will most attend to, and often their song is a mixture; as in the instance which I have before stated of the sparrow.

"I must own also, that I conceived from the experiment of educating the robin under a nightingale, that the scholar would fix upon the note which it first heard when taken from the nest; I imagined likewise that, if the nightingale had been fully in song, the instruction for a fortnight would liave been sufficient.

"I have, however, since tried the following experiment, which convinces me so much depends upon circumstances and perhaps caprice in the scholar, that no general inference or rulecan be laid down with regard to either of these suppositions.

"I edncated a nestling robin under a woodlarklinnet, which was full in song and liung very near to him for a month together; after which the robin was removed to another house, where he could only hear a skylark-linnet. The consequence was that the nestling did not sing a note of woodlark (though I afterwards hung him again just above the woodlarklimnet), but adhered entirely to the song of the skylark-limnet $*$."

* Philosophical Transactions, vol. lxiii. 
These opinions did not originate with Barrington, for we find it asserter by father Kircher, that "the young nightingales which are hatched uncler other birds, never sing till they are instructed by other nightingales*;" and the author of the "Physica Curiosae' says $\phi$, that the young are taught to sing by their mothers,- -both following A ristotle, who says of the nightingale, "she seems indeed to instruct her young ones, and to repeat to them certain passages for their initation, as the language does not come naturally in the same manner as the voice, but must be acquired by exercise and study +." The same view has been adopted by a recent Danish naturalist, M. Gamborg $\$$; and the Hon. and Rev. W. H. Herbert gives a similar statement, which, from his experience in keeping cage-birds, is entitled to our best consideration. "The nightingale," he remarks, " is peculiarly apt, in its first year, when confined, to learn the song of any other bird that it hears. Its beautiful song is the result of long attention to the melody of other birds of its species. 'The young whinchat, wheatear, and others of the genus Saxicola, which have little natural variety of song, are no less ready, in confinement, to learn from other species, and becone as much better songsters, as the nightingale degenerates, by borrowing from others. The bull-finch, whose natural notes are weak, harsh, and insignificant, has a greater facility than any other bird of learning human inusic. It is pretty evident that the Germans, who bring vast numbers of them to London, which they have taught to pipe, must have instructed them more by whistling to them than by an

* Musurgia, Cap. De Lusciniis.

+ Page 1200.

+ Hist. Anim。 ir. 49.

$\$$ Comment peut ou parrenir à perfectionner le Chant des Oiseaux de nos Bois? Sro. Copenhague, IS00. 
organ, and that these instructions have been accompanied by a motion of the head and body in accordance with the time, which habit the birds also acquire, and is, no donbt, of great use to them in regulating their song. The canary-bird, whose song, in its artificial state in Europe, is a compound of notes acquired from other birds, is able to learn the song of the nightingale, but is not able to execute it with the same power as the nightingale itself. I have never heard one that sung it quite correctly, but I have heard it approach near enough to prove that, with more careful education, it might learn it right. 'Those who have taken the most pains about it, have been contented with placing under nightingales young canaries, as soon as they can feed themselves; but such will necessarily have learned part at least of their parent's soug. 'The linnet and linnet-mule are said to be able to come nearer the execution of the nightingale, when properly instructed. The best way would be to use an experienced hen canary-bird, who will rear her young without the cock, and to take the cock away before the young ones are hatched: or to set the canary egrgs under a hen paired with a gold-fiuch, which, kept in a darkish sitıation, will probably not sing; to remove the cock, at all events, if it sings, as soon as possible; to place the young birds very close to the singing nightingale; and, as soon as practicable, to remove the hen canary also. 'The rearing of the canaly-bird by hand, even from the egrg, has been accomplished by artificial heat and unremitting care. Birds learn the song of others most readily when they are not in song themselves, and when they are darkened and covered, so that their attention is not distracted; for birds are amused by what they see as much as we are, when not alarmed by it. I had once a tame white-tluroat, which, when let out of its cage, appeared to take 
the greatest pleasure in minutely examining the figured patterns of the chair-covers, perhaps expecting to find something eatable among the leaves of the paitern. I reared a black-cap and some whitethroats, taken when a fortnight old, under a singing nightingale, and removed all other singing birds, but they sung their wild notes pretty truly; on the other hand, a black-cap, two years old, from hearing a nightingale sing a great deal, acquired two passages from its song, and executed them correctly, though not very powerfully. I understand that the robin, reared in a cage, is not observed to learn from other birds, but sings the wild note pretty accurately. I can at present suggest no key to these diversities; nor do I understand why the young nightingale, taken when the old birds cease to sing, will, in confinement, learn the note of other birds, and retain them, although it may hear its own species sing agrain as soon as they recommence in the autumn; and yet, at liberty, with the same cessation of the parental song, it would have learned nothing else; unless it be that from want of other amusement, it "listens more when it is confined*"

But though we were to grant all the facts stated by these authors to be rigidly correct, we should not be disposed to adopt their conclusion, which is plainly opposed by other facts within the power of every observer to verify. We do not, however, believe Kircher's story of nestling birds hatched under other birds never attempting to sing, any more than we should believe that a human infant in like manner deprived of the care of its own species would speak Hebrew or high Dutch. "A skylark," it has been stated, "was taken from the rest before it was fledged and reared by the hand in town,

* Notes to White's Selborne, edit. Svo. 1832. 
where it could not hear any of its own species; yet when it was grown, its song was not distinguishable from those in a wild state. Could it have acquired these notes, while in the nest, from the parent bird, in a similar way to what Dr. Darwin supposed infants to acquire a taste for Hogarth's line of beauty by fondling on their mothers' bosom* ? and could it have retained this musique de berceau (cradle music) in its memory for more than six months without ever attempting, as the birds'-men express it, even to record. 'There is one curious, though very anomalous fact, which might be adduced in support of this view. The celebrated Dr. Rush of Philadelphia was called to visit the Countess of $\mathbf{L}-\mathbf{L}-\mathbf{L}$ who was in a high fever. In her delirium, she uttered a number of outlandish speeches, which one of the attendants recognised to be pure Welsh. The Doctor was struck with the singularity of the circumstance, as the Countess, he was told, did not understand a word of Welsh. On inquiry, however, he found that she had been nursed by a Welsh woman, but had been removed before she could articulate a word, and had not heard Welsh spoken from that time till she had been seized with the fever $t$. But a solitary and anomalous fact like this will not authorize us to conclude that the young skylark retained in lilie manner the song of its field nurse +."

The theorists who maintain that the songs of birds are acquired by individual imitation, find no little difficulty in accounting for the uniformity which usually prevails among the notes of those of the same species. 'They tell us that the young birds learn the song of the parent birds by associating exclusively

* Zoonomia, \$ xvi.c. 1. p. 201.

+ American Museum, July, 1787.

J. Rennie on the Singing of Birds, Edinb. Mag. Jan. 1819, p. 10 . 
with them before they can provide for themselves, and that afterwards they frequent the same places as the rest of their kind ; but, unfortunately for this explaniation, the fact is that song-birds for the most part become silent after their young are hatched. Neither is it true, that song-birds associate exchnsively with their own species, and, although they did, it would not follow that they never liear other birds. How then does it happen, since they are, by the theory, so prone to imitation, that they never in a wild state intermingle the notes of others with those peculiar to their own species? Upon the principles of the theory every bird ouglit to be a polyglot.

We have in many instances verified the experiments of Barrington on caged birds, most of which when young will rearlily learn the notes of the birds in the same room. We have, for example, at present, a young cock green-bird (Fringilla chloris, TEmMINCK), which from hearing the call of the sparrows out of doors has acquired it perfectly, and from hanging near a black-cap, he has also learned many of its notes, though he executes them indifferently, perhaps from deficiency of voice. He has more recently attempted some of the notes of a robin whose cage hang's under his. Yet notwithstanding that he has thus learned part of the notes of three or four different birds, he can also utter the peculiar call-note of his own species, though we are pretty certain he has not heard it uttered since he left his parents' nest when only a few days old. But no wild green-bird ever learns in this manner the notes of various species, nor would our bird, we are well convinced, had he not been lept stationary in the cage, and consequently had the notes he has learned daily sounding in his ears, till he could not forget them. In a wild state, he would either have kept at a distance from other species, or would not have attended to them; 
whereas, in the cage, he could not avoid hearing the sparrows, the black-cap, and the red-breast*

Mr. Sweet is an advocate for the theory we are considering, from having observed similar facts without having adverted to the different circumstances in which wild and caged birds are placed. Of the red-start (Sylvic Phonicurus), he says, " it may be taught to sing any tune that is whistled or sung to it: one that I was in possession of for some years back, learnt the Copenhagen waltz, that it had frequently heard sung, only it would sometimes stop in the middle and say chipput, a name by which it was generally called, and which it would repeat every time I entered the room where it was, either by night or by dayt." M. Bechstein asserts, that the red-start "knows how to embellish its natural song (composed of several rather pretty strophes), by adding the notes of other birds with which it associates. One which had built under the eaves of my house imitated pretty closely a caged chaffuch in the window underneath; and my neighbour had another in his garden, which repeated some of the notes of a black-cap that had a nest hard by. This facility of appropriating the song of other birds, is rare in a wild state, and appears to be almost confined to this species +." Even this anomalous instance may be easily explained on the principle we have stated, for the red-start having its nest near where the caged chaffinch was stationed was forced to hear its notes till they were impressed on its memory.

The researches of comparative anatomy have thrown much light upon the peculiar structure of song-birds, though there remain still many points of interest for future investigation. This indeed, as

* J. R. † British Warblers, in loco. \. Taschenbuch, Art. Rothschwanzchen. 
we have already remarkerl, was a subject taken up by the earlier naturalists*; and most of their observations have been eonfirmed and extended by John Hunter, Girarlit, Vieq d'Azyr +, Malaearne, Baron Cuvier H, and Ranzani ø. Amongst other eurious facts, it is stated in Clayton's Ietter's from Virginia, that Dr. Moulin discovered that in birds, contrary to what takes place in man and in quadrupeds, there is almost a direet passage from one ear to the other, so that, if the drum (tympanum) of both ears be pierced, water, when poured in, will pass from the one to the other. There is no spiral shell (cochlea), but a small passage which opens into a cavity formed by two plates of bone, that eonstitute a double skull all round the head. The outer plate of bone is supported by many hundreds of small thread-like columns, or rather fibres. Now this passage was observed to be much larger in singing-birds than in others that do not sing,--so very remarkably so, that any person to whom the difference has once been shown, may easily judge by the head what bird has the faculty of singing, though he may be otherwise ignorant of its habits **. We have not seen any notice of this singular cireumstance by any other inquirer.

The remarks of Syme upon this subject are appropriate, and, so far as we know, eorrect. "The notes," he tells us, "of soft-billed birds are finely toned, mellow, and plaintive; those of the hard-billed species are sprightly, cheerful, and rapid. This difference proceeds from the construction of the vocal organs. As a large pipe of an organ produces a

* See page 225, et seq. † Oposcoli Scelti di Milano, viii. 88.

$$
\text { + Ném. Acad. des Sciences, pour } 1779 .
$$

§ Mém. della Societa Ital.iv. $18 . \quad \|$ Anat, Comp.iv. 454.

1 Elem. di Zoologia, iii. 1. p. 35, 4to. Bologna, 1821.

** Miscellanea Curiosa, iii. 291. 
deeper and more mellow-toned note than a small pipe, so the windpipe of the nightingale, which is wider than that of the canary, sends fortl a deeper and more mellow-toned note. Soft-billed birds, also, sing more from the lower part of the throat than the hard-billed species. This, togrether with the greater width of the tube in the nightingale and other softbilled warblers, fully accounts for their soft, round, mellow notes, compared with the shrill, sharp, and clear notes of the canary and other hard-billed songbirds *."

Most poets, in accordance with these remarks, have represented the notes of the nightingale as plaintive and sorrowful, though others have also spoken of them as sprightly and cheerful. Hence, to use the words of Lord Byron, " it has been much doubted whether the notes of this 'lover of the rose' are sad or merry t." 'This poet, indeed, has decided the matter most correctly when he says,

"Though his note is somewhat sad,

He'll try for once a strain more glad \$."

Looking upon this as the true state of the case, we are not much disposed to go into this apparently idle controversy; but the representations which the poets have given of the nightingale's song must interest every lover of nature, and therefore we shall select a few, were it only to repel a strange and unwarrantable misrepresentation by a recent periodical writer, who signs himself Anti-Philomel, of the

"Sweet bird, that shuns the noise of folly."

"In point of fact," says this reviler, "there is nothing either sad or sentimental in the song of the nightingale. It is an incessant tinkling, trilling,

* British Song-Birds.

+ Bride of Abydos, Notes, p. 65, ed. 8ro.

$\ddagger$ Ibid. p. 15, line 292. 
monotonous, yet laboured effort of execution; and with the exception of the 'jug, jug, jug,' which occasionally interrupts the thin and Rossinian character of its strains, there is not a poetical note in its whole gamiut. Philomel is the Henrietta Sontag of the woods-unimpassioned, artificial, but miraculous in point of delicacy of execution; and the fact of her being a night vocalist, instead of establishing her claims to sentimentality, as

'Most musical, most melancholy,'

proves only the self-conviction of the bird, that its strains are incompetent to vie with those of its fellowcloristers,-or, perhaps, an envious and invidious desire of distinction. The ancient apologue, of the nightingale expiring in the successful effort of rivalship with the poet's lute, proves that it has ever been suspected of a paltry and narrow jealousy of competition.

"Who, that has ever listened to the mellow vesper hymn of the blackbird, or the thrush-notes gushing in bursts of gladness from the heart of a hawthorn bush, but must acknowledge that there dwells more poetry in their music than in all the demi-semiquavers of the 'plaintive Philomel?' What lover of poetical justice but lougs to transpose the line of Petrarch,

'E garrir Progne,-—e pianger Filomele,' and distribute the garrizitura (chatter) to the tinkling nightingale*?" Others even go so far as to speak of the screeching or hissing of the nightingale. Sidonius $A$ pollinaris associates the " hissing nightingale" (Philomelam sibilantem) with the crinking of grasshoppers, the croaking of frogs, the screaming of geese, the cackling of hens, and the cawing of rooks $\uparrow$. In the same spirit Aristophanes is interpreted by some to say, the "striclulous nightingale" ("A $\eta \dot{\delta} \omega \nu$ * Court Journal, May 14th, 1831. † Epist, lib, xi。 
$\left.\lambda_{\iota \gamma v \mu v \theta o s} *\right)$; but Cinesias and Aldrovand think " tuneful" a better rendering, inasmuch, says Aldrovand, as "the whisper of the nightingale ought to be considered most melodious and delightful, not like the voice of dragons, which is justly termed hissing, but like the soothing sound of a breeze, softly blowing and sweetly murmuring among leaves $\dagger . "$ This writer may perhaps have taken the hint of his sentiments from Scaliger, who (as nearly as we can render his description) represents the "birdlet gurgling canticles, and babbling from its breast on the murmuring bankł." Martial also calls it " a garrulous bird §," and Strozius talks of its " chattering song\|."

A mongst the earliest notices of the nightingale we have met with, is one in the Odyssey 9 .

As when the months are clad in flowery green,

Sad Philomel in bowery shades unseen-

Now doom'd a wakeful bird to wail the beauteous boy,

So in nocturnal solitude forlorn,

A sad variety of woes I mourn.

Pope.

Euripides alludes to the great variety of the song of this bird when he makes Hecuba exhort Polixena to vary her voice like the nightingale (is $\tau^{\prime}$ 'A

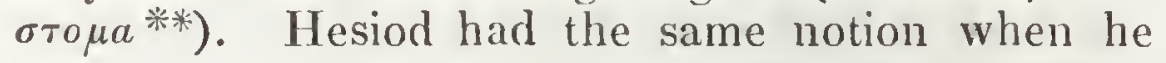
applies to the nightingale the epithet of "various-

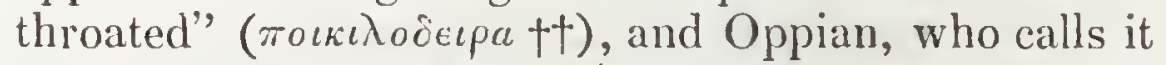

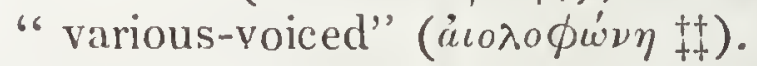

But by far the greater number of the poetical authorities, both ancient and modern, agree, as we

* In Avibus.

+ Aldrovand, Ornitholœgia, ii. 340 .

+ Hinc gutturillo Luscinilla cantillans

Hinc murmurante ripa garriens sinu.

$\S$ Flet Philomela nefas incesti Tereos, et quæ

Muta puella fuit, garrula fertur avis.

II Integrat Garrula vicinis carmen Philomela sub umbris.Erot. Lib. i.

I T. 520 .

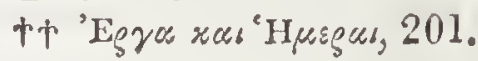

** Hecuba, act. 2.

r.t. Halieut, i. 728. 
have said, in representing the nightingale's song as monruful and plaintive. Thus Sophocles, in his 'A jax Flagellifer,' refers to it as an image of vociferous sorrow", and in his 'Electra' he calls it the "querulous nightingale." Petrarch agaain mentions its "lamenting '," and 'Tasso its "deploring" (El' usigmuol che plora). These poets, no doubt, were biassed by their classical recollections, since from Homer and Hesiod to Virgil, Ovid, and down to the "lamenting her hapless hymenrals" (plorans infelices hymences + ) of Baptista, the Mantuan, most, if not all, the poets of the south of Europe have sung in the same strain, in which they have been followed by those of our own country. 'Thomson, for instance, has

"All abandon'd to despair, she sings

Her sorrows through the night."

Coleridge, however, in some well-known lines on this bircl, has given a very different character of its song ; exclaiming-

"A melancholy bird? Oh! idle thought-

In nature there is nothing melancholy.

But some night-wandering man, whose heart was pierced

With the remembrance of a grierous wrong,

Or slow distemper, or neglected love,

(And so, poor wretch! fill'd all things with himself,

And made all gentle sounds tell back the tale

Of his own sorrow, he, and such as he,

First named these notes a melancholy strain,

And many a poet echoes the conceit.

We have learnt

A different lore: we may not thus profane

Nature's sweet roices, always full of lore

And joyance! 'Tis the morry nightingale

$$
\text { * Ajax Flag. v. } 630, \text { ж. r. } \lambda \text {. }
$$

+ E'l Roscignuol, che dolcentente ì l'ombra

'Tutte le notti si lamenta, e piague.

$$
\text { \$. Eglog, i. }
$$


That crowds and hurries and precipitates

With fast thick warble his delicious notes,

As he were fearful that an April night

Would be too short for him to utter forth

His love chaunt, and disburthen his full soul

Of all its music! * * *

\section{* * * Far and near}

In wood and thicket over the wide grove

They answer and provoke each other's songs,

With skirmish and capricious passagings,

- And murmurs musical, and swift jug, jug,

And one low piping sound more sweet than all,

Stirring the air with such an harmony,

That should you close your eyes you might almost

Forget it was not day *."

Chaucer, too, in his poem of the Flower and Leaf, says-

"The nightingale with so mery a note

Answered him, that atl the wood yrong, \&c."

But it may be doubted if the epithet merry here is to be taken exactly in the modern sense, any more than it is in the old expression "My merry men," in the address of a chief to his followers, or in the common phrase Merry England, where it appears to mean rather renowned or famous, than that we now call merry. Dryden, in his paraphrase of the Flower and Leaf, renders the above lines;

"The nightingale replied;

So sweet, so shrill, so varionsly she sung,

That the grove echoed and the valleys rung."

Considering this song merely as a piece of music, there can be no doubt that both the views that have thus been taken of it by the poets may be supported, though the following description, by the Abbé La Pluche, is nearer the truth than either. "The nightingale," he says, " passes from grave to gay; from a simple song to a warble the most varied;

* The Nightingale, written in April 1798. 
and from the softest trillings and swells to languishing and lamentable sighs, which he as quickly abandons, to return to his natural sprightliness*."

But leaving the musical character of this song out of consideration, it must be regarded as uniformly the produce of a joyous and sportive state of feeling. No bird sings when sad; for, though they can utter sounds of sorrow when robbed of their nests or their young, they never sing in such cases, as incorrectly represented to do by Virgil, when he says-

$$
\text { "___Complaining in melodious moans, }
$$

Sweet Philumel, beneath a poplar shade,

Mourns her lost young, which some rude village hind

Observing, from their nest unfledged has stole:

All night, she weeps, and, perch'd upon a bough,

With plaintive notes repeated fills the grove t." -TRAPP.

This error, indeed, was exposed more than two thousand years ago by Plato, who says justly, "Nobody can dream that any bird will sing when it is hungry, when it is cold, or when it is afflicted with any other pain, not even the nightingale itself, which is said to sing from grieft." Albertus Magnus too seems to have had a glimpse of the true state of the case. In opposition to Aristotle, who says, "The nightingale ceases to sing during incubation §," Albertus asserts that it does "sing while it is hatching;" and certain Platonists, he remarks, maintain that it cannot vivify the egrrs without singing, "which," adds the naturalist, "appears to be true; for the soft air and warmth elevating the temperature of the blood in these birds, stirs up in them the joyousness of song and the desire of rejoicing, the heat of the parent being higher during hatching than at any other period ll."

- Spectacle de la Nature, i. 156. \pm Phado.

+ Georg. iv. 511 . $\S$ Hist. Anim. v.9.

II Hist. Anim. apud Aldrovand, ii. 343. 


\section{Chapter XVI.}

SONG OF BIRDS CONTINUED.

Looking to the musical character of the songs of birds, without reference to the feelings of joy or of rivalry which seem to us at least to prompt them to sing, some authors have exerted their ingenuity in drawing up comparative tables of the several qualities exhibited by various species. 'These tables appear to us more curious than accurate; but we present the following as a sample.

Comparative Table of the Excellence of British Song Birds-20 being the point of Perfection. By the Hon. Daines Barrington, and Patrick Syme, EsQ. The letters B. and S. mark the names of these two authors.

\begin{tabular}{|c|c|c|c|c|c|}
\hline $\begin{array}{l}\text { Mellow- } \\
\text { ness. }\end{array}$ & $\begin{array}{l}\text { Spright- } \\
\text { liness. }\end{array}$ & $\begin{array}{l}\text { Plain- } \\
\text { tiveness. }\end{array}$ & $\begin{array}{l}\text { Com- } \\
\text { pass. }\end{array}$ & $\begin{array}{c}\text { Execu. } \\
\text { tion. } \\
19\end{array}$ & $\begin{array}{l}\text { Dura- } \\
\text { tion. } \\
\text {.. }\end{array}$ \\
\hline Nightingale.......... $\left\{\begin{array}{l}19 \\
19\end{array}\right.$ & $\begin{array}{l}14 \\
10\end{array}$ & $\begin{array}{l}19 \\
19\end{array}$ & $\begin{array}{l}19 \\
19\end{array}$ & $\begin{array}{l}19 \\
19\end{array}$ & $\ddot{19}$ \\
\hline Skvlark $\{4$ & 19 & 4 & 18 & 19 & $\because$ \\
\hline skylark........... & 19 & 4 & 18 & 19 & 18 \\
\hline Woodlark .......... $\begin{array}{l}18 \\
14\end{array}$ & $\begin{array}{r}4 \\
10\end{array}$ & $\begin{array}{l}17 \\
16\end{array}$ & $\begin{array}{l}12 \\
14\end{array}$ & $\begin{array}{r}8 \\
14\end{array}$ & $\ddot{14}$ \\
\hline Titlark........... & 12 & 12 & 12 & $\begin{array}{l}14 \\
12\end{array}$ & $\stackrel{14}{\because}$ \\
\hline Herk........... & 8 & 4 & 8 & 6 & 6 \\
\hline $\begin{array}{l}\text { Fieldlark } \ldots \ldots \ldots \ldots \ldots .2 \\
\text { Bullfinch........... }\end{array}$ & $\begin{array}{r}10 \\
6\end{array}$ & $\begin{array}{l}2 \\
6\end{array}$ & $\begin{array}{r}10 \\
6\end{array}$ & $\begin{array}{r}12 \\
6\end{array}$ & $\begin{array}{l}8 \\
5\end{array}$ \\
\hline Goldfinch & 19 & 4 & 12 & 12 & $\therefore$ \\
\hline Goldfinch ......... & 16 & 2 & 8 & 12 & 6 \\
\hline Chaffinch.......... & $\begin{array}{r}12 \\
8\end{array}$ & $\begin{array}{l}4 \\
0\end{array}$ & $\begin{array}{l}8 \\
3\end{array}$ & $\begin{array}{l}8 \\
4\end{array}$ & $\ddot{5}$ \\
\hline & 4 & 4 & 4 & 6 & $\therefore$ \\
\hline Greenfinch......... & 6 & 8 & 6 & 6 & 6 \\
\hline Hedge-Sparrow & 0 & 6 & 4 & 4 & $\cdots$ \\
\hline & 4 & 2 & 2 & 3 & 3 \\
\hline Sisken, or Aberdevine. & 16 & 2 & 10 & 12 & 8 \\
\hline Redpole. & 4 & 0 & 4 & 4 & $\ddot{*}$ \\
\hline Redpole............ & 4 & 0 & 4 & $\begin{array}{l}4 \\
0\end{array}$ & $\ddot{\circ}$ \\
\hline Blackbird .......... $\left\{\begin{array}{r}4 \\
16\end{array}\right.$ & $\begin{array}{l}4 \\
4\end{array}$ & $\begin{array}{l}0 \\
8\end{array}$ & $\begin{array}{l}2 \\
8\end{array}$ & $\begin{array}{l}2 \\
6\end{array}$ & $\ddot{7}$ \\
\hline Robin , sus & 16 & 12 & 12 & 12 & $\therefore$ \\
\hline$\cdots \cdots 12$ & 6 & 16 & 8 & 8 & 8 \\
\hline
\end{tabular}




\begin{tabular}{|c|c|c|c|c|c|}
\hline Reed-Sparrow........ $\begin{array}{l}\text { Mellow. } \\
\text { ness. } \\
0 \\
0\end{array}$ & $\begin{array}{l}\text { Spright- } \\
\text { IIness. } \\
4 \\
4\end{array}$ & $\begin{array}{l}\text { Plain- } \\
\text { tireness. } \\
0 \\
0\end{array}$ & $\begin{array}{l}\text { Coms } \\
\text { pass. } \\
2 \\
6\end{array}$ & $\begin{array}{l}\text { Execu- } \\
\text { tion. } \\
2 \\
6\end{array}$ & $\begin{array}{l}\text { Dura- } \\
\text { tion. } \\
\qquad \\
2\end{array}$ \\
\hline Black.oan $\quad 514$ & 12 & 12 & 14 & 14 & $\therefore$ \\
\hline Black-cap ......... 319 & 6 & 16 & 10 & 10 & 8 \\
\hline Wren ............ & 12 & 0 & 4 & 4 & $\cdots$ \\
\hline Greater Pettychaps...... 10 & $\begin{array}{r}8 \\
12\end{array}$ & 14 & $\begin{array}{r}4 \\
14\end{array}$ & $\begin{array}{r}4 \\
14\end{array}$ & $\begin{array}{r}4 \\
12\end{array}$ \\
\hline Redstart ............6 & 8 & 6 & 12 & 10 & 6 \\
\hline Willow Wren ......... 8 & 8 & 10 & 12 & 10 & 7 \\
\hline Golden crested Wren .... 2 & 6 & 2 & 8 & 6 & 5 \\
\hline Sedze Warbler......... 0 & 8 & 3 & 4 & 4 & $\mathbf{5}$ \\
\hline Solitary Thrush........8 & 4 & 19 & 12 & 10 & 10 \\
\hline Missel Tlirush .......... 18 & 4 & 10 & 10 & 8 & 10 \\
\hline Thrush........... & 4 & 4 & 4 & 4 & 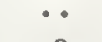 \\
\hline Linnet & 6 & 10 & 12 & 8 & 9 \\
\hline Linnet .............. 12 & 16 & 12 & 16 & 18 & $\because$ \\
\hline $\begin{array}{l}\text { Grey Linnet } \\
\text { Red-breasted Linnet....... } 2\end{array}$ & 18 & 4 & 16 & 16 & 10 \\
\hline & 16 & 4 & 14 & 16 & 8 \\
\hline 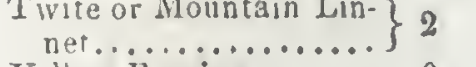 & 12 & 2 & 10 & 8 & 6 \\
\hline Tellow Buuting ......... 0 & 4 & 0 & 2 & 2 & 2 \\
\hline Lesser Redpole ...... & 14 & 4 & 8 & 8 & 6 \\
\hline Greater Redpole ........ 2 & 17 & 6 & 12 & 12 & 8 \\
\hline Canary...$\ldots \ldots \ldots \ldots 4$ & 19 & 6 & 19 & 19 & 16 \\
\hline
\end{tabular}

'Though birds of the same species very closely resemble each other in the general tenor of their song, individuals differ widely both in the introduction of particular passages, the result probably of accidental acquirements, and in skill of execution, as well as in intonation, the latter peculiarities obviously depending on physical varieties in their vocal organs. Wilson says he was so familiar with the notes of an individual wood-thrush (Turdus melodus) that he could recognise him above his fellows the moment he entered the woods*.

Mr. Knapp has the following excellent and accurate remarks on the same subject. "Birds," he says, " of one species sing, in general, very like each other, with different degrees of execution. Some counties may produce finer songsters, but without great variation in the notes. In the thrush, however, it is remarkable, that there seems to be no regular notes, each individual piping a voluntary of his 


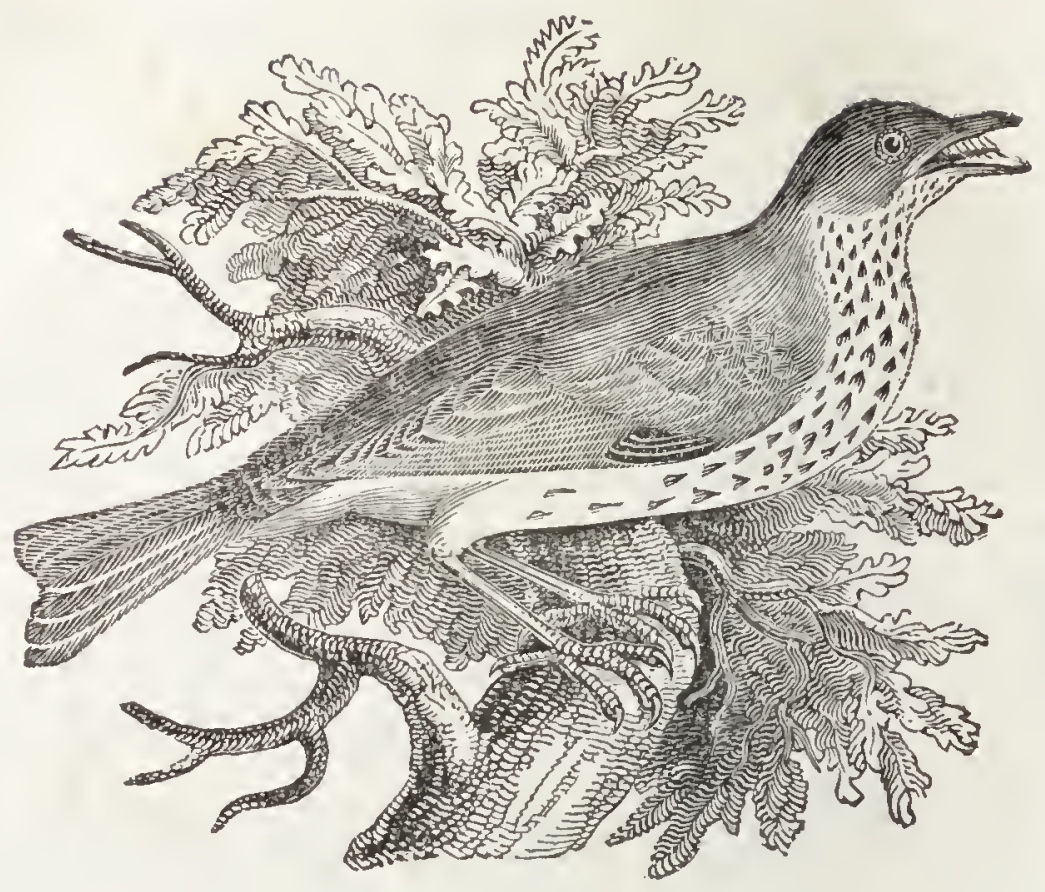

Wood-thrush.

own. 'Their voices may always be distinguished anid the choristers of the copse, yet some one performer will more particularly engage attention by a peculiar modulation or tone; and should several stations of these birds be visited in the same morning, few or none, probably, will be found to preserve the same round of notes, whatever is uttered seeming the effusion of the moment. At times a strain will break out perfectly unlike any preceding utterance, and we may wait a long time without noticing any repetition of it. During one spring an individual song-thrush, frequenting a favourite copse, after a certain round of tune, trilled out, most regularly, some notes that conveyed so clearly the words, ladybird! lady-bird! that every one lemarked the resemblance. He survived the winter, and in the ensuing spring, the lady-bird! lady-bird! was still the burden of our evening song; it then ceased, and 
we never heard this pretty modulation more. Though merely an occasional strain, yet I have noticed it elsewhere, -it thus appearing to be a favourite utterance*."

We have ourselves, in many instances, observed what might be not inappropriately called a different dialect among the same species of song-birds in different counties, and even in places a few miles distant from each other. 'This difference is more readily remarked in the chaffinch, dumnock, and yellow-hammer, than in the more melodious species $t$. The chaffinches, for example, in Normandy we observed to vary from those of Scotland by several notes; and among the yellow-hammers in Ireland, England, and Holland, we detected similar differences. We once heard a dunnock (Accentor modularis) in a garden at Blackheath sing so many additional notes to its common song that we concluded it was of a different species, till we ascertained, by watching the little musician, that it was not otherwise distinguished from its less accomplished brethren $\neq$. Of the chaffinch, Barrington says that those of Lssex are more esteemed than others oy the London bird-catchers; and Pennant tells us, be knew five gruineas paid for one which had an uncommon note, under which it was intended to train others $\S$. In Italy, as we learn from M. Montbeillard, the linnets of Abruzzo and of the March of Ancona are preferred $\|$.

In the case of the finer song birds, it requires a more practised ear to observe the differences, though these are still more considerable than in the species just mentioned. We have not, indeed, remarked so much variety as Mr. Kuapp has done in the song-

* Journ. of a Naturalist, 1. 27 1, 3d ed.

†.J. Rennie, on the Singing of Birds, Edinb. Mag. Jan. 1819, p. 11.

\$J. R. \$ Brit. Zool, ii. 336. \| Oiseaux, Art. La Linotte. 2 C 3 
thrush; but we have observed individuals, which severally exhibited both superiority and inferiority. Two summers ago we were absolutely annoyed by the unvaried monotony of one who had chosen his station near our garden, and who pertimaciously piped the same two or three notes for weeks together. Another song-thrush, in the same vicinity, and in August, too, when most of its brethren were mute from moulting, piped so clearly and with such variety of notes and cadence, at one time bursting into a loud commanding tone, and again sinking into " linked sweetness long drawn out," passing from sostemuto to staccato, from the pathetic to the merry glee of buoyant hilarity, that anybody but a naturalist would have felt convinced that the two birds were of distinct species. The song of the thrush, however, which became so tiresome by its monotory, was finely contrasted with that of a nightingale stationed in the same hedge, whose intonation and execution far excelled those of any other bird of the species we have ever heard. It might be, perhaps, that we were somewhat disposed to exaggerate the beauty of the nightingale's song in consequence of this striking contrast; yet, making every allowance on that account, there could be no doubt of the superior excellence of the notes .

It must be from some accidental peculiarities of this kind that the nightingales of Persia, Karamania, and Greece are said to sing better than those of Italy; while the Italian birds are more esteemed by amateurs than those of France, and the French than those of England. According to Pausanias, the nightingales which $\operatorname{sing}$ near the tomb of Orpheus are more melodious than elsewhere, and a similar superiority was also popularly believed to belong to those of Thrace t. Both of these opinions are also maintained * J. R. f In Bœot. 
by Philostratus*, though most probably no better founded than the legend current in Ireland, that the larks in the wild gloomy valley of Glandalough never $\operatorname{sing}$, having been miraculously silenced by St. Kevin during the building of the Seven Churches, because they broke the morning sleep of the wearied masons by their loud matin warblingst. Those who believe this story would do werl to ascertain whether any larks frequent the valley: it is certainly not a very likely place for their resort. Our own bird-catchers prefer the nightingales of Surrey to those of Middlesex. The nightingale, therefore, it would appear, is supposed to $\operatorname{sing}$ best in the east, and to decline in sweetness and richness of song in proportion as it is found farther to the north and the west. As the data from which these comparisons are made seem not a little vague, it is not easy to decide on their correctness; but a very good judge, Mr. Syme, concludes, from his own observation, that the common opinion is hypothetical.

"In 1802," he says, " being at Geneva, at the residence of a friend, about three miles from the town, in a quiet sequestered spot, surrounded by gardens and forests, and within hearing of the murmur of the Rhone; - there on a beautiful still evening, the air soft and balmy, the windows of the house open, and the twilight checquered by trees, there we heard two nightingales sing indeed most delightfully,--but not more so than one we heard down a stair, in a dark cellar, in the High-street in Edinburgh! - such a place as that described in 'The Antiquary;' no window, and no light admitted, but what came from the open cloor, and the atmosphere charged with the fumes of tobacco and spirits; it was a place where carriers lodged, or put up-and the heads of the

$$
\text { * In Narrat. Mirabil. }
$$

† Sir John Carr's Stranger in Ireland. 
porters and chairmen, carrying luggrage, nearly came in contact with the cage, which was hung at the foot of the staircase; - yet even here dirl this bird sing as mellow, as sweet, and as sprightly as did those at Geneva. We have often stopped to hear it, and listened with the greatest pleasure; and as the pieman passed with his jingling bell, a sound now seldom heard in the streets of Edinburgh, the bird seemed more sprightly, and warbled with renewed spirit and energy *"

The opinion that the nightingales of the north are inferior in song is by no means of modern origin, for we find the superiority of the Italian over the Scottish birds asserted both by Petrus Appanensis †, and by the Dutch naturalist Jonston-not Dr. Johnson, the lexicographer, as is commonly stated in books. This, however, is a mere theory, for it is very questionable whether the nightingale ever visits either Ireland $\ddagger$ or Scotland, though on the Continent it is found sparingly as far north as Sweden $\$$. We have only heard of one instance of the nightingale building in Scotland, namely, in the Earl of Egrlinton's woods in Ayrshirell; and though. Dr. Latham \&ा mentions two having been met with on the banks of the Forth in Stirlingshire, and Mr. Syme tells us of one in Dumfries-shire, and another in a garden in Leith walk, near Edinburgh ***, we consider the evidence on which these statements liave been made, at the best, doubtful.

'laking the inferiority of the song of nightingales visiting the north as a matter proved, and mixing up with this notion certain other circumstances equally

* British Song Birds, p. 97.

† In Problem. Aristot.

$\$$ Boterus apud Ald rovand, ii. 342 .

$\S$ Latham, Gen. Hist. of Birds, vii. 6, note.

\| J.R. If As above, p. 5, note.

*** Brit. Song Birds, p. 112 . 
dubious, Bufton has constructed thereupon one of his singular theories, which has now become established as part of the popular and the poetical creed.

"Sweetness of voice," says he, " and melody of song are qualities, which in birds are partly natural, partly acquired. 'Their great facility in catching. and repeating sounds enables them not only to borrow from each other, but often to copy the inflexions and tones of the human voice, and of our musical instruments. Is it not singular, that in all populous and civilized countries, most of the birds chant delightful airs, while in the extensive deserts of Africa and America, inlabited by roving savages, the winged tribes utter only harsh and discordant cries, and but a few species have any claim to melody? Must this difference be imputed to the difference of climate alone? The extremes of cold and heat operate, indeed, great changes on the nature of animals, and often form externally permanent characters and vivid colours. The quadrupeds, of which the garb is variegated, spotted, or striped, such as the panthers, the leopards. the zebras, and the civets, are all natives of the hottest climates. All the birds of the tropical regions sparkle with the most glowing tints, while those of the temperate countries are stained with lighter and softer shades. Of the three hundred species, that may be reckoned belonging to our climates, the peacock, the common cock, the golden oriole, the king-fisher, and the goldfinch, only can be celebrated for the variety of their colours; but nature would seem to have exhausted all the rich liues of the universe on the plumage of the birds of America, of Africa, and of India. These quadrupeds, clothed in the most splendid robes, - these birds, attired in the richest plumage, utter at the same time coarse, grating, or even terrible cries. Climate has, no doubt, a principal share in 
this phenomenon; but does not the influence of man contribute also to the effect*?"

Goldsmith gives a very different turn to the matter, denying, in fact, that song-birds are found in wild places. Speaking of small birds, he says, " as they are the favourites of man, so they are chiefly seen near him. All the great birds dread his vicinity, and keep to the thickest darkness of the forest, or the brow of the most craggy precipice; but these seldoin resort to the thicker parts of the wood; they keep near its edges, in the neighbourhood of cultivated fields, in the hedge-rows of farm-grounds, and even in the yard, mixing with the poultry. It must be owned, indeed, that their living near man is not a society of affection on their part, as they approach inhabited grounds merely because their chief provision is to be found there. In the depth of the desert, or the gloom of the forest, there is no grain to be picked up; none of those tender buds that are so grateful to their appetites; insects themselves, that make so great a part of their food, are not found there in abundance, their natures being unsuited to the moisture of the place. As we enter, therefore, deeper into uncultivated woods, the silence becomes more profound; everything carries the look of awful stillness; there are none of those warblings, none of those murmurs that awaken attention, as near the habitations of men; there is nothing of that confused buzz, formed by the united, though distant, voices of quadrupeds and birds; but all is profoundly dead and solemn. Now and then, indeed, the traveller may be roused from this lethargy of life, by the voice of a heron, or the scream of an eagle; but his sweet little friends and warblers have totally forsaken him. There is still another reason for these little birds avoiding the depths of the forest; which is, that their most formidable enemies are usually * Wood's Buffon, xi. 14. 
there. The greater birds, like robbers, choose the most dreary solitude for their retreats; and, if they do not find, they make a desert all around them. The small birds fly from their tyranny, and take protection in the vicinity of man, where they know their more unmerciful foes will not venture to pursue them *."

Understanding this to be laid down as a general principle, it is far from being consistent with fact; though it is partially true, as we shall elsewhere endeavour to show, that birds often follow the tract of cultivation. In the pine forests of Hudson's Bay, one of the wildest and most deserted places which could be mentioned, the pine grosbeak (Pyrrhula

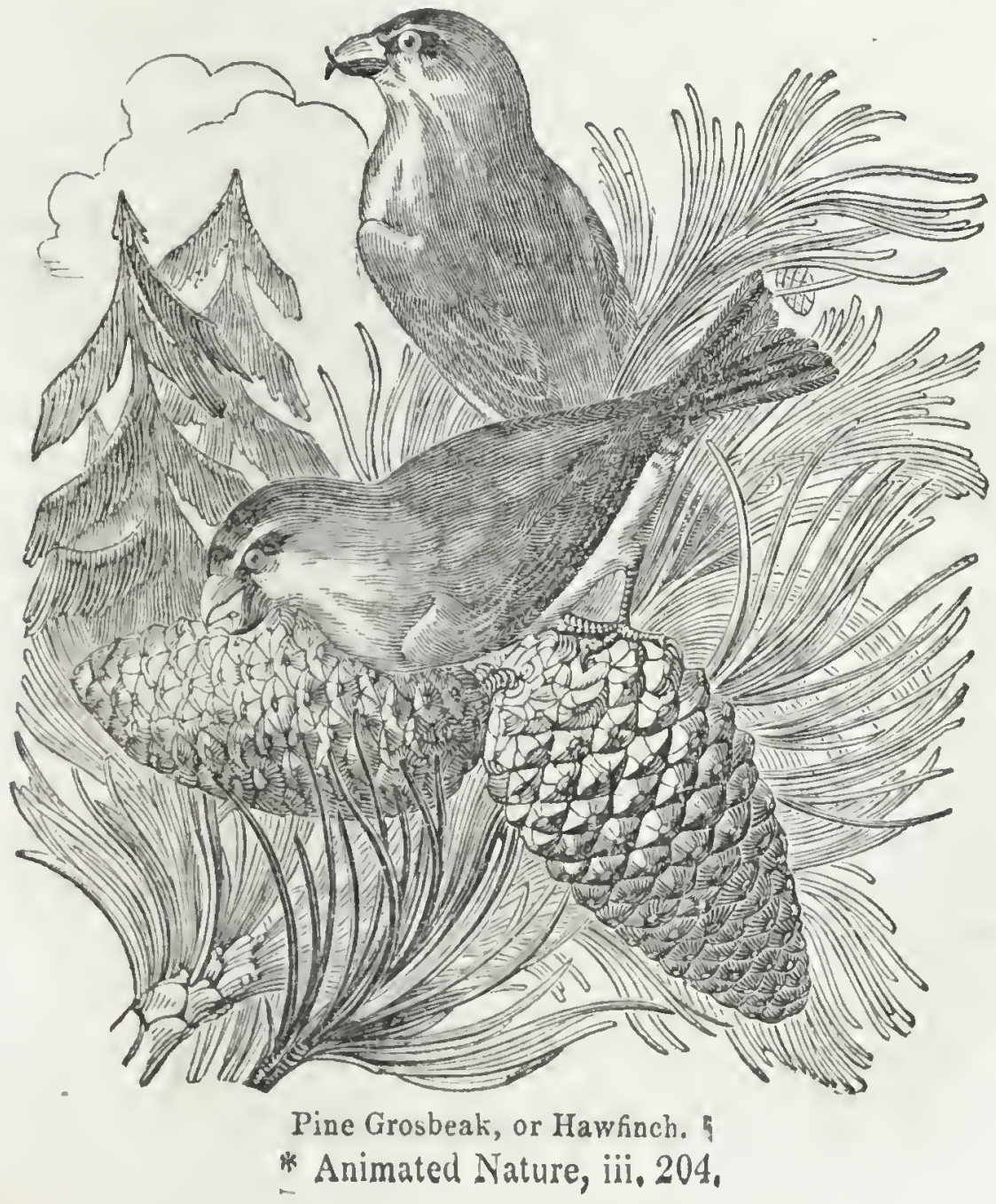


Enucleator, Tеммгск) is said to enliven the summer nights with its song*; and the same bird is found in the no less unfrequented forests of Siberia and Lapland $†$.

Captain Cook, when off the coast of New Zealand, says, "We were charmed the whole night with the sougs of innumerable species of birds from the woods which beautify the shores of this unfrequented island +."

With respect to the popular notion founded on the theoretical reasoning of Buffon, in the passage just quoted, M. Vaillant justly remarks, "It is quite a prejudice that the birds of warm climates are more brilliant than ours, - witness our king-fisher and jay ; or that they do not sing; for the song-birds, both in Africa and America, equal, and often surpass, our European birds §." The traveller, Bruce, also tells us that the song of the lark, in Abyssinia, did not appear to differ from that of the European larks; and M. Savigny, as we have already mentioned, heard the white-throat singing in Egypt. All the oriental poets, indeed, introduce the music of the groves as an indispensable accompaniment in their finest descriptions. King Solomon says, "The time of the singing of birds is come, and the voice of the turtle is heard in our land $\|$;" and the naturalist, Haselquist, found nightingales in Palestine, as M. Le Marie had done in Africa. The Persian poet, Hafiz, also, as well as the author of the 'Ramayuna,' and the Hindoo dramatist who wrote 'Sacontala,' are loud in their praises of the music of birds ; while in the Koran and the Arabian Tales they are often mentioned oा.

* Pennant, Arct. Zool.

W Voyages, i.

II Cant. ii. 12.

+ Latham, iii. 3.

I J. Rennie on the Singing of Birds, Edinb. Mag. Jan, 1819, p. 13. 
In speaking of the wood-thrush (Turdus melodus) of A merica, Wilson indignantly repels the assertions of Buffon, who represents this bird as destitute of any note but a single scream, and hence draws an argument for his absurd theory of its being the song-thrush of Europe, degenerated by food and climate, so that its cry is now harsh and unpleasant, as are, he says, the cries of all birds that live in wild countries, imhabited by savages. Wilson's description of the song of this bird is well worth giving. "'This sweet and solitary songster," he says, " inhabits the whole of North America, from Hudson's Bay to the Peninsula of Florida. He arrives in Pennsylvania about the 20th of April, or soon after, and returns to the South about the beginning of October. But at whatever time the wood-thrush may arrive, he soon announces his presence in the woods. With the dawn of the succeeding morning, mounting to the top of some tall tree, that rises from a low thick-shaded part of the woods, he pipes his few but clear and musical notes in a kind of ecstacy; the prelude or symphony to which strongly resembles the double-tongueing of a German flute, and sometimes the tinkling of a small bell; the whole song consists of five or six parts, the last note of each of which is in such a tone as to leave the conclusion evidently suspended; the finale is finely managed, and with such charming effect, as to soothe and tranquillize the mind, and to seem sweeter and mellower at each successive repetition. Rival songsters, of the same species, challenge each other from different parts of the wood, seeming to vie for softer tones and more exquisite responses. During the burning heat of the day they are comparatively mute; but in the evening the same melody is renewed and continued long after sunset. Those who visit our woorls, or ride out into the cointry at these hours, during the months of May 
and $J$ une, will be at no loss to recognise, from the above description, this pleasing musician. Even in dark, wet, and gloomy weather, when scarce a single chirp is heard from any other bird, the clear notes of the wood-thrush thrill through the drooping woods from morning to night; and it may truly be said that the sadder the day the sweeter is his song *."

There are upwards of twenty other American birds which Wilson characterizes in the same graphic manuer, such as the brown thrush (T.rufus), whose song is emphatic, full of variety, and so loud that in a serene morning, when the wind is hushed and before "the busy hum of men" begins, his voice may be distinguished at the distance of half a mile; the migratory thrush (T. migratorius), who is an early songster, frequently commencing before the snow has disappeared, and perching on a stake or fence, to begin the prelude to the general concert; the Baltimore oriole (Oriolus Baltimorus), whose notes consist of a clear mellow whistle, repeated at short intervals as he gleams among the branches, characterized by a certain wild plaintiveness and interesting simplicity, like that of a careless ploughboy whistling for amusement, and that even among the poplars of the American streets, amidst the din of coaches, and wheelbarrows, and the bawling of oyster-women;the Virginian nightingale (Loxia cardinalis), who sings from March till September with great clearness, melody, vivacity, variety, and sprightliness, many of his notes being as loud as those of a fife; and the song sparrow (Fringilla meloda), by far the earliest, the most unwearied, and sweetest of the American song-birds, whose notes resemble the beginning of the canary's song. But we may mention another instance still more adverse to the theory, that, namely, of the rice-bird (Emberiza oryzivora), * Amer. Ornith. i. 33. 
which is found not only in the moretemperate latitudes, but in Jamaica, and, we believe, other tropical localities. His song is bighly musical, and mounting and hovering on the wing, at a small height above ground, he chaunts out a jingling melody of varied notes, as if half a dozen birds were singing together. Some idea may be formed of it, by striking the high keys of a piano-forte singly and quickly, making as many contrasts as possible of high and low notes. Many of the tones are delightful, but the ear can with difficulty separate them. The general effect of the whole is good; and when ten or twelve are singing on the same tree, the concert is singularly pleasing. These examples we think conclusive against the theory, that there are none or only inferior song-birds in the furests of America .

Wa know less of the African birds, except those of Egypt and the Cape of Good Hope; but we have the high authority of M. Vaillant, already quoted, for the general fact, that they do sing well; and another distinguished French naturalist, M. Vieillot, has written an entire and splendid work on the "Singing Birds of the 'Tropiest.' One of the African birds (Emberiza paradisea) is well known from being frequently sent to Europe; and though it cannot vie with our nightingale and thrush, its warble is delightful, resembling, in some degree, that of our swallow, but more shrill and clear $\ddagger$.

Since birds sing in a pitch so irregular and with intervals so unsettled, exhibiting a total disregard to measure or rhythm, we may well ask, what malies their music pleasing? The cause has been traced

* Sec J. Reunie on American Song Birds, Mag. of Nat. Hist. i. 414.

$\uparrow$ Hist. Nat. des Dis. Ois. Chanteurs de la Zone Torride, fol. Paris, 1805. 
to association, for they seldom $\operatorname{sing}$ but in fine weather and when pleased; and, for the latter reason, even the sostenuto purring of the cat is not unpleasing. The variety and rapidity of their notes and intonation also awaken attention, and the contrast in their song between rapid flights of double-demisemi-quavers and lengthened and sweet minims, is often wonderful; as in the case of the soft and sustained notes of the nightingale, succeeded by a short and expressive passage of quicker sound. It is, no doubt, too much to say that we have borrowed all our music from birds, but some of it may, without much stretch of fancy, be considered as having been stolen from that source; for example, the following ${ }^{*}:-$

Flageolet.
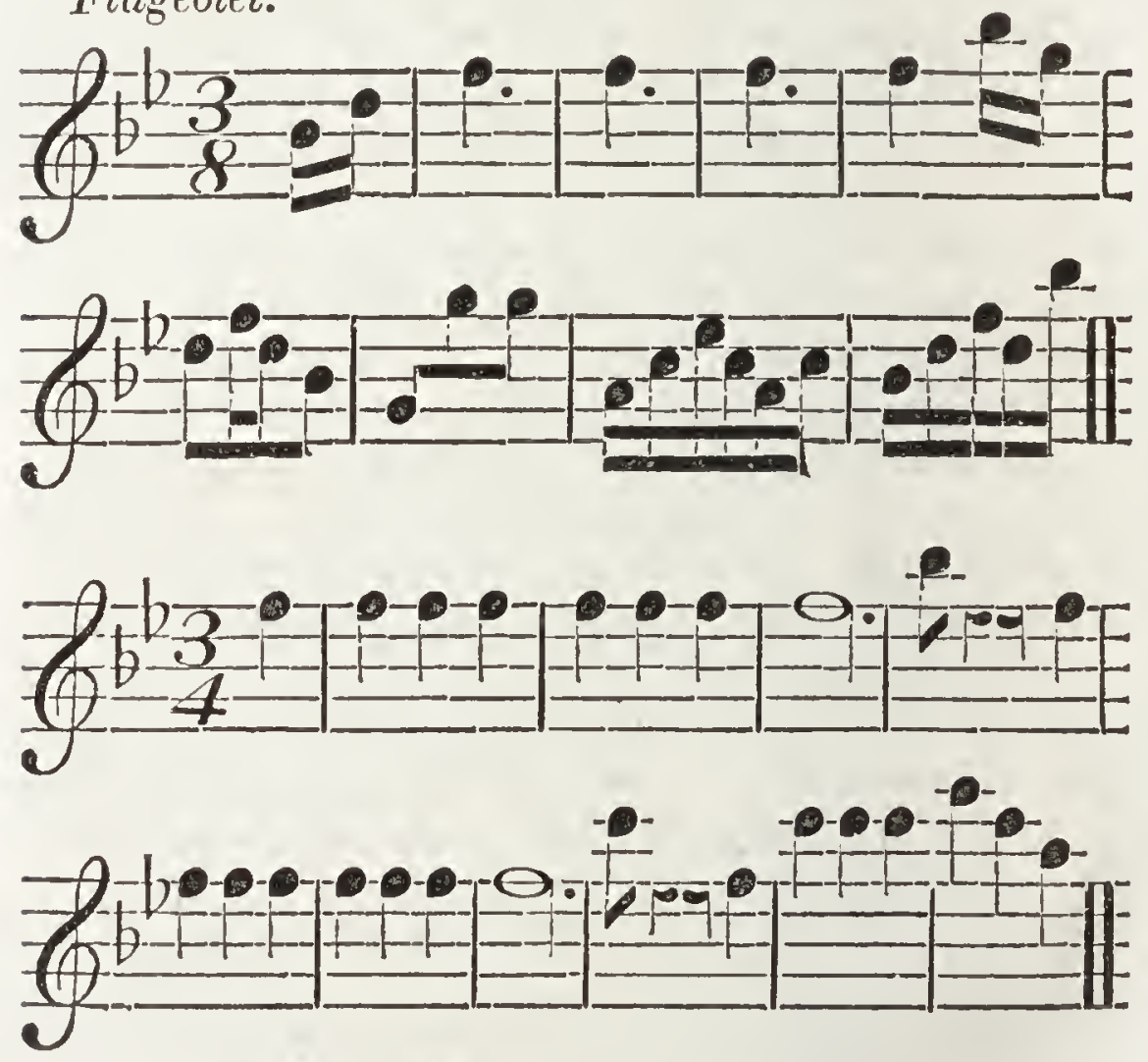

* New Monthly Mag. April, 1823. 
According to Mr. Mitford, "the cuckoo begins early in the season with the interval of a minor third, the bird then proceeds to a major third, next to a fourth, then to a fifth, after which his voice hreaks without attaining a minor sixth"," a circumstance long ago remarked by John Heywood †. The usual note of the cuckoo is the minor third, sung downwards, thus :-

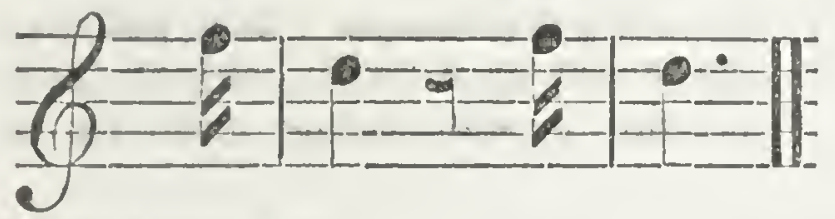

Or as Kircher gives it,

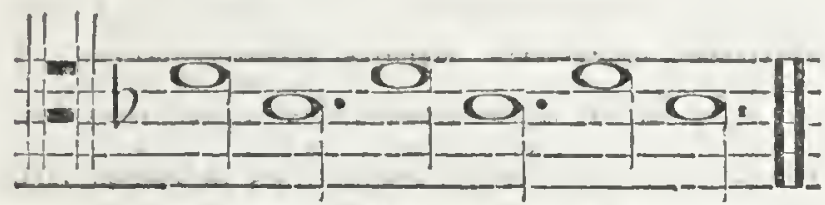

$\mathrm{Gu}-\mathrm{cu}, \quad \mathrm{Gu}-\mathrm{cu}, \quad \mathrm{Gu}-\mathrm{cu}+$.

But, according to White of Selborne, neither owls nor cuckoos keep to one note. "A friend," he says, "remarks, that many (most) of his owls hoot in B flat; but that one went almost half a note below $\mathrm{A}$. The pipe he tried their notes by was a common halfcrown pitch pipe, such as masters use for tuning of harpsichords; it was the common London pitch. A neighbour of mine, who is said to have a nice ear, remarks, that the owls about this village hoot in their different keys, in $\mathrm{G}$ flat or $\mathbf{F}$ sharp, in $\mathrm{B}$ flat and $\mathrm{A}$ flat. He heard two hooting to each other, the one in A flat and the other in B flat. Query: Do these different notes proceed from different species, or only from various individuals? The same person finds, upon trial, that the note of the cuckoo (of which we have but one species) varies in different individuals;

* Linn. Trans. vol, vii. \$ Musurgia, $i$.

† Epigtams, Black Letter, 1587. 
for, about Selborne wood, he found they were mostly in D; he heard two sing together, the one in D, and the other in D sharp, which made a disagreeable concert; he afterwards heard one in D sharp, and about Wolmer Forest, some in C. As to nightingales, he says that their notes are so short, and their transitions so rapid, that he cannot well ascertain their key. Perhaps in a cage or in a room their notes may be more distinguishable. This person has tried to settle the notes of a swift, and of several other small birds, but cannot bring them to any criterion *."

It is singular that scarcely any large bird is known to sing, though the crowing of the cock in the morning may perhaps, without much impropriety, be called singing. We have also observed that the crow (Corvus cornix) is sometimes heard in a calm morning to utter a peculiar plaintive note, very different indeed from its usual croaking, and characterized by an ascending minor third, slurred, not staccatoed, like the descending minor third of the cuckoot. Some are disposed to consider the cawing of rooks a species of song highly grateful, from its rural associations. "The rook," says Bingley, "has but two or three notes, and when he attempts a solo, we cannot praise his song; but when he performs in concert, which is his chief delight, these notes, although rough in themselves, being intermixed with those of the multitude, have, as it were, all their rough edges worn off, and become harmonious, especially when softened in the air, where the bird chiefly performs. We have this music in perfection, when the whole colony is raised by the discharge of a gun f." The chanting falcon (Accipiter musicus, DaudrN), however, is a more decided exception to the general rule,

* Hist. of Selborne, lett. 45. $\ddagger$ Anim. Biogr. ii. 249. + J. R. 
the male, according to M. Vaillant, being remarkable for its song, which it utters every morning and evening, and not uncommonly continues it the whole night. Each strain is continued in a loud tone for more than a minute, and after a pause it begins anew. While it is singing, it is so regardless of its own safety, that any one may approach very near it, but at other times it is suspicious, and takes flight on the slightest alarm*.

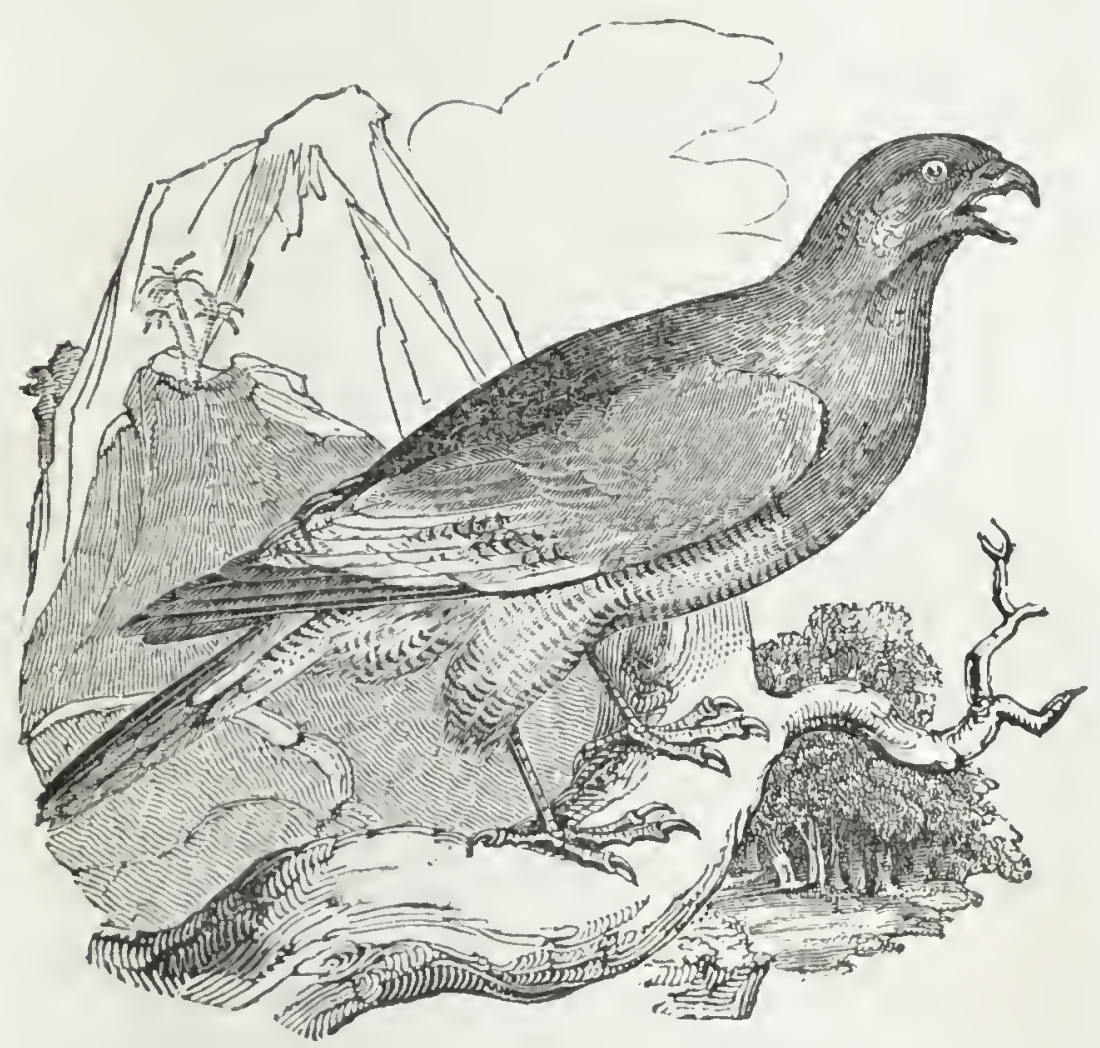

Chanting Falcon.

Another still more remarkable exception might be adduced in the instance of the swan, the largest of singing-birds, according to Albertus Magnus + , could we set down as facts all that has been said of it, not only by poets but by philosophers and naturalists.

* Oiseaux d'Afrique, i. 120.

+ Apud Aldrovandi Oraith. iii. 2. 
We agree with M. Antoine in thinking it not improbable that the popular and poetical notion of the singing of the swan was derived from the doctrine of the transmigration of souls, according to which the philosopher Pythagoras taught that the souls of poets passed at death into swans, and retained the powers of harmony they had possessed in their human form *.

There are several passages, however, in the writing's of the ancients which it may be interesting to notice in relation to this subject. Plato, in his Phædo, makes Socrates express himself as follows:"When swans perceive approaching death, they sing more merrily than before, because of the joy they have in going to the God they serve. But men, through the fear of death, reproach the swans, saying that they lament their death, and sing their grief in sorrowful notes." Then follows the remark we have already quoted, to the effect that no bird sings when it is either hungry or in sorrow: "Far less," concludes the speaker, "do the swans sing out of grief, which, by reason of thieir belonging to A pollo, are diviners, and sing more joyfully on the day of their death than before, as foreseeing the good that awaits them in the other world."

Aristotle again expressly says that "swans are wont to sing, particularly when about to die, and mariners in the Atrican seas have observed many of them singing with a mournful voice and some dyingt,"- - "expiring with the notes of their dying" hymn ", as M. Montbeillard has rendered it. Cicero says of Lucius Crassus that "he spoke with the divine voice of a swan about to die§;" and Pausanias affirms "the bird to be the glory of music,"

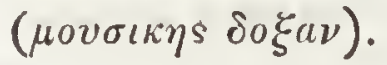

* Animaux Célébres, i. App. 66.

$\dagger$ Hist. Anim. ix. 12. \$ Oiseaux, Art. Le Cygne.

$\S$ De Oratore, iii. Præf。 
When grave philosophers and orators seem thus to be agreed, the authority of poets may be considered of less weight; yet it has appeared to us not a little remarkable, that Homer, though he mentions their noise, when "flying round the springs of Cayster, clangingly on sounding pinions*," makes no allusion to their singing, though Lucretius, Virgil, Ovid, Propertius, Silius Italicus, Claudian, and the rest of the Latin poets, in manifestly copying this very passage of Homer, render his expressive word "clang-

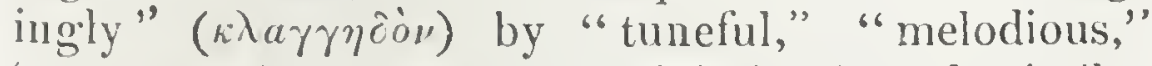
"canorous," "musical," "plaintive," and similar epithets.

It might have been supposed that naturalists would have been contented to adhere to the decision of Pliny, who says, "Some affirm that swans sing" lamentably a little before death, but untruely, I suppose, for experience in many has shown the contrary t." Yet this has not been the case, for some of them enter into the discussion with great minuteness. Elian, indeed, appears to waver in his opinion according to the book he last read, in one place appearing to deny it, because nobody had heard swans sing + , and in another agreeing with Aristotle and Hecatieus . Oppian, again, who is very copious in his accounts of the songs of birds, says, "They sing at the dawn before the rising of the sun, as if to be heard more clearly through the still air. 'They also sing on the sea beach, unless prevented by the sound of storms and boisterous weather, which would not permit them to enjoy the music of their own songs. Even in old age, when about to die, they do not forget their songs, though these are then more feeble than in youth, because they cannot so well erect their necks and expand their wings. They are

* Iliad, $\beta$.

¿ Hist. Var. i.

$\uparrow$ Hist. Nat, x. 23.

\$ De Auim. xx. 30, and xi. 1. 
invited to sing by Favonius, and as their limbs be: come slugrish, and their members deficient in strength when death approaches, they withdraw to some place where no bird may hear them sing, and no other swans impelled by the same cause may interrupt their requiem*."

Julius Scaliger, agrceing with Pliny, vituperates Cardan for lauding the nonsense of the poets, and the mendacity, as he terms it, of the Greeks about the singing of the swant; while Aldrovand, more philosophically, refers us to the structure of the organs of voice (before described $\ddagger$ ), as countenancing the poetical creed; for when we observe, he says, the great variety of modulation which can be produced from a military trumpet, and, going upon the axiom that nature does nothing in vain, compare the form of such a trumpet with the more ingenious mechanism of the swan's windpipe, we cannot but conclude that this instrument is at least capable of producing: the sounds which have been described by the ancient authors. He accordingly proceeds to corroborate this theory by the testimony of those who have actually heard swans singing. Amongst others, one Frederico Pendasio, a celebrated professor of philosophy and a person worthy of credit, told him he had frequently heard swans singing melodiously while he was sailing on the Mantuan lake. He also says that, according to one George Braun (Brown), the swans near London sung festal songs \$. Antonius Musa Brasavolus further affirms, that he had himself observed them singing when near death $\|$. The author of the 'Physicæ Curiosæ,' however, says, "I have been in many places where swans abound, but

* In Halieut.

+ Exercit. 232.

+ Page 248 .

$\$$ Ornithologia, iii. 9.

II Comment. ad Porphyr. Isagog. 
I never could hear them sing, nor have I seen any body who has"."

M. Montheillard, adopting the untenable notion, that the wild and the tame swan are the same species, says, "Though the swan is a silent bird, its rocal organs have the-same structure as in the most loquacious of water-fowl; yet the ordinary voice of the tame swan is rather low than canorous, being a sort of creaking, exactly like what is popularly termed the swearing of a cat, and which the Romans denoted by the initative word drensaret. 'This would seem to be the accent of menace or anger, nor does love appear to have a softer. Swans almost mute, like ours in a domestic state, could not be those melodious birds which have been so mueh celebrated. But the wild swan appears to have better preserved its prerogatives, and with the sentiment of entire liberty, it has also its tones. The bursts of its roice form a sort of modulated song, yet the shrill and scarcely diversified notes of its loud clarion sounds differ widely from the tender nelody, the sweet brilliant variety of our birds of songt."

When swans fight, Albertus Magnus says they hiss and emit a sort of bombilation not unlike the braying of an ass, but not so much prolonged \$. Aristophanes, in his comedy of the Birds, expresses the sounds by Tio, Tio, Tio, Tinx. M. Grouvelle says, "Their voice, in the season of pairing, more resembles a murmur than any sort of song," a conclusion similar to that of M. Morin, in his memoir entitled, "Why swans which sung so well in ancient times now sing so badly\|." M. Grouvelle adds, "There is a season

* P. 1170.

+ Grus gruat, inque glomis cygni prope flumina drensant.Ovid.

\$ Oiseaux, Art. Le Cygne.

\|l Mém, de l'Acad. des Inscript.

$\S$ Hist. Anim. 
when the swans assemble together, and form a sort of commonwealth; it is during severe colds. When the frost threatens to usup their domain, they congregate and dash the water with all the extent of their wings, making a noise which is leard very far, and which, whether in the day or in the night, is louder in proportion to the intensity of the frost. Their efforts are so effectual, that there are few instances of a flock of swans having quitted the water in the longest frosts; though a single swan which has strayed from the general body has sometimes been arrested by the ice in the middle of the canals."

We shall close the subject with the very minute observations of the Abbé Arnaud, derived from his own experience. "One can hardly say," the Abbé remarks, "that the swans of Chantilly sing: they cry; but their cries are truly and constantly modulated: their voice is not sweet; on the contrary, it is shrill, piercing, and rather disagreeable; I could compare it to nothing better than the sound of a clarionet winded by a person unacquainted with the instrument. Almost all the melodious birds answer to the song of man, and especially to the sound of instruments: I played long on the violin beside our swans, on all the tones and chords; I even struck unison to their own accents without their seeming to pay the smallest attention; but if a goose be thrown into the basin where they swim with their young, the male, after emitting some hollow sounds, rushes impetuously upon the goose, and seizing it by the neck, he plunges the head repeatedly under water, striking it at the same time with his wings; it would be all over with the goose, if it were not rescued. 'The swan, with his wings expanded, his neck stretched, and his head erect, comes to place himself opposite to his female, and utters a cry to which the female replies by another, which is lower by half a tone. 'The voice of 
the male passes from A (la) to B flat (si bemol); that of the female, from $\mathrm{G}$ sharp (sol dièse) to $\mathrm{A}$. The first note is short and transient, and has the effect which our musicians call sensible; so that it is not detached from the second, but seems to slip into it. Observe that, fortunately for the ear, they do not both sing at once; in fact, if while the male sounded $B$ flat, the female struck $A$, or if the male uttered $A$, while the female gave G sharp, there would result the harshest and most insupportable of discords. We may add, that this dialogue is subjected to a constant and regular rhythm, with the measure of two times. 'The inspector assured me that, during their amours, these birds have a cry still sharper, but much more agreeable *."

With respect to birds singing at night, it is a great mistake to suppose the nightingale to be the only night songster, because it is the loudest and finest. By the quotation given above from Captain Cook, it appears that in New Zealand several birds sing all night, and in America the mock-bird sings as finely at night as during the day. In Eugland the most remarkable night-singers, after the nightingale, are the sedge-bird (Curruca salicaria, Fleming), and the dipper (Cinclus aquaticus, Bechstein). Every summer for many years we have observed the sedgebird hurrying over its singular medley at all hours of the night, particularly by moonlight; and it seems peculiar to this bird, that it will sing the louder when a stone is thrown into the bush where it is singing, an experiment we have often tried, and usually with the same result. 'The dipper, we have no doubt, commonly sings during the night, but from the secluded streams which it frequents, it is seldom heard; though we have more than once heard it by accident on the river Ayr, and in the autumn of 1831

* Wood's Buffon, xix. 511 , note. 
we listened to one for a considerable time singing its finest notes two hours after sunset, on the romantic banks of the Devon, near the Rumbling Bridge, in Clackmannanshire.

Our other night song-birds seem only to sing occasionally, not regularly, such as the skylark, the redstart, and the red-breast. Among larger birds not usually reckoned song-birds, which emit their peculiar call-notes in the night, we may enumerate the quail, the corncrake, the partridge, the grouse, and more particularly the cock.

We have remarked that some species of cage-birds will readily sing at night when the candles are lit, while others will not sing a note. The black-cap, for example, mentioned in a former page, has never attempted to sing at night above once or twice; while Mr. Sweet found his redstart sing every night, as we find to be the case with our red-breasts. When a red-breast has been recently caught, indeed, he never attempts to sing during the day, and always essays his first cage-song after dark, venturing, by degrees, to extend his voice, befure he try it in open day. We have had birds of this species who would sing in this manner every night for several weeks, without singing a note during the day. At present (January) we have a bird of this kind which seldom begins before eight o'clock at night, after another in a neighbouring cage, which sings equally through the day and after dark, has finished singing for the evening**

It may be remarked also, that in cage-birds, though they will sometimes break out into their loudest notes at night, their song is for the most part soft, subdued, and warbling; such is the case at least with our redbreasts, and an aberdevine near them. Canaries and blackbirds, however, usually sing aloud at night, and * J, R, 
the nightingale, so far as we have remarked, always. We have, however, heard some of these night songs, which were manifestly uttered while the bird was asleep, in the same way as we sometimes takk during sleep-a circumstance remarked by Dryden, who says,

"The little birds in dreams their songs repeat *"

We have even observed this in a wild bird. On the night of the 6 th $A$ pril, 1811, about ten o'clock, a dunnock (Accentor modularis) was heard in a garden to go through its usual song more than a dozen times very faintly, but distinctly enough for the species to be recognised. The night was cold and frosty; but might it not be that the little musician was dreaming of summer and sunshine t? Aristotle, indeed, proposes the question, whether animals hatched from eggs ever dream + . Marcgrave in reply expressty says that his "parrot, Laura, often rose in the night and srattled while half asleep §."

* Indian Emperor.

+ J. Remie on the Singing of Birds, Edinb. Mag. Jan. 1819, p. 14.

$\ddagger$ Hist. Anim. v. $10 . \quad \oint$ Hist. Rerum Nat. 


\section{Chapter XVII.}

\section{IMITATION AND MIMICRY OF BIRDS.}

"Mimicry," says Lord Chesterfield, "which is the common and favourite amusement of little, low minds, is in the utmost contempt with great ones. It is the lowest and most illiberal of all buffoonery; we should neither practise it, nor applaud it in others*." Yet, in despite of his lordship's authority, mimicry and imitation are and will be practised, and relished and applauded, so long as men continue to receive pleasure from exercising their minds in making comparisons; for this exercise is always pleasing in proportion to the activity of mind, or the flow of associated ideas thereby produced-perhaps the true origin indeed of all our mental pleasures.

All this may be true so far as it goes-but the pleasure of making comparisons is only a particular iustance of the pleasure we have in perceiving similitude in dissimilitude-or sameness combined with variety; and this is the true principle of the phenomenon under consideration.

If we hear a parrot utter an imitation of the words "Pretty Poll," we immediately trace a series of resemblances or differences betweell the pronunciation of the words by the parrot and by a man; and if the bird comes near the sound, we are pleased in tracing the resemblance, while we admire the successfulness of the effort in accomplishing what might be previously supposed a difficult task for a bird-the overcoming of any difficulty having 
always the effect of exciting proportional admiration, from the sympathy of the passive spectator with the active agent, who feels his incapability of executing the same feat in all its particulars.

A story is told of Goldsmith, that having gone with Johmson and Burke to see an exhibition of puppets, his vanity was hurt at their praising the agility displayed by the figures, which, with characteristic simplicity, he volunteered to equal, and began accordingly, in good earnest, to skip over the chairs in the room, without reflecting that it was not exactly the agrility that had pleased them, and drawn forth their admiration, but the imitation of living actions, producing in their minds a train of comparison between the puppets and the motions of the animals imitated.

The truth of these views appears to be proved by the fact, that when the imitation is so perfect as to amount to a belief of its identity with what is imitated, no pleasure is produced by an observer, in consequence of his mind not being excited to institute a train of comparisons. In the case of the parrot, when the words are heard while the bird is unseen, the articulation never so nearly imitates humanity as to prevent the hearer from immediately recognizing the voice to be that of a bird; but were the imitation perfect (supposing the bird still unseen), instead of a hearer going into a comparison respecting the imitation, he would immediately infer that the words "Pretty Poll" were utterea by some person calling to a parrot, rather than suppose them to be uttered by a bird. We recollect an instance of a starling, which had been taught by an Ayrshire hair-dresser to repeat the words "Get up, Sir," with surprising correctness of articulation. The tone of voice was husky and whispering, and the first time we heard it from the bird, hanging in a dark 
corner of the shop, we could not imagine whence the words proceeded, and were led to fancy that it might be some idiot boy repeating, as is common in such cases, his favourite phrase; but no sooner did we learn the truth, than the correctness of the execution became a matter of comparison and of wonder *

But whatever may be the cause of the pleasure we take in hearing such imitations by birds, both of the sounds of one another and of animals of a different older, they are in many cases possessed of considerable interest. Except, however, in instances similar to those mentioned in a former chapter, we are very much disposed to doubt the current opinion respecting the mocking or mimicry of wild-birds. In Kent, Norfolk, and some other parts of England, the black-cap and the fauvette (Philomela hortensis) are both called the mock nightingale, under the notion, probably, of their imitating its song; but no person who is well acquainted with the nightingale's song could for a moment suppose the notes of either of these two birds to be an imitation of it, though they are both delightful songsters, and one of each species, at the time we write this, is trying to excel the other, in the garden opposite to our study. 'The black-cap indeed, and the fauvette, sing liker to each other than to the nightingale, and have one or two notes in common, though we cannot see any reason to conclude that these notes were reciprocally borrowed; any more than the common notes which may be observed in the several songs of the fauvette, the white-throat, and the babillard (Curruca garrula, BRrsson).

Another native bird, the sedge-bird (Ripacola salicaria), is represented by most of our naturalists as a genuine mock-bird. "The artificial notes," it has been remarked, " which wild birds acquire by imitation, are seldom altogether perfect, and may, in * J. R. 
most cases, be recognised as imitations. This remark is confirmed by the fact, that mock-birds, which may be considered as having no natural song of their own, cannot go through with any set of notes, without introducing tones foreign to the notes they are imitating. The mock-bird of this country" (Riprecola salicaria), "whose retired habits cause it to be but little attended to, may be heard hurrying over in succession the song of the wren, wagtail, and sky-lark, the twitter of the swallow, and the chirp of the sparrow and the chaffinch; but it often introduces a deep harsh note, which belongs to no other native bird, though it has a distant resemblance to the chirr of the white-throat. Indeed, the mockbird, both in its size and colour as well as in its habits, is so like the white-throat as to be often confounded with it *."

Now though we are willing to admit that there is considerable plausibility in this view of the matter, yet the circumstances appear susceptible of an explanation more likely, we think, to be true. From the sedge-bird frequenting the solitary banks of weedy streams and ditches, it can have few opportunities of hearing the notes of the chimney-swallow, and much less of the house-sparrow, even supposing it disposed to learn them. And among some hundreds of these birds which we have listened to in the most varied situations in the three kingdoms, all seemed to have very nearly the same notes, repeated in the same ordert; a fact which appears to us to be fatal to the inference of the notes being derived, not from one, but a number of other birds. For if this were so, it is not possible that these imitated notes should all follow in exactly or very nearly the same order in the song of each individual imitator in different and distant parts of the country. 'The

* Ediu. Mag., Jan, 1819, p. 10.

†J.R. 
close similarity of the notes to those alleged to be imitated cannot be denied; but taking all the circumstances into account, we think it much more probable that these resembling notes are original to the sedge-bird, and that we might, with equal justice, accuse the swallow and the sky-lark of borrowing from it.

There are several American birds, however, much more celebrated as mockers or imitators than our little sedge-bird. We shall only particularize three, the polyglot-chat, the blue-jay, and the bird universally designated the mocking-bird.

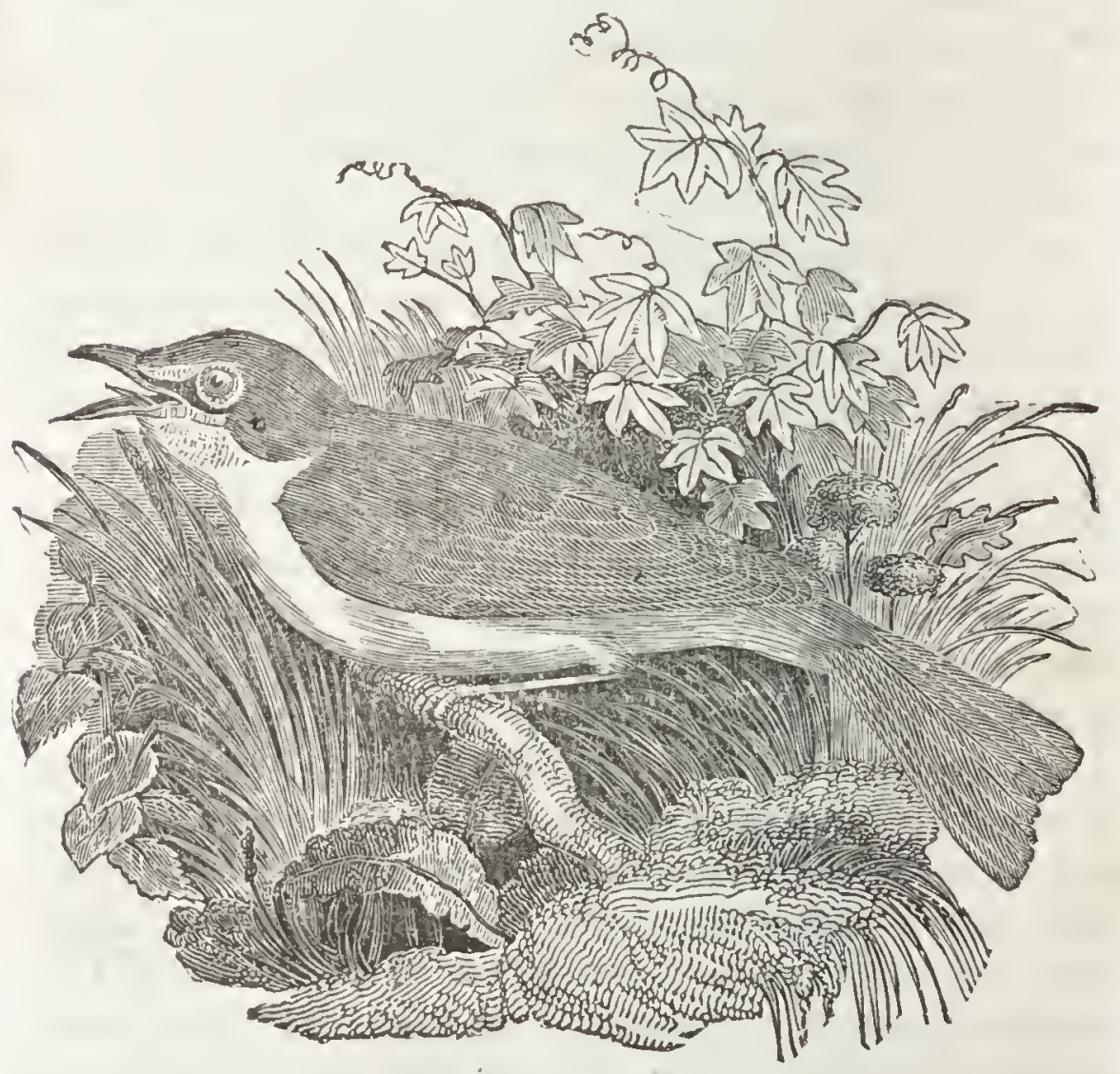

The Polyglot-Chat.

The polyglot-chat (Piprce polyglotta, WiLson) was first observed and figured by Catesby, who discovered its singular manners by the difficulty he 
had in shooting one. II observed also that it is no less adroit at dancing, than in the varied modulations of its voice. It is, says Wilson, in a highly characteristic sketch, "a very singular bird. In its voice and mamners, and the habit it has of keeping concealed while shifting and'vociferating around you, it differs from most other birds with which I am acquainted, and has considerable claims to originality of character. It arrives in Pennsylvania about the first week in May; its term of residence here being scarcely four months. When he has once taken up his residence in a favourite situation, which is almost always in close thickets of hazel, brambles, vines, and thick underwood, he becomes jealous of his possessions, and seems offended at the least intrusion; scolding every passenger as soon as they come in view, in a great variety of odd and uncouth monosyllables, which it is difficult to describe, but which may be readily imitated so as to deceive the bird himself, and draw him after you for a quarter of a mile at a time, as $I$ have sometimes amused myself in doing, and frequently without once seeing him. On these occasions his responses are constant and rapid, strongly expressive of anger and anxiety; and while the bird itself remains unseen, the voice shifts from place to place, among the bushes, as if it prow ceeded from a spirit. First are heard a repetition of short notes, resembling the whistling of the wing's of a duck or teal, beginning loud and rapid, and falling lower and slower till they end in detached notes; then a succession of others, something like the barking of young puppies, is followed by a variety of hollow guttural sounds, each eight or ten times repeated, more like those proceeding from the throat of a quadruped than that of a bird; which are succeeded by others not unlike the mewing of a cat, but considerably hoarser. All these are uttered with great vehemence, in such different keys, and with 
such peculiar modulations of voice, as sometimes to seem at a considerable distance, and instantly as if just beside you; now on this hand, now on that; so that from these manœuvres of ventriloquism, you are utterly at a loss to ascertain from what particular spot or quarter they proceed. If the weather be mild and serene, with clear moonlight, he continues gabbling in the same strange dialect, with very little intermission during the whole night, as if disputing with his own echoes; but probably with a design of inviting the passing females to his retreat, for when the season is further advanced they are seldom heard during the night.

"While the female chat is sitting, the cries of the male are still more loud and incessant. When once aware that you have seen him, he is less solicitous to conceal himself, and will sometimes mount up into the air, almost perpendicularly, to the height of thirty or forty feet, with his legs hanging; descending, as he rose, by repeated jerks, as if highly irritated, or, as is vulgarly said, 'dancing mad.' All this noise and gesticulation we must attribute to his extreme affection for his mate and young; and when we consider the great distance which in all probability he comes, the few young produced at a time, and that seldom more than once in the season, we can see the wisdom of Providence very manifestly in the ardency of his passions *."

We have introduced this description more to show the variety of note and voice which actually occurs in a bird, than as exhibiting an instance even of alleged imitation; for though it is said some of the sounds uttered by the polyglot-chat are "something like the barking of young puppies," and "others not unlike the mewing of a cat," it is not averred, as it is in the case of the bird called the mocking-bird, that these sounds are derived from imitation.

$$
\text { * Am. Ornith. i. } 92 .
$$


We have elsewhere taken notice of some interesting peculiarities in the American blue-jay* (Garrulus crislatus, Brisson), and shall now advert to what is said of its powers of imitation and numicry. "In the charming season of spring," says Wilson, "when every thicket pours forth harmony, the part performed by the jay always catches the ear. He appears to be, among his fellow-musicians, what the trumpeter is in a band, some of his notes having no distant resemblance to the tones of that instrument. Thus he has the faculty of changing through a great variety of modulations, according to the particular humour he happens to be in. When disposed for ridicule, there is scarce a bird whose peculiarities of song he cannot tune his notes to. When engaged in the blandishments of love, they resemble the soft chatterings of a duck, and while he nestles among the thick branches of the cedar, are scarce heard at a few paces distance; but no sooner does he discover your approach, than he sets up a sudden and vehement cry, flying off, and screaming with all his might, as if he called the whole feathered tribes of the neighhourhood to witness some outrageous usage he had received. When he hops undisturbed among the high branches of the oak and hickory, they become soft and musical; and his calls of the female a stranger would readily mistake for the repeated creakings of an ungreased wheelbarrow. All these he accompanies with various nods, jerks, and other gesticulations, for which the whole tribe of jays are so remarkable.

"He is not only bold and vociferous, but possesses a considerable talent for mimicry, and seems to enjoy great satisfaction in mocking and teasing other birds, particularly the little hawk (Falco sparverius), imitating his cry wherever he sees him, and squealing out as if caught; this soon brings a number of * Archit, of Birds, Chap. on Basket Makers, 
his own tribe around him, who all join in the frolic, darting about the hawk, and feigning the cries of a bird sorely wounded and already under the clutches of its devourer; while others lie concealed in bushes ready to second their associates in the attack. But this ludicrous farce often terminates tragically. The hawk singling ont one of the most insolent and provoking, sweeps upon him in an unguarded moment, and offers him up a sacrifice to his hunger and resentment. In an instant the tune is changed; all their buffoonery vanishes, and loud and incessant screams proclaim disaster.

"Wherever the jay has liad the advantage of education from man, he has not only shown himself an apt scholar, but his suavity of manners seems equalled only by his art and contrivances, though it must be confessed that his itch for thieving keeps pace with all his other acquirements. Dr. Mease, on the authority of Colonel Postell, of South Carolina, informs me that a blue jay, which was brought up in the family of the latter gentleman, had all the tricks and loquacity of a parrot, pilfered every thing he could conveniently carry off, and hid them in holes and crevices, answered to his name with great sociability when called on, could articulate a number of words pretty distinctly, and when he heard any uncommon noise or loud talking, seemed impatient to contribute his share to the general festivity (as he probably thought it) by a display of all the oratorical powers he was possessed of *."

Though this account, however, appears to be circumstantially and rather minutely given, we are disposed to consider the alleged imitations no better proved than those by which our native bird, the flusher (Lanius Collurio), is said to lure small birds within its beat by mimicking their notes, - a feat of ingenuity not borne out by any observation we have been able * Am. Oruith. i. 16. 
to make, though our altention has been for five summers directed to this point, in al district where the species abounds. We have, on the contrary, ascertained that the flusher utter's no call that has the nost distant resemblance to that of any other bird, its usual note being a harsh, disagreeable screech*.

The American mocking-bird attracted the notice of the earlier voyagers to the New World by the variety of its notes and the extraordinary compass and fineness of its voice, and above all by its apparent talent of mimicking the notes and cries of other birds and beasts. According also to Fernandez, Nieremberg, and Sir Hans Sloane, it is not satisfied with barely re-echoing the sounds imitated, but gives them a softness and grace not characteristic of the original, for which reason the Mexicans termed it the bird of four hundred tongues (Cencontlatotli). These writers also mention its mingling action with its song, accompanying the notes with measured movements expressive of successive emotions. In its preluding, it rises slowly with expanded wings, sinking back to the same spot, with its head hanging downwards, as the sky-lark may sometimes be observed to do. When it has advanced further in the performance, it ascends and descends on the wing in a spiral manner, and if the notes are brisk and lively, it describes in the air circles, crossing in all directions. When the notes are loud and rapid it flaps its wings with proportional rapidity, and when the notes are unequal it bounds and flutters in unison; but as it becomes apparently tired of exertion, its tones soften by degrees, melt into tender strains, and die away in a pause, which has a peculiarly fine effect, while at the same time it gradually diminishes its action, glides gently and smoothly above its station tree $\approx$ J. R. 
till the wavings of its wings become imperceptible, and finally ceasing, the little musician remains in the air suspended and motionless, as the kestril (Falco tinnunculus) may be seen to do when it watches for prey.

"I saw, heard, and admired," says Fernandez, "a small bird brought to Madrid, the queen of all singing birds, that could command any voice or tune. It is not bigger than a starling, white underneath, brown above, with some black and white feathers intermixed, especially next the tail, and about the head, which is encircled with the likeness of a silver crown. It is kept in cages to delight the ear, and for a natural rarity or rather wonder. It excels all birds in sweetness and variety of song and perfect command of its voice, imitating the note of any sort of bird whatsoever, and excelling its exemplar. It goes far beyond the nightingale. I myself kept it a long time*."

According to Goldsmith, who appears to speak from private information, as he does not here, as usual, translate nor follow Buffon, the mocking-bird " is possessed not only of its own natural notes, which are musical and solemn, but it can assume the tone of every other animal in the wood, from the wolf to the raven. It seems even to sport itself in leading them astray. It will at one time allure the lesser birds with the call of their mates, and then terrify them, when they have come near, with the screams of the eagle. There is no bird in the forest but it can mimic, and there is none that it has not at times deceived by its call. But, not like such as we usually see tamed for mimicking with us, and who have no particular merit of their own, the mock-bird is ever surest to please when it is most itself. At those times it usually frequents the houses of the American planters; and, sitting all * Hist. Anim. Nov. Hisp. 
night on the chimney top, pours forth the sweetest and the most various notes of any bird whatever*"

Pennant assures us that he himself heard "a caged one" in England "imitate the mewing of a cat, and the creaking of a sign in high winds," and that it not only sallg, but danced, performing a great many gesticulations. He further tells us that it imitates the notes of all birds, from the hummingbird to the eagle $\dagger$.

'The Hon. Daines Barrington, referring probably to the same bird, tells us that its notes were chiefly, if not entirely, imitations of the notes of other birds. "I have happened," he says, " to hear the American mocking-bird in great perfection, at Messrs. Vogels and Scott, in Love-lane, Eastcheap. During the space of one minute he imitated the wood-lark, chaffinch, blackbird, thrush, and sparrow. I was told also that he would bark like a dog; so that the bird seems to have no choice in his imitation; though his pipe comes nearest to our nightingale of any bird I have yet met with. With regard to the original notes, however, of this bird, we are still at a loss, as this call only be known by those who are accurately acquainted with the solng of the other American birds. Kalm, indeed, informs us that the natural song is excellent + ; but this traveller seems not to have been long enough in America to have distinguished what were the genuine notes. With us nimics do not often succeed but in imitations. I have little doubt, however, but that this bird would be fully equal to the song of the nightingale in its whole compass; but then, from the attention which the mocker pays to any other sort of disagreeable noise, these capital notes would be always debased by a bad mixture §."

Sonthey, in a few lines, embodies nearly all that

* Anim. Nat. iii. 219.

+ Arctic \%ool. ii. 334 .

+ Travels, i. 219.

\$ Phil. Trans, vol, 62. pt, ii. p. 284. 
the works we have quoted contain respecting this bird, which he calls-

"That cheerful one, who knoweth all

The songs of all the winged choristers;

And, in one sequence of melodious sounds,

Pours all their music*."

He adds in a note that "a negress was once heard to exclaim, "Please God Almighty, how sweet that mocking-bird sing! he never tire.' By day and night he sings alike; when weary of mocking others, the bird takes up its own natural strain, and so joyous a creature is it, that it will jump and dance to its own music. This bird is perfectly domestic, the Americans holding it sacred. Would that we had more of these humane prejudices in England, if that word may be applied to a feeling so good in itself and in its tendency + ."

By far the most circumstantial account, however, of this wonderful bird (which Ray has even gone so far as to place among the fabulous and doubtful species in his Appendix to Willughby's Ornithology) is given by Wilson in a characteristically graphic passage. "This celebrated and very extraordinary bird," he says, " in extent and variety of vocal powers, stands unrivalled by the whole feathered songsters of this or perhaps any other country; and shall receive from us all that attention and respect which superior merit is justly entitled to. The plumage of the mocking-bird, though none of the homeliest, has nothing gaudy or brilliant in it ; and, had he nothing else to recommend him, would scarcely entitle him to notice; but his figure is well proportioned, and even handsome. The ease, elegance, and rapidity of his movements, the animation of his eye, and the intelligence he displays in listening and laying up lessons from almost every species

$$
\text { * Madoc, ii. } 48 .
$$

+ Davies, Brazil, quoted by Southey, Madoc, ii. 235. 
of the feathered creation within his hearing, are really surprising, and mark the peculiarity of his genins. To these qualities we may add that of a voice, full, strong, and musical, and capable of almost every modulation, from the clear mellow tones of the wood-thrush, to the savage scream of the bald eagre. In measure and accent he faithfully follows his originals; in force and sweetness of expression he greatly improves upon them. In his native groves, mounted on the top of a tall bush or half-grown tree, in the dawn of the lewy morning, while the woods are alrcady vocal with a multitude of warblers, his admirable song rises pre-eminent over every competitor. The ear can listen to his music alone, to which that of all the others seems a mere accompaniment. Neither is his strain altogether imitative. His own native notes, which are easily distinguishable by such as are well acquainted with those of our various song-birds, are bold and full, and varied seemingly beyond all limits. They consist of short expressions of two, three, or at the most five or six syllables, generally interspersed with imitations, and all of them uttered with great emphasis and rapidity; and continued, with undiminished ardour, for half an hour, or an hour, at a time. His expanded wings and tail, glistening with white, and the buoyant gaiety of his action, arresting the eye, as his song irresistibly does the car. He sweeps romnd with enthnsiastic ecstasy; he mounts and descends as his song swells or dies away; and as iny friend Mr. Bartram has beautifully expressed it, "He bounds aloft with the celerity of an arrow, as if to recover or recall his very soul, expired in the last elevated strain *.' While thus exerting himself, a bystander, destitute of sight, would suppose that the whole feathered tribe had assembled togrether, on * Travels, p. 32, Introd. 
a trial of skill; each striving to produce his utmost effect; so perfect are his imitations. He many times deceives the sportsinan, and sends him in search of tirds that perhaps are not within miles of him; but whose notes he exactly imitates: even birds themselves are frequently imposed on by this admirable mimic, and are decoyed by the fancied calls of their mates; or dive with precipitation into the depth of thickets, at the scream of what they suppose to be the sparrow-liawk.

"The mocking-bird loses little of the power and energy of his song by confinement. In his domesticated state, when he commences his career of song, it is impossible to stand by uninterested. He whistles for the dog; Cæasar starts 11p, wags his tail, and runs to meet his master. He squeaks out like a hurt chicken, and the hen hurries about with hanging wings, and bristled feathers, clucking to protect its injured brood. The barking of the dog, the mewing of the cat, the creaking of a passing wheelbarrow, follow with great truth and rapidity. He repeats the tune taught him by his master, though of considerable length, fully and faithfully. He rmns over the quaverings of the canary, and the clear whistlings of the Virginia nightingale, or red-bird, with such superior execution and effect, that the mortified songsters feel their own inferiority, and become altogether silent; while he seems to triumph in their defeat by redoubling his exertions.

"This excessive fondness for variety, however, in the opinion of some, injures his song. His elevated imitations of the brown thrush are frequently interrupted by the crowing of cocks; and the warblings of the blue-bird, which he exquisitely manages, are mingled with the screaming of swallows, or the cackling of hells; amidst the simple melody of the robin we are suddenly surprised by the shrill reiterations of the whip-poor-will; while the notes of the kildeer, the blue 
jay, martin, baltimore, and twenty others, succeed, with such imposing reality, that we look round for the originals, and discover, with astonishment, that the sole performer in this singular concert is the admirable bird now before us. During this exhibition of his powers, he spreads his wings, expands his tail, and throws himself around the cage in all the ecstasy of enthusiasm, seeming not only to sing, but to dance, keeping time to the measure of his own music. Both in his native and domesticated state, during the solemn stillness of night, as soon as the moon rises in silent majesty, he begins his delightful solo; and serenades us the livelong night with a full display of his vocal powers, making the whole neighbourhood ring with his inimitable medley*."

It would be absurd after these well-authenticated facts to deny the imitative powers of this singular bird; yet it is worthy of remark, that most of the accounts concur in asserting its original unborrowed notes to be very varied and excellent, and we are thence disposed to infer that most of the alleged imitations are original also, as we think we have already pretty clearly shown those of our own sedgebird to be, though they too are commonly ascribed to imitation. It is hypothetically supposed indeed, "that during the day, its chief notes consist of the imitations of the songs of its neighbours; at night its song is more peculiarly its own," a gratuitous assumption countenanced by no fact nor any example from this or any other species. Our own sedge-bird, which sings all night long like the American mocking-bird, is as profuse of the notes alleged to be imitative when he sings at midnight as when he sings at noon; and there is no perceptible difference in the night songs of the nightingale, the dipper, and other night-singing birds, from their day music; 
except, as we have fancied, that the latter is less spirited and sprightly *

"The native notes of the mocking-bird," according to Wilson, "have considerable resemblance to those of the brown thrush (Turdus rufus), but may easily be distinguished by their greater rapidity, sweetness, energy of expression, and variety." We have already seen also, that he describes the part of the song not alleged to be imitative as "bold, full, and varied, seemingly beyond all limits;" so that we are at least borne out, by several strong facts, in our opinion of the whole song being original, and not the result of a confused medley of imitations.

It is a favourite topic with authors to compare the singing of the American mocking-bird and the European nightingale. " It may not be improper," says Daines Barrington, "to consider whether the nightingale may not have a very formidable competitor in the American mocking-bird, though almost all travel. lers agree, that the concert in the European woods is superior to that of the other parts of the grlobe." He adds, from his own observation, that its "pipe comes the nearest to our nightingale of any bird $\mathbf{I}$ lave yet met with + ."

Wilson, never having heard the nightingale, could not of course make the requisite comparison; but after quoting Barrington's sentiments, he exclaims, "What must we think of that bird, who, in the glare of day, when a multitude of songsters are straining their throats in melody, overpowers all competition; and, by the superiority of his voice, expression, and action, not only attracts every ear, but frequently strikes dumb his mortified rivals ; **** when the silence of night as well as the bustle of day bear witness to his melody; and when even in captivity, in a foreign country, he is declared by the best judges in that country, to be fully equal to the * J. R. + Phil, Trans, vol. 62, pt. ii. p. 284. 
song of their sweetest bird in its whole compass? The supposed degradation of his song," he adds, "by the introduction of extraneous sounds and unexpected imitations, is, in fact, one of the chief excellencies of this bird; as these changes give a perpetual novelty to his strain, keep attention constantly awake, and impress every hearer with a deeper interest in what is to follow. In short, if we believe in the truth of that mathematical axiom, that the whole is greater than a part, all that is excellent or delightful, amusing or striking, in the music of birds, must belong to that admirable songster, whose vocal powers are equal to the whole compass of their whole strains *"

So very different a view of the powers of this bird lias been stated by a recent author, that we cannot omit taking notice of it, premising, however, that it does not appear whether it has been formed from actual observation or merely from comparing the accounts given in books. "This bird," says the author, "not only sings with taste, and without monotony, but also with action and animation. It is, perhaps, one of the first of singing birds; but to place it above the nightingale, with Fernandez, Nieremburg, and others, can only be done by those who have never heard, or who have entirely forgotten the song of that delightful bird. 'The voice of the mocking-thrush is more loud and powerful, but by no means so agreeable within a certain distance. Its song has little of the softness, delicacy, and plaintive tenderness that so peculiarly characterize the nightingale during the season of love. As there is no bird among the Americans at all to be compared to the mockingbird, it is not astonishing that they should have exalted it into such an extraordinary character, and raised it above all other birds. They have, however, exaggerated its talents, in stating that it can imitate * Amer. Ornith。 ii. 21. 
completely, and in all their parts, the song of other birds, the cries of different quadrupeds, the crying of infants, the laughter of a young girl, and in being able to repeat entire airs on the same key in which it has heard them. It does not possess the imitative talent to this degree, even in captivity. The mewing of the cat, however, it takes off so completely as to deceive any ear*."

There can be little doubt, we think, that if the bird has been over-rated, and its powers exaggerated, by some who have described it, it is as much underrated in the passage just quoted. The most decisive testimony we have met with upon the point appears to be that of Audubon, who is well acquainted with the notes both of the nightingale and the mockingbird. "Some," he says, "have described the notes of the nightingale as occasionally fully equal to those of our bird. I have frequently heard both species in confinement, and in the wild state, and, without prejudice, have no hesitation in pronouncing the notes of the European philomel equal to those of a soubrette of taste, which, could she study under a Mozart, might perhaps, in time, become very interesting in her way; but to compare her essays to the finished talent of the mocking-bird, is, in my opinion, quite absurd. Good singing birds," he adds, "of this species, often bring a high price; they are long-lived, and very agreeable companions; their imitative powers are amazing, and they mimic with ease all their brethren of the forests, or of the waters, as well as many quadrupeds. I have heard it asserted, that they possess the power of imitating the human voice, but have never met with an instance of the display of the alleged faculty t."

It is rather a curious circumstance, characterizing, it would appear, the mocking-bird, as well as our

* Griffith's Cuvier, Anim. Kingd. vi. 540.j

t. Ornith. Biogr. p. 112. 
European birds, that the species distinguished for singing seldom learn to imitate human speech; while those which do not sing, such as the jay, the magpie, and the parrot, are well known as successful imitators. Although, however, this appears to be true, as a general rule, some singular exceptions are upon record in the case of individual birds. Mr. Syme, for instance, tells us of the red-breast, that he knows a lady who possesses one that very distinctly pronounces "How do ye do?" and several other words, taught it by repeating them often while giving it some favourite food*; and Pliny mentions, that "Agrippina the empress, wife to Claudius Cæsar, had a blackbird or a throstle, at what time I compiled this book, which could counterfeit man's speech, a thing never seen nor known before." Pliny states farther, that the two young Ciesars, Drusus and Germanicus, had "sundry nightingales taught to parle Greek and Latin : moreover, they would study upon their lessons, and meditate all day long; and from day to day come out with new words still, yea, and were able to continue a long speech and discourse t."

The most extraordinary instance on record, however, of the possession of this faculty, is given on the testimony of a friend, who witnessed the circumstances, by the celebrated naturalist Gesner, though the story appears so very marvellous that we cannot but suspect it to be exceedingly exaggerated:"Whilst I was at Ratisbou," says Gesner's friend, "I put up at an inn, the sign of the Golden Crown, where my host had three nightingales. What I am going to relate is wonderful, almost incredible, and yet is true. The nightingales were placed separately, so that each was shut up by itself in a dark cage. It happened at that time, being the spring of the year, when those birds are wont to sing indefatigably, that

* Brit. Song Birds, p. 126.

+ Holland's Plinie, i. 693. 
I was so afflicted with the stone, that I could sleep but very little all night. It was usual, then, about midnight, when there was no noise in the house, but all still, to hear the two nightingales jangling and talking with each other, and plainly imitating men's discourses. For my part I was almost astonished with wonder; for at this time, when all was quiet, they held conference together, and repeated whatever they had heard anorig the guests by day. Those two of them that were most notable, and masters of this art, were scarce ten feet distant from one another; the third hung more remote, so that I could not so well hear it as I lay a-bed. But it is wonderful to tell how those two provoked each other, and, by answering, invited and drew one another to speak; yet they did not confound their words, or talk both together, but rather uttered them alternately, and in course. Besides the daily discourse of the guests, they chaunted out two stories, which generally held them from midnight till morning; and that with such modulations and inflexions, as no man could have taken to come from such creatures. When I asked the host if they had been taught, or whether he observed their talking in the night, he answered, ' No.' The same said the whole family; but I, who could not sleep for nights together, was perfectly sensible of their discourse. One of their stories was concerning the tapster and his wife, who refused to follow him to the wars, as he desired her; for the husband endeavoured to persuade his wife, as far as I understood by the birds, that he would leave his service in that inn, and go to the wars, in hopes of plunder; but she refused to follow him, resolving to stay either at Ratisbon, or go to Nuremberg. There was a long and earnest contention between them, and all this dialogue the birds repeated; they even repeated the unseemly words which were cast out between them, and which ought rather to have been sup- 
pressed, and kept a secret; but the birds, not knowing the difference between modest, immodest, honest, and filthy words, did out with them. The other story was concerning the war which the Emperor was then threatening against the Protestants, which the bird probably heard from some of the generals that had conferences in the house. These things did they repeat in the night after twelve o'clock, when there was a deep silence; but in the day-time, for the most part, they were silent, and seemed to do nothing but meditate and revolve with themselves upon what the guests conferred about together as they sat at table, or in their walks. I verily had never believed our Pliny writing so many wonderful things concerning these little creatures, had I not myseif seen them with my eyes, and heard them with my ears uttering such things as I have related; neither yet can $I$ of a sudden write all, or call to remembrance every particular that I have heard *."

The marvellousness of this story, however, if it be a mere legendary fiction, is somewhat countenanced by the well-anthenticated accounts of a grey parrot (Psittacus erithacus) which belonged to Colonel O'Kelly. This extraordinary bird " not only," says Bingley, "repeated a great number of sentel ces, but answered many questions: it was also able to whistle many tunes. It beat time with all the appearance of science; and so accurate was its judgment, that if by chance it mistook a note, it would revert to the bar where the mistake was made, correct itself, and, still beating regular time, go through the whole with wonderful exactness. Its death was thus announced in the General Evening Post, for the 9th of October, 1802:- ' A few days ago died, in Half Moon-street, Piccadilly, the celebrated parrot of. Colonel O'Kelly. 'This singular * Gesner, Ornithologia. 
bird sang a number of songs in perfect time and tune; she could express her wants articulately, and give her orders in a manner approaching nearly to rationality. Her agge was not known; it was, however, more than thirty years, for previously to that period Mr. O'Kelly bought her at Bristol for a hundred guineas. 'The Colonel was repeatedly offered five hundred guineas a year for the bird, by persons who wished to make a public exhibition of her; but this, out of tenderness to the favourite, he constantly refused. The bird was dissected by Dr. Kennedy and Mr. Brookes; and the muscles of the larynx, which regulate the voice, were found, from the effect of practice, to be uncommonly strong *."

There are many persons now alive who have witnessed these scarcely credible performances. Amongst these the Hon. and Rev. W. H. Herbert says, "that wonderful bird, Colonel O'Kelly's parrot, which I had the satisfaction of seeing and hearing, (about the year 1799, if I recollect rightly,) beat the time always with his foot, turning round upon the perch while singing, and marking the time as it turned. This extraordinary creature sang perfectly about fifty different tunes of every kind, "God save the King,' solemn psalms, and humorous or low ballads, of which it articulated every word as distinctly as a man could do, without even making a mistake. If a bystander sang any part of the song, it would pause and take up the song where the person had left off without repeating what he had said. When moulting and unwilling to sing, it would answer all solicitations by turning its back and repeatedly saying, 'Poll's sick.' I am persuaded that its instructor had taught it to beat time $\uparrow^{\prime \prime}$

M. Montbeillard says he saw a parrot of the grey sort which grew old with its master and shared with

* Anim. Biog. ii. 227.

$\dagger$ Notes to White's Selborne, 8ro. edit. 1832. 
him the infirmities of age; and being accustomed to hear very frequently repeated the words "I am sick" (Je suis malade), when a person said to it, "How do you do, L'oll?" (Qu'as tu, Perroquet, qu'as tu), it replied, in a doleful tone, "I am sick," stretching itself the while over the fire, (Je suis malarde"). "The noble Philip Marmix, of St. Aldegond," says Clusius, "had a parrot whom I have often heard laugh like a man, when he was bidden to do so by the bystanders, in these words, 'Laugh, parrot, laugh (Riez, perroquet, rici). Yea, which was more wonderful, it would presently add, as if it had been endowed with reason, "What a great fool to make me laugh!' ( $O$ le grand sot, qui me fuict rive), which it was wont to repeat twice or thricet."

It would be easy to fill a volume with such anecdotes of parrots and other speaking birds, though many of them are evidently much over-coloured. We shall only add one more, on the respectable anthority of Mr. Syme, who tells us he "went, one morning, with a friend, to see a collection of birds belonging to a gentleman in Antigua-street, Edinburgh, and among these were some very fine starlings; one in particular, which cost five guineas. Breakfast was ready before we entered the room. When the bird was produced, it flew to its master's hand, and distinctly pronounced, 'Good morning, Sir,-breakfast-breakfast.' It afterwards hopped to the table, examined every cup, and, while thus employed, it occasionally repeated, "Brealifastbreakfast-bread and butter for Jack-tea, teabread for Jack-pretty Jack-pretty Jack.' One thing we observed was this, it often said the same word or sentence twice over, perhaps in imitation of the person by whom it had been taught

* Oiseaux, Art. Le Perroquet Cendré. p Atrebat. exotic. fol. Raphclengii, 1065. ${ }_{\downarrow}$ British Song Birds, p. 63 . 


\section{Chapter XVIII.}

LONGEVITY OF BIRDS.

It may be stated as a general principle that animals are long-lived, somewhat in proportion to their size; and that seems to have some comnexion with the rapidity of the circulation of the blood. In the larger animals, such as the elephant, the blood moves slowly; and in the smaller sorts, such as small birds or mice, the circulation is so rapid that the beats of the pulse can be counted with difficulty or not at all. We are not, however, disposed on this account to infer with the celebrated Boerhaave that the motion of the blood through the arteries and veins tends, by mechanical friction, to destroy the texture of the parts*. We are rather inclined to agree with Baron Haller in referring the apparent effect to the obstructions arising from the minuter vessels being obliterated $\dagger$.

Cullen, who partly adopts the opinion of Haller, proceeds upon the three principles that there is a different distribution of the blood in the different periods of life, that the vessels offer a greater resistance to the entrance and transmission of the fluids as age advances, and that the excitability gradually decreases. The quantity of the blood is most considerable in youth; and the arteries being then in a state of over-distension, while the system is at the same time more contractile and sensitive, the ten- 
dency is to increased action. The growth of the body depends on this. The functions being all in an active state, a large quantity of blood is formed, from which the inaterials are supplied that increase the body and make up for the daily waste going on. 'This addition of new matter and the force of the circulation distend the different parts and add to their bulk. The addition of new matter, after some time, and the degree to which the extension has been carried impede the further continuance of the process, and the power of the arteries becomes so balanced with reference to the condition of the system as to cause its present state to continue. 'The balance, however, is soon destroyed by the diminished action; and the veins being more easily distended than the arteries, and having experienced less alteration in their texture, while they also partake less of vital action, the blood is more disposed to accumulate in them*

This principle may be made still more plain by saying, that as age advances the fine hair-like bloodvessels, which branch off in every direction through the body, and more particularly through the skin and near the surface, become obstructed and imperforate, and consequently the skin and the other parts to which they run, not being supplied with their nourishment of fresh blood, shrink and wither; the internal parts becoming gradually more stiff and hard, and the skin first sallow and then dry and wrinkled. In such cases, when the smaller blood-vessels are obliterated, the larger ones swell with blood which cannot get vent, and this is the reason why we see old people's veins swell, as on the back part of the hands or feet.

Insects, though they have no circulating blood like the larger animals, furnish an analogical corro*Cullen's Physioiogy, p. 2 $₫ 9$. 
boration of the same views, for their parts soon becoming rigid and dry, old age comes rapidly upon them; few of them in their adult state living more than a few days or weeks, and some not many hours.

"Fishes," again, to use the words of Smellie, "whose bones are more cartilaginous than those of men and quadrupeds, are long of acquiring their utmost growth, and many of them live to great ages. Gesner gives an instance of a carp in Germany, which he knew to be one hundred years old. Buffon informs us that, in Count Maurepa's ponds he had seen carps of one hundred and fifty years of age, and that the fact was attested in the most satisfactory manner. He even mentions one which he supposed to be two hundred years old*. The element in which fishes live is more uniform, and less subject to accidental changes than the air of our atmosphere. Their bones, which are more of a cartilagrinous nature than those of land animals, admit of indefinite extension ; of course, their bodies, instead of suffering the rigidity of age at an early period, which is the natural cause of death, continue to grow much longer than those of most land animals t."

It is a very prevalent notion that in what is termed and supposed to be a state of nature, diseases (assumed to be wholly caused by artificial living) do not occur; and it is accordingly maintained that wild animals, from living in this state of nature, are exempted from disease t. $^{+}$But in opposition to this doctrine many strong facts might be adduced. We lately caught a mouse, which was in the last stage of malignant erysipelas, which carried it off in a few

* De Piscibus, p. 312. † Phil. of Nat. Hist. ii. 418, 8ro edit.

+ See Abernethy, Physiol. Lectures, and Rush's Medical Observations. 
hours*; and the common shrew (Sorex araneus, Fleming is often observed to be subject to great mortality in the autumnt, numbers of the dead bodies being found strewed in paths, by gateways, and in garden walks. Mr. Knapp is inclined to suppose these to have been destroyed by cats and other prowling animals, who do not eat them $\ddagger$; but we much doubt whether we can in this way account for the numbers frequently seen. At all events, we cannot so explain the following facts stated by $\mathrm{Mr}$. Marshall : at Ceylon, " in 1806, 1807, 1815, 1816, a murrain of a very malignant kind prevailed among. black cattle; at the same time a dreadfully fatal disease prevailed among the wild elephants, hogs, deer, and elks. In some places of the Batticuloë district, where wild hogs abound, the bodies of several hundreds of these animals were found collected within a very limited space $\S . "$ Dutertre mentions a similar mortality among pelicans, particularly the young birds, in September, 1656 , and says that " all the coasts of St. A lousia, of St. Vincent, of Becouya, and of all the Grenadines, were strewed with the dead carcases \|."

It is, indeed, as well remarked by Mr. Knapp, " difficult, from many circumstances, to form an accurate statement of the natural duration of animal life, the wild creatures being in great measure removed from observation, and those in a condition of domestication being seldom permitted to live as long as their hodily strength would allow. It was formerly supposed that the length of animal life was in proportion to its duration in utcro, or the space it remained in the parent, from conception to birth,

$$
\begin{gathered}
\text { * J. R. Fleming, Brit. Anim. p. } 8 . \\
+ \text { Journal of a Naturalist, p. } 148 . \\
\text { \$ Marshall, Diseases of Ceylon, p. } 16 . \\
\text { II Histoire Générale des Antilles, ii.271 }
\end{gathered}
$$


and the length of time it required to obtain maturity. This notion might have some support in reason and fact, occasionally, but in many cases was incorrect, and, in regard to birds, had no foundation. Herbivorous animals probably live longer than carnivorous ones, vegetable food heing most easily obtainable in all seasons, in a regular and requisite supply; whereas animals that subsist on flesh, or by the capture of prey, are necessitated at one period to pine without food, and at another gorged with superfluity: and when the bodily powers of rapacious creatures become impaired, existence is difficult to support, and gradually ceases; but with herbivorous animals in the same condition, supply is not equally precarious, or wholly denied. Yet it is probable that few animals, in a perfectly wild state, live to a natural extinction of life. In a state of domestication, the small number of carnivorous creatures about us are sheltered and fed with care, seldom are in want of proper foorl, and at times are permitted to await a gradual decay, continuing as long as nature permits, and by such attentions many have attained to a great age; but this is rather an artificial than a natural existence. Our herbivorous animals, being kept mostly for profit, are seldom allowed to remain beyond approaching age, and when its advances trench upon our emoluments by diminishing the supply of utility, we remove them. The uses of the horse, though time may reduce them, are often protracted; and our gratitude for past services-or interest in what remains, prompts us to support his life by prepared food, for easy digestion, or requiring little mastication, and he certainly by such means attains to a longevity probably beyond the contingencies of nature. I have still a favourite ponyfor she has been a faithful and able performer of all the duties required of her in my service for upwards 
of two and twenty years-and, though now above five and twenty years of age, retains all her powers perfectly, without any diminution, or symptom of decrepitude; the fineness of limb, brilliancy of eye, and ardour of spirit, are those of the colt, and though treated with no remarkable care, she has never been disabled by the illness of a day, or sickened by the drench of the farrier. With birds it is probably the same as with other creatures, and the eagle, raven, parrot, \&c., in a domestic state attain great longevity; and though we suppose them naturally tenacious of life, yet, in a really wild state, they would expire before the period which they attain when under our attention and care. And this is much the case with man, who probably outlives most other creatures; for though excess may often shorten, and disease or misfortune terminate his days, yet naturally he is a long-lived animal. His 'tirce score years and ten' are often prolonged by constitutional strength, and by the cares, the loves, the charities of human nature. As the decay of his powers awakens solicitude, duty and affection increase their attentions, and the spark of life only expires when the material is exhausted*."

The birds most celebrated for longevity are the raven, the pelican, and the eagle, though the evidence which we have met with, in proof of the common opinion respecting the long life of these birds, is not always so satisfactory as we could wish. 'To these may be added the sky-lark, which has been known to live in a cage, as Olinat says, ten years; while Raczynski mentions an instance in which one lived twenty-four years t."

* Journ. of a Nat. p. 181, Ist edit. + Ucceiliera, fol. Roma, 1684.

+ Hist. Nat. Pulonia, 4to. Gaed. 1745. 
In his chapter on "the Longest Lives," Pliny says, "Hesiod (the first writer, as I take it, who hath treated of this argument, and yet like a poet), in his fabulous discourse touching the age of man, said, forsooth, that a crow lives uine times as long as we; and harts or stags four times as long as he, but ravens thrice as long as they*." If we estimate accordingly a generation at thirty years, the age of the crow would be 270 years, that of the stag 1080 years, and that of the raven 3240 years; but if we interpret the terms used by both Hesiod and Pliny to signify a year, we should then have the life of the crow nine years, and of the raven 108, which is probably nearer the truth.

"No person, as far as I know," says Montbeillard, "has determined the age at which the young. ravens have acquired their full growth, and are capable of propagating. If in birds, as in quadrupeds, each period of life was proportional to the total space of existence, we might suppose that the crows required many years to reach their adult state, though it seems well ascertained that this bird sometimes lives a century or more. In many cities of France they have been known to attain to that distant period; and in all countries, and all ages, they have been reckoned as birds extremely long-lived. But the progress to maturity must be slow in this species, compared to the duration of their life; for towards the end of the first summer, when all the family consort together, it is difficult to distinguish the old from the young, and, very probably, they are capable of breeding the second year.$+ "$

Pigeons are reported to have lived from twenty to twenty-two years $\ddagger$; and even limnets, goldfinches,

* Holland's Plinie, vii. 48.

r Oiseaux, Art. Le Corbeau.

+ Smellie, Philos. of Nat. Hist. ii. 416, Sro. ed. 
and other small birds, have been known to live from fifteen to twenty-three years*

Willughby says, "We have been assured by a friend of ours, a person of very good credit, that his father kept a goose, known to be fourscore years of age, and as yet sound and lusty, and like enough to have lived many years longer, had he not been forced to kill her for mischievousness, worrying and destroying the young geese and goslins t." In another part of his valuable work, this writer tells us, "that he has been assured by credible persons, that a goose will live a hundred years and more f."

It has been supposed that the pelican derives its great longevity from the peculiar texture of its bones, which are thin, almost transparent, and exceedingly light. Even in captivity it has been observed to be more tenacious of life than most other birds. "Of a great number of pelicans kept in the menagerie at Versailles, none died in the space of twelve years; yet during that time some of almost every other species of animals died §."

It was reported, as Aldrovand has stated, by persons worthy of credit, that a pelican, eighty years of age (octogenariam), was kept by the Emperor Maximilian, and was held as a sort of auspicator in his camp. It was supposed to have been hatched in the time of Philip, the emperor's father. It was afterwards kept for a long time at the court of the empress, after it was no longer able, through old age, to use its wings, the expense of keeping it being four crowns a dayll. Turner mentions one which

*Willughby, Ornith.

$\uparrow$ Ornitholog. p. 14. Ibid. p. 256.

§ Mém. de l'Acad. des Sciences, p. 191.

|| Ornithologia, xix. 22. 
lived fifty years*; and Raczynski another, kept at the court of Bavaria for forty yearst.

"Eagles," says Pennant, " are remarkable for their longevity, and for their power of sustaining a long abstinence from food. A golden eagle, which has now been nine years in the possession of Owen Holland, esq. of Conway, lived thirty-two years with the gentleman who made him a present of it; but what its age was, when the latter received it from Ireland, is unknown. The same bird also furnishes a proof of the truth of the other remark, having once, through the neglect of servants, endured hunger for twenty-one days, without any sustenance whatsoever t."

The great age of the eagle is beautifully alluded to in the Psalms, where it is said of the righteous man, that his "youth is renewed like the eagle's §," a passage which greatly exercised the ingenuity of the ancient fathers and other commentators in fancying the manner in which the eagle did renew its youth. 'The greater number of them, and among these, St. Jerome, St. Ambrose, St. Gregory, Nicephorus, and Rabbi David, say that when the bird begins to feel advancing age from the weight of its feathers and the dimness of its eyes, it betakes itself to a fountain of water, and plunging therein, has its whole frame renovated. St. Damian adds, that before immersion, it so places itself in the focus of the sun's rays (ad circulum solis) as to set its wings on fire, and in this way to consume the old feathers $\|$; proving pretty plainly that St. Damian was not aware of the natural mode of birds renewing

* Hist. Avium. + Hist. Nat. Poloniæ.

\$ Brit. Zool. i. 123, 8vo. edit.

$\$$ Psal. ciii. 5, almost uniformly misquoted cii. in books. II Epist. ii. 18, 19, apud Physicæ Curiosæ, p. 1118. 
their feathers by moulting. Rabbi David adds, that when it clelays the operation too long it has not strength to rise from the water, and is frequently drowned *

St. Angustine says, that when the eagle becomes very old, the upper mandible of the beak grows so long that the bird can no longer feed, in which case it betakes itself to a rock or rough stone, and rubs its beak till the overgrown part is ground down into proper proportion $\dagger$.

Albertus Magnus gives a still more ingenious process of renewal, not however of his own invention, but quoted from Jorachus and Andetinus, whose works we presume are now lost. "They say," reports Albertus, "that an old eagke at the period the young ones are fledged, as soon as she has discovered a clear and copious spring, flies directly upwards even to the third region of the air, which we term the region of meteors, and when she feels warm, so as to be almost burning, suddenly dashing down and keeping her wings drawn back, she plunges into the cold water, which by the astringing of the externat cold increases the internal heat. She then rises from the water, flies to her nest, and nestling under the wings of her warm young ones, melts into perspiration, and thence with her old feathers she puts off her old age, and is clothed afresh; but while she undergoes this renovation, she makes prey of her young for food. But I can only," lie adds, "consider this as a miraculous occurrence, since in two eagles which I kept I observed no changes of this sort; for they were tame and docile, and moulted in the same manner as other birds of prey t."

* Comment. Esaix, cap. xiv. † In Psalm. ciii. 5.

† De Animal, xxiii. cap. de Aquila. 
It is very obvious that all these are mere fancies, and further, that there are few or no data by which to determine the age of wild birds. We have indeed observed among house-sparrows, individual cockbirds, in which the black markings were intermixed with white feathers; but whether this was the hoariness of age, or merely an accidental variety of colour, we had no means of ascertaining*. It has been long decided that the grey-headed crow is not an old carrion crow grown hoary with age as is popularly believed; but a different species (Corvus cornix).

$$
\text { * J. R. }
$$




\section{Chapter Xix.}

THE PHCENIX. - THE BL̈RNACLE GOOSE.

THE popular love of the marvellous has propagated stories respeeting the existence of birds, whose longevity far exeeeds all that has ever been related of the crow or the eagle. Of these, the most remarkable is the Phonix, of whieh therefore, as a specimen of fabulous ornithology, we will take the present opportunity of giving some aceount. 'The subject ought to prove not a little interesting, at least to the numerous individnals who trade, under the name of this bird, in insurance offices, iron eompanies, engine factories, stage-coaehes, steam-packets, race-horses, coffee-houses, and innumerable other heterogeneous things, whieh are imagined, we suppose, to derive a mysterious influenee from the name of Phonix. It may be well to begin with the first aeeount which has been transmitted to us of this bird-that of Herodotus, the father of history.

"'There is," says he, "a sacred bird, the name of which is the phœnix: I have not myself seen it, exeepting in a pieture, for it seldom visits even the Egyptians themselves, only every five hundred years, aecording to the statement of the people of Heliopolis; and they say that it never comes exeept when its sire dies. If it is like its pieture, it is of the following size and shape: its plumage is partly gold-eoloured, partly crimson; and it is completely similar to the eagle in outline and in bulk. They relate that this bird acts in the following manner, but I cannot give credit to their assertions: that depart- 
ing out of Arabia, it bring's its parent to the temple of the sun, having previously enveloped him with myrrh, and buries him in the temple of the sun: that it conveys him in the following manner; in the first place it shapes an egg of myrrh of such a volume as it is able to carry, and then tries whether it call carry it; after it has completed the trial, it hollows out the egg, and places its parent on the inside of it, and then closes with other myrrh that part of the eg. by which it introduced the body of its parent. Whe body lying in the inside, the weight is the same. Having thus enveloped him, it carries him into Eoypt to the temple of the sun. Such are the actions which they represent this bird as performin $\mathrm{g}^{*} . "$

The following description by Pliny is chiefly, if not wholly, derived from Herodotus. "The birds," he says, "of Ethiopia and India are for the most part of diverse colours, and such as a man is hardly able to decipher and describe; but the phonix of Arabia passes all others. Howbeit I cannot tell what to make of him : and first of all whether it be a tale or no that there is never but one of them in all the world, and the same not commonly seen. By report he is as big as an eagle; for colour, as yellow and bright as gold, (namely, all about the neck;) the rest of the body a deep red purple: the tail azure blue, intermingled with feathers among of rose carnation colour; and the head bravely adorned with a crest and penache finely wrought, having a tuft and plume thereupon right goodly to be seen. Manilius, the noble Roman senator, right excellently seen in the best kind of learning and literature, and yet never taught by any, was the first man of the Jong robe who wrote of this bird at large, and most exquisitely he reporteth, that never man was known to see

* Herodotus, Euterpe, 73. Laurent's Trans. 
him feeding; that in Arabia he is held a sacred bird, dedicated unto the sun; that he liveth 660 years, and when he groweth old and begins to decay, he builds himself a nest with the tivigs and branches of the canel or cinamon, and frankincense trees; and when he hath filled it with all sort of sweet aromatical spices, yieldeth up his life thereupon. He saith moreover that of his bones and marrow there breeds at first as it were a little worm, which afterwards proveth to be a pretty bird. And the first thing that this young new phœnix doth is to perform the obsequies of the former phœuix late deceased; to translate and carry away his whole nest into the city of the sun near Panchea, and to bestow it full devoutly there upon the altar. The same Manilius affirmeth that the revolution of the great year so much spoken of, agreeth just with the life of this bird, in which year the stars return again to their first points, and give significations of times and seasons as at the beginning; and withall that this yeare should begin at high noon that very day when the sun entereth the sign Aries: and by his saying, the year of that revolution was by him shewed when P. Licinius and M. Cormelius were consuls. Cornelius Valerianus writeth that whiles Q. Plautius and Sex. Papinius were consuls, the phœnix flew into AEgypt. Brought he was hither also to Rome in the time that Claudius Cresar was censor, to wit in the eight hundredth year from the foundation of Rome; and shewed openly to be seen in a full hall and generall assembly of the people, as appeareth upon the public records: howbeit, no man ever made any doubt but he was a counterfeit phonix, and no better *."

We shall not go into the particulars of what is said respecting the phouix by other ancient authors of inferior name, such as Solinus $t$, who uses nearly the * Holland's Plinie, i. 271. + Polyhist., cap. 46. 
same words with Pliny; Elian*, who marvels how it can calculate the exact number of years at the termination of which it is necessary to build its funeral nest, and how it can fly unerringly to Heliopolis; and Philostratust, who says the Egyptians sing elegiac hymns at its decease. We shall content our'selves with the notice which has been taken of it by Tacitus :-

"Paulus Fabius and Lucius Vitellius succeeded to the consulship (A. U. C. 787, A. D. 34). In the course of the year, the miraculous bird known to the world by the name of the phœenix, after disappearing for a series of ages, revisited Egypt. A phenomenon so very extraordinary could not fail to produce abundance of various speculation. The learning of Egypt was displayed, and Greece exhausted her ingenuity. The facts about which there seems to be a concurrence of opinions, with other circumstances, in their nature doubtful, yet worthy of notice, will not be unwelcome to the reader.

"That the phœnix is sacred to the sun, and differs from the rest of the feathered species, in the form of its head and the tincture of its plumage, are points settled by the naturalists. Of its longevity the accounts are various. The common persuasion is that it lives five hundred years, though by some writers the date is extended to fourteen hundred and sixtyone. The several eras when the phœnix has been seen are fixed by tradition. 'The first, we are told, was in the reign of Sesostris; the second in that of Amasis ; and in the period when Ptolemy, the third of the Macedonian race, was seated on the throne of Egypt, another phœuix directed its flight towards Heliopolis, attended by a group of various birds, all attracted by the novelty, and gazing with wonder at so beautiful an appearance, For the truth of this

* De Animalibus, vi. 58. + De Vit. Apollon. iii. 
account we do not presume to answer. The facts lie too remote; and covered, as they are, with the mists of antiquity, all further argument is suspended.

"From the reign of Ptolemy to 'Tiberius, the intermediate space is not quite two hundred and fifty years. From that circumstance it has been inferred by many that the last phœnix was neither of the genuine kind, nor came from the woods of Arabia. The instinctive qualities of the species were not observed to direct its motions. It is the genius, we are told, of the true phœnix, when its course of years is finished, and the approach of death is felt, to build a nest in its native clime, and there deposit the principles of life, from which a new progeny arises. The first care of the young bird, as soon as fledged and able to trust to its wings, is to perform the obsequies of his father. But this duty is not undertaken rashly. He collects a quantity of myrrh, and to try his strength, makes frequent excursions with a load on his back. When he has made his experience through a long tract of air, and gains sufficient confidence in his own vigour, he takes up the body of his father, and flies with it to the altar of the sun, where he leaves it to be consumed in flames of fragrance. Such is the account of this extraordinary bird. It has, no doubt, a mixture of fable; but that the phonix from time to time appears in Egypt, seems to be a fact sufficiently ascertained $*$."

After this statement we deem it superfluous to quote writers of inferior note, such as Pomponius Mlela, who talks of its "being regenerated," and "carrying its own bones to Heliopolist;" or Horus Apollo, who says it "dashes itself" on the ground till it is wounded, and another phœuix is generated from the blood thus shed+." Nor shall we detail all the * Tacitus, Hist. by Murphy, vi. 28.

+ De Litu Orbis, iii. 9. \$ Hieroglyphicis, i. 33.', 
fanciful descriptions to be met with in the works of the ancient Fatliers, who, as Mariana, the Spanish historian, remarks, considered its alleged appearance, in the reign of 'Tiberius, as a prognostic of the Resurrection, because it revives out of its own ashes. 'The following will, we think, satisfy the curious in this respect :-

"St. Ambrose, in Exameron, saith, of the humour or ashes of phœnix ariseth a new bird and wexeth, and, in space of time, he is clothed with feathers and wings, and restored into the kind of a bird, and is the most fairest bird that is, most like to the peacock in feathers, and loveth wilderness, and gathereth his meat of clean grains and fruits. Alanus speaketh of this bird and saith, that when the highest bishop Onyas had builded a temple in the city of Heliopoly in Egypt to the likeness of the temple of Jerusalem, and the first day of Easter, when he had gathered much sweet-smelling wood, and set it on fire upon the altar, to offer sacrifice to all men's sight; such a bird came suddenly, and fell into the middle of the fire, and was brent anon to ashes in the fire of the sacrifice; and the ashes abode there, and was besely kept and saved by the commandment of the priest: and, within three days of these ashes, was bred a little worm, that took the shape of a bird at the last, and flew into the wilderness.".

This account of a worm being generated out of the ashes of a sacrifice and afterwards becoming a bird, is precisely similar to the directions given by Virgil and Columella for the generation of bees from dead carcases, which originated in an imperfect knowledge of the natural history of insects $t$; while

* Bartholomew Glantville, de Propriet. Rerum, translated by Trevisa, fol. clxx. Black letter, Wynkyn de Worde, London, 1498.

中 This may be seen explained at length in 'Insect Transformations', pp. 1-10. 
the appearance of a bird alighting on the altar must have obviously arisen from some eagle or vulture ponncing npon the carcase of the animal sacrificed, a circumstance, we should imagine, of occasional occurrence when altars were situated in the open air, and which, in Greece or Rome, instead of the bird being considered a phonix, would have been hailed as an avatar (if we may borrow the Brahminical term) of Jupiter himself. 'llat such were the circumstances which, in process of time, were worked up into the fabulous and fanciful stories of the phonix we have not a doubt; and it appears to us that this is the only plausible and rational explanation which can be given, though a vast deal of leaming and no little ingenuity has been expended in support of other views.

Deusing *, for example, as well as Kirchmayer $\dagger$ and Laurenberg ${ }_{+}^{+}$, concludes that the phœnix was nothing else than a hieroglyphic character, signifying. that the study and knowledge of the heavenly bodies originated in Phœnicia, the golden colour of the head denoting the stars, and the variegated body the earth, and so of the other parts. In the Introduction, again, to the Latin 'Translation of Pennant's Indian Zoology, by the late Dr. Rheinhold Forster, we are gravely told that the phœnix means the conversion of the great year; because Pliny says the conversion of the great year corresponds with the life of the phenix; and Horapollo says the Egyptian priests paint the phonix as an emblem of the great year. 'The author, therefore, concludes by saying, "Every common year is a year of God; and the great year the sun of time, which, in the Eqyptian limgnage, would be Dsphenoeisch, and, on account

* Dissertatio de Phoenice.

$\dagger$ Disputat. Zoologicæ $\ddagger$ Acerra, Philol. Cent. Secund, Hist, xvii. 
of the harshness of the first letter, the Greeks would

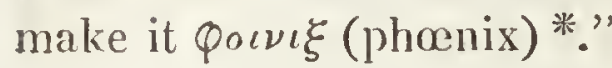

By the same mode of reasoning he might have made the phœnix to be like Hamlet's cloud, "almost in shape of a camel, backed like a weasel,-or very like a whale." Forster's explanation, indeed, reminds us much of certain other sage expounders of antiquity, such as the Abbé Bergier, who, rejecting Hardouin's opinion that Hercules was Moses $†$, undertakes to demonstrate that he was nothing more than a large causeway to prevent rivers from overflowing their banks, which rivers have been fabled to be serpents, boars, and lions, that he destroyed; while in the same spirit he imagines Jupiter to be rain, which impregnated Semele, a fountain, which brought forth Bacchus a marsh; and Prometheus he fancies to have been a quantity of mortar, or a batch of potter's clay; the eagle that preyed on his liver, the fire of a pottery liln; and Mount Caucasus, the hearth or rather the kilı itself $\ddagger$. The late Mr. Bryant, in a similar way endeavoured to prove all our early histories to be symbolical fables of Noah's Ark, and the Deluge §. And a more recent author, Mr. Faber, a disciple of Bryant's, seems strongly inclined to consider not only our celebrated outlaw (Robin Hood), but, more wonderful still, the present Isle of Bute, to be identical with the northern imaginary god, Woden or Odin\|.

When we see fancies so extravagant as these set forth by learned and grave authors, we need not wonder that the fable of the phœnix has received a

* Indian Zool. 4 to. ed. p. 16.

+ 'Hercules non alius quam Moses est.' Note on Cicero, De Nat. Deor. iii.

\$ L'Origine des Deux, Paris, 1774.

$\S$ Analysis of Ancient Mythology, passim.

\| Pagan Idolatry, ii.393-7. 
multitude of forms. 'The word phœnix, for instance, from signifying a palm-tree, as well as the fabulous bird, has given rise to some strange mistakes. 'Thus Tertullian translates, "The righteous shall flourish like the palm-tree*," by "The just shall flourish like the ploœnix ;" and Dr. Poole, following Amyot in translating Plutarch, uses these words: "Though the brain of the phœnixt be very sweet, it will cause the headache $+; "$ " as if the brains of the phonix were a no less common dish than the pith of the buds of the palm-tree, called the brain (cerebrum) by Pliny, are in the south of Europe, where they are served up with pepper and salt as a dessert §. It was a more plausible notion of Belon, (who went to the East, partly on purpose to ascertain the matter,) that the phonix was one of the birds of paradise (Paradisea), the Rhyntaces of Aristotle, who describes it in the old erroneous way as wanting legs, and using the long feathers of its tail to suspend itself from trees. The first Portuguese navigators also called the bird of paradise the bird of the sun (Passaros da sol).

The only plausible and rational view, as it appears to us, of the history of the phœnix, is well illustrated by what has been recorded of the birds of prey in the country where this fabulous bird is said to have exclusively appeared. Bruce, for example, gives the following account of the bird which he met with near Gondar, and which the Abyssinians call Abou Duch'n, or father long-beard (Gypaëtos barbatus? STorn). " 'This noble bird," says he, "was not the object of any chase or pursuit, nor stood in need of any stratagem to bring him within our reach. Upon the

* Psalm xcii. 12.

+ The original is rov ' $\gamma x \xi \varphi \alpha \lambda$ ay rou pouvixos.

$\ddagger$ Rules for the Preservation of Health, edit. 1684,

$\$$ Matheolius' Comment, on Dioscorides. 
highest top of the mountain Lamalmon, while my servants were refreshing themselves from that toilsome ringged ascent, and enjoying the pleasure of a most delightful climate, eating their dimner in the outer air, with several large dishes of boiled goats' flesh before them, this enemy, as he turned out to be to them, suddenly appeared: he did not stoop rapidly from a height, but came flying slowly along the ground, and sat down close to the meat within the ring the men lad made round it. A great shout or rather cry of distress called me to the place. I saw the eagle stand for a minute, as if to recollect himself; while the servants ran for their lances and shields. I walked up as nearly to him as I had time to do. His attention was fixed upon the flesh. I saw him put his foot into the pan, where there was a large piece, in water, prepared for boiling; but feeling the smart, which he had not expected, he withdrew it, and forsook the piece which he held. There were two large pieces, a leg and a shoulder, lying upon a wooden platter: into these he thrust both his claws and carried them off; but I thought he still looked wistfully at the large piece, which remained in the warm water. Away he went slowly along the ground as he had come. The face of the cliff over which criminals are thrown took him from our sight. 'The Mahometans that drove the asses were much alarmed, and assured me of his return. My servants, on the other hand, very unwillingly expected him, and thought he had already taken more than his share. As I had myself a desire of more intimate acquaintance with this bird, I loaded a rifle gun with ball, and sat down close to the platter by the meat. It was not many minutes before he came, and a prodigious shout was raised by my attendants, 'He is coming! he is coming!' enough to have dismayed a less courageous animal. Whether he was not quite 
so hungry as at his first visit, or suspected something from my appearance, I know not; but he made a short turn, and sat down about ten yards from me, the pan of meat being between me and him. As the field was clear before me, and I did not know but his next move might bring him opposite to some of my people, so that he might actually get the rest of the meat and make off, I shot him with the ball through the middle of his body, about two inches below the wing, so that he lay down upon the grass without a single flutter." It is worthy of remark that Bruce adds, "the feathers of the belly and breast were of a gold colour ", which might almost

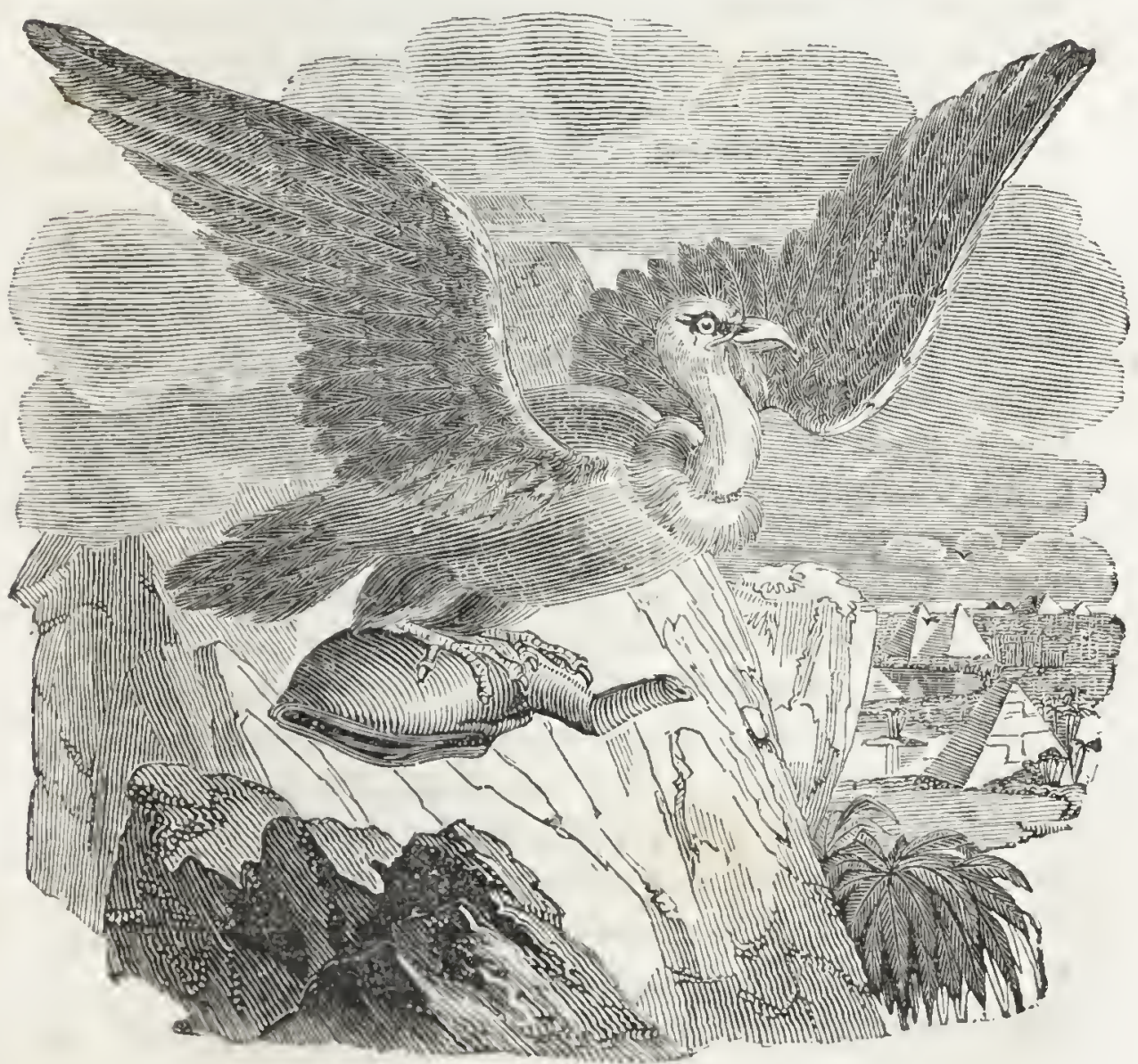

Lammer Geyer, Bearded Eagle, or Vulture, (Gypaëtos barbatus). * Travels to the Sources of the Nile, App. p. 155. 
pass for a translation from Pliny's description of the phœenix.

Pliny records a story of an eagle somewhat like that of Bruce, but approaching still more closely to the fable of the phornix. "There happened," he says, " a marvellous example about the city Sestos, of an eagle; for which in those parts there goes a great name of an eagle, and highly is she honoured there. A young maid had brought up a young eagle by hand; the eagle again, to requite her kindness, would first, when she was but little, fly abroad a birding, and ever bring part of that she had gotten unto her said nurse. In process of time, being grown bigger and stronger, would set upon wild beasts also in the forest, and furnish her young mistress continually with store of venison. At length, it fortuned that the damsel died; and when her funeral fire was set a burning, the eagle flew into the midst of it, and there was consumed into ashes with the corpse of the said virgin. For which cause, and in memorial thereof, the inhabitants of Sestos, and the parts there adjoining, erected in that very place a stately monument, such as they call Heroum, dedicated in the name of Jupiter and the Virgin, for that the eagle is a bird consecrated unto that god *."

'To these notices of the phœnix we may append, by way of further sample of fabulous ornithology, some of the strange relations that have been delivered by various writers touching another famous bird, the bernacle or claik (Anas bernicla, Willughby, $A$. leucopsis, Temminck), a species of goose, which is not uncommon during the autumn and winter in Britain and Holland, but retires farther north in the summer to breed. It measures two feet and a half in length, and is distinguished by its bill and feet, as 
well as the hind-head, neck, breast, wings, and tail being b'ack*, while the fore-head, throat, and all the under parts are pure white. It has sometimes been confounded with the brand or brent goose (Anas brenta, WILLUHBY); but the latter is much smaller, measming only twenty-two or twenty-three inches, and is difierently coloured.

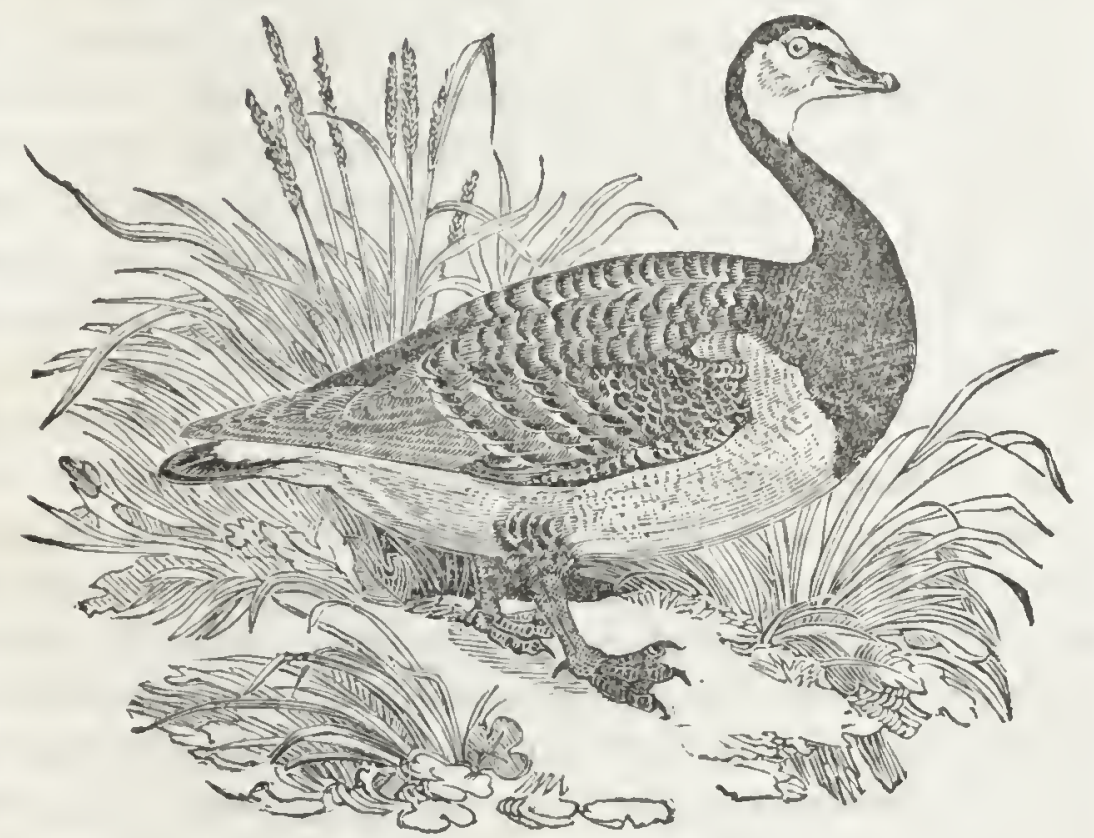

Bernacle, or Ciatk Goose.

This bird was not only fancied to originate from rotten timber as well as to grow on trees like some sorts of mushrooms (Agarici, Boleti, \&c.), but authors of no mean reputation both in Scotland and England assert that they have themselves actually witnessed this miraculous phenomenon; and from its having been first observed in this country, the continental naturalists were led to call the bernacle the Britısh bird by way of distinction. The Scottish historian, Boëce, being one of the oldest ocular witnesses

* Linnxus and Latham by mistake give it red feet, and call it Anas erythropus. 
whom we have met with, we shall give his own narrative as translated by Bellenden:-

" Rests now," says he, "to speak of the geese engendered of the sea named claiks. Some nen believes that thir (these) claiks grows on trees by the nebbis (bills). But their opinion is vain. And because the nature and procreation of thir (these) claiks is strange, we have made no little labour and diligence to search the truth and verity thereof, we have sailed through the seas where thir (these) claiks are bred, and finding by great experience that the nature of the seas is more relevant cause of their procreation than any other thing. And lowbeit thir (these) geese are bred many sundry ways, they are bred ay allanerly (only) by nature of the seas. For all trees that are cassin (cast) into the seas by process of time appears first worm-eaten, and in the small bores and holes thereof grows small worms. First they show their head and feet, and last of all they show their plumes and wings. Finally, when they are coming to the just measure and quantity of geese, they fly in the air, as other fowls do, as was notably proven in the year of God one thousand iiii hundred lxxx, in sight of many people beside the castle of Pitslegro, one great tree was brought by alluvion and flux of the sea to land. This wonderful tree was brought to the laird of the ground, quhilk (who) soon after gart (caused) divide it by one saw. Appeared then one mulitude of worms throwing themself out of sundry holes and bores of this tree. Some of them were rude as they were but new shapen. Some had both head, feet, and wings, but they had no feathers. Some of them were perfect shapen fowls. At last the people having ylk (each) day this tree in more admiration, brought it to the kirk of Saint Andrews beside the town of Tyre, where it remains yet to our days. And within 
two years after happened such one like tree to come into the firth of Tay beside Dundee, worm-eaten and holed, full of young geese in the same mamner. Suchlike into the port of Leith beside Edinburgh within few years after happened such one like case. One ship named the Christopher (after that she had lain iii years at one anchor in one of thir (these) isles) was brought to Leith. And becanse her timber (as appeared) failed, she was broken down. Incontinent (immediately) appeared (as afore) all the inward parts of her worm-eatin and all the holes thereof full of greese, on the same mamner as we have shown. Attoure (moreover) if any man would allege by vain argument, that this Christopher was made of such trees as grew allanerly (only) in the Isles, and that all the roots and trees that grows in the said Isles, are of that nature to be finaly by nature of seas resolved into geese; we prove the contrary thereof by one notable example, showen afore our ene (eyes). Master Alexander Galloway, parson of Kinkell, was with us in thir (these) Isles, griving his mind witl most earnest business to search the verity of thir (these) obscure and misty doubts. And by adventure lifted up one sea tangle (Laminaria saccharina? LAMOURoux), hanging full of mussel shells from the root to the branches. Soon after he opened one of thir (these) mussel shells, but then he was more astonished than afore. For he saw 110 fisl in it but one perfect shapen fowl small and great ay efferyng (proportional) to the quantity of the shell. This elerk knowing us right desirous of such vncouth (uncommon) things, came hastily with the said tangle, and opened it to us with all circumstance afore rehearsed. By thir (these) and many other reasons and examples we can not believe, that thir (these) claiks are produced by any nature of trees or roots thereof, but allanerly (only) 
by the nature of the ocean sea, quhilk (which) is the cause and production of many wonderful things. And because the rude and ignorant people saw oftimes the fruits that fell off the trees (quhilkis (which) stood near the sea) converted within short time into geese, they believed that yir (these) geese grew upon the trees hanging by their nebbis (bills), suchlike as apples and other fruits hangs by their stalks, but their opinion is nought to be sustained. For as soon as thir (these) apples or fruits falls off the tree into the sea flood, they grow first wormeatin. And by short process of time are altered into geese *."

Passing over for the present a number of foreign authorities, we shall take in preference that of Turner, the most distinguished English naturalist of his day, and who peculiarly devoted himself to the study of birds, upon which he has left us a little volume in Latin, collected from the ancients, with comments upon each species from what he himself had actually observed. Speaking of two species of geese mentioned by Aristotle, Turner says, "The first goose is now by us called brant or bernicle, and is less than the wild goose, the breast being of a black and the other parts of an ash colour. It flies in the manner of geese, is noisy, frequents marshes, and is destructive to growing corn. Its flesh is not very savoury, and is little esteemed by the wealthy. Nobody has ever seen the nest or egg of the bernicle; nor is this marvellous, inasmuch as it is without parents, and is spontaneously generated in the following manner. When at a certain time an old ship, a plank, or a pine-mast rots in the sea, something like fungus at first breaks out thereupon, which at length puts on the manifest form of birds. After-

* Hector Boëce, Cosmographie of Albioun, by Bellenden, black letter, Edinburgh, (supposed) 1541, cap. xiiii. 
wards these are clothed with feathers, and at last become living and flying fowl. Should this appear to any one to be fabulous, we might adduce the testimony not only of the whole people who dwell on the coasts of England, Ireland, and Scotland, but also that of the illustrious historiographer Gyraldus, who has written so eloquently the history of Ireland, that the bernicles are produced in no other way. But since it is not very safe to trust to popular reports, and as I was, considering the singularity of the thing, rather sceptical even with respect to the tesmony of Gyraldus, - while I was thinking over the subject,-I consulted Octavian, an Irish clergyman, whose strict integrity gave me the utmost confidence in him, as to whether he considered Gyraldus worthy to be trusted in what he had written. 'This clergyman then professed himself ready to take his oath upon the Gospels, that what Gyraldus had recorded of the generation of this bird was most true; for he himself had seen with his eyes, and also handled those lialf-formed birds; and he said fartler, that if I remained a comple of months longer in London, he would have some of them sent to me $\mathrm{w}^{*}$."

After the publication of his own work on birds, the same 'Turner wrote to the celebrated Gesner, affirming that "the bernicle or brant is produced in the manner of mushrooms, from rotten ships," and that "these are everywhere to be found along the coasts of Wales, Ireland, and Scotland, still imperfect and without feathers, but with the distinct form of birds." Turner further informs Gesner, that "besides the brant or bernicle, there is another bird," we suppose he means the solan goose or gannet (Pelecamus bassanus), "which takes its origin from a tree. These trees grow upon the sea-coast of Scotland, upon which small bodies like mushrooms * Avium Præcip. Hist. Art. Anser. 
are produced, at first unformed, but gradually acquiring the shape of birds, and when they al'e of some bigness they hang a short time by the beak and then fall into the water, where they become living birds. All which, being affirmed by men of credit, I not only dare believe myself, but also persuade others to believe ${ }^{*}$."

A more recent English authority is that of Gerard, the botanist, who has an express article in his celebrated Herbal " upon the goose-tree," with which our readers, we think, may be both amused and surprised. "What our eyes have seen," says Gerard, "and hands have touched, we shall declare. There is a small island in Lancashire, called the Pile of Foulders, wherein are found broken pieces of old and bruised ships, some whereof have been cast thither by shipwreck, and also the trunks and bodies with the branches of old and rotten trees, cast up there likewise; whereon is found a certain spume or froth, that in time breedeth unto certain shells, in shape, like those of the mussel, but sharper pointed, and of a whitish colour, wherein is contained a thing in form like a lace of silk finely woven as it were together, of a whitish colour; one end wereof is fastened unto the inside of the shell, even as the fish of oysters and mussel are; the other end is made fast unto the belly of a rude mass or lump, which, in time, cometh to the shape and form of a bird: when it is perfectly formed, the shell gapeth open, and the first thing that appeareth is the foresaid lace or string; next come the legs of the bird hanging out, and as it groweth greater it openeth the shell by degrees till at length it has all come forth, and hangeth only by the bill; in short space after it cometh to full maturity, and falleth into the sea, where it gathereth feathers, and groweth * Gesner, De Avibus, iii. 107, \&c. 
to a fowl bigger than a mallard and lesser than a goose, having black legs, and bill or beak, and feathers black and white, spotted in such manner as our magpie, called in some places pie-annet, which the people of Lancashire call by no other name than tree-goose; which place aforesaid, and of all those places adjoyning, do so much abound therewith, that one of the best is bought for three-pence. For the truth hereof, if any doubt, may it please them to repaire to me, and $I$ shall satisfy them by the testimony of good witnesses *."

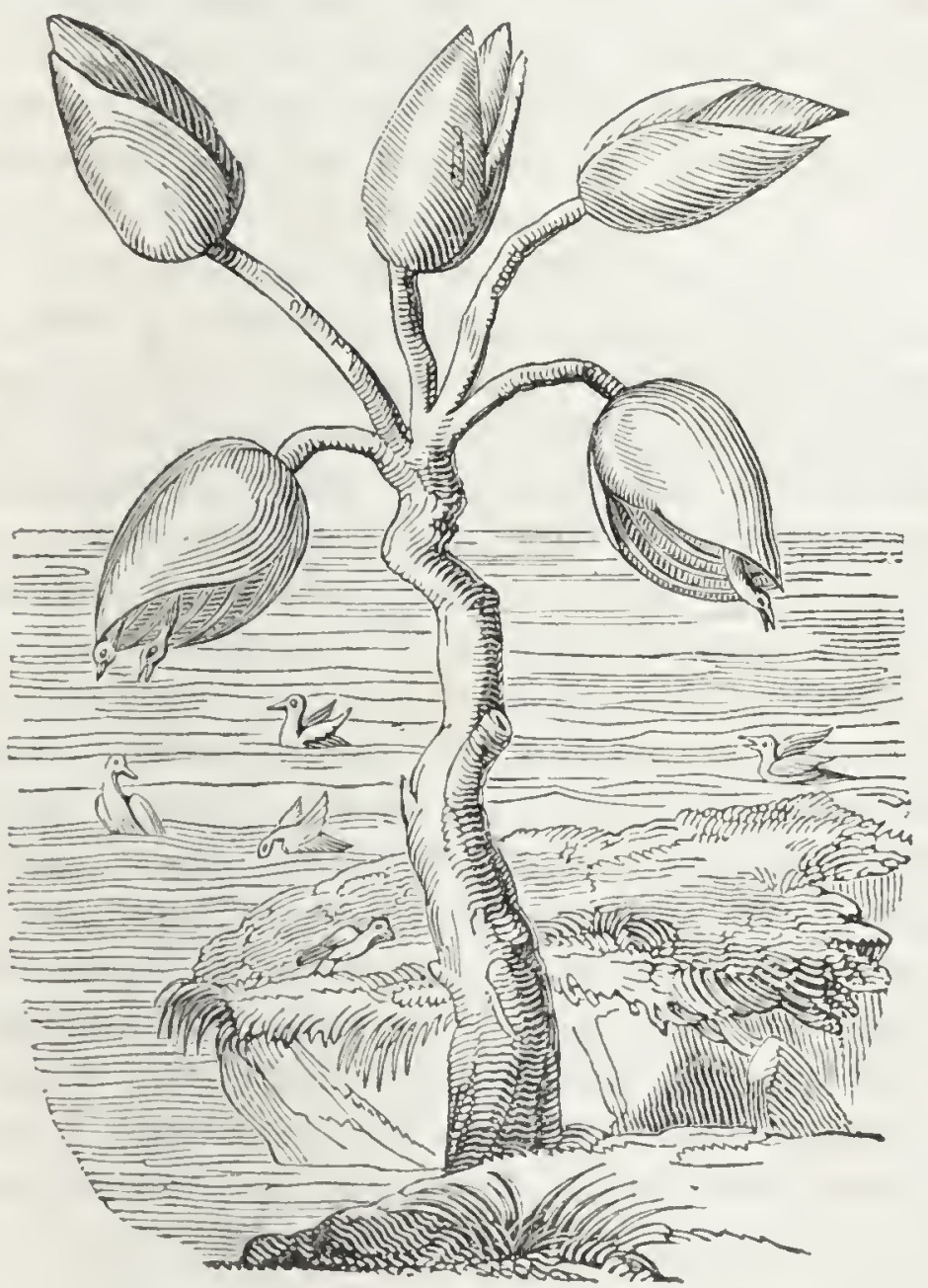

Bernacle Goose-'l'ree, frum Gerard's Herbal. * Gerard's Herbal, p. 1587. 
Bauhin adds to this marvellous story, that if the leaves of this tree fall upon land they become birds, and if into the water they are transmuted into fishes*. 'The celebrated Cardan is another of those who affirm that he himself, when he was at Edinburgl, saw the phenomenon of which he had heard from the narrative we have already given from Boëthius, and went twice to the port of Leith to investigate the matter. He remarks with great simplicity that the circumstance that the Hebridean sea should engender geese is "not a whit more marvellous than that mice, on the authority of Aristotle, are generated from the ground, or that the soil of Egypt should grow hares and goats, inasmuch as nature always produces what is most suitable to a placet."

From these wonderful stories, our island acquired amongst the learned of other countries a high reputation for fertility. Munster, accordingly, has an express chapter "on the extraordinary fertility of England and Scotland," in which he tells us, that " in Scotland are found trees which produce fruit rolled up in the leaves, and this, in due time, falling in to the water it hangs over, is converted into a living bird, and hence the tree is called the goose-tree. 'The same tree grows also in the island Pomona, situated not far from Scotland, towards the north. Lest you should imagine," he adds, "that this is a fiction devised by modern writers, I may mention that all the old cosmographers, particularly Saxo Grammaticus, take notice of this tree +." Montbeillard is hence inclined to think that Pomona, the largest of the Orkney islands, derived its name from being the supposed orchard of these goose-bearing trees $\xi$.

* Bauhin's Pinax, iii, 514.

$\uparrow$ Cardau, De Varietat. Rerum, vii. 36 .

$\ddagger$ Cosmographiæ, ii. $\quad \&$ Oiseaux, Art. La Bernache. 
The trees themselves Fulgrosus represents as similar to willows, as those who had seen them in Ireland and in the Orlineys informed him *.

The same circumstances are related and credited by Bishop Leslie in his Scottish Chronicles; by Bishop Majolus in his treatise on the Dog-days; by Odoric in lis acconnt of the 'I'artarian Lamb; by the celebrated Scaliger in his Exereitations; by Baptista P'orta, Kircher, Lobel. Isidore, Delrio, Torquemada, Bartholomew Glantville; and what is no less wonderful, by the distinguished naturalists Aldrovand, Gesner, and Johnston, while Count Mayer wrote an entire volume upon the subject, entitled a "Treatise of the Tree-Bird (without father or mother) of the Orkney Istes, similar to a Gooset.' In this sage production, the archiatral and imperial Count, as he styles himself, decides that the bernacle goose does not originate either from fruits or worms, but from shells, of which he opened a hundred, and found in all of them the embryos of the goose completely formed; "like chicks in the eggs of pullets, having" beaks, eyes, feet, wings, and even the down of commencing plumage, with all the other members of a young bird." He thence proceeds to discuss the sort of nourishment which these embryo geese require while remaining in the sea-shells, which increase gradually, he says, with the contained animal as do the shells of oysters, snails, and tortoises. He likewise discusses systematically, according to the Peripatetic philosophy, the several causes of the bernacle goose-efficient, material, formal, and final. For proof of the possibility of the thing, he gravely refers to the existence of hobgoblins, and he ascribes the production to the immediate influence of the stars; and even goes the irreverent length of considering 
the vegetable origin of these animals $*$ an emblem of the Saviour $\uparrow$.

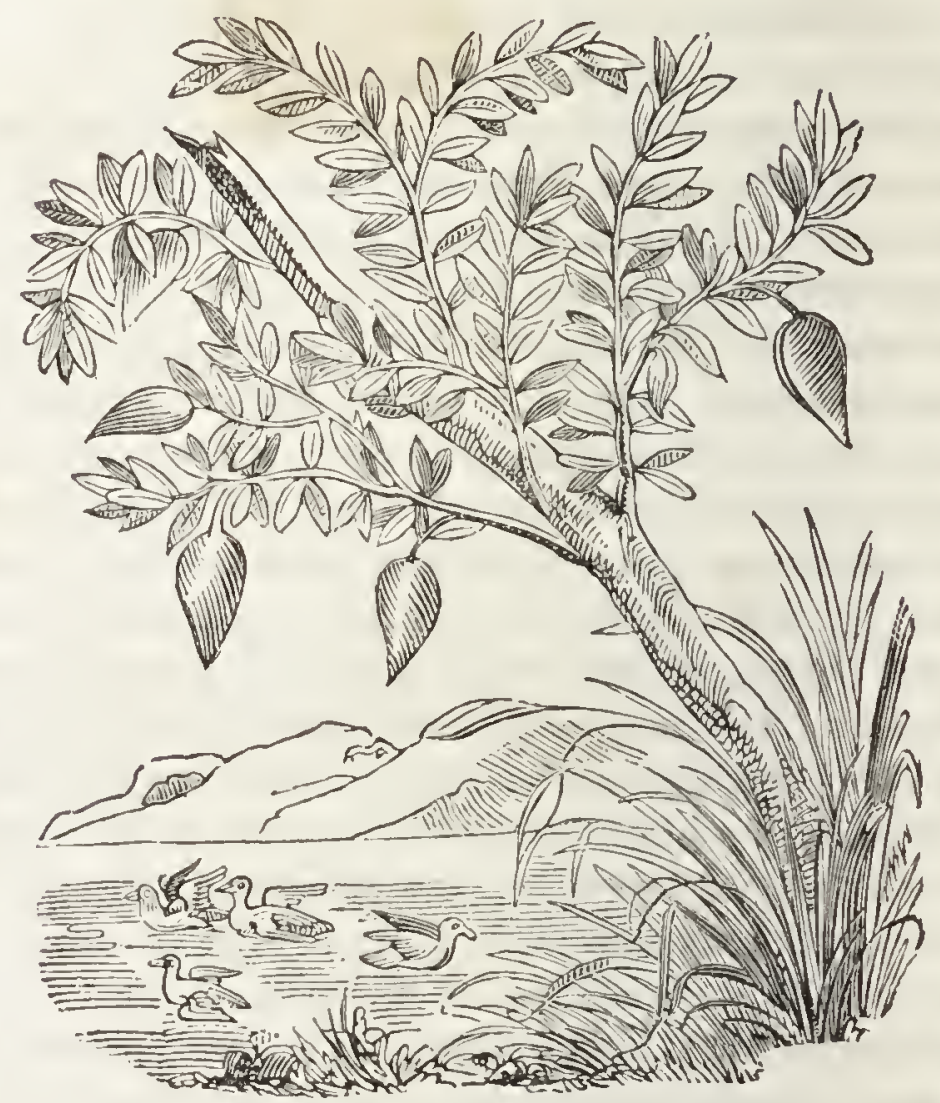

Bernacle Goose-Tree from Aldrovand.

Among'st our owu countrymen, in times approaching to our own, we find similar records of ocular testimony, from which it will suffice to quote the following by Sir Robert Moray, which was published as anthentic by the Royal Society. "In the western islands of Scotland," says Sir Robert, "the west ocean throws upon their shores great quantities of very large weather-beaten timber; the most ordinary trees are fir and ash. Being in the island of Uist,

\section{* See Insect Transformations, pp. 129-32.}

+ The title of one of his chapters is "Quod finis proprius hujus volucris generationis sit, ut referat duplici sua natura, vegetabili ct animali, Christum Deum et hominem, qui quoque, sine patre et matre, ut illi, existit." 
I saw lying upon the shore, a cut of a large fir tree, of about two feet and a half in diameter, and nine or ten feet long, which lad lain so long out of the water, that it was very dry; and most of the shells that had formerly covered it were worn or rubbed off. Only on the parts that lay next the ground, there still hung multitudes of little shells, that were of the colour and consistence of mussel shells. 'This barnacle-shell is thin about the edges, and about half as thick as broad. Every one of the shells hath some cross-seams or sutures, which, as I remember, divide it into five parts. These parts are fastened one to another, with such a film as mussel-shells have. 'These shells are hung at the tree by a neck, longer than the shell, of a kind of filmy substance, round and hollow, and creased not unlike the windpipe of a chicken, spreading out broadest where it is fastened to the tree, from which it seems to draw and convey the matter which serves for the growth and vegetation of the shell, and little bird within it. In every shell that I opened I found a perfect sea-fowl : the little bill, like that of a goose, the eyes marked; the head, neck, breast, wings, tail, and feet formed; the feathers everywhere perfectly shaped, and blackish coloured; and the feet like those of other waterfowl, to my best remembrance *."

Long before the days, however, of these credulous authors whom we have quoted, the celebrated Albertus Magnus (who died at Cologne in 1280) expressly says that the stories about the tree-geese (Banmgäns) are "altogether absurd," and for the best possible reason, "as I myself," he adds, "and many of my friends along with me, have seen them pair, lay egrs, and nurse their young $t^{\prime}$ " He subjoins an excellent description of the bird, such as Limmæus

* Philosophical Trausactions.

+ Hist. Anim. xxiii. editio, Venetiis, 1495. 
himself could not have surpassed. Belon, the ornithologist, also saw these geese, which he calls nuns from their colour, lay their eggs and hatch their young, and laughs at the vulgar notion of their being engendered in rotten ship-timber*. About a century before Belon, the celebrated Eneas Sylvius Piccolomini, afterwards Pope Pius II., not being disposed to believe the miraculous origin of the bernacle groose without evidence, made eager inquiry after it when he was in Scotland, the result of which was, to use his own words, that "the miracle fled to remoter regions, and that the famous goose-tree was not to be found in Scotland, but in the Orkney Islands †!" Gerard de Vera, being apparently unacquainted with the writings of Albertus Magnus and Belon, and even of his countryman, Clusius, gives an account of their mode of breeding as a new discovery. "On the west side of Greenland," says he, "was a great winding and flat shore, resembling an island, where we found many eggs of the bernacles, which the Dutch call Rot-geese. We found, also, some of them hatching, which, on being driven away, cried rot, rot, rot (hence the Dutch name). One we killed with a stone, and cooked it, with about sixty eggs, which we had carried on board. These birds were identically tlie same with the bernacles, or rot-geese, which came annually in great numbers about Wierengen in Holland, though, from it being hitherto unknown where they laid their eggs and reared their young, anthors have not scrupled to write that they are bred on trees in Scotland $\ddagger$. After these ocular testimonies, it would be utterly superfluous to detail the learned reasonings of Deusing $\S$ and the author of

* Oiseaux, p. 15S, edit. Paris, 1555.

+ Historia de Europa, cap. 46, edit. Helmstadt, 1700.

\$. Trois Navig. faites par les Hollandois au Septentrion, p. 113, edit. Paris, 1599.

$\$$ De Anseribus Scoticis, 12mo, Groningæ, 1659. 
the 'Physica Curiosa' against the miraculous origin of the bernacle goose.

'The origin of the absurdities we have quoted may all be traced to the singular form of a multivalve shell, which Linnæus has done wrong, we think, in designating goose-bearing (Lepas anatifera, Linv.); as "feathered" (plumata) would have been more appropriate and less in the style of fible. Bose, Cuvier, and other modern conchologists have formed the equally objectionable generic term Anatifa. 'The shell itself, which is about an inch and a half long when full grown, is composed of five valves, exceedingly smooth, and of a bluish white colour, with yellow margins. The peduncle, or footstalk, supposed to be the neck of the young groose, is white and cartilaginous, and varies in length from half an inch or less to several feet. What was taken for feathers are the fingers (tentacula) of the shell-fish, of which twelve project in an elegant curve, and are userl by it for making prey of small fish.

These shells are chiefly found adhering to the bottoms of ships and pieces of timber floating in the sea. Colonel Montagu mentions his having seen a fir plank, more than twenty feet long, which was drifted on the coast of Devonshire, completely covered from end to end with bernacle shells. They are sometimes also, though more rarely, found on rocks: we have collected specimens on the basalt rocks at the Giants' Causeway in Ireland, and on the conglomerate sandstone at Weinyss Bay, Renfrewshire *

It shows how exceedingly difficult it is to eradicate popular fables, that, "even of late years," as Bingley mentions, "an attempt was made to impose upon the credulity of the public, by an exhibition in London of a large collection of these shells, as shells from which, as the advertisements stated, the bernacle * J. R. 


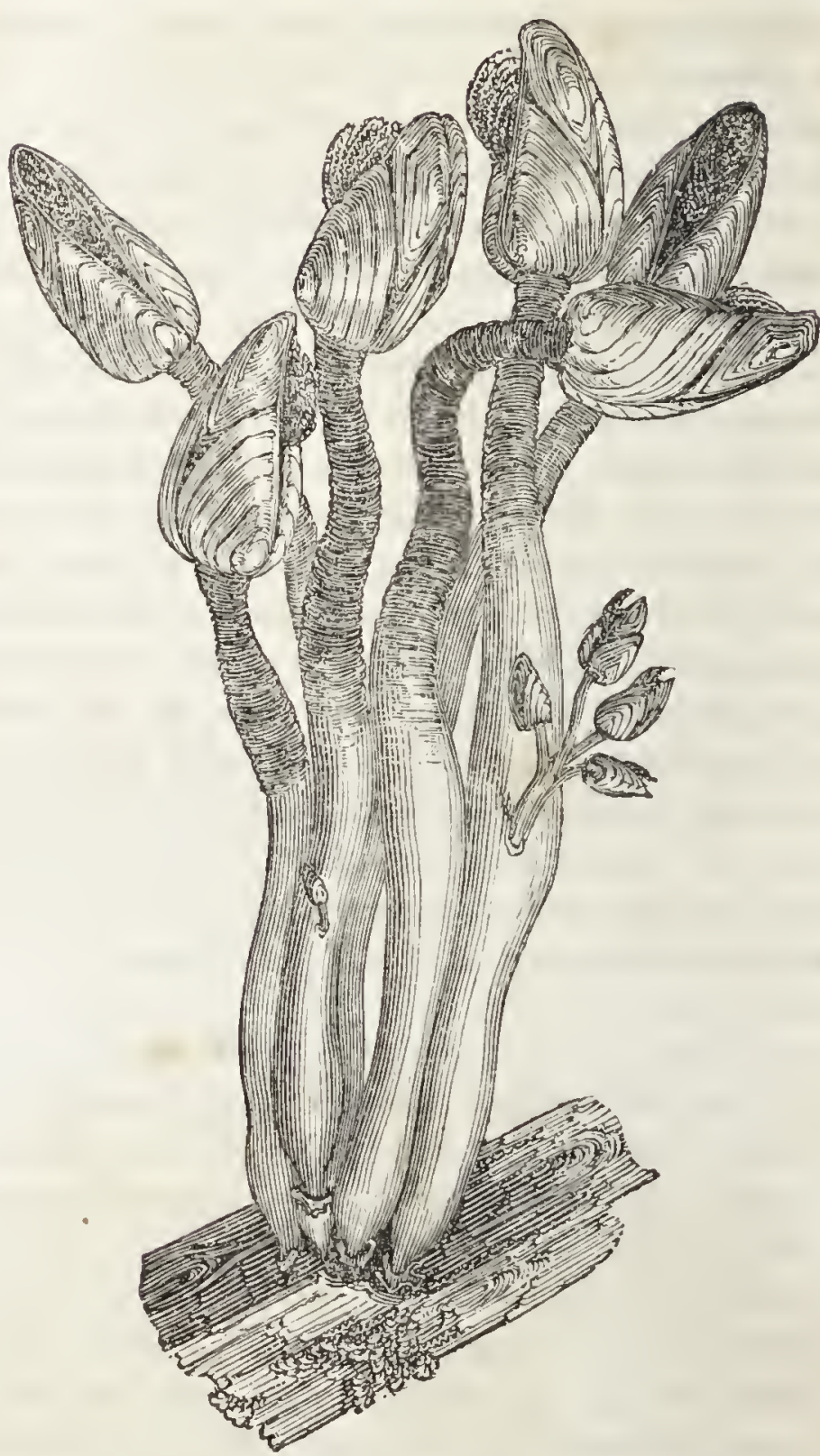

Bernacle Shell (Lepas anatifera, Linn. I. plumata, NoBIs. Anatifa lavis, Bosc.)

geese were produced*." Yet Bingley himself, following Linnæus, calls it " the goose-bearing bernacle!"

It is indeed an opinion, we believe, universally held

* Animal Biog. ir. 305, 6th ed. 
among the more uninformed of the Scottish peasantry at the present day, that the soland goose, or gannet (Sula alba, Maver), not the bernacle, grows by the bill upon the cliffs of the Bass, of Ailsa, and of St. Kilda; and we have even heard this maintained by persons of good education, the notion having no doubt arisen from confounding the fables respecting the bernacle with the prodigious number of the gannets bred on those rocky islets. Some idea of their multitude may be formed from the fact, that the proprietor of the $\mathbf{B}$ ass is said to make $130 l$. per annum by them *, and from Martin's estimating the consumption of the inhabitants of St. Kilda alone at 22,600 of the young gannets, besides a countless number of egrns, which are preserved throughout the year in pyramidal stone buildings, closely covered with turft. This provision is procured at the hazard of the lives of the fowlers, who have to clamber on the rocks at a prodigious height over a raging sea, or to be lowered down to the nests from above, and, hanging in mid

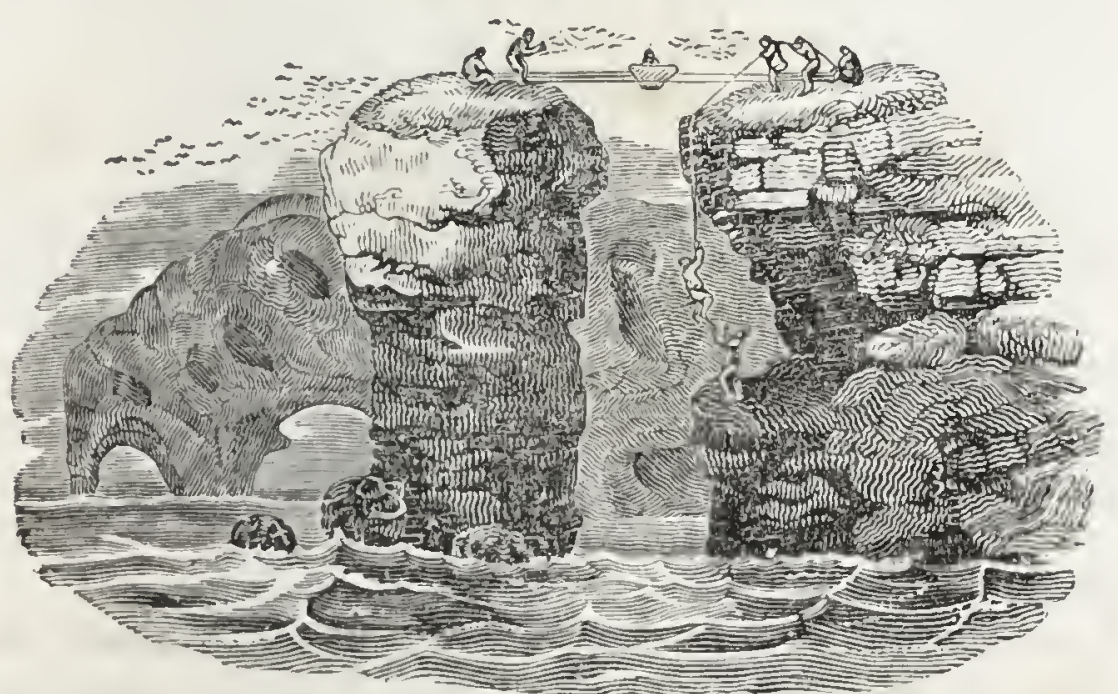

Fowlers of St. Kilda.

* Voyage to St. Kilda, p. 27.

+ Ray's Select Remains, p. 193. 
air, to place their whole dependance on the uncertain footing of the individual who holds the suspension rope at the top of the precipice. 'Thus precariously supported, the fowler stations himself upon the most dangerous ledges, and having ransacked all the nests within his reach, he moves off by means of a pole to some new station.

The fable of the geese growing on these sea-rocks by their bills may also be partly illustrated by the account given of one of their breeding-places by Harvey, the celebrated discoverer of the circulation of the blood. "There is," says he, "a small island which the Scotch call the Bass, not above a mile in circuit, the surface of which, in the months of May and June, is so strewed with nests, eggs, and young birds, that it is difficult for a person to set down his foot without treading on them; while so vast is the multitude of those which fly overhead, that, like clouds, they darken the sun and the sky, and such is their clangorous noise, that you can scarcely hear the voice of your companions. If from the summit of the lofty precipice you look towards the sea which spreads below, you will perceive, wherever you turn your eyes, birds in countless multitudes, and of various kinds, swimming and hunting for their prey. If, sailing round, you survey the impending cliff, you will see, in every crag and fissure of the indented rock, birds of all sorts and sizes, which would outnumber the stars that appear in a clear uight. If, from a distance, you behold the flocks roving about the island, you would imagine them to be a vast swarm of bees *."

It would appear that certain vague reports respecting flying-fish led to similar fables, as we learn from Redi, who, in writing to Kircher, says, "I might well be accused of credulity should I believe * Exercit. de Generatione Animal. ii. 
that there are found in the Chinese sea scaly fishes, of a saffron colour, which live in the water throughout the winter, but at the arrival of spring, having cast off their scales, assume feathers and wings, and unfolding their wings fly to the mountains, where they remain throughout the summer and autumn, after which they return to their old form, and again sink into the water. And although you, most learned father, in your work on China, do not obscurely hint that you believe this, nevertheless I am of opinion that you are not sincere in your belief, and that you have introduced it for no other purpose than to afford a noble instance of your lofty mind, and profound erudition, by investigating and explaining the reasons of this reciprocal transmutation, which may be true, although at variance with the general laws of nature *."

* Experimenta circa varias Res Naturales, p. 150.

FINIS.

Printed by William Clowes, Duke Street, Lambeth. 



weve

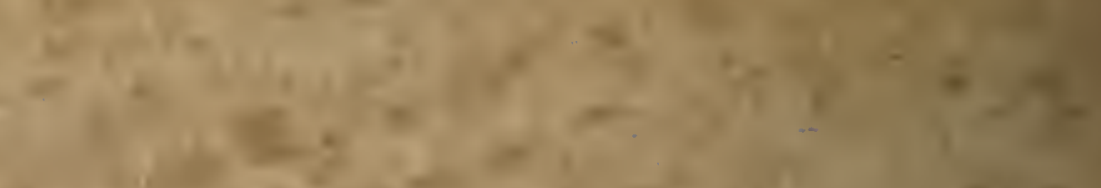

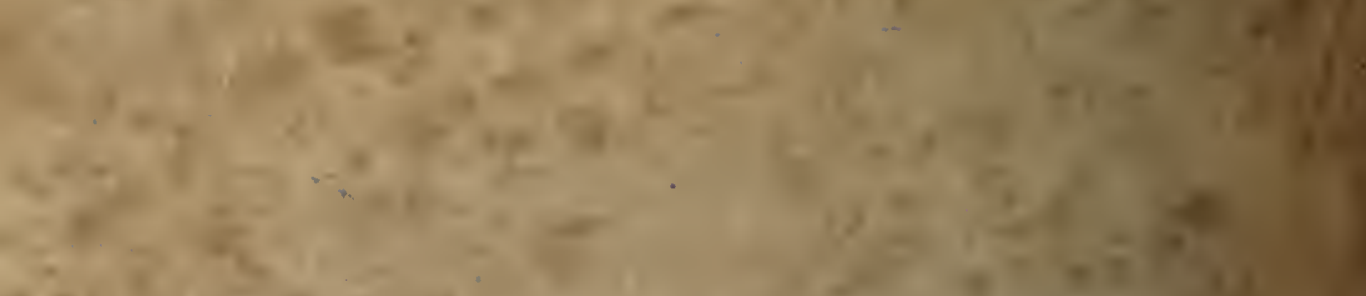

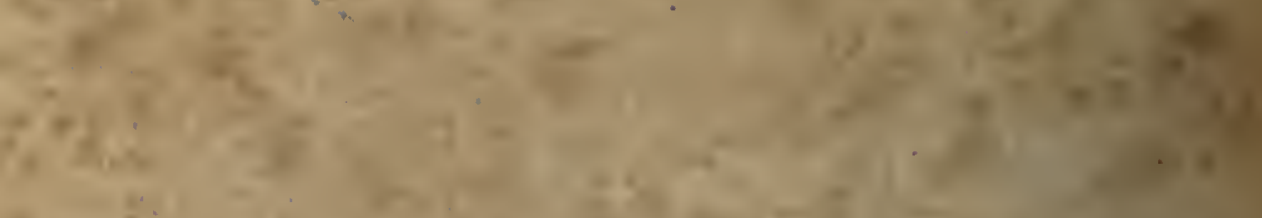

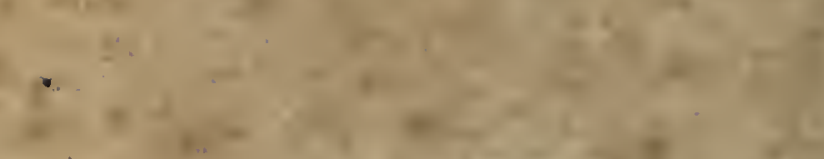

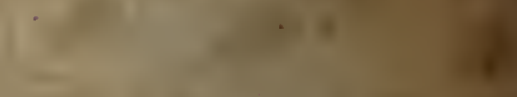

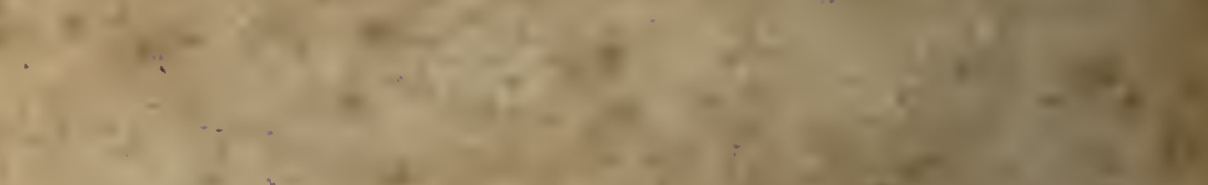

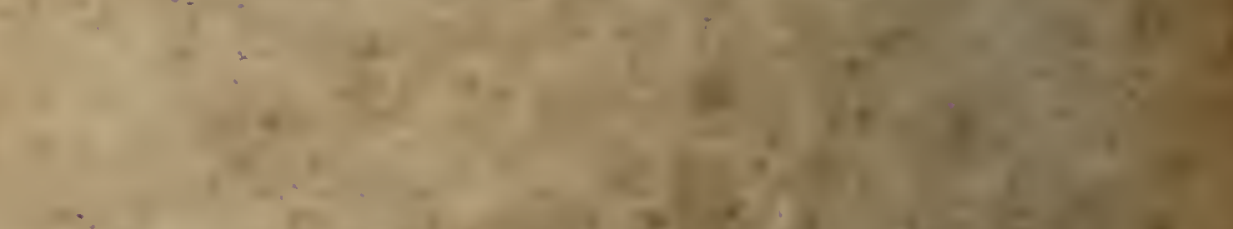

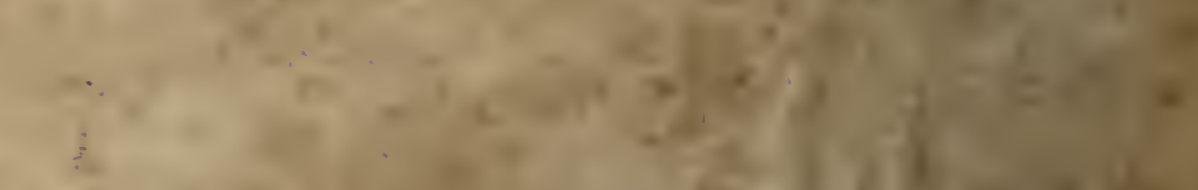

s

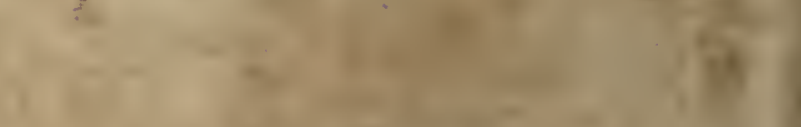

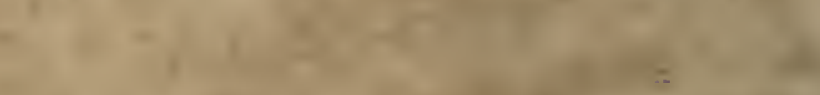

$\cos x=02$

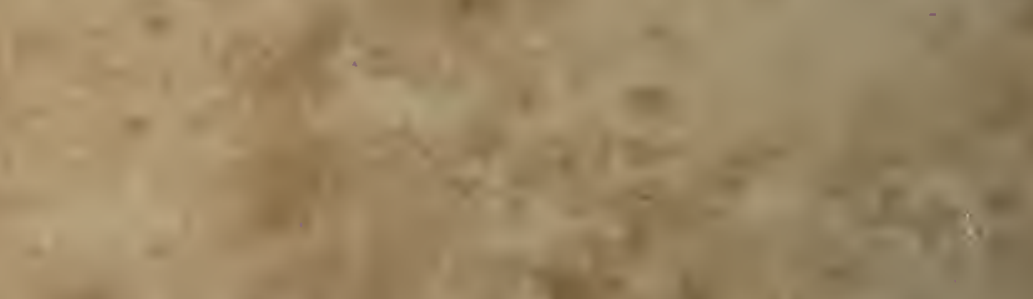

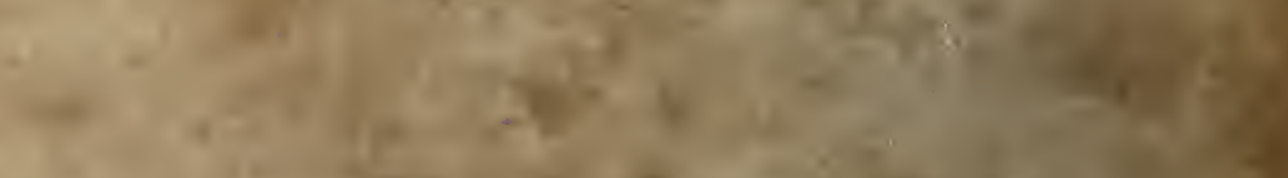

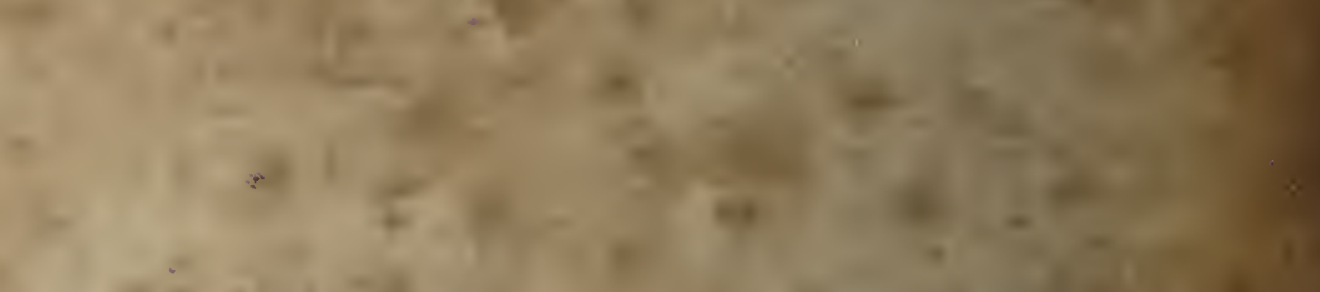

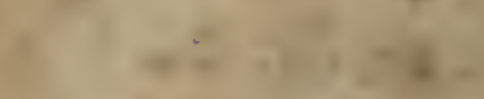

$(5-10=0.89$

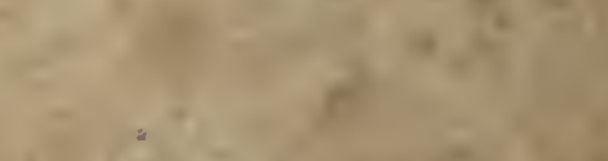

$29+2+8,00$

$6 x+2=0$

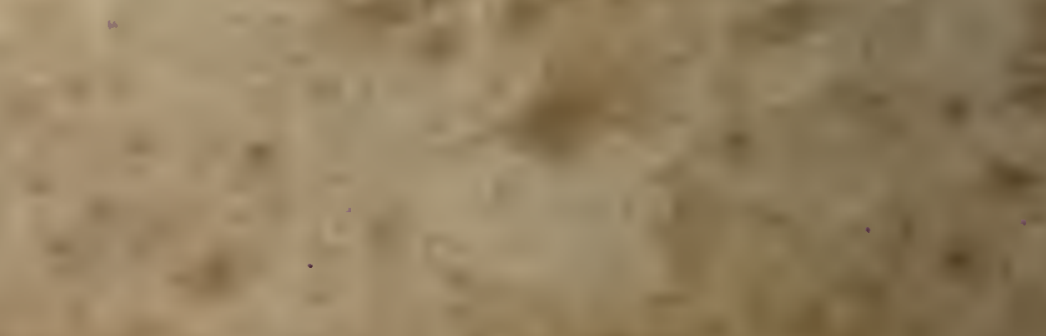

*ै.5

a

$x^{2}=$

$\operatorname{ten} 3$

$+3$

(1) 